\title{
Descoberta direta e eficiente de regras de associação ótimas
}

\author{
Alinson Sousa de Assunção
}



SERVIÇO DE PÓS-GRADUAÇÃO DO ICMC-USP

Data de Depósito:

Assinatura:

\title{
Descoberta direta e eficiente de regras de associação ótimas
}

\author{
Alinson Sousa de Assunção \\ Orientador: Prof. Dr. Alneu de Andrade Lopes \\ Dissertação apresentada ao Instituto de Ciências \\ Matemáticas e de Computação - ICMC-USP, como parte \\ dos requisitos para obtenção do título de Mestre em \\ Ciências - Ciências de Computação e Matemática \\ Computacional. VERSÃO REVISADA
}

USP - São Carlos

Fevereiro de 2012 
Ficha catalográfica elaborada pela Biblioteca Prof. Achille Bassi e Seção Técnica de Informática, ICMC/USP, com os dados fornecidos pelo(a) autor(a)

Assunção, Alinson Sousa de

Descoberta direta e eficiente de regras de associação ótimas / Alinson Sousa de Assunção; orientador Alneu de Andrade Lopes -- São Carlos, 2011.

$151 \mathrm{p}$.

Dissertação (Mestrado - Programa de Pós-Graduação e Ciências de Computação e Matemática Computacional) Instituto de Ciências Matemáticas e de Computação, Universidade de São Paulo, 2011.

1. Regras de Associação. 2. Mineração de Dados. I. Lopes, Alneu de Andrade, orient. II. Título. 



\section{Agradecimentos}

Aos meus pais, Benedito Filho de Assunção e Maria das Dores de Sousa Assunção, pelo apoio e carinho indispensáveis à minha vida.

Ao meu querido irmão Amaury Sousa de Assunção e familiares que sempre estiveram presentes na minha jornada.

Ao meu orientador Alneu de Andrade Lopes, cujo apoio, dedicação, competência e paciência permitiram a conclusão deste trabalho.

À minha amada namorada Waldejane Sousa Alencar pelo carinho e compreensão nos momentos em que não estive presente.

Aos amigos e companheiros do Labic, Biocom, Labes e Lot, pela ajuda, conselhos e ótimas discussões.

Aos meus amigos de moradia pela harmoniosa companhia.

Ao CNPq pelo suporte financeiro e à USP pelas instalações.

À todos que de alguma maneira contribuíram para a finalização deste trabalho. 


\section{Resumo}

Um dos principais interesses na descoberta do conhecimento e mineração de dados é a indução de regras de associação. Regras de associação caracterizam as relações entre os dados a partir de um conjunto de dados estruturado com transações, onde cada transação contém um subconjunto de itens. Seja $X$ e $Y$ dois conjuntos de itens disjuntos, então a regra $X \rightarrow Y$ define um relacionamento, isto é, a dependência ou a co-ocorrência entre os conjuntos $X$ e $Y$. Um dos algoritmos mais conhecidos para geração de regras de associação é o algoritmo Apriori. Ele explora regras de associação que respeitam o limiar suporte mínimo, ou seja, as regras devem aparecer em uma quantidade mínima de transações. Esse limiar tem a capacidade de controlar a quantidade de regras extraídas durante a mineração. Entretanto, a frequência ou suporte não consegue medir o nível de interesse de uma regra. Para medir a importância ou interesse de uma regra em relação a outras foram desenvolvidas medidas de interesse. Tais medidas são calculadas a partir das frequências dos conjuntos de itens $X, Y$ e do par $X Y$. Apesar das medidas de interesse realizarem uma filtragem das regras desinteressantes, elas não acarretam na diminuição no tempo de execução da mineração. Para vencer essa dificuldade, técnicas que exploram diretamente regras de associação ótimas foram desenvolvidas. Um conjunto de regras de associação ótimas é um conjunto de regras que otimiza uma determinada medida de interesse. Na literatura existem muitos trabalhos que buscam esse tipo de conjunto de regras de forma direta e eficiente. O trabalho corrente segue esta mesma direção e visou a melhoria dessa tarefa por descobrir uma quantidade arbitrária de regras de associação ótimas. As abordagens anteriores apresentam um entrave em especial, que é a utilização do algoritmo Apriori. Tal técnica realiza uma busca em largura sobre os conjuntos de itens. No entanto, as técnicas mais promissoras que descobrem regras ótimas realizam busca em profundidade sobre o espaço de busca de regras. Em virtude dessa característica, neste trabalho foi adotada a técnica FP-growth, que realiza uma busca em profundidade sobre os conjuntos de itens explorados. Além da adoção da técnica FP-growth, fo- 
ram desenvolvidas novas estratégias de poda e uma nova estratégia de busca na travessia do espaço de regras. Todas essas inovações foram adicionadas aos algoritmos desenvolvidos no corrente trabalho e proporcionaram melhor eficiência (tempo de execução) em relação ao algoritmo baseline em todos os testes. Tais testes foram realizados sobre conjuntos de dados reais e artificiais. 


\section{Abstract}

The induction of association rules is one of the main interests in knowledge discovery and data mining. Association rules describe the relationships between data from a transactional dataset, so that each transaction contains a subset of items. Let $X$ and $Y$ be two disjoint itemsets, then any rule $X \rightarrow Y$ defines a relationship that represents the dependence or co-occurrence between itemsets $X$ and $Y$. Apriori is the best-known algorithm to generate association rules. It generates association rules that satisfy a user defined minimum support threshold. This means the rules should occur at least in an arbitrary number of transactions from a dataset. This threshold limits the number of association rules generated by Apriori. Yet, it is not possible to measure the interest of a rule through support. For that, interestingness measures were developed to assess the importance or interest of a rule. The values of these interestingness measures are obtained through frequencies of $X, Y$ and $X Y$. However, it is still an expensive task mining all the association rules and then filter them according to an interestingness measure. To overcome this difficulty, techniques to induce optimal association rules have been developed. Optimal association rules are a ruleset that optimize an arbitrary interestingness measure. In the literature, there are many papers which aim at searching for optimal association rules directly and efficiently. The current MSc thesis follows this direction, aiming at improving this objective. Previous approaches share one obstacle in particular: the use of Apriori. This algorithm performs a breadth-first search on the itemsets space. However, the most promising techniques to find optimal rules perform a depth-first search on the space of rules. Hence, in this research we adopted the FP-growth algorithm, which performs a depth-first search on the itemsets space. Besides using this algorithm, new rule pruning techniques and a new search space traversing on the space rules were developed. The algorithms developed in the current research contain all these innovations. In all tests, the proposed algorithms surpassed the baseline algorithms in terms of efficiency. These tests were conducted on 
real and articial datasets. 


\section{Sumário}

Lista de Figuras . . . . . . . . . . . . . . . $\mathrm{xv}$

Lista de Tabelas . . . . . . . . . . . . . . . . . . . . xix

Lista de Algoritmos . . . . . . . . . . . . . . . . . xxi

Lista de Abreviaturas . . . . . . . . . . . . . . . . . . . xxiii

1 Introdução 1

1.1 O Problema . . . . . . . . . . . . . . . . . . 3

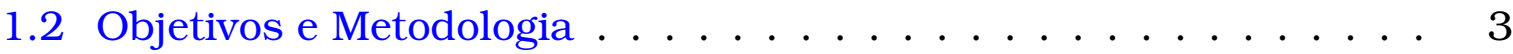

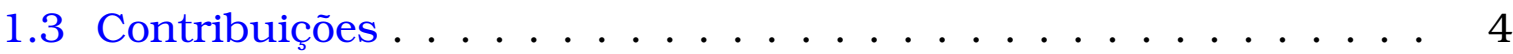

1.4 Organização da Monografia . . . . . . . . . . . . . . . 4

2 Regras de Associação $\quad 7$

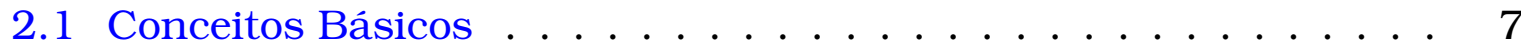

2.1.1 Tipos de Conjunto de Dados . . . . . . . . . . . 8

2.1 .2 Itemset e Suporte . . . . . . . . . . . . . . . 8

2.2 Algoritmos que exploram regras de associação . . . . . . . . . 9

2.2.1 Algoritmo Apriori . . . . . . . . . . . . . . . . . 10

2.2 .2 FP-growth . . . . . . . . . . . . . . . . 15

2.3 Avaliação das Regras de Associação . . . . . . . . . . . . . . . . . 22

2.4 Considerações Finais . . . . . . . . . . . . . . . . . . . 27

3 Geração Eficiente de Regras Interessantes 29

3.1 Mineração baseada em restrições . . . . . . . . . . . . . . . 30

3.1.1 Regras redundantes e Melhoria mínima . . . . . . . . . . 31

3.1 .2 Padrões Hiper-cliques . . . . . . . . . . . . . . . . 31

3.2 Mineração baseada em heurísticas . . . . . . . . . . . . . 33

3.2.1 Técnicas baseadas em agrupamento . . . . . . . . . 33

3.2.2 Técnicas baseadas em algoritmos genéticos . . . . . . . . 34

3.3 Mineração baseada em regras ótimas . . . . . . . . . . . . . . . . 34

3.3.1 Fronteira Suporte-Confiança . . . . . . . . . . . . . . 35 
3.3.2 Enumeração e Otimização de Regras Significantes . . . . . 37

3.3.3 Conjunto de Regras Informativas - (Informative Rule Set IRS) . . . . . . . . . . . . . . . . . . 39

3.3.4 K-Optimal Rules - Webb . . . . . . . . . . . . . 40

3.3.5 K-Optimal Rules Discovery - KORD . . . . . . . . . . . . 40

3.4 Considerações Finais . . . . . . . . . . . . . . . 46

4 Técnicas para a Descoberta Direta de Regras Ótimas 47

4.1 Estratégia de Busca . . . . . . . . . . . . . . . . 48

4.1.1 Travessia similiar ao KORD . . . . . . . . . . . . 50

4.1.2 Travessia com pesquisa implícita de regras . . . . . . . 52

4.2 Algoritmos KORD-growth . . . . . . . . . . . . . . 56

4.2.1 Algoritmo KORD-growth1 . . . . . . . . . . . . 56

4.2.2 Algoritmo KORD-growth2 . . . . . . . . . . . . 60

4.3 Aplicação das Podas . . . . . . . . . . . . . . . . . . 64

4.3.1 CP1 - Conjunto de Podas 1 . . . . . . . . . . . 67

4.3.2 CP2 - Conjunto de Podas $2 \ldots$. . . . . . . . . 68

4.3.3 CP3 - Conjunto de Podas 3 . . . . . . . . . . . . . 68

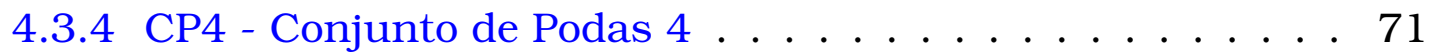

4.3.5 PA1 - Conjunto de prevenções de acesso 1 . . . . . . . . 74

4.3.6 PA2 - Conjunto de prevenções de acesso 2 . . . . . . . 75

4.3.7 PA3 - Conjunto de prevenções de acesso $3 \ldots$. . . . . . 77

4.4 Considerações Finais . . . . . . . . . . . . . . . 78

5 Experimentos e Resultados $\quad \mathbf{8 1}$

5.1 Recursos Utilizados . . . . . . . . . . . . . . . . . . 82

5.1 .1 Algoritmos . . . . . . . . . . . . . . 82

5.1 .2 Conjunto de Dados . . . . . . . . . . . . 84

5.2 Detalhes da avaliação experimental . . . . . . . . . . . . . . 84

5.3 Resultados e Análise . . . . . . . . . . . . . . . . 88

5.3.1 Comparativo entre os algoritmos que descobrem regras ótimas . . . . . . . . . . . . . . . 89

5.3.2 Comparativo entre os algoritmos que extraem padrões fre-

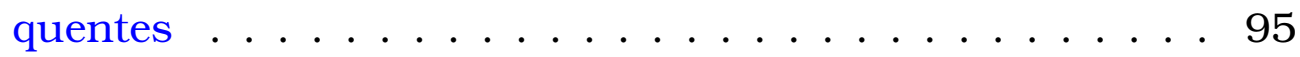

5.3.3 Quando não se conhece o suporte mínimo que garanta $\mathrm{k}$ regras ótimas . . . . . . . . . . . . . . 101

5.4 Considerações Finais . . . . . . . . . . . . . . . 102

6 Conclusão 105 
A Exemplo de execução

A. 1 Para o KORD-growth $1 \ldots \ldots \ldots$

A.2 Para o KORD-growth $2 \ldots \ldots \ldots \ldots \ldots \ldots \ldots$

B Resultados dos Experimentos 133

B.1 Experimentos que envolvem o tamanho máximo do antecedente para uma regra . . . . . . . . . . . . . . . . . 133

B.2 Segundo Experimento . . . . . . . . . . . . . . . . . . . 139

$\begin{array}{ll}\text { Referências } & 151\end{array}$ 


\section{Lista de Figuras}

2.1 Geração e poda de k-itemsets candidatos por juntar pares de $(k-$ 1)-itemsets frequentes. . . . . . . . . . . . . . . 14

2.2 Estruturas de dados que armazenam itemsets. . . . . . . . . . 15

2.3 Construção de uma FP-tree. . . . . . . . . . . . . . . . . 17

2.4 Construção de uma FP-tree com ordem crescente da frequência dos itens. . . . . . . . . . . . . . . . . 18

2.5 Caminhos utilizados para descobrir FIs que terminam em $e, d, c$, b e $a \ldots \ldots \ldots \ldots \ldots \ldots \ldots \ldots \ldots$

2.6 Exemplo de aplicação do algoritmo FP-growth para encontrar os FIs que terminam em $e \ldots \ldots \ldots \ldots \ldots \ldots \ldots 22$

3.1 Distribuição de Suporte de um Conjunto de Dados . . . . . . . . . 32

3.2 Fronteira suporte-confiança. . . . . . . . . . . . . . . . 36

3.3 Espaço de busca dos possíveis antecedentes para 4 itens. . . . . . 41

3.4 Espaço de busca do algoritmo KORD para 4 itens. Em cada nó os possíveis consequentes estão em vermelho e situados sob os possiveis antecedentes. . . . . . . . . . . . . . . 42

4.1 Ordens de busca em profundidade dos possíveis itemsets antecedentes. Visualização do percorrimento segue da esquerda para a direita da árvore. . . . . . . . . . . . . . . . 50

4.2 Espaço de busca dos possíveis itemsets antecedentes. . . . . . . . 51

4.3 Espaço de busca da travessia de regras realizada pelo método KORD. . . . . . . . . . . . . . . . . . 52

4.4 Exibição de todas as possíveis regras no espaço de busca da travessia de regras realizada pelo método KORD. . . . . . . . . . . 53

4.5 Espaço de busca da travessia explícita de regras. . . . . . . . . . . 54

4.6 Exibição de todas as possíveis regras no espaço de busca da travessia com pesquisa implícita de regras. . . . . . . . . . . . 55 
5.1 Contagem da frequência do itemset $\{b, d\}$ em uma árvore FP-tree. Este itemset é coberto por três transações, então sua frequência é 3. . . . . . . . . . . . . . . . . . . . . 84

5.2 Desempenho dos algoritmos que descobrem regras ótimas para o conjunto de dados accidents. . . . . . . . . . . . . . . . . . . 90

5.3 Desempenho dos algoritmos que descobrem regras ótimas para o conjunto de dados census. . . . . . . . . . . . . . . . . . . 90

5.4 Desempenho dos algoritmos que descobrem regras ótimas para o conjunto de dados chess. . . . . . . . . . . . . . . . . . 90

5.5 Desempenho dos algoritmos que descobrem regras ótimas para o conjunto de dados connect-4. . . . . . . . . . . . . . . . . . . 91

5.6 Desempenho dos algoritmos que descobrem regras ótimas para o conjunto de dados kosarak. . . . . . . . . . . . . . . . . 91

5.7 Desempenho dos algoritmos que descobrem regras ótimas para o conjunto de dados mushroom. . . . . . . . . . . . . . . . . 91

5.8 Desempenho dos algoritmos que descobrem regras ótimas para o conjunto de dados pumsb. . . . . . . . . . . . . . . . . . . 92

5.9 Desempenho dos algoritmos que descobrem regras ótimas para o conjunto de dados retail. . . . . . . . . . . . . . . . . . 92

5.10 Desempenho dos algoritmos que descobrem regras ótimas para o conjunto de dados T1OI4D1OOK. . . . . . . . . . . . . . . 92

5.11 Desempenho dos algoritmos que descobrem regras ótimas para o conjunto de dados T4OI1OD1OOK. . . . . . . . . . . . . 93

5.12 Desempenho dos algoritmos Apriori, FP-growth e KORD-growth1-CP para o conjunto de dados accidents. . . . . . . . . . . 96

5.13Desempenho dos algoritmos Apriori, FP-growth e KORD-growth1-CP para o conjunto de dados census. . . . . . . . . . . . . . 97

5.14 Desempenho dos algoritmos Apriori, FP-growth e KORD-growth1-CP para o conjunto de dados chess. . . . . . . . . . . . . 97

5.15Desempenho dos algoritmos Apriori, FP-growth e KORD-growth1-CP para o conjunto de dados connect-4. . . . . . . . . . . 97

5.16Desempenho dos algoritmos Apriori, FP-growth e KORD-growth2 para o conjunto de dados kosarak. . . . . . . . . . . . 98

5.17Desempenho dos algoritmos Apriori, FP-growth e KORD-growth1-CP para o conjunto de dados mushroom. . . . . . . . . . . 98

5.18Desempenho dos algoritmos Apriori, FP-growth e KORD-growth1-CP para o conjunto de dados pumsb. . . . . . . . . . . 98

5.19Desempenho dos algoritmos Apriori, FP-growth e KORD-growth2 para o conjunto de dados retail. . . . . . . . . . . . . . 99 
5.20 Desempenho dos algoritmos Apriori, FP-growth e KORD-growth2 para o conjunto de dados T1OI4D10OK. . . . . . . . . . 99

5.21 Desempenho dos algoritmos Apriori, FP-growth e KORD-growth2 para o conjunto de dados T4OIIOD1OOK. . . . . . . . . . 99 


\section{Lista de Tabelas}

2.1 Matriz Binária Atributo-Valor . . . . . . . . . . . . . 8

2.2 Comjunto de Dados com Transações . . . . . . . . . . . . . . . . . 9

2.3 Conjunto de Dados com Transações . . . . . . . . . . . . . . . . 16

2.4 Lista dos itemsets frequentes ordenados pelos seus correspondentes sufixos. . . . . . . . . . . . . . . 20

2.5 Tabela de Contingência para duas variáveis binárias $X$ e $Y$. . . 25

3.1 Grupos de itens para o conjunto de dados pumsb. . . . . . . . 33

5.1 Características dos conjuntos de dados utilizados nos experimen-

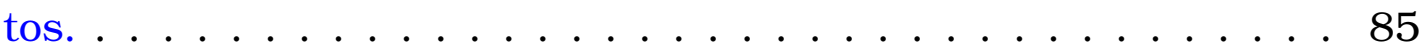

5.2 Estatísticas dos conjuntos de dados utilizados nos experimentos. 85

5.3 Tabela com os tempos de execução em segundos dos algoritmos que descobrem 1000 regras ótimas. Suporte mínino estabelecido por $\frac{1}{N}$ e tamanho máximo do antecedente das regras igual a quatro. Em negrito encontra-se o melhor resultado. . . . . . . . . 102

A. 1 Conjunto de Dados .................... 110

B.1 Experimentos para o conjunto de dados accidents com algoritmos que exploram regras ótimas. . . . . . . . . . . . . . . . 133

B.2 Experimentos para o conjunto de dados accidents com algoritmos que exploram padrões frequentes. . . . . . . . . . . . . . . . . 134

B.3 Experimentos para o conjunto de dados census com algoritmos que exploram regras ótimas. . . . . . . . . . . . . . . . . . . 134

B.4 Experimentos para o conjunto de dados census com algoritmos que exploram padrões frequentes. . . . . . . . . . . . . . . . . . 134

B.5 Experimentos para o conjunto de dados chess com algoritmos que exploram regras ótimas. . . . . . . . . . . . . . . . . . . 134

B.6 Experimentos para o conjunto de dados chess com algoritmos que exploram padrões frequentes. . . . . . . . . . . . . . 135 
B.7 Experimentos para o conjunto de dados connect-4 com algoritmos que exploram regras ótimas. . . . . . . . . . . . . . . . . 135

B.8 Experimentos para o conjunto de dados connect 4 com algoritmos que exploram padrões frequentes. . . . . . . . . . . . . . 135

B.9 Experimentos para o conjunto de dados kosarak com algoritmos que exploram regras ótimas. . . . . . . . . . . . . . . . 135

B.10Experimentos para o conjunto de dados kosarak com algoritmos que exploram padrões frequentes. . . . . . . . . . . . 136

B.11Experimentos para o conjunto de dados mushroom com algoritmos que exploram regras ótimas. . . . . . . . . . . . . . . 136

B.12Experimentos para o conjunto de dados mushroom com algoritmos que exploram padrões frequentes. . . . . . . . . . . . 136

B.13Experimentos para o conjunto de dados pumsb com algoritmos que exploram regras ótimas. . . . . . . . . . . . . . . . . . . 136

B.14Experimentos para o conjunto de dados pumsb com algoritmos que exploram padrões frequentes. . . . . . . . . . . . . 137

B.15Experimentos para o conjunto de dados retail com algoritmos que exploram regras ótimas.

B.16Experimentos para o conjunto de dados retail com algoritmos que exploram padrões frequentes. . . . . . . . . . . . . . 137

B.17Experimentos para o conjunto de dados T1OI4D100K com algoritmos que exploram regras ótimas. . . . . . . . . . . . . . . 138

B.18Experimentos para o conjunto de dados T1OI4D10OK com algoritmos que exploram padrões frequentes. . . . . . . . . . . . . 138

B.19Experimentos para o conjunto de dados T40I10D100K com algoritmos que exploram regras ótimas. . . . . . . . . . . . . . . 138

B.20Experimentos para o conjunto de dados T4OI1OD100K com algoritmos que exploram padrões frequentes.

B.21Experimentos para o conjunto de dados accidents com algoritmos que exploram regras ótimas. . . . . . . . . . . . . . . . . . . . . 139

B.22Experimentos para o conjunto de dados accidents com algoritmos que exploram padrões frequentes. . . . . . . . . . . . . 139

B.23Experimentos para o conjunto de dados census com algoritmos que exploram regras ótimas. . . . . . . . . . . . . . . . . . . . . 140

B.24Experimentos para o conjunto de dados census com algoritmos que exploram padrões frequentes. . . . . . . . . . . . . . . 140

B.25Experimentos para o conjunto de dados chess com algoritmos que exploram regras ótimas. . . . . . . . . . . . . . . . . . . 140

B.26Experimentos para o conjunto de dados chess com algoritmos que exploram padrões frequentes. . . . . . . . . . . . . 141 
B.27Experimentos para o conjunto de dados connect-4 com algoritmos que exploram regras ótimas. . . . . . . . . . . . . . . 141

B.28Experimentos para o conjunto de dados connect 4 com algoritmos que exploram padrões frequentes. . . . . . . . . . . . . . 141

B.29Experimentos para o conjunto de dados kosarak com algoritmos que exploram regras ótimas. . . . . . . . . . . . . . . . . . . 142

B.30Experimentos para o conjunto de dados kosarak com algoritmos que exploram padrões frequentes. . . . . . . . . . . . . . . . 142

B.31Experimentos para o conjunto de dados mushroom com algoritmos que exploram regras ótimas. . . . . . . . . . . . . . . . 142

B.32Experimentos para o conjunto de dados mushroom com algoritmos que exploram padrões frequentes. . . . . . . . . . . . . 143

B.33Experimentos para o conjunto de dados pumsb com algoritmos que exploram regras ótimas. . . . . . . . . . . . . . . . . 143

B.34Experimentos para o conjunto de dados pumsb com algoritmos que exploram padrões frequentes. . . . . . . . . . . . . . 143

B.35Experimentos para o conjunto de dados retail com algoritmos que exploram regras ótimas. . . . . . . . . . . . . . . . . . . 144

B.36Experimentos para o conjunto de dados retail com algoritmos que exploram padrões frequentes. . . . . . . . . . . . . . . . . 144

B.37Experimentos para o conjunto de dados T1OI4D100K com algoritmos que exploram regras ótimas. . . . . . . . . . . . . . . . 144

B.38Experimentos para o conjunto de dados T10I4D100K com algoritmos que exploram padrões frequentes. . . . . . . . . . . . 145

B.39Experimentos para o conjunto de dados T40I1OD100K com algoritmos que exploram regras ótimas. . . . . . . . . . . . . . . 145

B.40Experimentos para o conjunto de dados T40I10D100K com algoritmos que exploram padrões frequentes. . . . . . . . . . . . 145 


\section{Lista de Algoritmos}

2.1 Geração dos itemsets frequentes - Algoritmo Apriori . . . . . . . . . 12

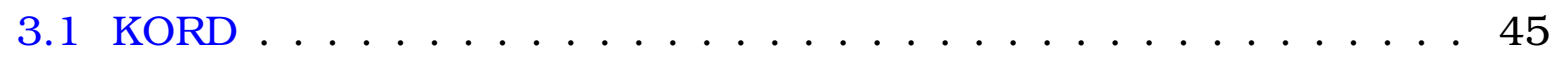

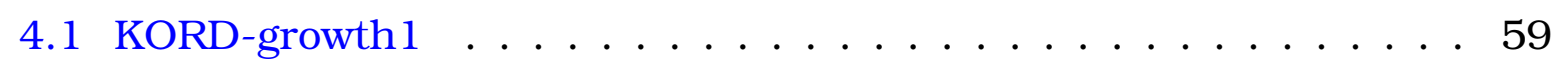

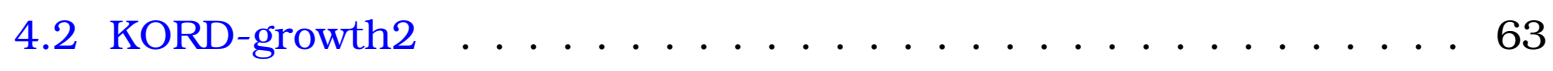




\section{Lista de Abreviaturas}

FI Frequent Itemset

CSP Cross-support Patterns

IRS Informative Rule Set 


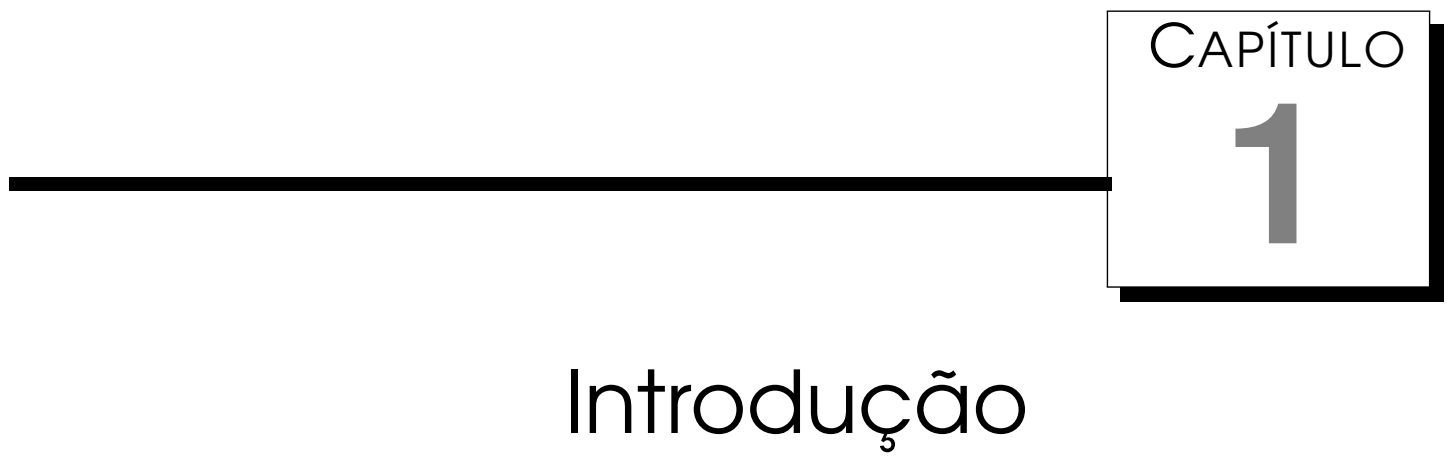

$\mathcal{E}$ mpresas que atuam no varejo acumulam grande quantidade de dados enquanto comercializam seus produtos diariamente. Por exemplo, em um supermercado todas as vendas dos produtos são registradas ao passarem pelo caixa. A utilização de mineração de dados visa extrair informação útil ou padrões em tais dados com o intuito de dar suporte às estratégias de vendas ou à identificação de tendências. Uma das técnicas de mineração de dados que busca esses objetivos é a extração de regras de associação. Tais regras descrevem padrões das co-ocorrências de determinados produtos nas vendas registradas em um período de tempo, isto é, se a ocorrência de um conjunto de produtos $X$ em uma venda implicou na ocorrência de um conjunto de produtos $Y$, com uma dada probabilidade.

A indução de regras de associação é um processo que se originou da análise da cesta de mercadorias (Agrawal et al., 1993). Cada cesta é representada por uma transação e rotulada por um identificador, juntamente com os itens, que são os produtos comprados por um dado cliente. Pela análise desses dados, propõe-se encontrar tendências ou regularidades no comportamento das compras de clientes. Portanto, a prospecção de regras de associação torna-se útil para descobrir relacionamentos interessantes, que são muitas vezes desconhecidos por especialistas, em grandes quantidades de dados (Tan et al., 2006). Esta técnica também é utilizada em outros domínios, nos quais o relacionamento entre objetos pode fornecer conhecimento útil, tal como bioinformática (Creighton e Hanash, 2003), mineração Web (Feldman et al., 1998), mineração de textos (Wong et al., 1999; Lopes et al., 2007) e data streams (Jiang e Gruenwald, 2006; Shin e Lee, 2008).

Após o trabalho percursor sobre regras de associação (Agrawal et al., 
1993), muitos algoritmos para induzir esse tipo de regra foram propostos (Agrawal e Srikant, 1994; Yen e Chen, 1996; Zaki et al., 1997; Han et al., 2000). O processo de geração de regras de associação geralmente abrange duas etapas: (i) identificar os conjuntos de itens ou itemsets a partir de um conjunto de dados e (ii) produzir as regras a partir dos itemsets gerados na primeira etapa. Grande parte das pesquisas tem focado atenção na identificação dos itemsets, em virtude de sua maior complexidade de tempo em relação à segunda etapa (Han et al., 2000).

Um dos principais problemas da indução de regras de associação é que pode ser gerada uma grande quantidade de possiveis regras. No caso de um supermercado, há milhares de produtos à venda. Desta forma, pode haver bilhões ou trilhões de possiviveis regras (Borgelt e Kruse, 2002). Para limitar a quantidade de regras de associação que serão disponibilizadas são necessárias restrições. Na formulação original do problema de induzir regras de associação foi proposta a restrição suporte mínimo (Agrawal et al., 1993). Suporte revela a significância estatística dos itens que compõem a regra, itemset ou padrão, ou seja, descreve a fração de ocorrência do padrão em um conjunto de dados. Se um conjunto de itens ou itemset respeitar a restrição suporte mínimo ele é considerado um conjunto de itens frequente. No restante do trabalho esse termo será representado pelo acrônimo FI (Frequent Itemset).

A restrição suporte mínimo apenas controla a quantidade de regras que são exploradas. Nesse conjunto de regras de associação existem regras que são óbvias ou irrelevantes e regras que podem ser úteis ou interessantes para um usuário. Medidas de interesse são requeridas para estabelecer um ranking de interesse entre elas (Brin et al., 1997). A primeira medida de interesse definida para estabelecer a importância de uma regra foi a medida confiança (Agrawal e Srikant, 1994). Confiança mede a probabilidade condicional do consequente da regra em relação ao antecedente. Por exemplo, se uma regra $X \rightarrow Y$ tem confiança $c$, isto significa que $c \%$ de todas as transações que contém $X$ também conterá $Y$. Além da medida confiança outras medidas de interesse foram desenvolvidas. Essas medidas geralmente são baseadas em estatística e teoria da informação (Tan e Kumar, 2000). Tais medidas de interesse são consideradas objetivas, em virtude de não receberem nenhuma informação prévia a partir de um usuário. Medidas que consideram informação ad hoc de um usuário são conhecidas por medidas de interesse subjetivas.

Apesar de a utilização das medidas de interesse facilitar a inspeção das regras de associação, tais medidas não ajudam na eficiência da mineração. Muitas vezes, as regras mais interessantes são aquelas cujo suporte é bem pequeno. Para encontrá-las é necessário que o suporte mínimo seja relativamente baixo. Nesse caso, o tempo de mineração pode aumentar exponenci- 
almente, sendo impraticável em aplicações sensíveis ao tempo e conjuntos de dados muito grandes. Para vencer esta dificuldade, algoritmos eficientes são requeridos para restringir o espaço de busca e verificar somente um subconjunto de todas as regras que respeitam o suporte mínimo, sem descartar as regras de associação importantes (Bayardo e Agrawal, 1999; Webb, 2000). Estas regras importantes devem otimizar uma medida de interesse pré-estabelecida.

\subsection{O Problema}

O problema discutido nesse trabalho pode ser definido da seguinte forma. Descobrir, de forma direta e eficiente, um conjunto de regras de associação que otimiza uma determinada medida de interesse objetiva. Alguns trabalhos anteriores buscam resolver esse problema utilizando estratégias de podas. Seguindo esta estratégia, pode ser citado o trabalho de Morishita e Sese (2000), que por meio de upper bounds ou limitantes superiores da medida de interesse chi-quadrado buscou-se limitar seções do espaço de busca e potencializar a busca por regras que otimizam tal medida. Outra estratégia interessante foi a definição da fronteira suporte-confiança por Bayardo e Agrawal (1999). Tal fronteira foi desenvolvida para otimizar um conjunto de medidas de interesse objetiva. Também existem os trabalhos de Webb (2000) e Webb e Zhang (2005), que exploravam a geração de regras de associação ótimas para qualquer medida de interesse objetiva de forma eficiente.

\subsection{Objetivos e Metodologia}

O trabalho desenvolvido teve como objetivo geral a descoberta direta de regras de associação ótimas (que otimizam uma medida de interesse e respeitam restrições de busca) de forma eficiente. Para isso, foi necessário a melhoria de alguns aspectos encontrados nos algoritmos mais recentes que realizam essa mesma tarefa.

As técnicas anteriores utilizam o algoritmo Apriori para geração dos FIs. Esse algoritmo possui a característica de busca em largura, ou seja, são explorados todos os FIs de tamanho $k$ por vez. No entanto, a técnica descrita no trabalho de Webb e Zhang (2005) explora os antecedentes utilizando a característica de busca em profundidade. Diante disso, a hipótese desse trabalho é que seria mais interessante e robusto utilizar algoritmos que exploram FIs da mesma maneira, que é o caso do algoritmo FP-growth, desenvolvido por Han et al. (2000). Por conhecer a limitação da utilização do algoritmo Apriori para exploração dos FIs, os seguintes objetivos são expostos para conseguir melhorar o desempenho da tarefa de descoberta das regras de associação ótimas, 
que são:

1. adequar o algoritmo FP-growth para a contagem da frequência das regras na tarefa de descoberta;

2. adicionar novas podas na estratégia de busca; e

3. elaborar uma nova estratégia de busca, isto é, uma nova travessia sobre o espaço das possíveis regras.

A utilização do algoritmo FP-growth foi motivada pela sua característica de busca em profundidade. Isto propicia maior eficiência enquanto o tamanho da regra aumenta. Isso acontece porque a árvore FP-tree, que é explorada pelo FP-Growth, diminui enquanto são procurados FIs de maior tamanho. Além disso, para que a técnica desenvolvida seja de fato eficiente é necessário que seções do espaço de busca sejam removidas. Isto é realizado por meio de podas e restrições. Muitas dessas, herdadas de trabalhos anteriores e outras implementadas durante este trabalho. Pode-se também elaborar uma nova estratégia de busca, para diminuir a ocorrência de redundâncias na contagem da frequência de alguns itemsets durante a travessia sobre as possíveis regras.

Com a aplicação dos objetos já definidos, foram desenvolvidos três algoritmos baseados no algoritmo KORD, que é o algoritmo desenvolvido no trabalho de Webb e Zhang (2005). A avaliação foi uma comparação do desempenho dos algoritmos desenvolvidos em relação ao tempo levado para gerar o mesmo conjunto de regras ótimas pelo algoritmo KORD. Os experimentos mostraram que as inovações implementadas foram úteis para se conseguir melhor eficiência no tempo de geração das regras ótimas sobre alguns conjuntos de dados reais e artificiais.

\subsection{Contribuições}

As contribuições deste trabalho se referem à eficiência dos algoritmos desenvolvidos em conjuntos de dados com diferentes características. Isto é, em todos os testes pelo menos um algoritmo desenvolvido teve melhor eficiência (tempo de execução) que o algoritmo baseline na geração de regras ótimas. Portanto, sistemas sensíveis ao tempo de mineração e que requerem regras de associação ótimas podem ser beneficiadas pelas inovações implementadas.

\subsection{Organização da Monografia}

A estrutura do trabalho é organizada da seguinte maneira. No Capítulo 2 é apresentada a definição de regras de associação. Além disso, os algoritmos 
Apriori e FP-growth são descritos em detalhes. O conceito sobre medidas de interesse é apresentado, assim como uma lista de algumas das medidas mais difundidas na literatura. Um apanhado geral sobre os trabalhos relacionados é apresentado no Capítulo 3. No Capítulo 4 são apresentadas as inovações propostas, que se referem aos algoritmos desenvolvidos e às podas implementadas. No Capítulo 5 são exibidos todos os experimentos que foram realizados para mostrar a eficiência dos algoritmos desenvolvidos. Os resultados são descritos no final desse capítulo. Uma revisão sobre todo o trabalho desenvolvido é descrita no Capítulo 6, além disso são apresentadas as limitações e as contribuições do trabalho na pesquisa de descoberta de regras de associação ótimas. 


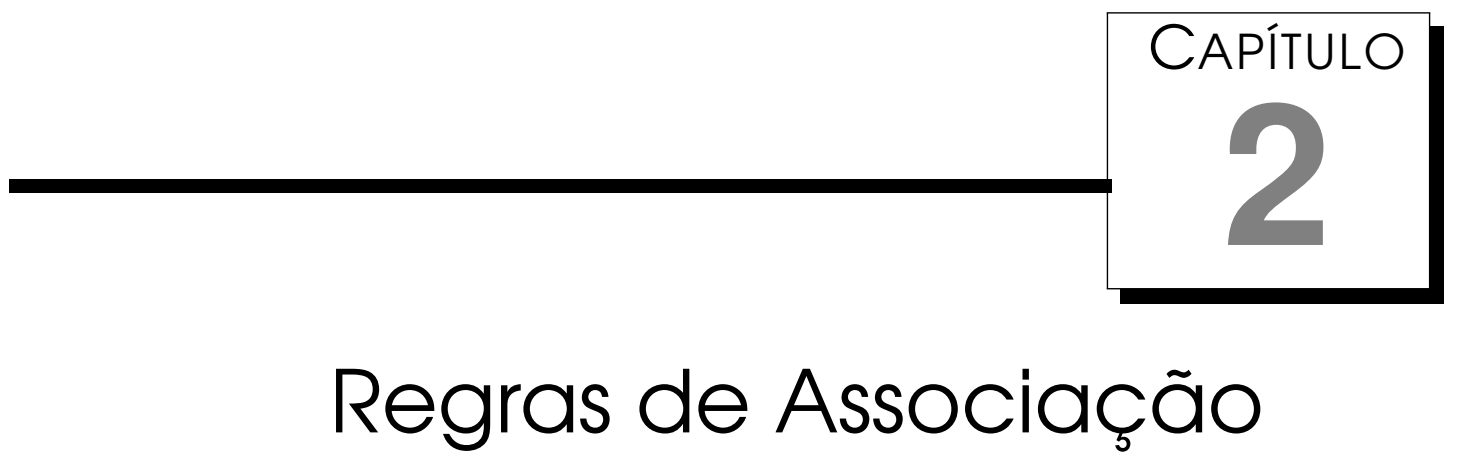

Um dos principais interesses na área de descoberta do conhecimento em bases ou conjuntos de dados (Knowledge Discovery in Databases - KDD) é a geração ou extração de regras de associação. Regras de associação caracterizam as co-ocorrências entre conjuntos de itens a partir de um conjunto de dados estruturado como transações, nas quais cada transação contém um subconjunto de itens.

A formalização do problema de regras de associação foi definida por Agrawal et al. (1993). Tal problema considera um conjunto de atributos binários que são chamados de itens $I=\left\{i_{1}, i_{2}, \ldots, i_{n}\right\}$. Um conjunto de transações é conhecido por $T$, onde cada transação $t$ é um conjunto de itens, sendo que $t \subseteq I$. Para cada transação é associado um identificador que é chamado TID. Uma transação $t$ contém $X$, que é um subconjunto de $I$, se $X \subseteq t$. Uma regra de associação é uma implicação da forma $X \rightarrow Y$, onde $X \subset I, Y \subset I$ e $X \cap Y=\emptyset$.

A regra $X \rightarrow Y$ é suportada pelo conjunto de transações $T$ com confiança $c$ se $c \%$ das transações em $T$ que contém $X$ também contém $Y$. A regra $X \rightarrow Y$ tem suporte $s$ no conjunto de transações $T$ se $s \%$ das transações em $T$ contém $X \cup Y$. A partir de um conjunto de transações $T$, o problema de minerar regras de associação consiste em gerar todas as regras que tem suporte e confiança maior que o suporte mínimo (chamado de minsup) e confiança mínima (chamada de minconf), sendo que ambos são definidos pelo usuário.

\subsection{Conceitos Básicos}

Nas sub-seções seguintes, os conceitos básicos sobre regras de associação são identificados e descritos. 


\subsubsection{Tipos de Conjunto de Dados}

O conjunto de dados envolvido na tarefa de minerar regras de associação é composto por transações e em cada transação é mantido um conjunto de itens. Considere um supermercado ou uma loja de varejo qualquer. O conjunto de produtos comprados por um cliente constitui uma transação, enquanto que um produto individual é um item. Esse tipo de dado é também chamado de cesta de mercadorias porque os itens encontrados em cada registro são os produtos de uma cesta de mercadorias de uma pessoa.

Dados na forma de transações são uma coleção de conjuntos de itens. No entanto, podem ser vistos como um conjunto de registros cujos campos são atributos assimétricos (Tan et al., 2006). Quando um registro é formado por atributos assimétricos, significa que somente a presença, valor do atributo diferente de zero, é considerada importante. Diante disso, há duas formas de representar conjuntos de dados estruturados com transações, que são comentadas a seguir.

Matriz binária atributo-valor: neste tipo de matriz há somente dois valores para cada atributo, isto é, valores binários são empregados para cada atributo. Cada exemplo ou registro pode ser considerado uma transação. A Tabela 2.1 apresenta um exemplo de matriz atributo-valor binária.

Conjunto de dados com Transações: nesta representação de dados cada registro é chamado de transação e recebe uma identificação, chamada TID. A Tabela 2.2 apresenta um exemplo de um conjunto de dados estruturado por transações.

Tabela 2.1: Matriz Binária Atributo-Valor

\begin{tabular}{|c|c|c|c|c|c|}
\hline Cerveja & Fraldas & Leite & Ovo & Pão & Refrigerante \\
\hline 0 & 0 & 1 & 0 & 1 & 0 \\
\hline 1 & 1 & 0 & 1 & 1 & 0 \\
\hline 1 & 1 & 1 & 0 & 0 & 1 \\
\hline 1 & 1 & 1 & 0 & 1 & 0 \\
\hline 0 & 1 & 1 & 0 & 1 & 1 \\
\hline
\end{tabular}

\subsubsection{Itemset e Suporte}

Considere $I=\left\{i_{1}, i_{2}, \ldots, i_{n}\right\}$ o conjunto de todos os itens das cestas de mercadorias e $T=\left\{t_{1}, t_{2}, \ldots, t_{n}\right\}$ o conjunto de todas as transações. Cada transação $t_{i}$ contém um subconjunto de itens de $I$. Uma coleção de zero ou mais itens é denominada um conjunto de itens ou itemset. Se um itemset contém $k$ itens, 
Tabela 2.2: Comjunto de Dados com Transações

\begin{tabular}{|l|l|}
\hline TID & \multicolumn{1}{|c|}{ Itens } \\
\hline 1 & Leite, Pão \\
\hline 2 & Cerveja, Fraldas, Ovos, Pão \\
\hline 3 & Cerveja, Fraldas, Leite, Refrigerante \\
\hline 4 & Cerveja, Fraldas, Leite, Pão \\
\hline 5 & Fraldas, Leite, Pão, Refrigerante \\
\hline
\end{tabular}

ele é chamado de $k$-itemset. Por exemplo, \{Cerveja, Fraldas, Leite $\}$ é um exemplo de um 3-itemset. O conjunto vazio é um itemset que não contém nenhum item.

Uma transação $t_{j}$ é dita conter um itemset $X$, se $X$ for um subconjunto de $t_{j}$. Por exemplo, a segunda transação mostrada na Tabela 2.2 contém o itemset $\{$ Fraldas, Pão $\}$ mas não $\{$ Leite, Pão\}. A Equação 2.1 define o conjunto de transações coberto por um determinado itemset.

$$
\sigma(X)=\left\{t_{i} \mid X \subseteq t_{i}, t_{i} \in T\right\}
$$

Uma propriedade importante de um itemset é sua frequência, que se refere à quantidade de transações que contém um itemset específico. Matematicamente, frequência ou suporte absoluto de um itemset $X$ pode ser definido pela Equação 2.2.

$$
\text { sup_abs }(X)=|\sigma(X)| \text {, onde }|C| \text { representa a cardinalidade do conjunto } C \text {. }
$$

No conjunto de dados exibido na Tabela 2.2, o suporte absoluto para $\{$ Cerveja,Fraldas, Leite\} é igual a dois, pelo fato de haver somente duas transações contendo todos os três itens. De acordo com a Equação 2.3, a cobertura é igual a 0.4 , e de acordo com a Equação 2.4 o suporte relativo deste mesmo itemset é $40 \%$, onde $N$ é a quantidade de transações.

$$
\begin{gathered}
\operatorname{cober}(X)=\frac{\text { sup_abs }(X)}{N} \\
\sup (X)=\frac{\text { sup_abs }(X)}{N} \times 100 \%
\end{gathered}
$$

\subsection{Algoritmos que exploram regras de associação}

Uma abordagem para minerar regras de associação pode ser por meio da força-bruta, ou seja, computar o suporte e a confiança para qualquer regra 
possivel. Esta abordagem é muito cara em virtude de haver uma quantidade exponencial de regras que podem ser extraídas de um conjunto de dados. Mais precisamente, a partir de um conjunto de dados que contém $d$ itens, a quantidade total de possíveis regras extraídas pode ser obtida pela Equação 2.5 encontrada em Tan et al. (2006). Essas regras podem conter até $d-1$ itens no antecedente ou no consequente. Neste trabalho de mestrado, apenas regras de associação com somente um item no consequente são de interesse. Dessa forma, a quantidade total de possiveis regras extraídas pode ser obtida pela Equação 2.6. Uma abordagem via força-bruta também seria inviável, em virtude de haver uma quantidade exponencial de possíveis regras desse tipo.

$$
\begin{gathered}
R=\sum_{k=1}^{d-1}\left[\left(\begin{array}{l}
d \\
k
\end{array}\right) \times \sum_{j=1}^{d-k}\left(\begin{array}{c}
d-k \\
j
\end{array}\right)\right] \\
R=3^{d}-2^{d+1}+1 . \\
R^{\prime}=\left(\begin{array}{l}
d \\
1
\end{array}\right) \times \sum_{k=1}^{d-1}\left(\begin{array}{c}
d-1 \\
k
\end{array}\right) \\
R^{\prime}=d \times\left(2^{d-1}-1\right) .
\end{gathered}
$$

Muitos algoritmos que mineram regras adotam uma estratégia comum, que é decompor o problema de produzir regras de associação em duas subtarefas principais (Tan et al., 2006), a geração dos itemsets frequentes e a geração das regras de associação propriamente dita.

Geração dos Itemsets Frequentes: encontra todos os itemsets que satisfazem o limiar minsup;

Geração das Regras de Associação: extrai todas as regras com confiança superior a minconf a partir dos FIs encontrados no passo anterior.

Em virtude de a geração dos FIs acarretar em maior custo computacional em relação à geração das regras, muita pesquisa foi dedicada à geração eficiente dos FIs. A seguir, dois algoritmos que mineram FIs e que podem gerar regras de associação a partir deles são descritos.

\subsubsection{Algoritmo Apriori}

O algoritmo Apriori foi um dos primeiros algoritmos para indução de regras de associação e está entre os mais conhecidos (Agrawal e Srikant, 1994). Para entender como funciona esta técnica, são esboçadas a seguir as suas principais etapas. 
Geração dos Itemsets Frequentes

Um itemset é considerado frequente se seu suporte for maior ou igual ao limiar minsup que é escolhido na definição do problema. Em geral, um conjunto de dados que possui $k$ itens pode potencialmente gerar cerca de $2^{k}-1$ itemsets candidatos. Baseado nisso, o principal gargalo na geração dos FIs é a contagem do suporte de cada itemset candidato. Isto acontece porque é necessário comparar cada candidato contra toda transação do conjunto de dados. Se o itemset candidato estiver contido em uma transação, seu suporte será incrementado. Tal abordagem é custosa e requer cerca de $O(N M w)$ comparações, onde $N$ é a quantidade de transações, $M=2^{k}-1$ é a quantidade de itemsets candidatos e $w$ é a largura máxima da transação (Tan et al., 2006).

Conhecendo estas limitações, há várias maneiras de superá-las. O algoritmo Apriori adota as seguintes estratégias para vencer estes desafios (Tan et al., 2006):

- reduzir a quantidade de itemsets candidatos $(M)$;

- reduzir a quantidade de comparações.

O algoritmo Apriori foi o primeiro algoritmo de mineração de regras de associação que explorou o uso do suporte para controlar o crescimento da quantidade dos itemsets candidatos. Tal controle é feito da seguinte maneira. Se um itemset for infrequente, isto é, se seu suporte estiver abaixo do limiar minsup, então todos os superconjuntos de itens que contenham este itemset também são infrequentes. Isto se deve pela propriedade anti-monotônica da medida suporte, pois o suporte para um itemset nunca excede o menor suporte de todos os seus subconjuntos de itens. Esta propriedade é muito importante para que seja feita a poda no espaço de busca dos itemsets candidatos.

O Algoritmo 2.1 mostra um pseudo-código da parte do algoritmo Apriori que gera os FIs. Seja $C_{k}$ o conjunto dos $k$-itemsets candidatos e $F_{k}$ o conjunto dos $k$-itemsets frequentes.

- Inicialmente, o algoritmo conta o suporte de cada item no conjunto de dados. Após terminar este passo, o conjunto de todos os 1-itemsets frequentes, $F_{1}$, são conhecidos (passos 1 e 2).

- Em seguida, o algoritmo, por utilizar os $(k-1)$-itemsets frequentes encontrados na seção anterior, gera os novos $k$-itemsets candidatos (passo 5). A geração dos candidatos é implementada utilizando a função chamada apriori-gen, descrita mais adiante.

- Para contar o suporte dos candidatos, o algoritmo precisa percorrer todo o conjunto de dados (passos 6 a 11). 
- Após contar o suporte de todos os candidatos, se o suporte de qualquer itemset candidato for menor que o limiar minsup, o algoritmo elimina tais itemsets do conjunto de itemsets candidatos (passo 12).

- O algoritmo termina quando não houver novos FIs gerados, isto é, $F_{k}=$ $\varnothing$ (passo 13).

A parte da geração dos FIs do algoritmo Apriori possui duas características importantes. Primeiro, ele é um algoritmo level-wise, isto é, aumenta gradativamente o tamanho dos FIs, começando dos 1-itemsets frequentes até o tamanho máximo possivel. Segundo, ele emprega uma estratégia gerar-etestar. Em cada iteração, são gerados novos itemsets candidatos a partir dos FIs encontrados na iteração anterior. Então, o suporte de cada candidato é contado e testado pelo limiar minsup. Aqueles candidatos que sobrevivem à poda, tornam-se os novos FIs. A quantidade total de iterações necessárias pelo algoritmo é $k_{\max }+1$, onde $k_{\max }$ é o tamanho máximo dos FIs.

\section{Geração e Poda dos Candidatos}

A função apriori-gen gera os itemsets candidatos por realizar as duas operações seguintes.

1. Geração dos Candidatos: esta operação gera os novos $k$-itemsets candidatos baseados nos $(k-1)$-itemsets frequentes encontrados na iteração anterior.

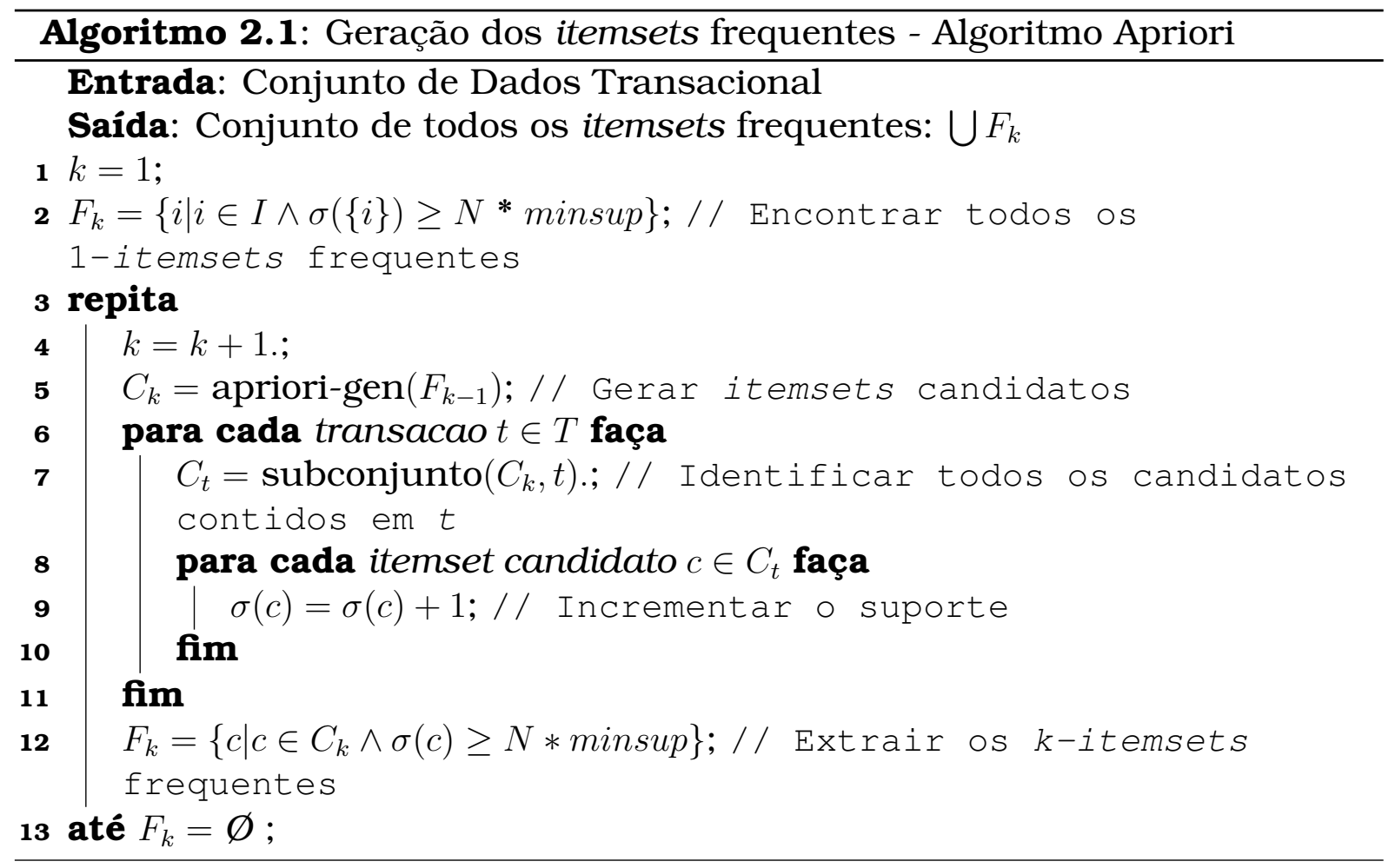


2. Poda dos Candidatos: esta operação elimina os $k$-itemsets candidatos utilizando a estratégia de poda baseada no suporte.

Para ilustrar a operação da poda dos candidatos considere um $k$-itemset candidato, $X=\left\{i_{1}, i_{2}, \ldots, i_{n}\right\}$. O algoritmo deve determinar se todos os subconjuntos imediatos, $X-\left\{i_{j}\right\}\left(\forall_{j}=1,2, \ldots, k\right)$, são frequentes. Se pelo menos um deles for infrequente, então $X$ é imediatamente podado. Esta abordagem pode efetivamente reduzir a quantidade de itemsets candidatos considerados durante a contagem do suporte.

Na função apriori-gen, a geração dos candidatos é realizada da seguinte forma. Os pares de $(k-1)$-itemsets frequentes são juntados somente se seus primeiros $k-2$ itens forem idênticos. Deixe $A$ e $B$ serem um par de $(k-$ 1)-itemsets frequentes. $A$ e $B$ são juntados se eles satisfazem as seguintes condições:

$$
a_{i}=b_{i}(\text { para } i=1,2, \ldots, k-2) \text { e } a_{k-1} \neq b_{k-1}
$$

Na Figura 2.1, os FIs $\{$ Fraldas, Pão $\}$ e $\{$ Fraldas, Leite $\}$ são juntados para formar o 3-itemset $\{$ Fraldas, Leite, Pão\}. O algoritmo não consegue juntar $\{$ Cerveja,Fraldas\} com $\{$ Fraldas, Leite $\}$ porque o primeiro item de ambos itemsets são diferentes. Na verdade, se $\{$ Cerveja, Fraldas, Leite $\}$ fosse um candidato viável, ele seria gerado por juntar $\{$ Cerveja, Fraldas $\}$ com $\{$ Cerveja, Leite $\}$. Este exemplo ilustra dois aspectos do método: a completude da geração dos candidatos, isto é, nenhum FI é deixado de fora, e as vantagens de utilizar ordenamento lexicográfico dos itens para evitar candidatos duplicados. Entretanto, em virtude de cada candidato ser obtido por juntar um par de $(k-1)$-itemsets frequentes, um passo de poda de candidato é necessário para assegurar que os restantes $k-2$ subconjuntos do candidato sejam frequentes.

\section{Contagem do Suporte}

A contagem do suporte é o processo de determinar a frequência da ocorrência para todo itemset candidato que sobrevive ao passo de poda de candidatos da função apriori-gen. A contagem do suporte é implementada nos passos 6 a 11 do Algoritmo 2.1. Uma abordagem para fazer isso é comparar cada transação contra todo itemset candidato e incrementar seu suporte. Esta abordagem é computacionalmente cara, especialmente quando a quantidade de transações e itemsets candidatos é grande.

Há muitas maneiras eficientes para realizar a contagem da frequência dos itemsets. Para isso, é necessário que os itemsets candidados sejam alocados em estruturas de dados robustas. Pode-se citar três das estruturas mais comuns para este fim (Ceglar e Roddick, 2006): 


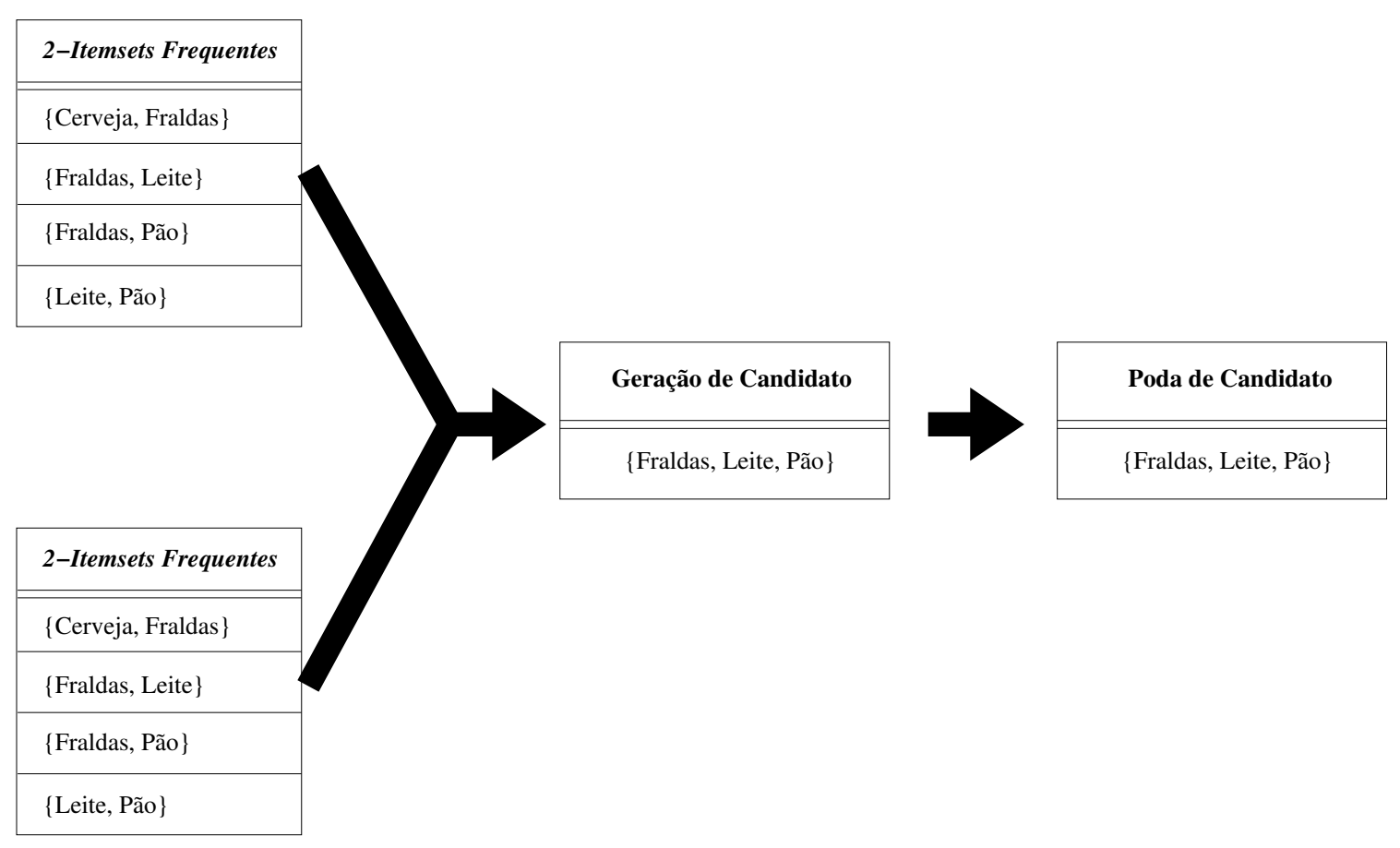

Figura 2.1: Geração e poda de k-itemsets candidatos por juntar pares de $(k-$ 1)-itemsets frequentes.

- Hash-Tree - HT;

- Enumeration-Set Tree - EST; e

- Prefix-Tree - PT.

A estrutura de dados HT é uma combinação das estruturas b-tree e hashtables e foi introduzida por Agrawal e Srikant (1994). A estrutura é efetivamente uma $b$-tree, na qual todo nó interno é uma hashtable e todo nó folha contém um conjunto de itemsets. Quando um nó folha alcança sua cota de itemsets, a HT se expande para substituir o nó folha por uma nova hashtable, e os itemsets são colocados em novos nós dentro dessa hashtable.

EST é uma árvore ordenada onde cada nó $n$ representa um itemset, e cada item deste itemset possui uma aresta que o representa. Cada nível dessa árvore contém itemsets de mesmo tamanho. Por exemplo, os nós localizados no terceiro nível da árvore contém itemsets válidos de tamanho 3.

Uma PT, embora fundamentalmente equivalente, difere-se da EST. Pois cada caminho total de itens situado em uma PT registra a sobreposição de transações. Assim, cada nó que representa um item mantém guardado a quantidade de transações que ele compartilha com todos os seus ancestrais. Isto fica evidente na Figura 2.2, onde as duas árvores são estruturalmente equivalentes. A diferença é que na EST qualquer informação de um itemset está contido em um nó somente, ao passo que na árvore de prefixos, a mesma informação é compartilhada e acumulada durante a travessia para o nó em 
questão. Para maior clareza, as informações do itemset $\{b, c\}$ são marcadas em ambas as árvores na Figura 2.2.

Muitos algoritmos utilizam essas estruturas de dados robustas para contar a frequência dos itemsets de maneira eficiente. Borgelt e Kruse (2002) desenvolveram um algoritmo Apriori que utiliza a estrutura de dados PT.

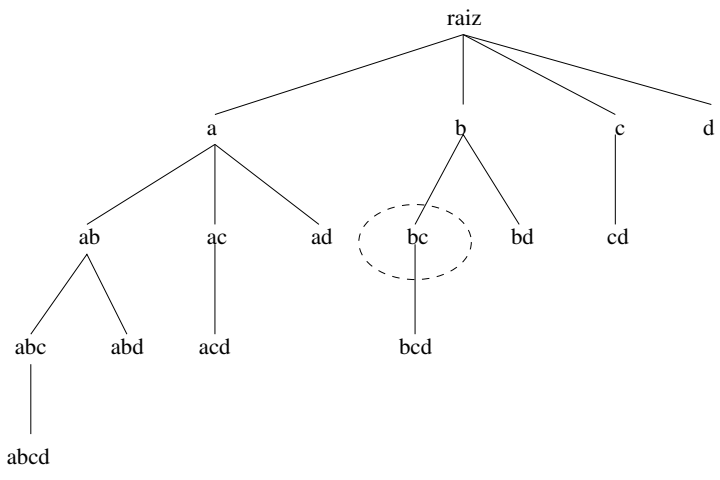

(a) Enumeration Set

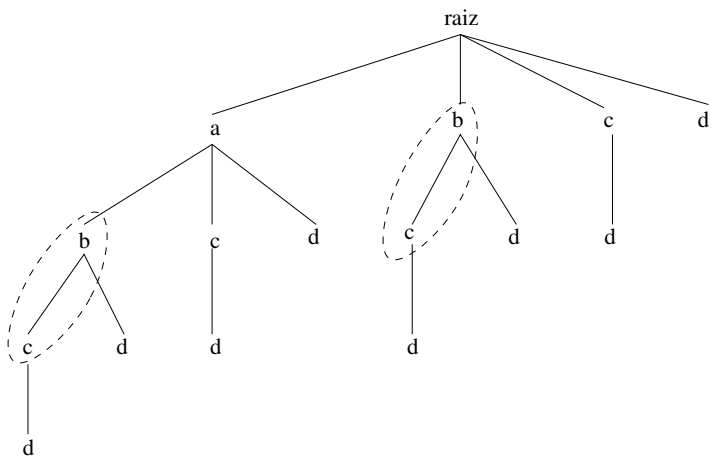

(b) Prefix Tree

Figura 2.2: Estruturas de dados que armazenam itemsets.

\subsubsection{FP-growth}

Uma alternativa para a extração dos FIs é o algoritmo FP-growth (Han et al., 2000). Este algoritmo possui uma distinção bem significativa do algoritmo Apriori, pelo fato de não apresentar o paradigma de gerar-e-testar. Assim, o algoritmo FP-growth extrai os FIs sem a necessidade de geração de candidatos. O FP-growth possui uma estrutura de dados compacta que é chamada de FPtree, similar à Prefix Tree comentada na seção anterior. Essa estrutura é uma codificação do conjunto de dados e por meio dela os FIs são extraídos.

A tarefa de extração dos FIs realizada pelo FP-growth utiliza a estratégia dividir-para-conquistar. Primeiro, há a compressão do conjunto de dados em uma FP-tree, que armazena a informação da frequência dos itemsets. Em seguida, cada item frequente possui, a partir da FP-tree, uma estrutura especial comprimida de todos os possíveis itemsets que podem ser formados com este item. Desta forma, divisões sucessivas do conjunto de dados, representado pela FP-tree, são realizadas separadamente para descobrir os FIs. Resumidamente, a construção da FP-tree e a mineração dos FIs sobre ela são as principais etapas do algoritmo FP-growth. Os detalhes dessa abordagem são apresentados em seguida, baseados em Tan et al. (2006).

Descrição e construção de uma FP-tree

Uma árvore FP-tree é construída a partir de um conjunto de dados formado por transações. Para isso, são necessárias apenas duas passagens pelo 
conjunto de dados. Na primeira passagem, é encontrado o conjunto dos 1itemsets frequentes. Esse conjunto deve ser ordenado de forma decrescente conforme o suporte de cada item. Este ordenamento é importante em virtude dos itens encontrados nos caminhos da FP-tree seguirem a mesma ordem.

Em seguida, mais uma passagem é realizada sobre o conjunto de dados. Uma leitura de cada transação é feita por vez e esta transação é mapeada por um caminho na FP-tree. Como diferentes transações podem conter muitos itens em comum, seus caminhos podem ser sobrepostos. Quanto mais caminhos sobrepostos existirem, maior compressão pode ser alcançada pela FP-tree, conforme explicado à frente. Tal estrutura deve ser mantida em memória para que haja melhor eficiência na mineração.

Tabela 2.3: Conjunto de Dados com Transações

\begin{tabular}{|l|l|}
\hline TID & \multicolumn{1}{|c|}{ Itens } \\
\hline 1 & $\{\mathrm{a}, \mathrm{b}\}$ \\
\hline 2 & $\{\mathrm{~b}, \mathrm{c}, \mathrm{d}\}$ \\
\hline 3 & $\{\mathrm{a}, \mathrm{c}, \mathrm{d}, \mathrm{e}\}$ \\
\hline 4 & $\{\mathrm{a}, \mathrm{d}, \mathrm{e}\}$ \\
\hline 5 & $\{\mathrm{a}, \mathrm{b}, \mathrm{c}\}$ \\
\hline 6 & $\{\mathrm{a}, \mathrm{b}, \mathrm{c}, \mathrm{d}\}$ \\
\hline 7 & $\{\mathrm{a}, \mathrm{f}\}$ \\
\hline 8 & $\{\mathrm{a}, \mathrm{b}, \mathrm{c}\}$ \\
\hline 9 & $\{\mathrm{a}, \mathrm{b}, \mathrm{d}\}$ \\
\hline 10 & $\{\mathrm{~b}, \mathrm{c}, \mathrm{e}\}$ \\
\hline
\end{tabular}

A Tabela 2.3 apresenta um conjunto de dados que contém dez transações e seis itens. Na Figura 2.3 é exibida a evolução de uma FP-tree completa. Cada nó da árvore contém o rótulo de um item juntamente com um contador que informa a quantidade de transações mapeadas por aquele caminho. Inicialmente, a FP-tree contém somente o nó raiz representado pelo símbolo NULO. A árvore FP-tree é formada da seguinte maneira:

1. O conjunto de dados é lido uma vez para determinar o suporte de cada item. Itens infrequentes são descartados. Os itens frequentes devem ser ordenados. Neste exemplo os itens são ordenados de forma decrescente em relação à frequência. Para o conjunto de dados visualizado na Tabela 2.3, $a$ é o item mais frequente, seguido por $b, c, d$ e $e$. O item $f$ é infrequente, pois seu suporte é 1 e o limiar minsup é 2.

2. O algoritmo realiza uma segunda passagem sobre o conjunto de dados para construir a FP-Tree. Depois de ler a primeira transação, $\{a, b\}$, os nós rotulados com $a$ e $b$ são criados. Então, um caminho é formado, (nulo $\longrightarrow \mathrm{a} \longrightarrow \mathrm{b}$ ), para codificar a transação. Todo nó ao longo desse caminho 


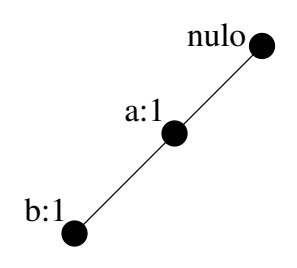

(a) Após ler TID=1

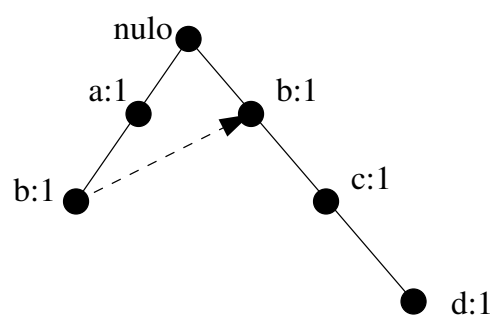

(b) Após ler TID=2

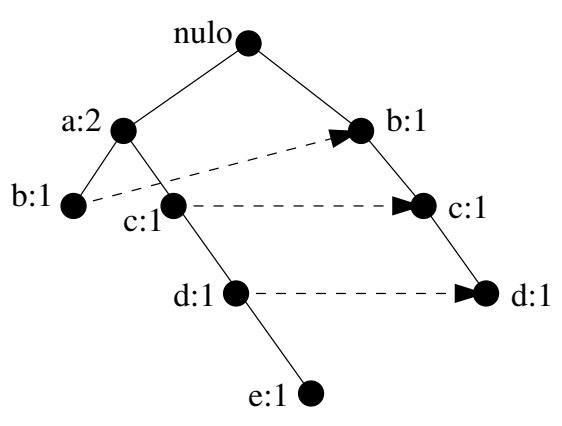

(c) Após ler TID=3

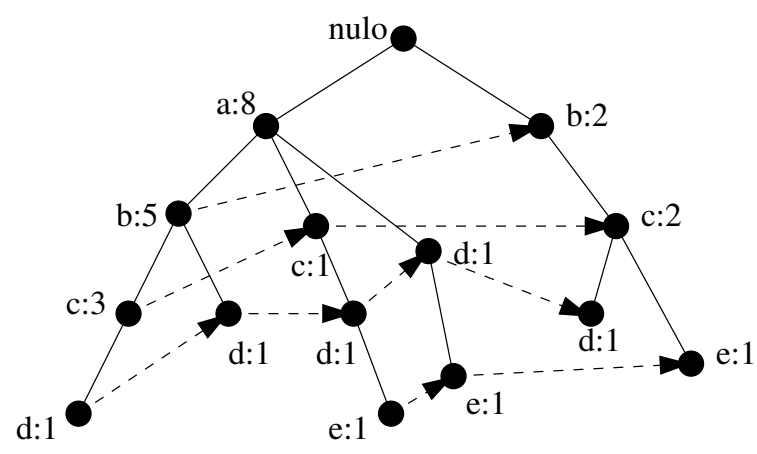

(d) Após ler TID=10

Figura 2.3: Construção de uma FP-tree.

tem frequência igual a 1. Caso a frequência do item $b$ fosse maior que $a$, o caminho deveria ser da forma (nulo $\longrightarrow \mathrm{b} \longrightarrow \mathrm{a}$ ), visto que a ordem pré-estabelecida é da forma decrescente à frequência dos itens.

3. Após leitura da segunda transação, $\{b, c, d\}$, um novo conjunto de nós é criado para os itens $b, c$ e $d$. Um caminho então é formado para representar a transação pela conexão dos nós, (nulo $\longrightarrow \mathrm{b} \longrightarrow \mathrm{c} \longrightarrow \mathrm{d}$ ). Todo nó ao longo desse caminho tem frequência igual a 1. Embora as duas transações lidas tenham um item em comum, que é o item $b$, seus caminhos são disjuntos, pois as transações não compartilham um prefixo em comum. Isto é, a primeira transação inicia com o item prefixo $a$ e a segunda transação inicia com o item prefixo $b$, que inviabiliza a sobreposição desses dois caminhos na FP-tree.

4. A terceira transação $\{a, c, d, e\}$, compartilha um item prefixo em comum, o item $a$, com a primeira transação. Como resultado, o caminho para a terceira transação, (nulo $\longrightarrow \mathrm{a} \longrightarrow \mathrm{c} \longrightarrow \mathrm{d} \longrightarrow \mathrm{e}$ ), sobrepõe com o caminho para a primeira transação. Em virtude do seu caminho sobreposto, a frequência para o nó a é incrementada para 2, enquanto a frequência para os nós recém criados, $c, d$ e e, é igual a 1 .

5. Este processo continua até toda transação ter sido mapeada em um dos 
caminhos encontrados na FP-tree. A FP-tree resultante após leitura de todas as transações é visualizada na Figura 2.3.

Normalmente, o tamanho de uma FP-tree é menor que uma árvore não comprimida em virtude de frequentemente haver transações sobrepostas no conjunto de dados. O melhor cenário é quando todas as transações possuem os mesmos itens, com isso, a FP-tree mantém somente um único ramo de nós. O pior caso é quando cada transação contém um conjunto único de itens. Desta maneira, a FP-tree é similar ao conjunto de dados original.

O tamanho de uma FP-tree também depende de como os itens são ordenados. Se a ordenação dos itens é o contrário daquele definido anteriormente, ou seja, de forma crescente à frequência dos itens, a FP-tree resultante pode ser visualizada na Figura 2.4. A árvore aparenta ser mais densa, por causa da maior quantidade de ramos que saem do nó raiz, de 2 para 5, e a quantidade de nós para os itens mais frequentes aumentarem de 3 para 12 . No entanto, o ordenamento de forma decrescente à frequência não implica necessariamente em uma menor FP-tree (Tan et al., 2006).

Uma FP-tree também mantém uma lista de ponteiros conectando nós que tenham os mesmos itens. Esses ponteiros, representados por linhas pontilhadas, facilitam o acesso rápido dos itens na árvore e ajudam nas sucessivas compressões da mesma. Na próxima seção, é explicado como a FP-tree e seus ponteiros são utilizados para a geração dos FIs.

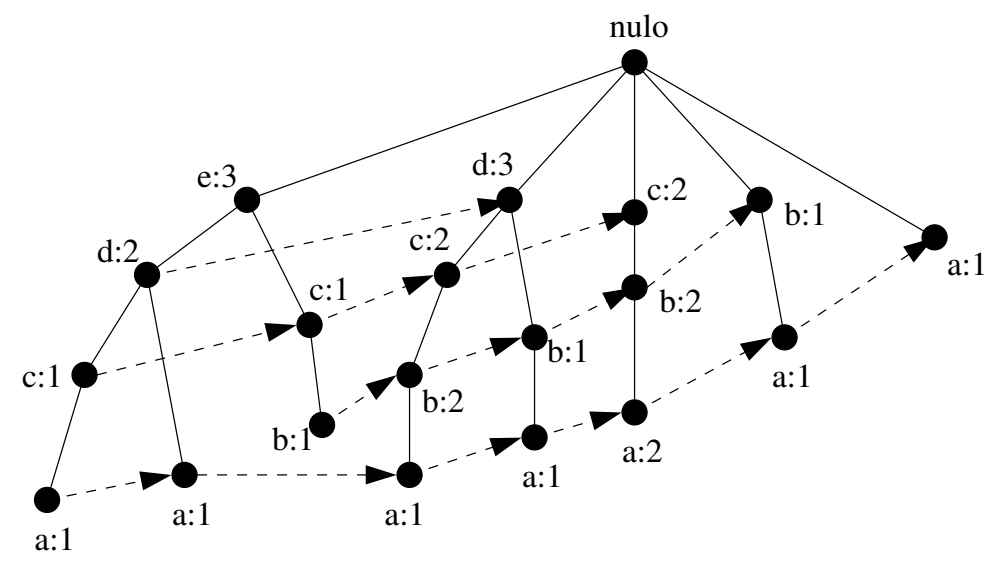

Figura 2.4: Construção de uma FP-tree com ordem crescente da frequência dos itens.

\section{Geração dos Itemsets Frequentes}

O algoritmo FP-growth explora FIs a partir de uma FP-tree. Ele explora esta árvore de maneira bottom-up. Ao utilizar a árvore FP-tree definida na Figura 2.3, o algoritmo explora os FIs que terminam primeiro em $e$, depois por $d, c, b$ e finaliza em $a$. Visto que cada transação é mapeada por um caminho na FPtree, é possivel explorar os FIs que terminam com um item em particular, por 
exemplo o item $e$, inspecionando somente os caminhos que contenham o nó $e$. Esses caminhos podem ser acessados eficientemente por utilizar os ponteiros associados com este nó. Os caminhos extraídos são exibidos na Figura 2.5. Os detalhes de como processar os caminhos para obter os FIs serão explicados em seguida.

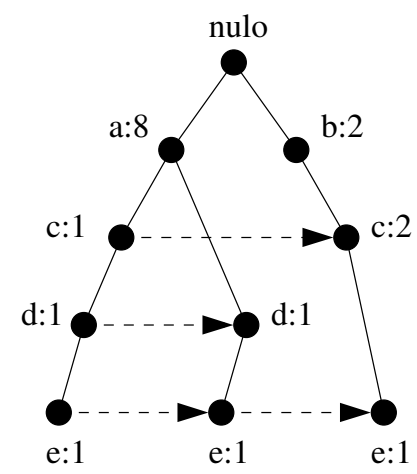

(a) Caminhos contendo o nó e

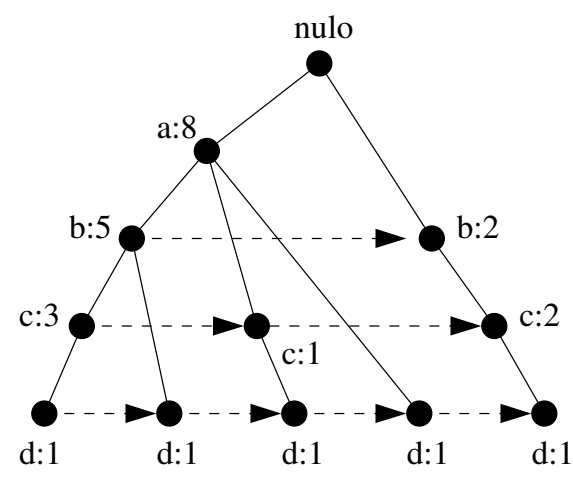

(b) Caminhos contendo o nó d

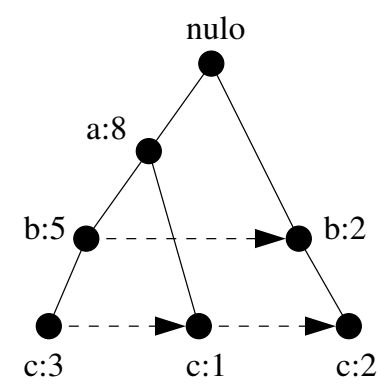

(c) Caminhos contendo o nó c

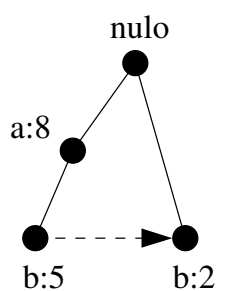

(d) Caminhos contendo o nó b

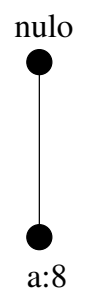

(e) Caminhos contendo o nó a

Figura 2.5: Caminhos utilizados para descobrir FIs que terminam em $e, d, c, b$ e $a$.

Depois de encontrar os FIs que terminam em $e$, o algoritmo avança para procurar os FIs que terminam em $d$ processando os caminhos associados com o nó $d$, que podem ser observados na Figura 2.5(b). Esse processo continua até todos os caminhos associados com $c, b$ e $a$ sejam processados. Os caminhos para esses itens são mostrados nas Figuras 2.5(c), (d) e (e). Os FIs obtidos a partir do conjunto de dados da Tabela 2.3 podem ser verificados na Tabela 2.4 .

$\mathrm{O}$ algoritmo FP-growth encontra todos os FIs que terminam com um particular sufixo pelo emprego de uma estratégia de dividir-para-conquistar para partir o problema em pequenos subproblemas. Por exemplo, para extrair os FIs que terminam em $e$, deve-se inicialmente verificar se $e$ é frequente. Se ele for frequente, o próximo passo é considerar o subproblema de encontrar os FIs que terminam em $d e$, seguido por $c e$, be e $a e$. Por sua vez, cada um desses subproblemas são decompostos em menores subproblemas. Pela união de todos os FIs descobertos por cada um desses subproblemas, são conhecidos os FIs que terminam em $e$. A abordagem dividir-para-conquistar é a estratégia 
Tabela 2.4: Lista dos itemsets frequentes ordenados pelos seus correspondentes sufixos.

\begin{tabular}{|c|l|}
\hline Sufixo & \multicolumn{1}{|c|}{ Itemsets Frequentes } \\
\hline e & $\{e\},\{e, d\},\{e, d, a\},\{e, c\},\{e, a\}$ \\
\hline d & $\{d\},\{d, c\},\{d, c, b\},\{d, c, a\},\{d, b\},\{d, b, a\},\{d, a\}$ \\
\hline c & $\{c\},\{c, b\},\{c, b, a\},\{c, a\}$ \\
\hline b & $\{b\},\{b, a\}$ \\
\hline a & $\{a\}$ \\
\hline
\end{tabular}

chave empregada pelo algoritmo FP-growth.

Para uma observação mais completa de como resolver os subproblemas, considere a tarefa de encontrar os FIs que terminam no item sufixo $e$. Tal exemplo foi retirado em Tan et al. (2006).

1. O primeiro passo é obter todos os caminhos onde e está contido. Os caminhos obtidos são chamados de caminhos de prefixo e são visualizados na Figura 2.5(a).

2. A partir dos caminhos de prefixo, a frequência de $e$ é obtida pela adição das frequências associadas ao nó $e$. Assumindo que a frequência mínima é $2,\{e\}$ é declarado um FI pois sua frequência é 3.

3. Visto que $\{e\}$ é frequente, o algoritmo tem que resolver os subproblemas de encontrar a frequência dos itemsets $d e, c e$, be e ae. Para resolver estes subproblemas, é necessário que antes os caminhos de prefixo sejam convertidos em uma FP-tree condicional, que é estruturalmente similar a uma FP-tree, exceto que é usado para encontrar FIs que terminam com um item em particular. Uma FP-tree condicional é obtida da seguinte maneira:

(a) Inicialmente, a frequência dos nós deve ser atualizada em virtude de alguns caminhos incluírem transações que não contêm o item $\{e\}$. Por exemplo, o caminho mais à direita na Figura 2.6(a), (nulo $\longrightarrow$ b:2 $\longrightarrow \mathrm{c}: 2 \longrightarrow \mathrm{e}: 1)$, inclui uma transação $\{b, c\}$ que não contém o item $\{e\}$. Portanto, as frequências do caminho devem ser ajustadas em 1 para refletir a quantidade atual de transações contendo $\{b, c, e\}$.

(b) Os caminhos são truncados pela remoção dos nós que contém $e$. Esses nós podem ser removidos porque somente são consideradas transações que contenham o item $\{e\}$ e os subproblemas utilizados para encontrar os FIs de, ce, be e ae não necessitam mais de informação relacionada aos nós que contêm $e$. 
(c) Alguns itens podem não ser mais frequentes após a atualização das frequências dos caminhos de prefixo. Por exemplo, o nó $b$ aparece somente uma vez e tem frequência igual a 1 , que significa que há somente uma transação contendo o itemset $b, e$. O item $\{b\}$ pode ser ignorado de forma segura, pois os itemsets formados com ele são infrequentes.

A FP-tree condicional para e é visualizada na Figura 2.6(b). A árvore é diferente dos caminhos prefixos de em virtude da atualização das frequências e a remoção dos nós $b$ e $e$.

4. FP-growth utiliza a FP-tree condicional de $e$ para resolver os subproblemas de encontrar os FIs que terminam em de, ce, e ae. Para encontrar os FIs que terminam em de, os caminhos de prefixo para de, Figura 2.6(c), são obtidos a partir da FP-tree condicional para $e$. As frequências associadas com o nó $d$ são somadas e é obtida a frequência para o itemset $\{d, e\}$. Visto que a frequência é igual a $2,\{d, e\}$ é declarado FI. Em seguida, o algoritmo contrói a FP-tree condicional para de usando a abordagem descrita no passo 3. Após a atualização das frequências e remoção do item infrequente $c$, a FP-tree condicional para de é visualizada na Figura 2.6(d). Visto que a FP-tree condicional contém somente um item, a, cuja frequência é igual ao suporte mínimo, o algoritmo extrai o FI $\{a, d, e\}$ e segue para o próximo subproblema, que é gerar os FIs que terminam em ce. Depois de processar os caminhos de prefixo para ce, Figura 2.6(e), somente o itemset $\{c, e\}$ é frequente. O algoritmo avança para resolver $\mathrm{O}$ próximo subproblema e encontra $\{a, e\}$ como único FI restante.

Este exemplo ilustra a abordagem dividir-e-conquistar usada no algoritmo FP-growth. Em cada passo recursivo, uma FP-tree condicional é construída para atualizar as frequências ao longo dos caminhos de prefixo e remover todos os itens infrequentes. Em virtude dos subproblemas serem disjuntos, FP-growth não gera itemsets duplicados.

FP-growth é um algoritmo interessante pois ilustra como uma representação compacta do conjunto de dados pode proporcionar geração de FIs de forma eficiente. Além disso, para certos conjuntos de dados, FP-growth supera o algoritmo Apriori padrão em várias ordens de magnitude (Tan et al., 2006).

Além do algoritmo original do FP-growth (Han et al., 2000), algumas variações desta técnica foram implementadas. Um estudo sobre a eficiência destas variações pode ser encontrado em Said et al. (2009). 


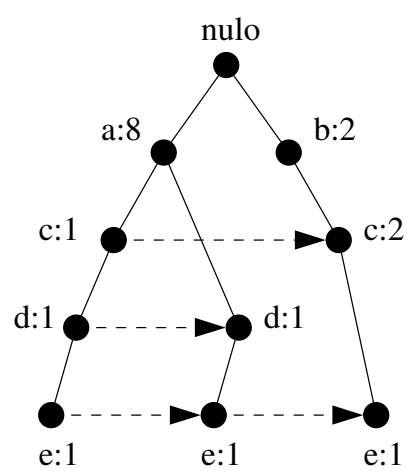

(a) Caminhos de prefixo terminando em e

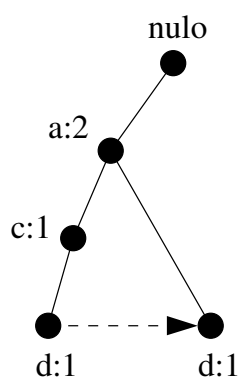

(c) Caminhos de prefixo terminando em de

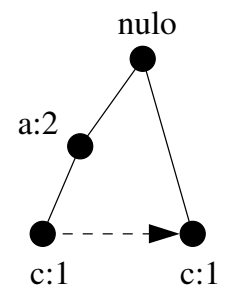

(e) Caminhos de prefixo terminando em ce

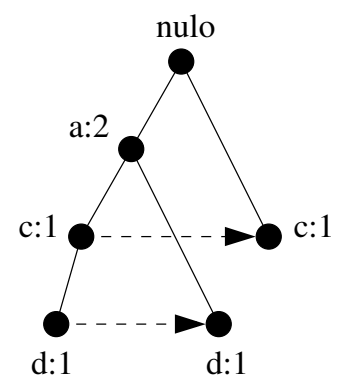

(b) FP-tree condicional para e

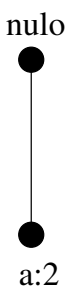

(d) FP-tree condicional para de

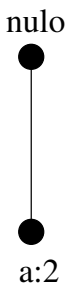

(f) Caminhos de prefixo terminando em ae

Figura 2.6: Exemplo de aplicação do algoritmo FP-growth para encontrar os FIs que terminam em $e$.

\subsection{Avaliação das Regras de Associação}

Como visto no decorrer deste capítulo, a maioria dos algoritmos que descobrem regras de associação utilizam a estratégia dos FIs, como por exemplo o algoritmo Apriori (Agrawal e Srikant, 1994). Essa estratégia descobre todos os FIs que tenham suporte acima do limiar minsup ou suporte mínimo, que é definido pelo usuário. A partir desses FIs são produzidas as regras de associação. Esta abordagem, pode ser eficiente se houver poucos FIs. No entanto, esta estratégia sofre algumas limitações (Webb e Zhang, 2005):

1. Se o minsup não for tão baixo, muitos FIs que podem ser de interesse não serão descobertos. Por exemplo, em supermercados, produtos mais caros dificilmente são comprados juntos, ou seja, possuem uma baixa frequência. No entanto, é de muito interesse conhecer o comportamento de consumidores com alto poder aquisitivo. 
2. Caso o minsup for muito baixo, o processo de mineração das regras de associação pode ser impraticável. Isto depende da dimensionalidade e quantidade de transações.

3. Somente o suporte pode restringir a quantidade de FIs. Isto não é possível por meio da medida confiança. Desta forma, restringir a busca pela medida suporte não garante a geração de todas as regras interessantes.

Normalmente, uma quantidade excessiva de regras de associação é gerada quando o minsup é relativamente pequeno. Porém, apenas uma pequena quantidade dessas regras são provavelmente interessantes para qualquer especialista. Isso se deve ao fato da grande maioria das regras geradas serem óbvias ou irrelevantes. Portanto, não acarretando em nenhum conhecimento novo e útil. Outra dificuldade é encontrada na medida confiança. Esta medida não consegue medir a independência entre os participantes da regra. Isto pode caracterizar em uma falsa ideia de interesse ou resultados contraintuitivos (Tan e Kumar, 2000). Para vencer estas dificuldades, medidas de interesse são utilizadas para encontrar somente àquelas regras ou padrões que possam ser interessantes ou de relevância no domínio em que se almeja minerar.

Para definir adequadamente as medidas de interesse é necessário estabelecer um conjunto de critérios que sejam bem aceitos para avaliar a qualidade das regras ou padrões. Estes critérios podem ser objetivos e subjetivos.

Os critérios objetivos podem ser estabelecidos por argumentos estatísticos (Tan et al., 2006). Regras que envolvem um conjunto de itens mutuamente independentes ou que ocorrem em uma pequena fração de transações no conjunto de dados podem não conter nenhuma informação relevante. A aplicação de medidas de interesse objetivas pode considerar tais regras desinteressantes. Isto é alcançado em virtude de se levar em conta a correlação (co-ausência e co-ocorrência) entre os participantes da regra por meio de técnicas estatísticas. Exemplos dessas medidas são suporte e confiança, que já foram descritos na definição de regras de associação.

Em relação aos critérios subjetivos, um padrão é considerado desinteressante se ele for óbvio, ou seja, um especialista já conhece esse padrão e seu conhecimento não acarreta em informação nova. Por exemplo (Tan et al., 2006), a regra Manteiga $\rightarrow$ Pão não é novidade e não é considerada interessante, pois pode ser considerada óbvia para um especialista, apesar de apresentar alto suporte e alta confiança. Enquanto que a regra Fralda $\rightarrow$ Cerveja pode ser considerada interessante. Isto acontece porque esta regra não é esperada e sugere um novo conhecimento que pode ser proveitoso e trazer benefícios. A tarefa de encontrar regras interessantes por meio de informações subjetivas é difícil, por causa da necessidade em conhecer previamente informações dos 
especialistas de domínio. Como o foco do trabalho são as medidas de interesse objetivas, a seguir, é descrito em maiores detalhes, o conceito acerca de tais medidas.

Por causa das dificuldades encontradas com as medidas suporte e confiança, outras medidas foram definidas para medir o interesse das regras de associação. As medidas objetivas avaliam as regras de acordo com valores quantitativos, ou seja, a partir da frequência dos participantes da regra.

Para que uma medida objetiva seja considerada uma boa medida, ela deve satisfazer três propriedades (Piatetsky-Shapiro e Frawley, 1991). Dada uma regra $X \rightarrow Y$, sendo que são conhecidos o seu interesse $K$ e as probabilidades dos seus membros, $P(X), P(Y)$ e $P(X, Y)$ :

Propriedade 1: se $K=0$, então $X$ e $Y$ são estatisticamente independentes;

Propriedade 2: $K$ aumenta monotonicamente com $P(X, Y)$ quando $P(X)$ e $P(Y)$ permanecem constantes;

Propriedade 3: $K$ decresce monotonicamente com $P(X)$ (ou $P(Y)$ ) quando todos os outros parâmetros $P(X, Y)$ e $P(Y)$ (ou $P(X)$ ) se mantém inalterados.

Estas propriedades são bem-conhecidas e também aplicadas em várias medidas objetivas.

A partir dos seguintes valores, $P(X), P(Y)$ e $P(X, Y)$, é possivel conhecer o valor de muitas medidas de interesse objetivas. Para conhecer o valor de outras medidas de interesse objetivas é necessário conhecer outros valores das relações entre o antecedente e o consequente de uma regra. Isto pode ser obtido por meio de uma Tabela de Contingência.

A Tabela 2.5 mostra um exemplo de tabela de contingência para um par de variáveis binárias. A notação $P(\bar{X})$ serve para indicar a razão da quantidade de transações que $X$ não está contido. Cada $P(i, j)$ na tabela significa uma razão de frequência. Por exemplo, $P(X, Y)$ significa a razão da quantidade de transações que $X$ e $Y$ aparecem juntos, ou seja, seu suporte. No caso de $P(X, \bar{Y})$, significa a razão da quantidade de transações em que $X$ aparece e $Y$ não. O termo $P(X)$ representa a soma da primeira linha, isto é, o suporte de $X$, enquanto $P(Y)$ é a soma da primeira coluna e representa o suporte de $Y$.

Medidas objetivas podem ser divididas em duas categorias. Estas categorias são simétricas e assimétricas. Uma medida $K$ é simétrica quando não importa a ordem da implicação da regra, isto é, $K(X \rightarrow Y)=K(Y \rightarrow Y)$ e assimétrica quando a ordem da implicação altera o resultado da medida, $K(X \rightarrow Y) \neq K(Y \rightarrow X)$.

A seguir é apresentada a descrição de algumas medidas de interesse objetivas simétricas e assimétricas que servem para avaliar a qualidade e correlação 
Tabela 2.5: Tabela de Contingência para duas variáveis binárias $X$ e $Y$

\begin{tabular}{|l|l|l|l|}
\hline & $Y$ & $\bar{Y}$ & \\
\hline$X$ & $P(X, Y)$ & $P(X, \bar{Y})$ & $P(X)$ \\
\hline $\bar{X}$ & $P(\bar{X}, Y)$ & $P(\bar{X}, \bar{Y})$ & $P(\bar{X})$ \\
\hline & $P(Y)$ & $P(\bar{Y})$ & 1 \\
\hline
\end{tabular}

das regras de associação. Inicialmente, as medidas objetivas simétricas são relatadas.

Cobertura é uma medida que se refere ao suporte do antecedente de uma regra e ao suporte de um itemset. Considere a regra $X \rightarrow Y$, então a sua cobertura é de acordo com a Equação 2.7.

$$
\text { cober }=P(X)
$$

Confiança é uma medida de interesse que se refere à probabilidade condicional do consequente dado um antecedente. Considere a regra $X \rightarrow Y$, então a sua confiança é de acordo com a Equação 2.8;

$$
\operatorname{conf}=P(Y \mid X)=\frac{P(X, Y)}{P(X)}
$$

Lift ou Fator de Interesse (Brin et al., 1997) esta medida de interesse objetiva surgiu para superar o problema da medida confiança, que não leva em consideração o suporte do itemset que aparece no consequente da regra e assim não consegue medir o desvio da independência estatística. Esta medida calcula a razão entre a confiança da regra e o suporte do consequente da regra, de acordo com a Equação 2.9.

$$
I=\frac{P(X, Y)}{P(X) P(Y)} \text { ou } \frac{P(Y \mid X)}{P(Y)} \text {. }
$$

Lift pode ser interpretada da seguinte maneira: quando lift $=1$ significa que $X$ e $Y$ são independentes, se lift $>1$ ambas são correlacionadas positivamente e quando lift $<1$ há correlação negativa entre $X$ e $Y$.

Coeficiente de Correlação é uma medida que analisa relacionamentos entre par de variáveis. Para variáveis binárias, tal medida é calculada pela Equação 2.10.

$$
\phi=\frac{P(X, Y)-P(X) P(Y)}{\sqrt{P(X) P(Y) P(\bar{X}) P(\bar{Y})}}
$$


O coeficiente de correlação leva em consideração a co-ocorrência e coausência entre o antecedente e o consequente de uma regra. Esta medida tem variação de - 1 (Correlação Negativa Perfeita) a 1 (Correlação Positiva Perfeita). Quando as variáveis são estatisticamente independentes, $\phi=$ 0 . Esta medida é análoga ao coeficiente de correlação de Pearson para variáveis contínuas (Tan e Kumar, 2000).

all-Confidence (Omiecinski, 2003) é uma medida que identifica correlação entre os membros de uma regra. Seu valor não é alterado pelas transações que não contêm os itens envolvidos na regra, isto é, são consideradas apenas transações que contém os itens participantes da regra. $h$ é dado pela Equação 2.11.

$$
h=\min \left[\frac{P(X, Y)}{P(X)}, \frac{P(X, Y)}{P(Y)}\right]
$$

Odds ratio (Mosteller, 1968) representa a probabilidade dos diferentes efeitos de um item. Por exemplo, considere uma regra de associação $X \rightarrow Y$ juntamente com a tabela de contingência exibida na Tabela 2.5. Se $Y$ está presente, então a probabilidade de encontrar $X$ na mesma transação é $\frac{P(X, Y)}{P(\bar{X}, Y)}$. Por outro lado, se $Y$ for ausente, então a probabilidade de encontrar X é $\frac{P(X, \bar{Y})}{P(\bar{X})}$. Se não houver associação entre $X$ e $Y$ então a probabilidade de encontrar $X$ em uma transação deve ser mantida, independentemente da presença de $Y$. Portanto, utiliza-se a razão dessas probabilidades (Equação 2.12) para determinar o grau de associação entre $X$ e $Y$. Odds ratio varia de 0 a $+\infty$.

$$
\alpha=\frac{P(X, Y) P(\bar{X}, \bar{Y})}{P(X, \bar{Y}) P(\bar{X}, Y)}
$$

Kappa (Tan e Kumar, 2000) assim como o coeficiente de correlação, leva em consideração a co-presença e co-ausência dos itens. É definido de acordo com a Equação 2.13.

$$
k=\frac{P(X, Y)+P(\bar{X}, \bar{Y})-P(X) P(Y)-P(\bar{X}) P(\bar{Y})}{1-P(X) P(Y)-P(\bar{X}) P(\bar{Y})}
$$

Piatetsky-Shapiro $(P S)$ (Piatetsky-Shapiro e Frawley, 1991) é análogo ao Fator de Interesse $I$ e é medido de acordo com a Equação 2.14. Seu domínio varia de $-0,25$ a 0,25 .

$$
P S=P(X, Y)-P(X) P(Y)
$$


IS-Measure (Tan e Kumar, 2000) é uma medida que leva em conta o suporte e o interesse de uma regra. É medido de acordo com a Equação 2.15.

$$
I S=\frac{P(X, Y)}{\sqrt{P(X) P(Y)}}
$$

Jaccard (Tan et al., 2004) é uma medida muito utilizada em recuperação de informação para medir a similaridade entre documentos. Jaccard é calculada pela Equação 2.16.

$$
\zeta=\frac{P(X, Y)}{P(X)+P(Y)-P(X, Y)}
$$

A seguir, são descritas medidas de interesse objetivas assimétricas, na qual a ordem da implicação altera o seu resultado. Embora tais medidas sejam análogas à medida confiança, elas capturam a dependência entre as partes da regra com mais robustez.

Convicção (Brin et al., 1997), da mesma forma que confiança, a convicção mede a força da implicação de uma regra de acordo com a Equação 2.17.

$$
V=\frac{P(X) P(\bar{Y})}{P(X, \bar{Y})}
$$

Fator de Certeza (Brin et al., 1997) é uma versão assimétrica do Fator de interesse. Varia de -1 a 1, de acordo com a Equação 2.18.

$$
F=\frac{P(Y \mid X)-P(Y)}{1-P(Y)}
$$

Added value foi introduzido por Sahar e Mansour (1999) como uma versão assimétrica do Fator de interesse. Varia de -0.5 a 1, conforme a Equação 2.19 .

$$
A V=P(Y \mid X)-P(Y)
$$

\subsection{Considerações Finais}

Neste capítulo foram apresentados os conceitos relacionados à definição de regras de associação, assim como dois do algoritmos (Apriori e FP-growth) que descobrem os FIs. Além disso, foram apresentadas medidas utilizadas para avaliação de regras, conhecidas como medidas de interesse objetivas. 
Medidas de interesse selecionam as regras interessantes e filtram as desinteressantes. Entretanto, essas medidas são utilizadas na fase de pósprocessamento e portanto não melhoram a eficiência da geração das regras de associação.

Para descobrir de forma eficiente regras de associação que otimizam medidas de interesse objetivas foi necessário o desenvolvimento de técnicas que exploram essas regras diretamente. Algumas técnicas que realizam esse objetivo são descritas em detalhes no próximo capítulo. 


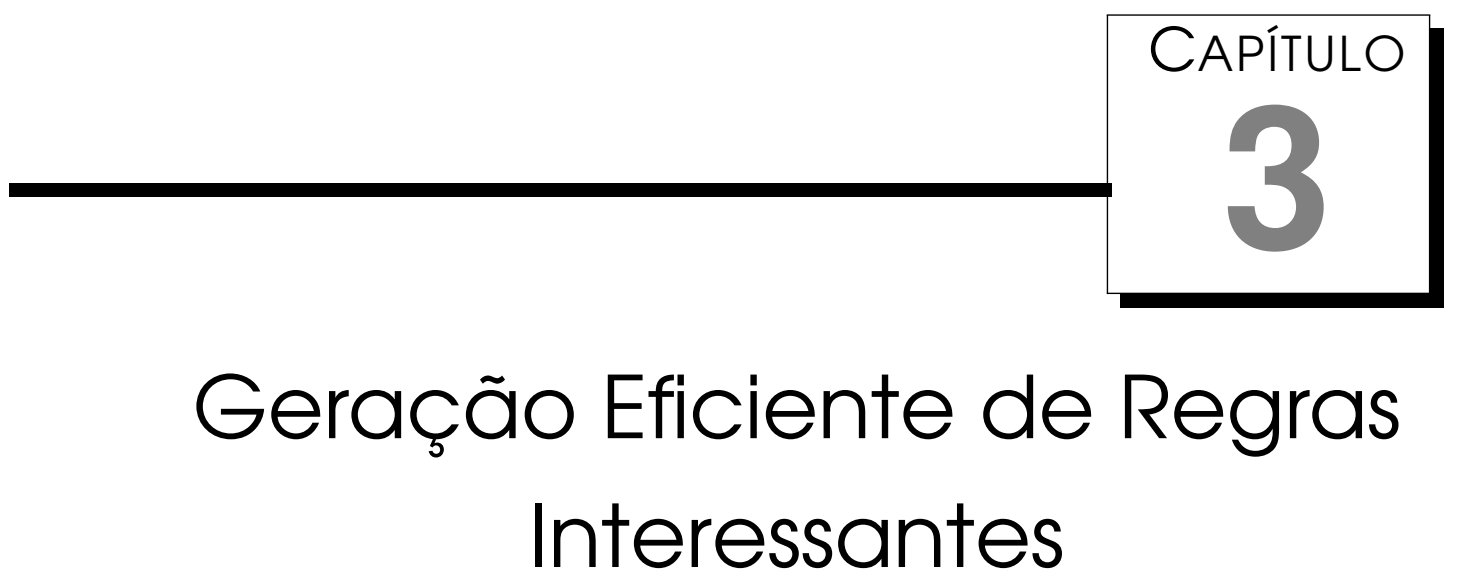

Como já se sabe, uma grande quantidade de regras de associação é gerada quando o limiar minsup ou suporte mínimo é relativamente baixo. Isto é, quanto menor é o suporte mínimo, maior é a quantidade de regras geradas e mais custoso é o processo de mineração dessas regras. Para selecionar as regras interessantes e filtrar as desinteressantes foram propostas várias medidas de interesse. Entretanto, estas medidas funcionam como uma fase de pós-processamento e portanto não melhoram a eficiência da tarefa de mineração das regras. Muitos trabalhos focam a geração eficiente das regras de associação de tal forma que otimizam alguma medida de interesse (Webb, 2000; Li e Zhang, 2003). Neste capítulo são descritos trabalhos correlatos que compartilham este mesmo objetivo.

Uma forma simples para melhorar a eficiência da geração de regras é remover da busca itens que não são de interesse, isto é, itens que um usuário não deseja que faça parte da mineração. Lopes et al. (2007) efetuam uma busca por regras de associação que são empregadas na visualização de documentos textuais. Nesse contexto, termos e documentos são considerados, respectivamente, itens e transações. A intenção é utilizar as regras para a cobertura de tópicos relacionados a um conjunto de documentos. Um dos entraves desse trabalho é a grande quantidade de regras que podem ser geradas, e isso dificulta a escolha das melhores. Além disso, as regras descobertas e selecionadas devem garantir uma boa descrição dos tópicos em relação aos documentos.

Outra dificuldade tratada nesse trabalho é o problema de atributos irrele- 
vantes. Tais atributos não são de interesse ao usuário, pois não acarretam informação útil. Para encontrá-los foi definida uma medida que leva em consideração a relevância dos termos na regra. Essa relevância é refletida pela combinação de termos que descrevem um conjunto de documentos (grupo de documentos) e minimamente descrevem outros. Conforme essa medida, alguns termos (itens) são considerados na busca das regras e outros são descartados pelo baixo interesse. Portanto, adotando esta estratégia, além de encontrar boas regras para resolução do problema, o método ganha maior eficiência em virtude da remoção de alguns termos (itens). No entanto, a remoção de itens ou termos depende do problema em questão e não pode ser generalizada para qualquer caso.

A tarefa de descoberta de regras interessantes tem sido abordada ao longo dos anos de várias maneiras. Para atacar esse problema, as abordagens desenvolvidas utilizam restrições e heurísticas para diminuir o espaço de possibilidades de regras e com isso minimizar o tempo da mineração. Isto significa que é preciso limitar a quantidade de FIs considerados durante o processo. Conforme Bayardo e Agrawal (1999), as estratégias para descoberta de regras interessantes podem ser divididas de três formas:

- por restrições;

- por heurísticas; e

- por buscar regras ótimas.

Trabalhos que exploram essas estratégias são descritos a seguir. Vale ressaltar que o trabalho desenvolvido nesta pesquisa se encaixa na exploração por regras ótimas, mas podem ser inseridas restrições e heurísticas que podem ajudar no trabalho de busca por regras interessantes.

\section{1 Mineração baseada em restrições}

Uma das maneiras para minerar regras de associação é com a utilização de restrições. Suporte mínimo é um exemplo de restrição que controla a quantidade de FIs gerados durante a mineração. Quanto menor for o suporte mínimo, maior é a quantidade de FIs exploradas. Diferentemente do suporte mínimo, as medidas de interesse apenas controlam a quantidade de regras de associação oriundas dos FIs. Portanto, não acarreta em diminuição do tempo de mineração. Restrições que controlam a quantidade de regras e ao mesmo tempo se preocupam com a qualidade delas são descritas a seguir. 


\subsubsection{Regras redundantes e Melhoria mínima}

Regras de associação redundantes possuem itens no antecedente da regra que são ocasionadas por outros itens no antecedente (Zaki, 2000). Tais regras que mantém essas características não informam nenhum conhecimento novo. Uma forma de evitar regras redundantes do tipo $X \rightarrow Y$ é pela equivalência da cobertura entre uma regra mais geral e outra específica, isto é, quando acontece a igualdade $\operatorname{cober}(X)=\operatorname{cober}(X-Z)$, onde $\exists Z \in X$. Essa equivalência implica em outras igualdades, como o suporte $\sup (X \rightarrow Y)=\sup (X-Z \rightarrow Y) \mathrm{e}$ a confiança $\operatorname{con} f(X \rightarrow Y)=\operatorname{con} f(X-Z \rightarrow Y)$. Percebe-se que não houve uma maior confiança e portanto a especialização da regra é apenas uma redundância da regra mais geral.

Outra restrição utilizada para explorar regras interessantes é a melhoria mínima ou improvement mínimo (Bayardo et al., 1999). A melhoria de uma regra é definida como a menor diferença entre sua confiança e a confiança de qualquer regra mais geral com o mesmo consequente. O usuário deve definir um limiar de melhoria mínima e a melhoria de qualquer regra mais especializada deve ser maior ou igual que essa restrição. Tal restrição é mais poderosa que a restrição para evitar regras redundantes (Webb, 2007). A definição da melhoria de uma regra especializada $X \rightarrow Y$ é da forma

$$
\text { melhoria }(X \rightarrow Y)=\operatorname{conf}(X \rightarrow Y)-\max _{Z \subset X} \operatorname{conf}(Z \rightarrow Y) .
$$

Se o valor da melhoria for positivo, significa que a especialização da regra fez com que a confiança aumentasse. Isto significa que o item adicionado contribuiu para melhorar a predição da regra. Regras com melhoria negativa podem ser descartadas, pois não contribuem para melhorar a confiança em relação às regras mais gerais. A melhoria de uma regra redundante não pode ser maior que zero. Portanto, restrições para regras com melhoria positiva eliminam todas as regras redundantes. Essas restrições discutidas contribuem para diminuir o tempo gasto na mineração, pois descartam FIs desinteressantes durante a busca.

\subsubsection{Padrões Hiper-cliques}

Na Figura 3.1 é ilustrada a distribuição do suporte dos itens encontrados no conjunto de dados censitário pumsb (Frank e Asuncion, 2010). Tal conjunto geralmente é utilizado como benchmark para avaliar o desempenho de algoritmos que exploram regras de associação. Sobre esse conjunto de dados é possivel observar que $81.5 \%$ dos itens tem suporte inferior a $1 \%$, enquanto que 0.95\% dos itens tem suporte superior que 90\%. Essa característica é muito propícia para geração de padrões suporte-cruzado ou (cross-support patterns - 
CSP). Tais padrões são FIs que envolvem itens com suportes substancialmente diferentes (Xiong et al., 2003).

Distribuição do Suporte do Conjunto de Dados Pumsb

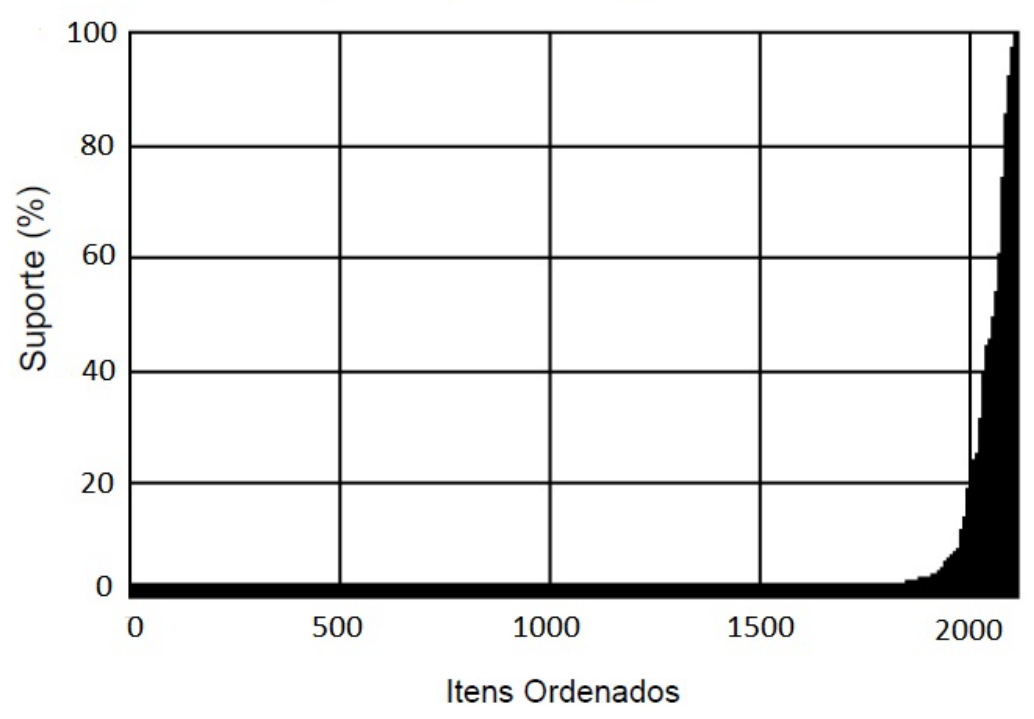

Figura 3.1: Distribuição de Suporte de um Conjunto de Dados

Para entender melhor a característica dos CSP, os itens distribuídos na Figura 3.1 são divididos em 5 grupos, conforme a Tabela 3.1. No primeiro grupo está contido a maioria dos itens. Para que sejam explorados FIs a partir desse grupo é necessário que o suporte mínimo seja menor que $1 \%$. No entanto, tal limiar degradará o desempenho dos algoritmos que capturam estes FIs. Se o suporte mínimo for relativamente baixo, por exemplo, 0.5\%, muitos CSP envolvendo itens do grupo 1 (itens raros) e do grupo 5 (itens mais frequentes) serão gerados. Esses CSP possuem baixa correlação, pois a presença de um item encontrado no grupo 5 não necessariamente influencia a ocorrência de um item situado no grupo 1. Sabendo disso, há a necessidade de desenvolver técnicas que eliminam esses tipos de padrões para tornar a busca eficiente.

Uma alternativa ao suporte mínimo e que possui propriedade anti-monotônica é a medida all-confidence (Omiecinski, 2003). Esta medida representa a confiança mínima de todas as regras de associação extraídas a partir de um FI. Os padrões oriundos a partir dessa medida são considerados padrões hiper-cliques e por conseguinte não têm suporte-cruzado. Desta forma, é possivel encontrar eficientemente FIs e regras com alta afinidade, isto é, alta correlação.

No trabalho de Xiong et al. (2003), a medida all-confidence é chamada de h-confidence. Para um FI da forma $X=\left\{i_{1}, i_{2}, \ldots, i_{n}\right\}$, a Equação 3.2 calcula o h-confidence.

$$
h-\operatorname{confidence}(X)=\frac{\sup \left(\left\{i_{1}, i_{2}, \ldots, i_{n}\right\}\right)}{\max _{1 \leq k \leq n}\left\{\sup \left(\left\{i_{k}\right\}\right)\right\}}
$$


Tabela 3.1: Grupos de itens para o conjunto de dados pumsb.

\begin{tabular}{|c|c|c|c|c|c|}
\hline Grupo & G1 & G2 & G3 & G4 & G5 \\
\hline Suporte & $0-1 \%$ & $1 \%-5 \%$ & $5 \%-40 \%$ & $40 \%-90 \%$ & $>90 \%$ \\
\hline$N^{o}$ Itens & 1735 & 206 & 101 & 51 & 20 \\
\hline
\end{tabular}

A medida $h$-confidence possui propriedade anti-monotônica e pode ser utilizada como restrição no algoritmo de busca da mesma forma que acontece quando se utiliza o suporte mínimo. Para que isso aconteça é necessário conhecer o limitante superior desta medida. Para um itemset $X$, a Equação 3.3 estabelece essa propriedade. Essa definição de limitante superior é útil para descrever a propriedade de suporte-cruzado. Os itemsets com limitante superior inferior que um limiar arbitrário de $h$-confidence são garantidos serem CSP e não é preciso conhecer seu suporte.

$$
\operatorname{upper}(X)=\frac{\min _{1 \leq l \leq n\left\{\sup \left(\left\{i_{l}\right\}\right)\right\}}}{\max _{1 \leq k \leq n\left\{\sup \left(\left\{i_{k}\right\}\right)\right\}}}
$$

Tal restrição garante com eficiência a descoberta de regras com alta correlação conforme algumas medidas de interesse, como Jaccard e IS-Measure. No entanto, outras medidas de interesse não possuem tais propriedades e são eliminadas durante a busca.

\subsection{Mineração baseada em heurísticas}

As técnicas que mineram regras e são baseadas em heurísticas tentam encontrar regras que são preditivas, mas não garantem a completude para medidas de interesse do conjunto de regras descobertas (Bayardo e Agrawal, 1999).

\subsection{Técnicas baseadas em agrupamento}

Alguns trabalhos que utilizam agrupamento de dados foram desenvolvidos para descobrir regras de associação interessantes. Zhao et al. (2004) propuseram uma nova medida de interesse baseada em agrupamento. O interesse de uma regra é medido pela dissimilaridade entre os clusters. Desta forma, regras desinteressantes são filtradas enquanto que as interessantes são mantidas. Este método é ineficiente para encontrar regras com alta correlação, visto que o algoritmo busca por regras que tenham maior dissimilaridade entre os itens. No entanto, o critério julgado pelo autor é que regras interessantes tenham pouca relação entre si. 
Em Plasse et al. (2007), algoritmos de agrupamento de dados são utilizados para agrupar atributos com alta correlação. A partir de cada grupo de atributos ou itens são geradas regras de associação. Vários métodos de agrupamento são utilizados e suas partições são comparadas. Poucas regras foram produzidas e dentre elas foram encontradas regras raras com forte associação. Como avaliação, um ranking utilizando a medida de interesse Jaccard é feito sobre as regras de associação extraídas. A metodologia proposta foi aplicada sobre dados de uma indústria automobilística.

\subsubsection{Técnicas baseadas em algoritmos genéticos}

Algoritmos Genéticos também foram empregados para a descoberta de regras de associação interessantes. Wakabi-Waiswa e Baryamureeba (2007) propuseram a combinação de três medidas objetivas (Comprehensibility, $J$ Measure e predictive accuracy) para o cálculo do fitness de regras que são consideradas indivíduos na população de soluções e outras modificações são feitas na fase de cruzamento e mutação para indução de novas regras. O trabalho proposto por Yan et al. (2005) é considerado independente do conjunto de dados. Ele tenta superar o problema da definição do limiar suporte mínimo e propõe a descoberta de regras de associação interessantes por meio de uma estratégia de mineração evolutiva, chamada de ARMGA. Nesta abordagem, baseada em algoritmo genético, não são requeridas restrições definidas por usuário, como suporte e confiança. Portanto, o problema de minerar regras de associação interessantes é modelado como um problema multi-objetivo em virtude de haver várias soluções em paralelo durante o processo de busca. Entretanto, neste tipo de abordagem não são garantidos resultados ótimos, ou seja, regras de associação que otimizam alguma medida de interesse podem não ser descobertas.

\subsection{Mineração baseada em regras ótimas}

O problema da geração direta de regras ótimas foi primeiramente idealizado por Webb (1995). Em sua abordagem eram procuradas regras para classificação com alta predição (alta confiança) de forma eficiente. Depois, foram investigadas técnicas que forneciam uma alternativa para a abordagem de FIs. A intenção era descobrir associação entre conjuntos de itens sem que fosse necessário encontrar os FIs primeiro. Tais técnicas dependem de comparações entre regras de associação e essas comparações evitam que regras com pouca qualidade sejam geradas. Este problema é considerado NP-difícil (Morishita e Sese, 2000). Muitas abordagens para a descoberta de regras ótimas foram desenvolvidas e são descritas com detalhes em seguida. 


\subsubsection{Fronteira Suporte-Confiança}

Bayardo e Agrawal (1999) propuseram um método para gerar as regras consideradas ótimas conforme o framework de suporte e confiança. Além disso compararam estas regras ótimas com várias medidas objetivas conhecidas. Eles mostraram que as regras mais interessantes se situavam ao longo da fronteira de suporte-confiança, dado um conjunto de regras $X \rightarrow Y$, no qual o consequente $Y$ seja fixo. Tan et al. (2004) relataram que o motivo deste método encontrar as regras ótimas para um dado consequente fixo é que a medida objetiva torna-se uma função de apenas dois parâmetros, as probabilidades $P(X, Y)$ e $P(X)$, ou seja, o suporte da regra $P(X, Y)$ e a confiança da regra $P(Y \mid X)$. A razão de algumas medidas objetivas se encontrarem ao longo da fronteira de suporte-confiança é porque são funções monotônicas em relação ao suporte e/ou confiança. A seguir são descritas as particularidades do método.

Um conjunto de medidas de interesse respeita a primeira fronteira de suporte e confiança, sc-optimal, que é definida pelas seguintes propriedades. Considere as duas seguintes condições que estabelecem a ordem entre regras $\leq_{S C}$. Conhecendo as regras $r_{1}$ e $r_{2}, r_{1} \leq_{S C} r_{2}$, se e somente se:

1. $\sup \left(r_{1}\right) \leq \sup \left(r_{2}\right) \wedge \operatorname{conf}\left(r_{1}\right)<\operatorname{conf}\left(r_{2}\right)$, ou

2. $\sup \left(r_{1}\right)<\sup \left(r_{2}\right) \wedge \operatorname{conf}\left(r_{1}\right) \leq \operatorname{conf}\left(r_{2}\right)$.

A fronteira definida por estas duas propriedades, sc-optimal, é apresentada na Figura 3.2. As regras situadas fora desta fronteira falham as restrições de otimalidade da busca.

Da mesma forma, um conjunto de medidas de interesse respeita as seguintes propriedades de ordem de regras. Considere a seguinte ordem $\leq_{S \neg C}$ tal que $r_{1} \leq_{S \neg C} r_{2}$ se e somente se:

1. $\sup \left(r_{1}\right) \leq \sup \left(r_{2}\right) \wedge \operatorname{conf}\left(r_{1}\right)>\operatorname{conf}\left(r_{2}\right)$, ou

2. $\sup \left(r_{1}\right)<\sup \left(r_{2}\right) \wedge \operatorname{conf}\left(r_{1}\right) \geq \operatorname{conf}\left(r_{2}\right)$.

O conjunto de regras que satisfaz essas propriedades forma uma fronteira inferior, $s \neg c$-optimal, e é visualizada na Figura 3.2. A seguir é explicado o motivo de algumas medidas de interesse respeitarem essas fronteiras.

Uma medida de interesse $\mathcal{M}$ é representada por $\leq_{S C}$ da seguinte maneira:

1. $\mathcal{M}(r)$ é monotônica no suporte sobre as regras com a mesma confiança;

2. $\mathcal{M}(r)$ é monotônica na confiança sobre as regras com o mesmo suporte; 


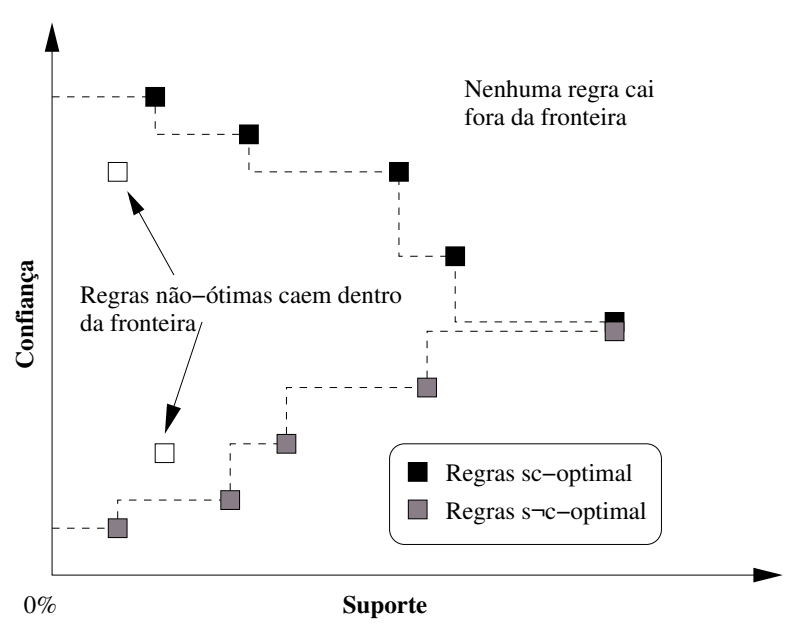

Figura 3.2: Fronteira suporte-confiança.

Este comportamento pode ser visualizado na fronteira suporte-confiança da Figura 3.2. Uma medida de interesse que respeita $\leq_{S C}$ é a medida Lift:

$$
\operatorname{Lift}(X \rightarrow Y)=\frac{P(Y \mid X)}{P(X)}
$$

Como observado, Lift é monotônica pela confiança e não é afetada pelo suporte da regra quando a confiança é mantida fixa. Tais características foram observadas nas medidas $P S$ e Convicção.

Uma medida de interesse $\mathcal{M}$ é representada por $\leq_{S \neg C}$ da seguinte maneira:

1. $\mathcal{M}(r)$ é monotônica no suporte sobre as regras com a mesma confiança;

2. $\mathcal{M}(r)$ é anti-monotônica na confiança sobre as regras com o mesmo suporte;

As medidas entropia, gain e chi-quadrado são afetadas por esse comportamento e as provas disso podem ser obtidas em Bayardo e Agrawal (1999).

O algoritmo para recuperar as regras ótimas é uma variante do DenseMiner (Bayardo et al., 1999). O Dense-Miner minera regras a partir de uma EST (Figura 2.2) e retorna toda regra que satisfaz um conjunto de restrições, como suporte mínimo e confiança mínima. A modificação do Dense-Miner implica em explorar somente o conjunto de regras $R$ potencialmente ótimas em qualquer ponto do espaço de busca. Enquanto uma regra $r$ é enumerada por um nó do EST e satisfaz todas as restrições, ela é comparada com toda regra já mantida no conjunto $R$. Se a regra $r$ for melhor que toda regra já presente em $R$, conforme os critérios $\leq_{S C}$ ou $\leq_{S \neg C}$, então ela é inserida em $R$. Além disso, qualquer regra em $R$ que é pior que $r$ é removida. Terminando a busca, $R$ é considerado um conjunto ótimo. Outras podas contidas no DenseMiner podem ser utilizadas para aprimorar a busca. Um problema de utilizar Dense-Miner é que ele utiliza uma busca em largura e para superar isso, o 
algoritmo foi atualizado para efetuar uma busca best-first. Outra modificação é a utilização de podas inclusivas como proposto por Webb (1995). Tais podas acontecem quando a adição de um item ao itemset do antecedente não modifica as estatísticas de uma regra. Desta forma, não é necessário continuar a especialização daquele itemset.

\subsubsection{Enumeração e Otimização de Regras Significantes}

Morishita e Sese (2000) desenvolveram um método para gerar eficientemente regras de associação significantes, isto é, regras que otimizam medidas de interesse objetivas baseadas em estatística. Para alcançar isso, foi considerado a utilização do algoritmo Apriori para descobrir os FIs. O método desenvolvido realiza estimativas de limitantes superiores (upper bound) para podar regiões do espaço de soluções.

Esse trabalho investigou que a utilização do suporte e confiança não é uma boa estratégia para encontrar regras bem correlacionadas. Então foi sugerido realizar uma busca direcionada por meio de um critério estatístico. Esses critérios são representados por medidas de interesse objetivas. Para podar o espaço de busca de regras e acelerar o desempenho do método foi desenvolvido um limitante superior $u(X \rightarrow Y)$ pela utilização da propriedade convexa das funções de tais medidas objetivas (Morishita e Sese, 2000). Por estabelecer um corte $\tau$ dentre o domínio de uma medida objetiva $\mathcal{M}$, se $u(X \rightarrow Y)<\tau$, para qualquer itemset mais especifico $W$, onde $X \subseteq W, \mathcal{M}(W \rightarrow Y) \leq u(X \rightarrow Y)<\tau$. Então pode-se podar o itemset $W$ da busca.

Pelo conhecimento da propriedade do limitante superior para uma medida objetiva, foram estabelecidos dois problemas para descoberta de regras significantes (Morishita e Sese, 2000):

1. problema de enumeração de regras de associação; e

2. problema de otimização de regras de associação.

Ambos os problemas são apresentados em seguida.

Problema de enumeração de regras

A utilização de um valor que pertence ao domínio de uma medida objetiva $\mathcal{M}$ ao invés de suporte e confiança motiva a consideração do seguinte problema de enumeração, que é enumerar todas as regras de associação significantes que tem valor da medida $\mathcal{M}$ não menor que um limiar ou corte definido por um usuário.

Em aplicações reais, frequentemente há interesse em um particular itemset $Y$ e é importante encontrar itemsets que sejam bem correlacionados com $Y$. 
Desta forma, pode-se restringir e formalizar o problema de enumeração como a seguir (Morishita e Sese, 2000).

Problema de Enumeração: para um consequente fixo $Y$, enumerar todas as regras de associação correlacionadas da forma $X \rightarrow Y$ que tem valor de medida $\mathcal{M}$ não menor que um valor limiar ou corte definido por um usuário, $\tau$.

Seja $\mathcal{M}(X)$ o valor de uma medida objetiva qualquer para a regra $X \rightarrow$ $Y$. Então, o objetivo é desenvolver uma maneira eficiente de enumerar $\{X \mid$ $\mathcal{M}(X) \geq \tau\}$. O problema de enumerar regras é resolvido da seguinte forma. Busca-se a sequência de itens para $X$ começando pelo 1-itemset e acrescenta a cada iteração um novo item em $X$. Para avaliar a necessidade de geração de regras mais específicas é calculado o limitante superior $u(X \rightarrow Y)$. Se $u(X \rightarrow$ $Y)<\tau$, significa que qualquer regra, $W \rightarrow Y$, formada pelo superconjunto do itemset $X$, onde $X \subseteq W$, não será uma regra significante, $\mathcal{M}(W) \leq u(X \rightarrow Y)<$ $\tau$, e portanto pode-se realizar a poda com sucesso.

\section{Problema de otimização de regras}

Em muitas aplicações práticas, enfrenta-se frequentemente uma situação em que muitas regras de associação são geradas. Para resolver este problema, pode-se ordenar estas regras de acordo com medidas de interesse e visualizar somente as mais significantes. Ao invés de computar todas as regras, pode-se diretamente computar as $k$ regras mais significantes. Além disso, focar nessas $k$ regras ajuda a abandonar itemsets não importantes mais cedo na busca e portanto acelerar o desempenho. Formalmente, o problema é definido como segue (Morishita e Sese, 2000).

Problema de Otimização: para um consequente $Y$ fixo, computar a regra de associação ótima da forma $X \rightarrow Y$ que maximiza uma medida objetiva $\mathcal{M}$ ou listar as $k$ soluções que otimizam tal medida.

Se a quantidade máxima de itens no itemset $X$ for tratado como uma variável, o problema é NP-difícil, mas em aplicações reais, a quantidade máxima é usualmente limitada por uma constante e portanto o problema é tratável (Morishita e Sese, 2000). Para resolver o problema de otimização eficientemente é estendida a ideia para resolver o problema de enumeração. Durante a busca dos itemsets $X$, deve-se conhecer o valor da medida $\mathcal{M}$ para a n-ésima regra. Esse valor é estabelecido como limiar ou corte $\tau$ temporário até que a n-ésima regra seja atualizada com um maior valor. Se $u(X \rightarrow Y)<\tau$, nenhum superconjunto de $X$ precisa ser explorado e portanto a busca pode ser podada. 
A ideia de poda com a informação de limitante superior é uma técnica bem comum em otimização combinatorial, mas a novidade da proposta de Morishita e Sese (2000) é sua utilização durante a geração dos itemsets mais especializados. Alguns trabalhos anteriores abordam a travessia da árvore de busca de itemsets de maneira best-first. Bayardo e Agrawal (1999) considerou várias medidas objetivas e apresentou um método com base na fronteira de suporte-confiança, discutida na Seção 3.3.1, para buscar regras ótimas. Mas se o foco for em medidas que possuem a propriedade de função convexa, podese reduzir ainda mais o espaço de busca utilizando limitantes superiores.

\subsubsection{Conjunto de Regras Informativas - (Informative Rule Set - IRS)}

Li et al. (2001) propuseram um conjunto de regras que evitam predições redundantes. Durante a mineração, este conjunto de regras informativas, IRS, satisfaz duas condições:

1. contêm regras que satisfazem o limiar suporte mínimo $P(X \rightarrow Y) \geq$ minsup; e

2. exclui todas as regras mais específicas que não possuem maior confiança que nenhuma de suas regras mais gerais, $P(Y \mid X) \leq P(Y \mid X-Z)$, onde $Z \subset X$.

Li e Zhang (2003) propuseram o algoritmo DIG (Direct Interesting Rule Generation) que gera diretamente regras de associação que otimizam 12 medidas de interesse. Esse método explora o IRS utilizando a metodologia do algoritmo Apriori e podas baseadas nas condições relatadas anteriormente. Li e Zhang (2003) também provaram que o conjunto IRS otimiza tais medidas de interesse. Experimentos mostraram que o DIG é mais eficiente que o Apriori, pois a restrição para encontrar os IRS impede a exploração de FIs que formam regras redundantes. No entanto, tal tarefa fica restrita aos critérios que respeitam o conjunto IRS e não garante $k$ regras com maior valor de medida de interesse.

Uma extensão desse trabalho considera o conjunto de regras informativas como conjunto de regras ótimas ( $\mathrm{Li}, 2006)$. Esse conjunto é relacionado com o conjunto de regras que respeitam a restrição de melhoria mínima igual a zero. Tais regras possuem confiança maior que a confiança de suas respectivas regras mais gerais. 


\subsubsection{K-Optimal Rules - Webb}

Webb (2000) desenvolveu o algoritmo OPUS_AR para descobrir regras de associação ótimas de acordo com medidas de interesse, baseado na técnica OPUS (Webb, 1995). OPUS_AR realiza uma busca em árvore através do espaço dos possíveis itemsets do antecedente e mantém em cada nó um conjunto de consequentes em potencial. Esse algoritmo descobre $k$ regras que otimizam uma medida de interesse e que satisfazem as restrições definidas por um usuário. Tal abordagem é escalável, pois evita a geração dos FIs que podem produzir regras desinteressantes. Para seguir esta abordagem, um usuário precisa especificar uma medida de interesse, $\lambda$, um conjunto de restrições, $R$, e a quantidade de regras a serem descobertas, $k$. Então, o algoritmo retorna $k$ regras que otimizam $\lambda$ sob as restrição $R$. Esse algoritmo supera os trabalhos de Bayardo e Agrawal (1999) e de Morishita e Sese (2000).

Webb e Zhang (2005) estenderam esta abordagem ao desenvolverem o algoritmo KORD. KORD possui uma estratégia mais robusta no que se refere à travessia dos possíveis antecedentes. Além disso, novas podas foram inseridas, melhorando a eficiência da técnica. A seguir são descritos os pontos mais importantes dessa técnica.

\subsubsection{K-Optimal Rules Discovery - KORD}

O algoritmo KORD foi desenvolvido por Webb e Zhang (2005). Sua função é descobrir de forma eficiente uma quantidade $k$ de regras de associação que otimizam uma medida de interesse e que satisfaça outras restrições de busca. Ele estende o algoritmo OPUS_AR no que se refere à travessia dos itemsets antecedentes e avaliação das regras a partir de um conjunto fixo de itemsets consequentes. Além disso, são inseridas mais podas em relação ao OPUS_AR. Para limitar ainda mais o espaço de busca e diminuir o tempo gasto na mineração, Webb e Zhang (2005) propuseram um conjunto de prevenções de acesso (PA). Prevenções de acesso são técnicas que evitam o acesso desnecessário ao conjunto de dados para a contagem do suporte de uma regra, porém não exclui regiōes do espaço de busca. Tais prevenções são descritas na Seção 4.3 do próximo capítulo.

Para o funcionamento de tal abordagem, não há necessidade que as medidas de interesse possuam propriedades monotônicas. A busca é realizada pela enumeração dos possíveis itemsets que podem ocupar o antecedente de uma regra e em cada ponto da busca é mantido um conjunto fixo de itemsets consequentes. Se as especializações dos itemsets antecedentes forem promissoras, a busca continua.

Como muitas medidas de interesse não possuem propriedades monotôni- 
cas, as técnicas de indução de regras de associação, como o Apriori, não realizam com eficiência a tarefa de descoberta das regras ótimas. Para resolver este problema é necessário que a busca por essas regras seja feita da seguinte forma: deve-se manter um conjunto fixo de itemsets para o consequente e procurar todas as possíveis combinações para o itemset do antecedente. Desta forma, busca-se uma sequência de itens do itemset antecedente, começando pelo menor itemset, $|X|=1$, e acrescenta-se um item a cada iteração neste itemset. Portanto, a busca feita para a descoberta de regras ótimas é realizada como um processo que começa com regras gerais (com um item no antecedente) e continua com especializações sucessivas (regras formadas pela adição de novos itens no antecedente). A Figura 3.3 mostra como é o espaço de busca dos possiveis antecedentes para 4 itens.

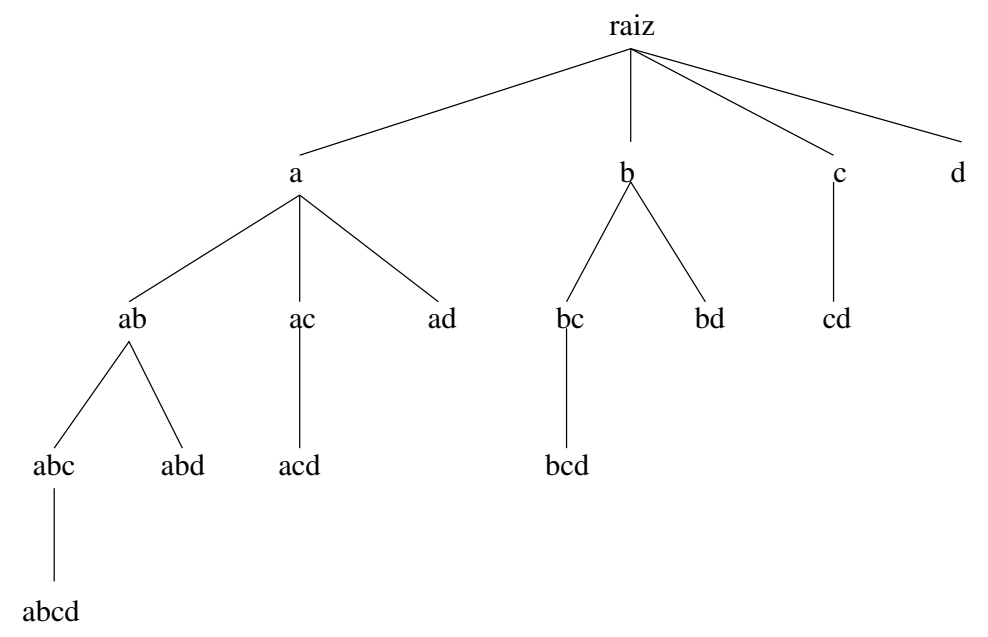

Figura 3.3: Espaço de busca dos possiveis antecedentes para 4 itens.

Um importante componente para a eficiência da busca nesse contexto é minimizar a quantidade de regras que precisam ser consideradas. Uma abordagem importante para a eliminação de regras desinteressantes é a aplicação de podas. Suponha que um itemset do antecedente $X$ está sob investigação. Então pode ser medido o limitante superior (upper bound) das relações entre este antecedente e cada possível consequente em cada nó da busca. Se não houver regras promissoras para nenhum consequente, não há mais necessidade em investigar os superconjuntos para aquele itemset $X$, ou seja, não é preciso adicionar mais itens para avaliação de regras mais especializadas. Um novo itemset antecedente é procurado e novos testes são realizados para a tarefa de descoberta das regras ótimas. Há outras maneiras para se podar seções do espaço de busca. Isto será investigado mais adiante.

Como a tarefa em questão enumera as possibilidades de qualquer regra, seções do espaço de busca precisam ser identificados para que a sua poda seja realizada adequadamente. Para realização da travessia no espaço de busca são identificadas duas estratégias plausíveis, onde o conjunto de consequen- 
tes é formado por itemsets de tamanho $|X|=1$ :

1. para cada potencial consequente explorar o espaço dos possíveis antecedentes; ou

2. para cada potencial combinação de antecendentes explorar o espaço dos possiveis consequentes.

A primeira estratégia apresenta maior simplicidade, pois envolve uma simples iteração para cada consequente. No entanto, isso implica gerar várias vezes um mesmo antecedente, uma vez para cada consequente que é considerado. Isso provoca uma alta sobrecarga computacional. Diante desse entrave a segunda estratégia é favorecida. A segunda estratégia, ilustrada na Figura 3.4, explora o espaço de possibilidades dos itemsets no antecedente buscando do geral ao específico. Pode-se observar que o tamanho dos antecedentes aumenta à medida que avança na árvore. Durante este processo, para cada antecedente em consideração, são procurados os possiveis consequentes. Para o itemset antecedente $\{b\}$, os possiveis consequentes são os itens $\{a\},\{c\}$ e $\{d\}$. Quando a busca prossegue para o seguinte antecedente mais especializado $\{b, a\}$, os possiveis consequentes são os itens $\{c\}$ e $\{d\}$. A quantidade de consequentes determina a quantidade de possíveis regras naquele nó da árvore de busca.

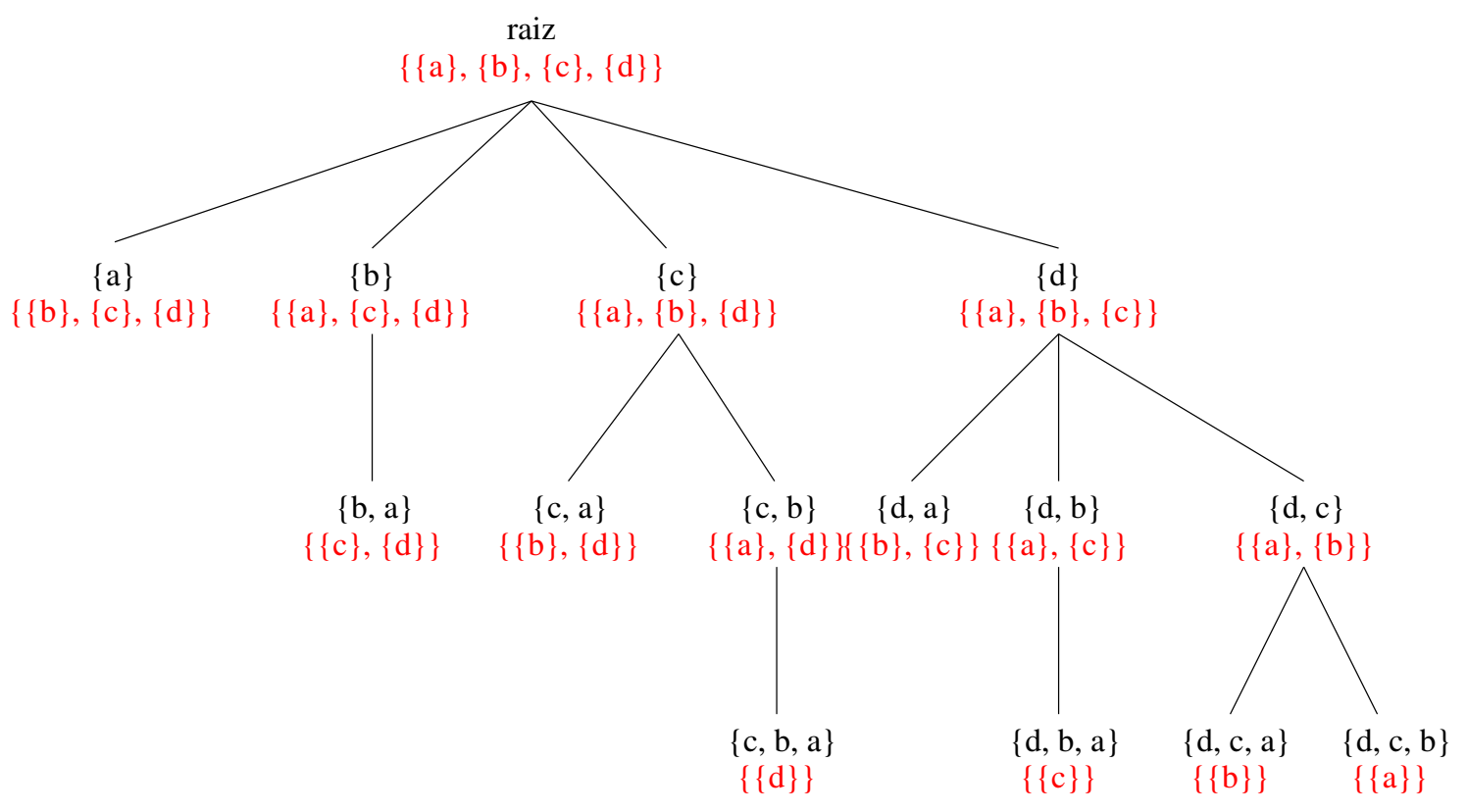

Figura 3.4: Espaço de busca do algoritmo KORD para 4 itens. Em cada nó os possiveis consequentes estão em vermelho e situados sob os possíveis antecedentes.

Tal organização da estratégia de busca deve proporcionar somente uma passagem para cada possivel antecedente. São podadas regiões do espaço de 
busca potenciais antecedentes que não possam conter nenhuma regra promissora com qualquer itemset no consequente sob uma avaliação de otimalidade. Isto pode acontecer de duas formas. As podas podem descobrir a inviabilidade de tal antecedente e suas prováveis especializações, e as podas aplicadas aos consequentes podem excluí-los daquele espaço de busca, não sendo necessário especializar o antecedente em questão.

Por exemplo, quando o antecedente $\{c\}$ é inspecionado, há três possíveis consequentes, que são os itens $\{a\},\{b\}$ e $\{d\}$. Se o consequente $\{d\}$ for excluído pela aplicação de uma poda qualquer, restarão os consequentes $\{a\} \mathrm{e}$ $\{b\}$. A busca deve avançar, pois ainda existem consequentes que podem formar regras promissoras com antecedentes mais especializados a partir do antecedente $\{c\}$. Então os próximos antecedentes investigados são $\{c, a\}$ e $\{c, b\}$. Para o antecedente $\{c, a\}$ haverá apenas o consequente $\{b\}$ para avaliação e para o antecedente $\{c, b\}$ haverá o consequente $\{a\}$. A partir do antecedente $\{c, a\}$ não é mais possível obter antecedentes mais especializados. Porém, a partir do antecedente $\{c, b\}$ ainda é possível avançar para $\{c, b, a\}$. No entanto, o único consequente possível seria o item $\{d\}$. Portanto, tal busca não é necessária, pois o consequente $\{d\}$ foi podado quando o antecedente $\{c\}$ foi avaliado. Em virtude da inviabilidade do consequente $\{d\}$ em formar regras promissoras de serem ótimas, muitas regiões do espaço de busca foram podadas e algumas regras não precisaram ser avaliadas.

A relativa eficiência desta abordagem dependerá do custo das passagens sobre o conjunto de dados (menor favorecimento à busca direta), da quantidade de FIs considerados (menor favorecimento ao algoritmo Apriori) e da quantidade de combinações de antecedentes que deve ser explorada (menor favorecimento à busca direta). O Algoritmo 3.1 ilustra como é realizado o método KORD. Tal algoritmo realiza chamadas recursivas e possui três argumentos (Webb e Zhang, 2005):

antecedente_Atual é o conjunto de itens encontrados no antecedente da regra que está sendo considerado no momento.

antecedentes_Disponiveis é o conjunto de itens que podem ser adicionados para formar antecedentes mais específicos das regras a serem exploradas. consequentes_Disponiveis é o conjunto de itemsets que podem aparecer no consequente de uma regra no espaço de busca a partir daquele ponto.

No algoritmo KORD existe uma variável global chamada solucao_Atual, que é a solução para a tarefa de busca, onde são mantidas as regras consideradas ótimas. Inicialmente a solucao_Atual é vazia. Na chamada inicial do KORD, o conjunto antecedente_Atual é vazio, enquanto os conjuntos antecedentes_Disponiveis e consequentes_Disponiveis mantêm todos os possíveis itens. 
O algoritmo KORD inicia a busca por regras com apenas um item no antecedente e continua a busca por novas regras pela adição de novos itens através da chamada recursiva. Na linha 2 ele considera cada item $P$ encontrado no conjunto antecedentes_Disponiveis e o adiciona no antecedente_Atual para formar o novo_Antecedente, na linha 4. Em seguida, são considerados todos os possíveis consequentes através do laço que começa na linha 9. Então, as possíveis regras novo_Antecedente $\rightarrow Y$ podem ser avaliadas, para cada $Y \in$ novos_Consequentes_Disponiveis. Caso satisfaçam as restrições de busca, as regras são adicionadas na solucao_Atual, na linha 16.

Depois de avaliadas todas as possiveis regras entre o recém antecedente novo_Antecedente e os consequentes presentes no conjunto novos_consequentes_Disponiveis, se pelo menos um consequente sobreviver às podas é realizada a chamada recursiva, na linha 27, com os seguintes argumentos: novo_Antecedente, novos_Antecedentes_Disponiveis e novos_Consequentes_Disponiveis. O argumento novos_Antecedentes_Disponiveis é formado a partir dos itens encontrados na variável ate_Agora, que mantém todos os itens $P$ que sobrevivem aos conjuntos de podas CP1 e CP2 durante cada iteração do laço da linha 2. O argumento novos_Consequentes_Disponiveis, mantém todos os consequententes que sobreviveram aos conjuntos de podas CP3 e CP4.

Regiões do espaço de busca que não podem conter regras promissoras são excluídas da busca por meio de podas. A eficiência do algoritmo KORD é diretamente relacionada com a capacidade das podas eliminarem regiões não promissoras. Para funcionarem, tais podas dependem dos valores das variáveis menor Medida, menorCobertura, menorConfianca, quantidade de regras $k$, e tamanho máximo do antecedente, tamMaxAnt. A restrição menor Medida é atualizada para o valor da k-ésima regra encontrada até o momento. Desta forma, seu valor cresce dinamicamente dependendo do valor da k-ésima regra encontrada na solucao_Atual. Toda vez que uma regra é adicionada à variável global solucao_Atual e a quantidade de regras excede $k$ é realiza uma ordenação, de forma decrescente, pelo valor da medida de interesse das regras e elimina aquela presente na posição $(k+1)$ no ranking. Quando a busca é finalizada, a solucao_Atual contém todas as regras que otimizam a medida de interesse em questão e que satisfazem as outras restrições de busca.

As podas de regras e prevenções de acesso utilizadas no algoritmo KORD podem ser aplicadas em diferentes regiões do Algoritmo 3.1. Na Seção 4.3 do próximo capítulo são descritas essas técnicas e informadas quando são aplicadas pelo conjunto de podas (CP) e pelo conjunto de prevenções de acesso (PA). 


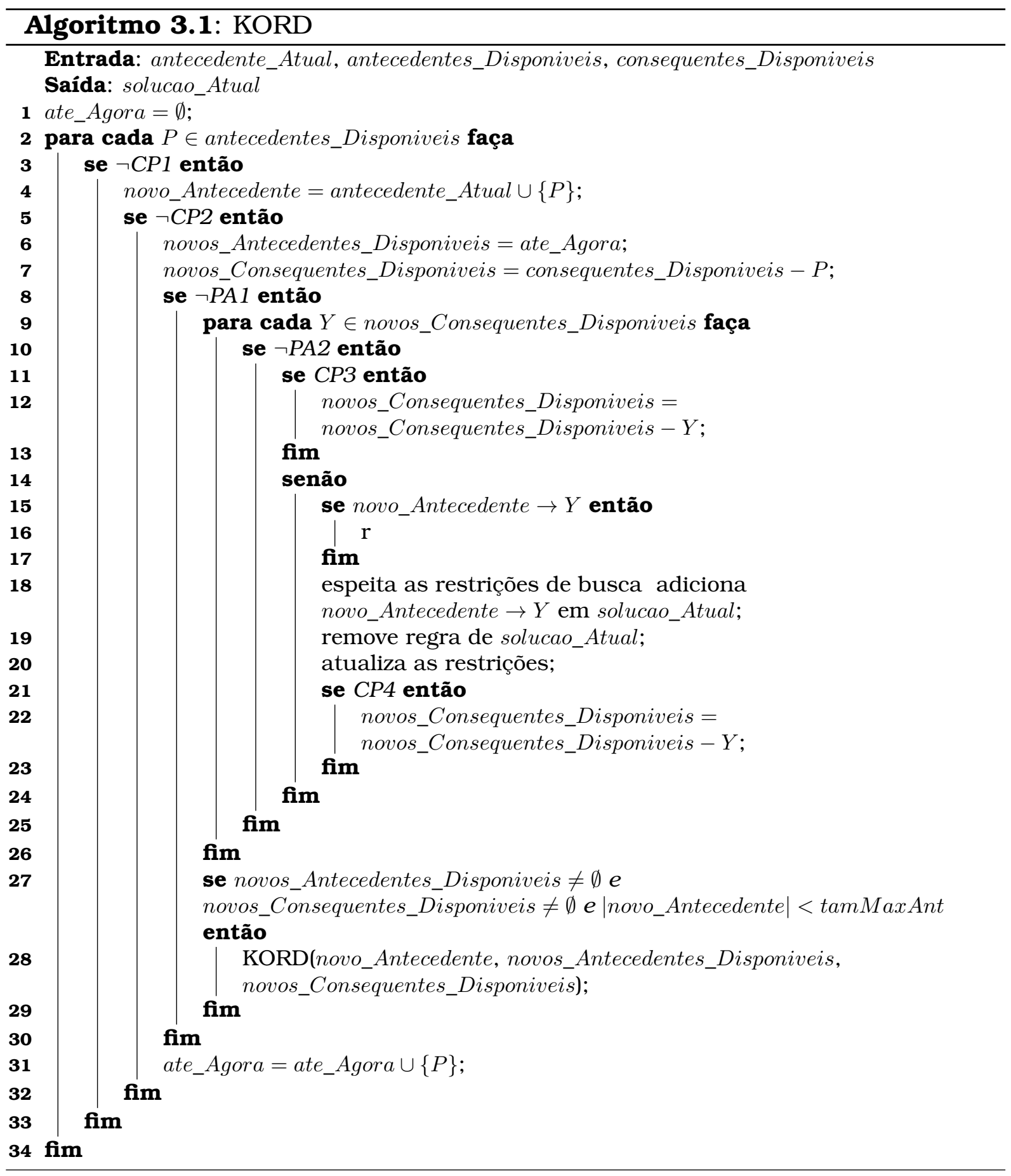

\section{Atualização dinâmica das restrições}

Embora as restrições menor Suporte e menorCobertura sejam inicializadas por um usuário, seus valores podem ser atualizados durante a busca. Tais mudanças podem ser úteis para podar mais regiões do espaço de busca e poupar avaliação das regras. De acordo com Webb e Zhang (2005), estas restrições podem ser atualizadas na linha 18 após uma regra ser inserida na solucao_Atual.

1. Se menorSuporte $<$ menorCobertura $\times$ menorConfianca, então menorSuporte $=$ menorCobertura $\times$ menorConfianca. 
2. Se menorCobertura $<$ menorSuporte, então menorCobertura $=$ menorSuporte.

3. Se menorSuporte $<$ menor Medida, então menorSuporte $=$ menor Medida.

\subsection{Considerações Finais}

Muitas técnicas foram desenvolvidas para gerar de forma eficiente regras de associação interessantes. Algumas buscam este objetivo por meio de restrições, que podem impedir itens e itemsets de serem explorados. Outra forma é por meio de heurísticas, que buscam regras com qualidade utilizando técnicas que exploram os dados, por exemplo, agrupamento e algoritmos genéticos. No entanto, tais abordagens dificilmente otimizam as medidas de interesse objetivas. Regras que otimizam essas medidas são consideradas regras ótimas. Alguns métodos que tratam o problema de descobrir regras ótimas foram abordados neste capítulo. Tais técnicas podem explorar a fronteira de suporte-confiança e o espaço de busca de todas as possíveis regras. Este espaço de busca é uma árvore de itemsets e algumas regiões são podadas em virtude de não proporcionarem regras ótimas.

O objeto motivacional deste trabalho é o algoritmo KORD. Ele utiliza o algoritmo Apriori para contagem da frequência dos itemsets e realiza a prospecção por regras ótimas por meio da travessia dos possíveis antecedentes e consequentes. Dessa forma, cada combinação é investigada uma única vez durante a busca. Para economizar tais investigações são utilizadas podas, que tem um impacto significativo na eficiência da técnica.

Para a proposta deste trabalho, utiliza-se a técnica FP-growth para a contagem da frequência dos itemsets, que se mostra robusta quando o suporte mínimo é baixo. Além disso, atualmente FP-growth é a abordagem mais rápida encontrada na literatura (Said et al., 2009). Esta técnica realiza uma busca em profundidade e isso se mostra ideal na busca dos FIs. 


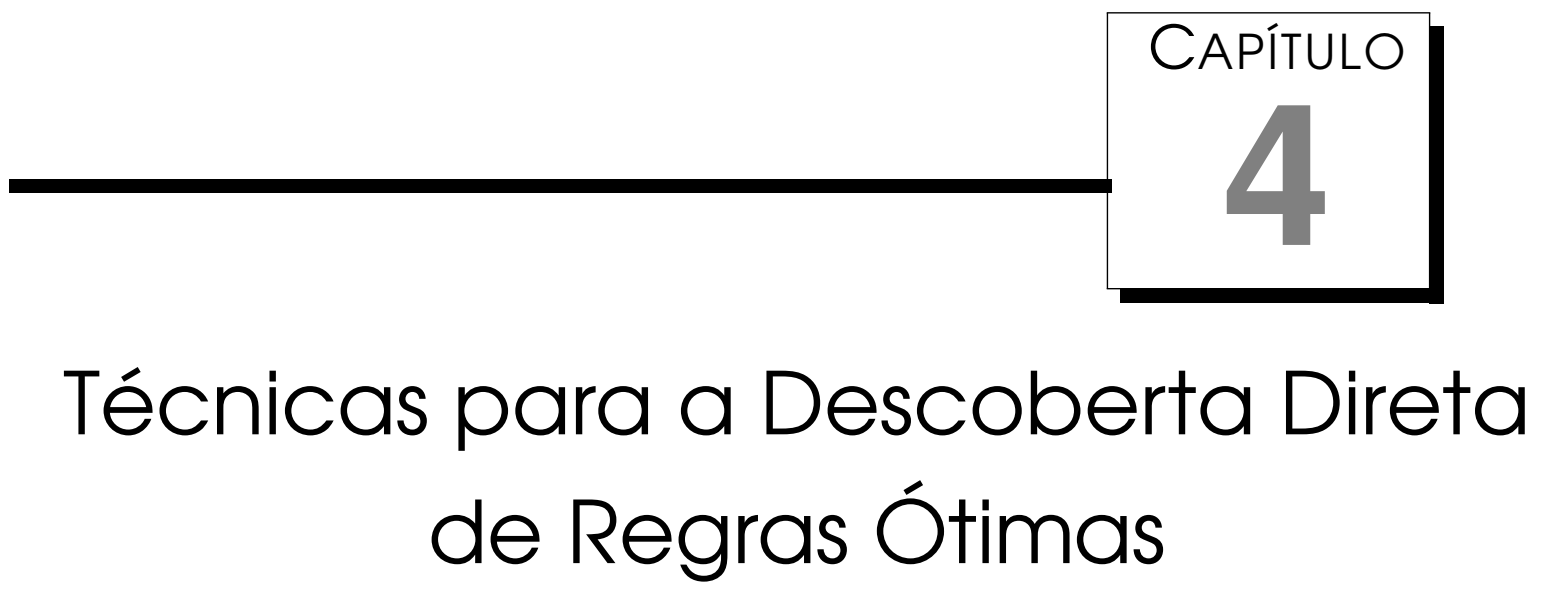

Em mineração de dados muitas regras de associação podem ser exploradas e isto provoca uma imensa dificuldade na inspeção de boas regras por parte de um usuário. Pois, independentemente da dimensão do conjunto de dados é gerada uma quantidade exponencial de regras. Por causa disso, houve a necessidade de direcionar a busca por regras interessantes. Isto começou pelo uso de medidas de interesse de uma regra em particular, baseadas, na sua maioria, em estatística. No entanto, a utilização de medidas de interesse é realizada após a geração de todas as regras que satisfazem as restrições da tarefa de mineração. Portanto, tais medidas não melhoram a eficiência da descoberta de regras. Para resolver este problema, foram desenvolvidas técnicas robustas para exploração direta de regras de associação ótimas. Essas propostas visam a descoberta de regras que otimizam uma determinada medida de interesse sem que haja a necessidade de explorar todas as possíveis regras que satisfazem as restrições da mineração.

Dentre essas técnicas inovadoras, que buscam diretamente regras ótimas, pode ser enfatizado o algoritmo KORD desenvolvido por Webb e Zhang (2005). Essa técnica explora regras ótimas por realizar uma travessia do espaço de regras, ou seja, as combinações entre antecedentes e consequentes que formam são inspecionadas de forma eficiente. Para não explorar todas essas combinações foram desenvolvidas podas. Tais podas excluem espaços de busca onde há a garantia de não haver regras ótimas. A contagem da frequência dos possíveis antecedentes, consequente e do par antecedente-consequente é feita pela utilização do algoritmo Apriori. Tais características encontradas no 
algoritmo KORD propiciam a descoberta direta e eficiente de regras ótimas.

Neste capítulo são descritas as inovações para o problema de descoberta das regras de associação que otimizam uma determinada medida de interesse objetiva. Essas inovações são: (1) utilização do algoritmo FP-growth para contagem da frequência dos itemsets envolvidos na busca; (2) desenvolvimento de novas podas e prevenções de acesso para evitar espaços de busca que não possuem regras ótimas; e (3) desenvolvimento de uma nova estratégia de travessia de regras. Desta forma, pela aplicação de tais inovações, dois algoritmos foram desenvolvidos: KORD-growth1 e KORD-growth2.

Inicialmente, são descritas as estratégias de busca para o problema utilizando a técnica FP-growth. Em seguida, por explorar as estratégias de busca são discutidos os dois algoritmos desenvolvidos neste trabalho. Também são apresentadas e discutidas as podas e prevenções de acesso utilizadas pelos algoritmos.

\section{1 Estratégia de Busca}

Muitos trabalhos que buscam encontrar, diretamente e de forma eficiente, regras que otimizam uma medida de interesse objetiva foram relatados no capítulo anterior. Alguns desses trabalhos tratam essa tarefa como um problema de otimização combinatória, que para otimizar a descoberta de regras algumas seções do espaço de busca são podadas. Estas seções são excluídas da mineração em virtude de não possuírem soluções para a tarefa. O algoritmo KORD, que é baseado nessa ideia, realiza uma pesquisa branch-and-bound que enumera todas as possiveis regras de associação através de uma árvore de busca (Webb e Zhang, 2005). Tal pesquisa descarta subconjuntos candidatos considerados infrutíferos, baseada em estimativas de limitantes superiores e inferiores da medida de interesse sendo otimizada.

Nesta seção, são discutidas estratégias, baseadas no algoritmo KORD, de como realizar a busca por regras ótimas utilizando a técnica FP-growth e uma nova abordagem de travessia de regras. Os algoritmos anteriormente desenvolvidos utilizam o algoritmo Apriori para contagem da frequência dos itemsets. A adoção do algoritmo FP-growth nessa proposta deve-se à busca em profundidade feita pelo método KORD. Dessa forma, o custo computacional para contagem do suporte das regras mais específicas deve ser menos custoso em virtude das sucessivas compressões da árvore de padrões frequentes, FP-tree.

Uma condição para que a tarefa de descoberta de regras ótimas seja realizada com eficiência é que cada regra de associação seja avaliada uma única vez, isto é, a técnica deve evitar redundância da avaliação de regras durante a 
busca. Para alcançar isso, é necessário desenvolver um modo para percorrer, uma única vez, cada possível itemset situado no antecedente de uma regra. Além disso, é preciso conhecer os possiveis itemsets pertencentes ao consequente da regra, como também o seu tamanho. Portanto, pode-se resumir a forma da travessia das possíveis regras como a seguir.

- Deve-se conhecer o conjunto de itemsets que devem ser encontrados no consequente da regra; e

- cada possível regra e antecedente devem ser avaliados uma única vez.

De forma semelhante ao encontrado no método KORD, neste trabalho é utilizado um conjunto fixo de itemsets como consequentes. Somente itemsets com um item são considerados, ou seja, 1-itemset. A adoção de um único item no itemset consequente deve-se aos seguintes motivos, definidos por Webb e Zhang (2005).

- Regras com um item no consequente têm sido de grande interesse aos usuários.

- Há um aumento substancial da quantidade de regras quando da adoção de regras com mais de um item no consequente.

- O desempenho da tarefa é aprimorado quando da adoção de um único item no consequente, pois diminui o espaço de busca.

Pela utilização da metodologia do algoritmo FP-growth, duas estratégias de travessia de regras são apresentadas e discutidas a seguir.

1. Travessia similiar ao KORD; e

2. travessia com pesquisa implícita de regras.

A travessia dos possiveis itemsets dos antecedentes de ambas as estratégias é a mesma que ocorre no algoritmo KORD. A metodologia do algoritmo KORD funciona da seguinte maneira. Enumera-se, através de especializações, os possíveis itemsets antecedentes e para cada antecendente são considerados um conjunto fixo de consequentes. As estratégias definidas neste trabalho devem utilizar a metodologia do algoritmo FP-growth. Portanto, para conhecer a frequência de cada possivel itemset antecedente é necessário realizar sucessivas especializações de uma FP-tree.

A travessia dos possiveis antecedentes depende exclusivamente de como os itemsets são minerados a partir da árvore FP-tree. Para formar tal FPtree qualquer ordem dos itens nos caminhos de prefixo pode ser estabelecida. 
Porém, não se sabe de antemão qual ordenação leva à formação da menor árvore. Para diminuir a indecisão de qual ordem seguir, a ordenação dos itens pode ser estabelecida pela frequência. Se a formação da árvore FPtree seguir uma ordem decrescente em relação à frequência, os itens mais frequentes se situarão nos níveis mais altos dos caminhos representados na FP-tree. Caso contrário, se for seguida uma ordem crescente, os itens mais frequentes ficarão nos níveis mais baixos. Assim, a proposta aqui empregada adota a ordenação decrescente em relação à frequência dos itens. Isto é, a formação de uma FP-tree segue a mesma estratégia definida na Seção 2.2.2.

As especializações dos possiveis antecedentes podem seguir duas ordens na árvore de busca, que podem ser chamadas de pós-ordem e pré-ordem. Por exemplo, considere quatro itens $a, b, c$ e $d$, ordenados de forma crescente pela frequência, $P(d) \leq P(c) \leq P(b) \leq P(a)$. Conforme a Figura 4.1, os antecedentes formados a partir do item $d$ podem crescer de duas formas, seguindo uma busca em profundidade. Pode-se realizar uma busca pós-ordem, por iniciar pelo item $a$ formando o antecedente $\{d a\}$ e em seguida os antecedentes $\{d b\},\{d b a\},\{d c\},\{d c a\},\{d c b\}$ e $\{d c b a\}$, ou pela busca pré-ordem, por começar por $c$ formando o antecedente $\{d c\}$ e em seguida por $\{d c b\},\{d c b a\},\{d c a\},\{d b\},\{d b a\}$ e $\{d a\}$. Percebe-se que o item $d$ seria o item prefixo do nó mais profundo da árvore FP-tree minerada.

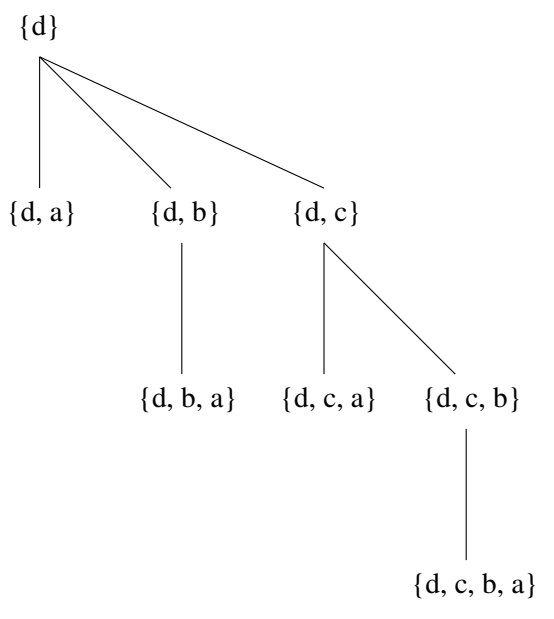

(a) Pesquisa Pós-Ordem

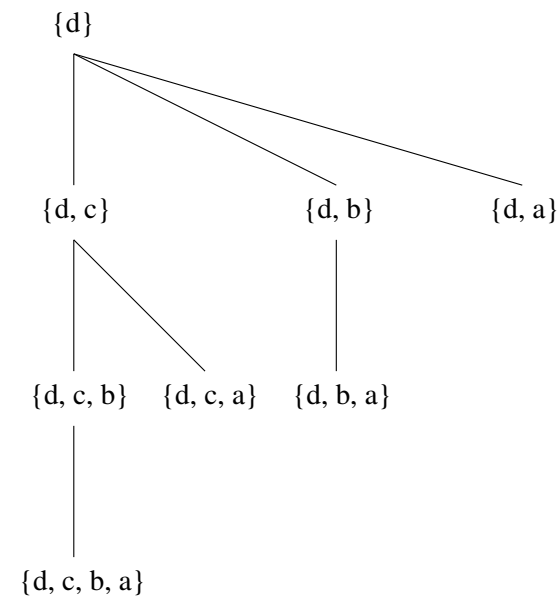

(b) Pesquisa Pré-Ordem

Figura 4.1: Ordens de busca em profundidade dos possíveis itemsets antecedentes. Visualização do percorrimento segue da esquerda para a direita da árvore.

\subsubsection{Travessia similiar ao KORD}

Na primeira estratégia de travessia de regras utilizando FP-growth, a travessia das possíveis regras é semelhante àquela adotada pelo algoritmo KORD. Enquanto são explorados os possiveis antecedentes é importante conhecer os 
possiveis consequentes e calcular o suporte das regras, que corresponde ao suporte do itemset formado pelo par antecedente-consequente. Considere, por exemplo, apenas quatro itens $a, b, c$ e $d$ para a tarefa de descoberta, ordenados de forma crescente pela frequência, $P(d) \leq P(c) \leq P(b) \leq P(a)$. Por seguir a pesquisa pós-ordem, o espaço de busca para cada possível antecedente pode ser representado pela Figura 4.2.

Pela visualização da Figura 4.3, pode-se observar, em vermelho, um conjunto fixo de possíveis consequentes em cada ponto da busca. Os possíveis consequentes para o itemset antecedente $\{a\}$ são os itens $b, c$ e $d$. Os suportes das regras $\{a\} \rightarrow\{b\},\{a\} \rightarrow\{c\}$ e $\{a\} \rightarrow\{d\}$ são obtidos pela compactação da árvore FP-tree mantida por cada consequente, que são as árvores FP-tree condicionais de $b, c$ e $d$. Como não é possível explorar mais itemsets específicos a partir de $a$, a busca por antecedentes segue para o item $b$. Na Figura 4.4, é possivel observar todas as possiveis regras, para 4 itens, nos seus respectivos pontos de busca.

Para o itemset antecedente $\{b\}$, os possiveis consequentes são os itens $a, c$ e $d$. Os suportes das regras $\{b\} \rightarrow\{c\}$ e $\{b\} \rightarrow\{d\}$ são obtidos utilizando as árvores FP-tree condicionais de $c$ e $d$. Não é possivel conhecer o suporte da regra $\{b\} \rightarrow\{a\}$ a partir da FP-tree condicional mantida pelo consequente a. Se pelo menos um dos consequentes $c$ ou $d$ sobreviverem à aplicação de uma poda, a busca para um antecedente mais específico é permitida. Nesse caso, seria avaliado o itemset antecedente $\{b, a\}$. Os suportes das possíveis regras $\{b, a\} \rightarrow\{c\}$ e $\{b, a\} \rightarrow\{d\}$ podem ser obtidos por meio das árvores FP-tree condicionais oriundas dos itemsets pesquisados anteriormente, $\{c, b\}$ e $\{d, b\}$. O itemset antecedente $\{d, c, b, a\}$ não é verificado em virtude de não existir consequentes para ele.

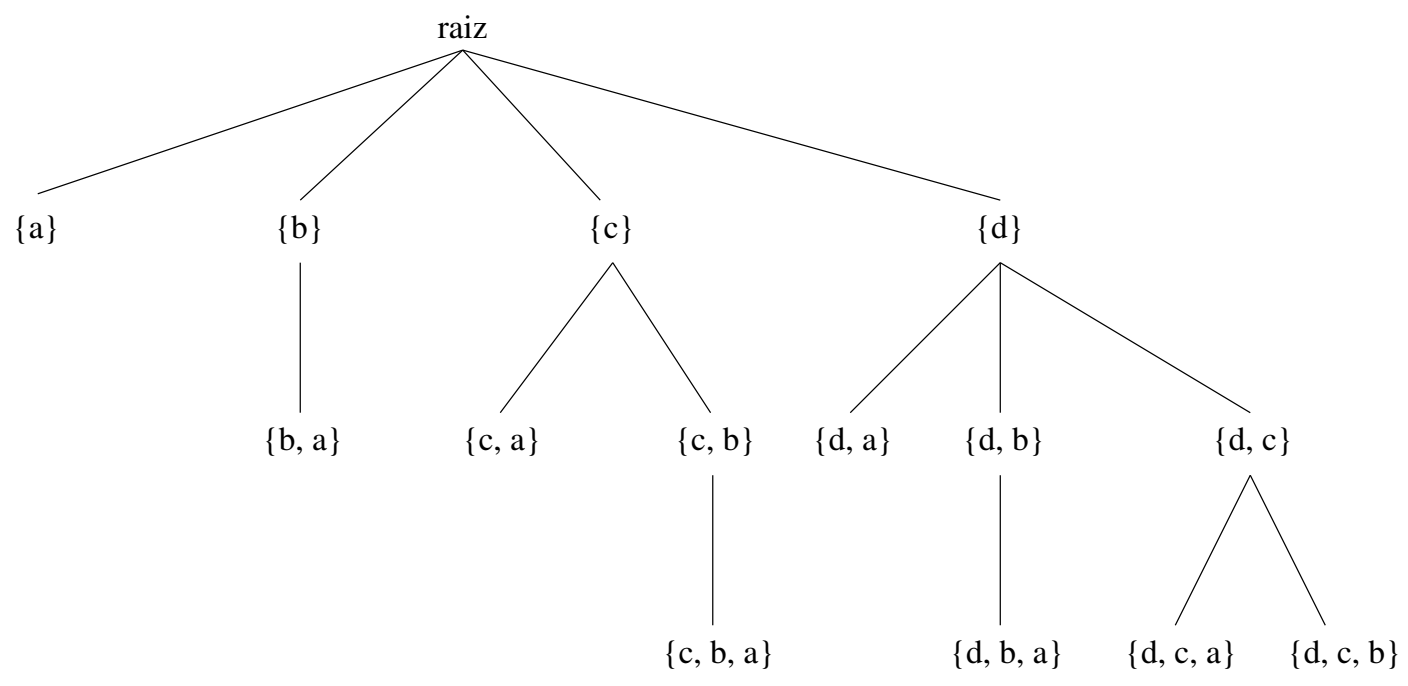

Figura 4.2: Espaço de busca dos possiveis itemsets antecedentes.

Em algumas regiões do espaço de busca não é possível conhecer o su- 


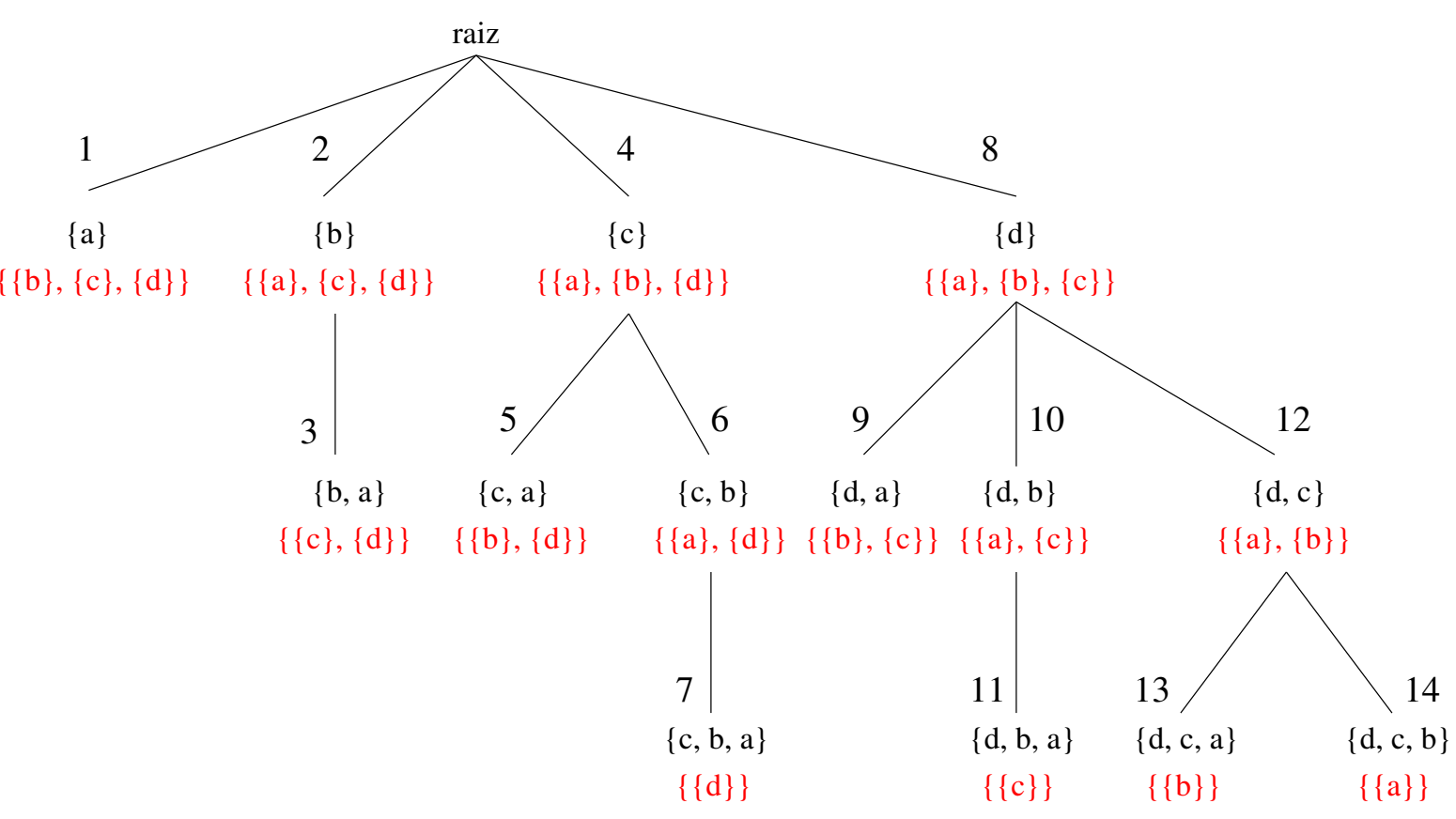

Figura 4.3: Espaço de busca da travessia de regras realizada pelo método KORD.

porte de uma regra por meio do algoritmo FP-growth, como foi o caso da regra $\{b\} \rightarrow\{a\}$, no ponto de busca 2 . Isto acontece em virtude da mineração da árvore FP-tree ter uma sequência pré-determinada. Por exemplo, o suporte da regra $\{d\} \rightarrow\{b\}$, no ponto de busca 8 , não é possível de ser obtida por meio da FP-tree condicional do consequente $b$. Para isso, uma alternativa seria obter uma FP-tree condicional de $d$ e a partir desta FP-tree seria obtida a árvore de caminhos de prefixo de $b$ para que se conhecesse seu suporte. No entanto, se tal estratégia fosse adotada, um dos passos seguintes da busca seria avaliar a regra $\{d, c\} \rightarrow\{b\}$, no ponto de busca 12 . O suporte desta regra não seria alcançado pela utilização da árvore FP-tree condicional oriunda de $\{d, b\}$. A partir desta árvore somente é possível minerar a frequência do itemset $\{d, b, a\}$. Sabendo disso, seria necessário obter uma nova FP-tree condicional de $d$ e minerá-la até alcançar $\{d, c, b\}$. Estas operações são muito custosas e redundantes, pois seria preciso copiar toda a árvore FP-tree condicional do primeiro item do itemset sob investigação. O suporte dessas regras que não é alcançado por meio da árvore FP-tree condicional do consequente pode ser obtido utilizando qualquer algoritmo que descobre FIs, como o Apriori.

\section{1.2 Travessia com pesquisa implícita de regras}

No algoritmo KORD cada possível regra de associação é avaliada uma única vez. No entanto, isso não garante que o itemset que forma uma regra seja verificado também uma única vez. Pois, para um itemset frequente com $k$ itens é possível formar $k$ regras quando considerado somente um item no 


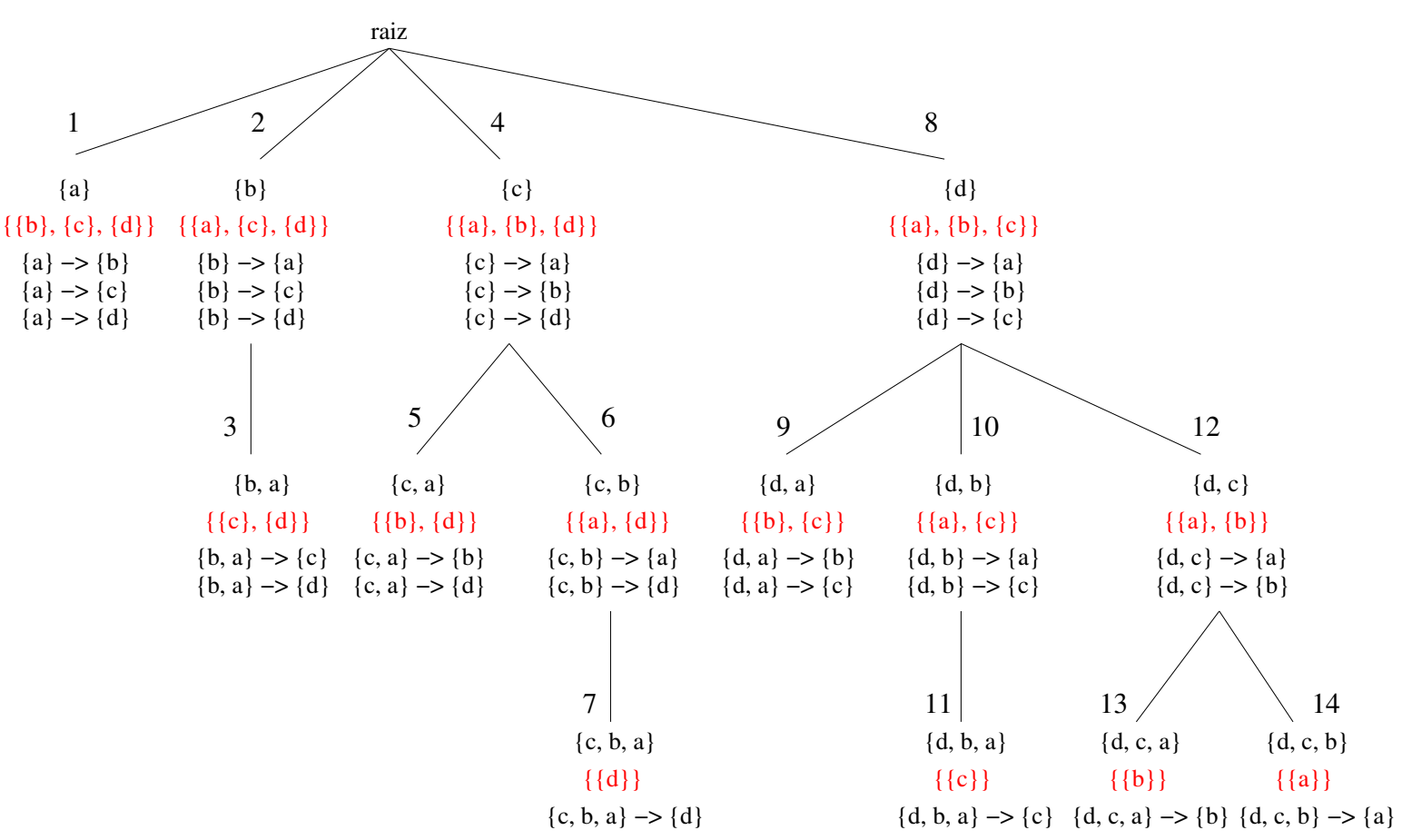

Figura 4.4: Exibição de todas as possíveis regras no espaço de busca da travessia de regras realizada pelo método KORD.

consequente. Por exemplo, o itemset $\{a, b, c\}$ possui três itens e é possível formar três regras com um item no consequente: $\{a, b\} \rightarrow\{c\},\{a, c\} \rightarrow\{b\}$ e $\{b, c\} \rightarrow\{a\}$. Na Figura 4.3, observa-se que utilizando a metodologia de travessia similar ao KORD, um itemset de tamanho $k$ é verificado no máximo $k$ vezes. Por exemplo, no espaço de busca ilustrado nessa figura, o itemset $\{a, b, c, d\}$ pode formar até quatro regras nos pontos de busca $7,11,13$ e 14. Se esses quatro pontos de busca forem considerados, então é necessário contar a frequência para um mesmo itemset quatro vezes, ou seja, haverá redundância de computações.

Neste trabalho foi elaborada uma estratégia de travessia com pesquisa implícita de regras para evitar a contagem desnecessária da frequência do itemset que forma mais de uma regra. A utilização dessa estratégia obriga avaliar $k$ regras, para um itemset de tamanho $k$, em um único ponto do espaço de busca. Isso reflete em uma busca realizada de forma explícita e implícita. A busca explícita é a busca que segue a mesma metodologia do algoritmo KORD e é visível na Figura 4.5. A busca implícita é a busca necessária para explorar as outras possíveis regras em cada ponto de busca e não é visível na Figura 4.5. Portanto, é necessário somente recuperar a frequência do possível antecedente para cada regra explorada implicitamente, pois já é conhecida a frequência do itemset que forma as regras. Esses antecedentes são formados pelo uso do item consequente no lugar de qualquer item do antecedente. $\mathrm{O}$ item substituído é utilizado como consequente da regra.

A pesquisa implícita em cada ponto de busca explorado deve ser realizada 
da seguinte forma. Considere um itemset antecedente $X=\left\{x_{1}, x_{2}, x_{3}, \ldots, x_{n}\right\}$ e um item consequente $Y$. Além da regra $X \rightarrow Y$, as possiveis regras que podem ser geradas são as seguintes:

$$
\begin{gathered}
Y, x_{2}, x_{3}, \ldots, x_{n} \rightarrow x_{1} \\
x_{1}, Y, x_{3}, \ldots, x_{n} \rightarrow x_{2} \\
x_{1}, x_{2}, Y, \ldots, x_{n} \rightarrow x_{3} \\
\vdots \\
\vdots \\
x_{1}, x_{2}, x_{3}, \ldots, Y \rightarrow x_{n}
\end{gathered}
$$

Pode-se observar, no ponto de busca 2 da Figura 4.5, que os possíveis consequentes para o itemset antecedente $\{b\}$, são os itens $c$ e $d$. O item $a$ não é considerado, pois não é possivel conhecer a frequência do itemset $\{a, b\}$ a partir da FP-tree condicional de $a$. Então, como é possível avaliar a regra $\{b\} \rightarrow\{a\}$ ? Esta regra é avaliada após o item $a$ ser considerado antecedente e o item $b$ for o consequente, no ponto de busca 1. Como o suporte da regra $\{a\} \rightarrow\{b\}$ é conhecido pela FP-tree condicional de $b$, então o suporte da regra $\{b\} \rightarrow\{a\}$ também é, assim como a frequência do consequente $\{a\}$, que é de fácil obtenção, pois é um itemset composto por um único item. Resta conhecer a frequência do novo antecedente, que deve ser obtida de uma outra forma.

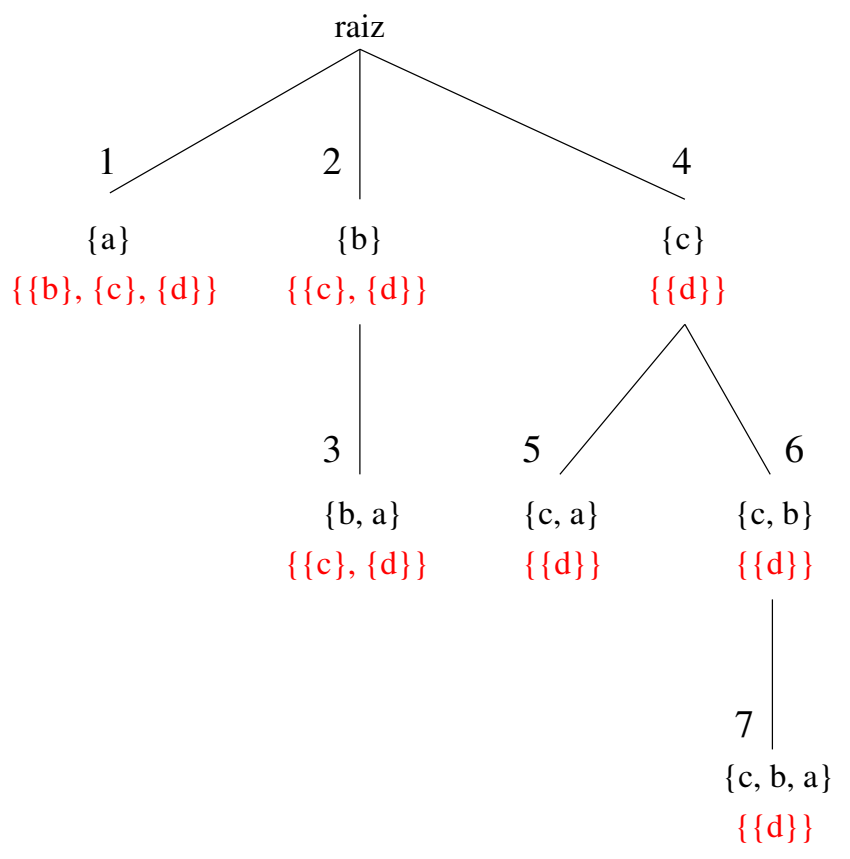

Figura 4.5: Espaço de busca da travessia explícita de regras.

Por seguir esta estratégia, no ponto 3 do espaço de busca ilustrado na Figura 4.5, as possíveis regras que poderão ser avaliadas são descritas a seguir. A primeira regra considerada é $\{b, a\} \rightarrow\{c\}$, e a partir dela podem ser 
verificadas as regras $\{c, a\} \rightarrow\{b\}$ e $\{b, c\} \rightarrow\{a\}$. A segunda regra considerada é $\{b, a\} \rightarrow\{d\}$, e a partir desta podem ser verificadas as regras $\{d, a\} \rightarrow\{b\}$ e $\{b, d\} \rightarrow\{a\}$. Percebe-se que não é necessário investigar os itemsets antecedentes formados pelo item $d$. Tais antecedentes serão investigados pela pesquisa implícita de regras.

Na Figura 4.6, pode-se observar todas as possíveis regras, para 4 itens, nos seus respectivos pontos de busca. As regras dentro dos retângulos pertecem à pesquisa implícita. Para recuperar a frequência dos novos antecedentes das regras encontradas na pesquisa implícita é necessário utilizar outra metodologia para recuperação da frequência, como o algoritmo Apriori. Neste trabalho, também foi desenvolvido um meio para descartar algumas regras formadas por esses antecedentes. Isso foi implementado para que o desempenho não seja sacrificado com a utilização de outras técnicas que recuperam a frequência de um itemset. Em seguida são apresentados os algoritmos desenvolvidos conforme as estratégias discutidas anteriormente.

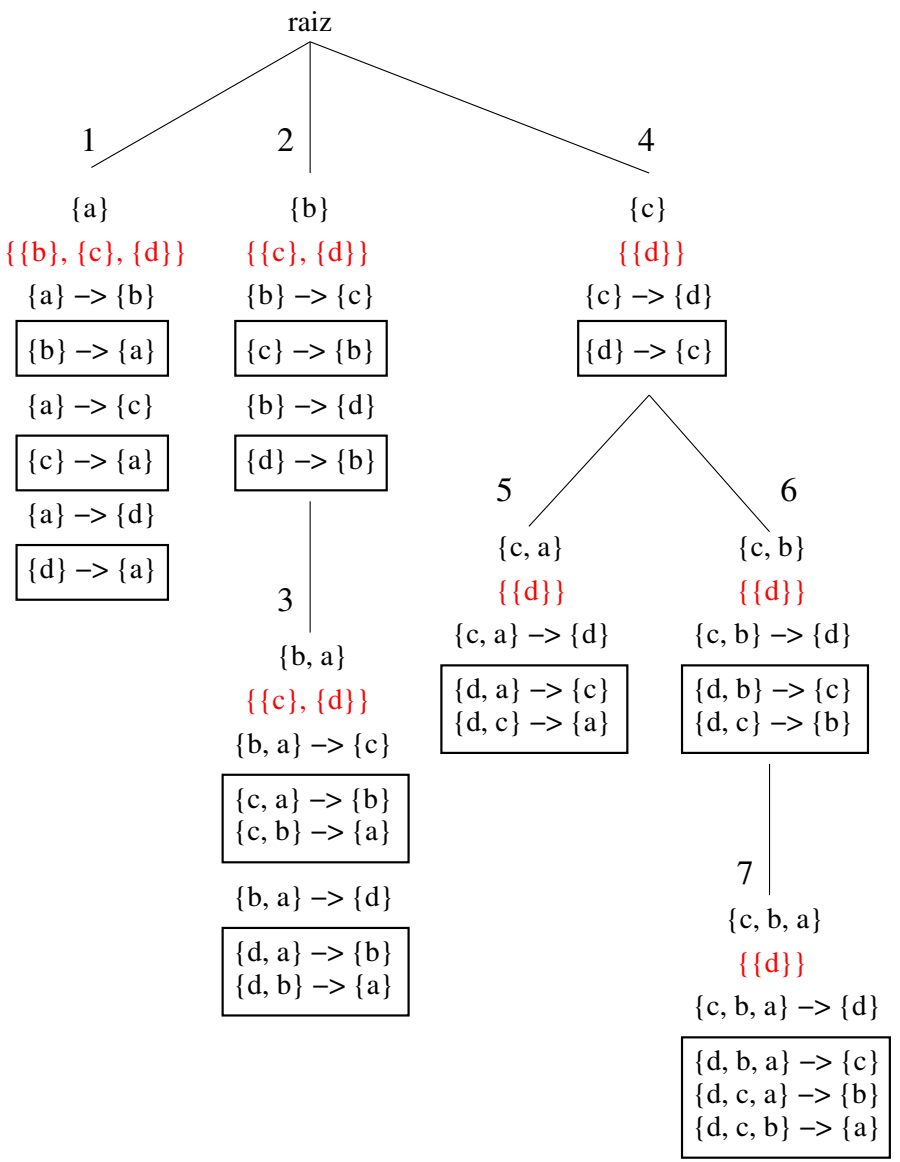

Figura 4.6: Exibição de todas as possíveis regras no espaço de busca da travessia com pesquisa implícita de regras. 


\subsection{Algoritmos KORD-growth}

Nesta seção são apresentados os dois algoritmos desenvolvidos propostos para a tarefa de descoberta das regras ótimas. Eles satisfazem as duas estratégias de busca definidas na seção anterior. O primeiro algoritmo se chama KORD-growth 1 e realiza uma busca semelhante ao KORD. O último se chama KORD-growth2 e faz uma busca por regras ótimas de forma inovadora, de acordo com a travessia de regras com pesquisa implícita.

\subsubsection{Algoritmo KORD-growth 1}

O Algoritmo KORD-growth 1 ilustrado pelo Algoritmo 4.1 realiza a busca por regras ótimas de forma similar ao KORD de Webb e Zhang (2005). Tal algoritmo é um procedimento recursivo que possui quatro parâmetros de entrada, apresentados a seguir.

antecedente_Atual é o itemset antecedente recentemente avaliado.

antecedentes_FPtree mantém uma árvore FP-tree condicional que é usada para minerar a frequência dos possíveis antecedentes explorados durante a busca.

antecedentes_Disponiveis conjunto de itens que podem ser inseridos ao antecedente das regras a serem exploradas.

consequentes_Disponiveis conjunto de todos os possíveis consequentes das possíveis regras que serão avaliadas.

Na chamada inicial do procedimento KORD-growth1, o parâmetro antecedente_Atual é vazio. O segundo parâmetro antecedentes_FPtree mantém inicialmente a árvore FP-tree que preserva a frequência de todos os itemsets antecedentes. Essa FP-tree é minerada durante a busca conforme a metodologia FPgrowth, descrita na Seção 2.2.2. O terceiro parâmetro antecedentes_Disponiveis inicialmente mantém todos os itens que são frequentes. Se for estabelecida que a busca siga a ordenação pré-ordem, os itens devem ser ordenados de forma crescente à frequência. Se for escolhida a ordenação pós-ordem os itens devem ser ordenados de forma decrescente à frequência. O último parâmetro, consequentes_Disponiveis, inicialmente mantém todos os consequentes que formarão regras com os antecedentes considerados pela busca.

Cada consequente encontrado em consequentes_Disponiveis mantém o item consequente $Y$, a sua cobertura e o suporte da última regra que foi coberta pelo consequente em questão. Esse suporte da última regra é importante para o cálculo de algumas prevenções de acesso. Além disso é mantida uma árvore 
FP-tree que é utilizada para contar a frequência da regra. Cada consequente também mantém uma variável binária que indica se há ou não uma árvore FP-tree. Caso não haja árvore FP-tree, o suporte da regra deve ser obtido por outra técnica. Daqui em diante, o termo cobertura será utilizado para se referir à frequência de um itemset ao invés de suporte. O termo suporte será referido apenas para regras.

Algumas restrições são necessárias para serem utilizadas na tarefa de descoberta e devem ser inicializadas pelo usuário:

menorCobertura cobertura mínima para uma regra ou antecedente;

menorSuporte suporte mínimo para uma regra;

menorConfiança confiança mínima para uma regra;

medidaObjetiva medida de interesse objetiva utilizada na busca;

menorMedida menor valor de medida de interesse para a tarefa de busca;

tamMaxAnt tamanho máximo do itemset antecedente; e

$\mathbf{k}$ quantidade de regras requeridas.

Essas restrições são utilizadas para o cálculo de podas e prevenções de acesso. Qualquer regra explorada na tarefa de descoberta deve respeitar as restrições citadas acima. As restrições menorCobertura, menorSuporte e menorConfianca podem variar de $0 \%$ a $100 \%$. A menor Medida depende da medida de interesse objetiva escolhida para a busca, que se refere a medidaObjetiva, e tamMaxAnt pode ser qualquer inteiro maior que zero. A restrição $k$ se refere à quantidade de regras requeridas pelo usuário e pode ser qualquer inteiro maior que zero.

Como já dito anteriormente, a busca feita pelos algoritmos desenvolvidos depende de como é realizada a exploração dos FIs pelo algoritmo FP-growth através da mineração de uma FP-tree. Sabendo isso, três funções são necessárias para conhecer a frequência dos itemsets explorados. Tais funções são relacionadas e descritas a seguir:

obterCaminhoPrefixo função que explora os caminhos de prefixo que mantém um item $P$ a partir de uma FP-tree condicional.

obterSuporte função que conta a frequência do itemset novo_Antecedente a partir dos caminhos de prefixo recém explorados pela função obterCaminhoPrefixo(0.

obterFP-treeCondicional função que forma uma FP-tree condicional a partir do item corrente $P$ e dos caminhos de prefixo recém explorados. 
O Algoritmo KORD-growth1 mantém dois laços ou loops. O primeiro laço, que começa na linha 2 , visa percorrer cada item $P$ encontrado no conjunto de itens disponíveis antecedentes_Disponiveis. Desta forma, novos antecedentes mais específicos são explorados durante a busca, isto é, cada item $P$ verificado é inserido na variável novo_Antecedente, especializando o antecedente antecedente_Atual. Por exemplo, se o conjunto antecedentes_Disponiveis for $\{c, d, e\}$ e antecedente_Atual for $\{a, b\}$, então os novos antecedentes explorados na busca serão: $\{a, b, c\},\{a, b, d\}$ e $\{a, b, e\}$. Portanto, cada novo antecedente será da forma novo_Antecedente $=$ antecedente_Atual $\cup\{P\}$, na linha 4 . Para conhecer a cobertura de novo_Antecedente, é necessário obter os caminhos de prefixo para $P$, antCaminhoPrefixo, a partir da árvore FP-tree condicional antecedentes_FPtree na linha 5 através da função obterCaminhoPrefixo(). A frequência do novo_Antecedente é mantida pela variável coberturaAntecedente e é obtida através da função obterSuporte() na linha 6, que tem como parâmetro os caminhos de prefixo recém explorados antCaminhoPrefixo.

O segundo laço é encontrado na linha 10, dentro do primeiro laço, e existe para atravessar cada possivel consequente a partir de consequentes_Disponiveis. Uma condição, na linha 12, permite apenas que consequentes diferentes de $P$ sejam verificados. Cada consequente poderá formar regra com o antecedente novo_Antecedente recém obtido. Até o momento já são conhecidos o antecedente novo_Antecedente, o consequente $Y=$ consequente. $Y$ e suas coberturas, coberturaAntecedente e coberturaConsequente = consequente.cobertura. Sendo assim, é possível e necessário avaliar a regra novo_Antecedente $\rightarrow Y$. Para avaliar a regra novo_Antecedente $\rightarrow Y$ resta conhecer o seu suporte. Para conhecer o suporte da regra é preciso obter os caminhos de prefixo do itemset que forma tal regra. Esses caminhos de prefixo são representados pela variável regraCaminhoPrefixo, caso haja uma árvore FP-tree para ser minerada. Tais caminhos podem ser obtidos na linha 16 através da função obterCaminhoPrefixo(), que tem como argumentos o corrente item $P$ e a árvore FP-tree condicional do consequente corrente.

O suporte da regra é armazenado na variável suporteRegra e é obtido através da função obterSuporte() na linha 17, que tem como argumento os caminhos de prefixo regraCaminhoPrefixo. Se consequente não mantiver uma árvore FPtree, o suporte da regra deve ser obtido de uma outra maneira, na linha 20. Se a regra novo_Antecedente $\rightarrow Y$ respeitar todas as condições e restrições impostas, ela é adicionada no conjunto de soluções solucao_Atual na linha 23. Na linha 31 é obtida uma FP-tree condicional para o consequente que sobreviveu aos conjuntos de podas CP3 e CP4.

O conjunto de soluções para a tarefa de descoberta de regras ótimas, solucao_Atual, é mantida globalmente e é iniciada vazia. Para ser inserida em 


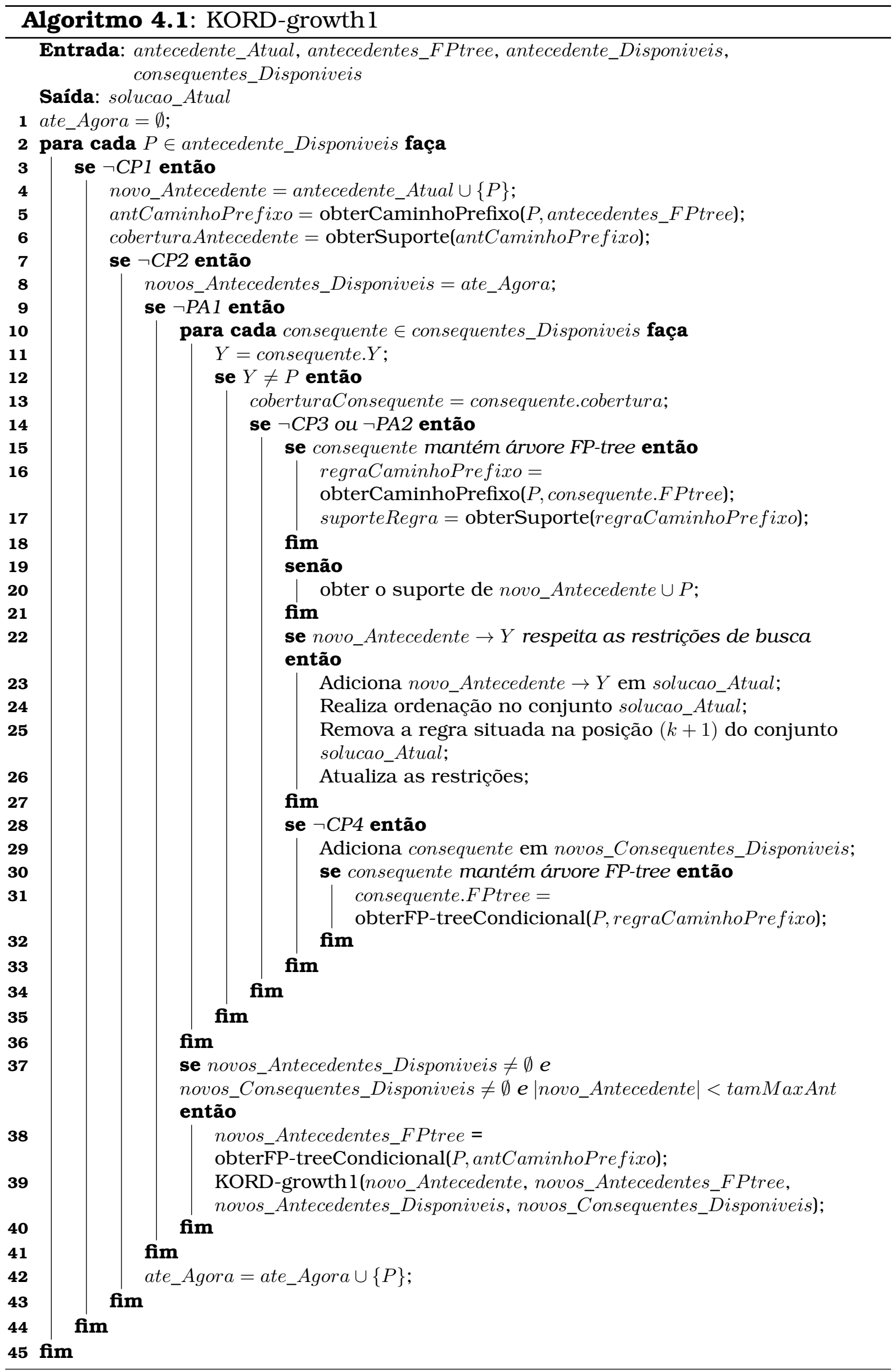


solucao_Atual, qualquer regra deve respeitar todas as restrições impostas pela busca. Além disso, todas as $k$ regras mantidas em solucao_Atual são ordenadas de forma decrescente sobre o valor da medida de interesse objetiva determinada pela tarefa. Toda vez que uma nova regra for inserida em solucao_Atual, linha 23, ela deve ser inserida na posição $k+1$. Depois disso, uma ordenação sobre solucao_Atual é realizada, linha 24. Após a ordenação desse conjunto, a regra que ficar na posição $k+1$ é excluída, linha 25. A restrição menor Medida é atualizada pelo valor da medida objetiva da regra que é situada na posição $k$. No final da tarefa de descoberta, o algoritmo KORD-growth 1 tem como saída o conjunto solucao_Atual, que mantém as $k$ regras de associação ótimas que otimizam uma medida de interesse objetiva arbitrária.

No momento da chamada recursiva, na linha 39, é necessário que os conjuntos novos_Antecedentes_Disponiveis, novos_Consequentes_Disponiveis não sejam vazios e que o tamanho do novo_Antecedente seja menor que a variável tamMaxAnt. Se isso for satisfeito, a função obterFP-treeCondicional() deve ser chamada para formar uma nova árvore FP-tree condicional novos_Antecedentes_FPtree para o item $P$. Tal FP-tree condicional será o segundo parâmetro da chamada recursiva. O primeiro parâmetro da chamada recursiva é o antecedente recentemente avaliado novo_Antecedente. O terceiro parâmetro, novos_Antecedentes_Disponiveis, recebe, na linha 8, os itens mantidos no conjunto ate_Agora. Esses itens farão parte dos antecedentes mais específicos que posteriormente poderão ser explorados. O conjunto novos_Consequentes_Disponiveis mantém todos os consequentes que sobrevivem às podas existentes durante a busca, na linha 29. Se houver pelo menos um consequente disponível, novos_Consequentes_Disponiveis é usado como terceiro parâmetro da chamada recursiva. Após a chamada recursiva, cada item $P$ é inserido no conjunto ate_Agora. O objetivo do conjunto ate_Agora é manter os itens $P$, na linha 42, que sobrevivem aos dois primeiros conjuntos de podas, CP1 e CP2, encontrados nas linhas 3 e 7. Na Seção A.1 do Apêndice A é ilustrado um exemplo de execução para o KORD-growth1.

\subsubsection{Algoritmo KORD-growth2}

Nesta seção, é apresentado o algoritmo KORD-growth2, que implementa a estratégia da travessia de regras com pesquisa implícita e realiza o mesmo objetivo do KORD e KORD-growth1, que é a descoberta de regras ótimas. O algoritmo KORD-growth2 difere do KORD-growth 1 por realizar pesquisa implícita de regras. Portanto, é possivel remover os possiveis consequentes que não mantém uma FP-tree.

O algoritmo KORD-growth2, ilustrado no Algoritmo 4.2, mantém um procedimento recursivo que possui quatro parâmetros: 
antecedente_Atual é o itemset antecedente recentemente avaliado.

antecedentes_FPtree mantém uma árvore FP-tree condicional que é usada para minerar a frequência dos possíveis antecedentes explorados durante a busca.

antecedentes_Disponiveis conjunto de itens que podem ser inseridos ao antecedente das regras a serem exploradas.

consequentes_Disponiveis conjunto de todos os possiveis consequentes que podem formar regras junto com o antecedente novo_Antecedente. Cada consequente mantém uma árvore FP-tree condicional ao respectivo itemset no consequente. A partir de cada FP-tree são obtidos os suportes das regras.

A chamada inicial do algoritmo KORD-growth2 é similar ao KORD-growth 1 e as mesmas restrições de busca são adotadas.

O Algoritmo KORD-growth2 mantém dois laços ou loops. O primeiro laço, que começa na linha 2 , visa percorrer cada item $P$ encontrado no conjunto de itens disponiveis para os antecedentes, antecedentes_Disponiveis. Desta forma, novos antecedentes mais específicos são explorados durante a busca, isto é, cada item verificado é inserido na variável novo_Antecedente, especializando o antecedente_Atual. Para conhecer a cobertura de novo_Antecedente = antecedente_Atual $\cup\{P\}$, é necessário obter os caminhos de prefixo para $P$, antCaminhoPrefixo, a partir da árvore FP-tree condicional antecedentes_FPtree na linha 5 através da função obterCaminhoPrefixo(0. A frequência do novo_Antecedente recentemente explorado é mantida pela variável coberturaAntecedente. Esse valor é obtido na linha 6, utilizando os caminhos de prefixo antCaminhoPrefixo como parâmetro através da função obterSuporte().

O segundo laço começa na linha 10, dentro do primeiro laço, e existe para atravessar cada possivel consequente a partir de consequentes_Disponiveis. Em virtude da adoção da pesquisa pós-ordem e da pesquisa implícita de regras, na linha 12 há uma condição que permite apenas a investigação dos consequentes com frequência menor que o item $P$, isto é, apenas àqueles que possuem árvore FP-tree. Até o momento já são conhecidos o antecedente novo_Antecedente, o consequente $Y=$ consequente. $Y$ e suas coberturas, coberturaAntecedente e coberturaConsequente $=$ consequente.cobertura

Para avaliar a regra novo_Antecedente $\rightarrow Y$ é necessário conhecer o seu suporte. A obtenção do suporte da regra é possível por extrair os caminhos de prefixo a partir da FP-tree condicional armazenada no consequente correntemente levado em consideração. Esses caminhos de prefixo são representados pela variável regraCaminhoPrefixo e são obtidos na linha 15 a partir da função 
obterCaminhoPrefixo(), que tem como argumentos o corrente item $P$ e a árvore FP-tree condicional do consequente correntemente avaliado.

O suporte da regra é armazenado na variável suporteRegra e é obtido através da função obterSuporte() na linha 16, que tem como argumento a variável regraCaminhoPrefixo. Se a regra novo_Antecedente $\rightarrow Y$ respeitar todas as condições e restrições impostas pela tarefa, ela é adicionada no conjunto de soluções solucao_Atual na linha 18. Na linha 25 é obtida uma FP-tree condicional para o consequente que sobreviveu aos conjuntos de podas CP3 e CP4.

O conjunto de soluções para a tarefa de descoberta de regras ótimas, solucao_Atual, é mantida globalmente e é iniciada vazia. Para ser inserida em solucao_Atual, qualquer regra deve respeitar todas as restrições impostas pela busca. Além disso, todas as $k$ regras mantidas em solucao_Atual são ordenadas de forma decrescente sobre o valor da medida de interesse objetiva determinada pela tarefa. Toda vez que uma nova regra for inserida em solucao_Atual, linha 18, ela deve ser inserida na posição $k+1$. Depois disso, uma ordenação sobre solucao_Atual é realizada na linha 19, de forma decrescente do valor da medida objetiva utilizada na busca. Após a ordenação desse conjunto, a regra que ficar na posição $k+1$ é excluída, linha 20. A restrição menor Medida é atualizada pelo valor da medida objetiva da regra que é situada na posição $k$. No final da tarefa de descoberta, o algoritmo KORD-growth2 tem como saída o conjunto solucao_Atual, que mantém as $k$ regras de associação ótimas que otimizam uma arbitrária medida de interesse objetiva.

Como descrito na estratégia da travessia de regras com pesquisa implícita, um itemset de tamanho $k$ pode formar $k$ regras se houver um item no consequente. Essas regras são obtidas pela busca implícita realizada no Algoritmo KORD-growth2, na linha 22. Na avaliação implícita são conhecidos previamente o suporte do itemset que forma as regras e a cobertura dos possiveis consequentes. Desta forma, para avaliar as regras é necessário somente minerar a cobertura dos possiveis antecedentes. Tal procedimento é descrito na Seção 4.3.7, onde também é explicado a aplicação da prevencão de acesso 7 situada no conjunto de prevenções PA3. Após cada regra ser inserida no conjunto solucao_Atual durante a pesquisa implícita, é realizada as etapas de ordenação do conjunto solucao_Atual e posterior remoção da regra situada na posição $(k+1)$ desse mesmo conjunto.

No momento da chamada recursiva, linha 33 do Algoritmo 4.2, é necessário que os dois últimos parâmetros não sejam vazios, novos_Consequentes_Disponiveis $\neq \emptyset$ e novos_Antecedentes_Disponiveis $\neq \emptyset$, e que o tamanho do itemset novo_Antecedente, que é o primeiro parâmetro, seja menor que a variável tamMaxAnt. Se isso for satisfeito, a função obterFP-treeCondicional0 deve ser chamada para formar uma nova árvore FP-tree condicional novos_Anteceden- 
tes_FPtree para o item $P$. Tal FP-tree condicional será o segundo parâmetro da chamada recursiva. O terceiro parâmetro, que é a variável novos_antecedentes_Disponiveis recebe os itens mantidos no conjunto ate_Agora na linha 8. Esses itens, adicionados em ate_Agora, na linha 36, farão parte dos antece-

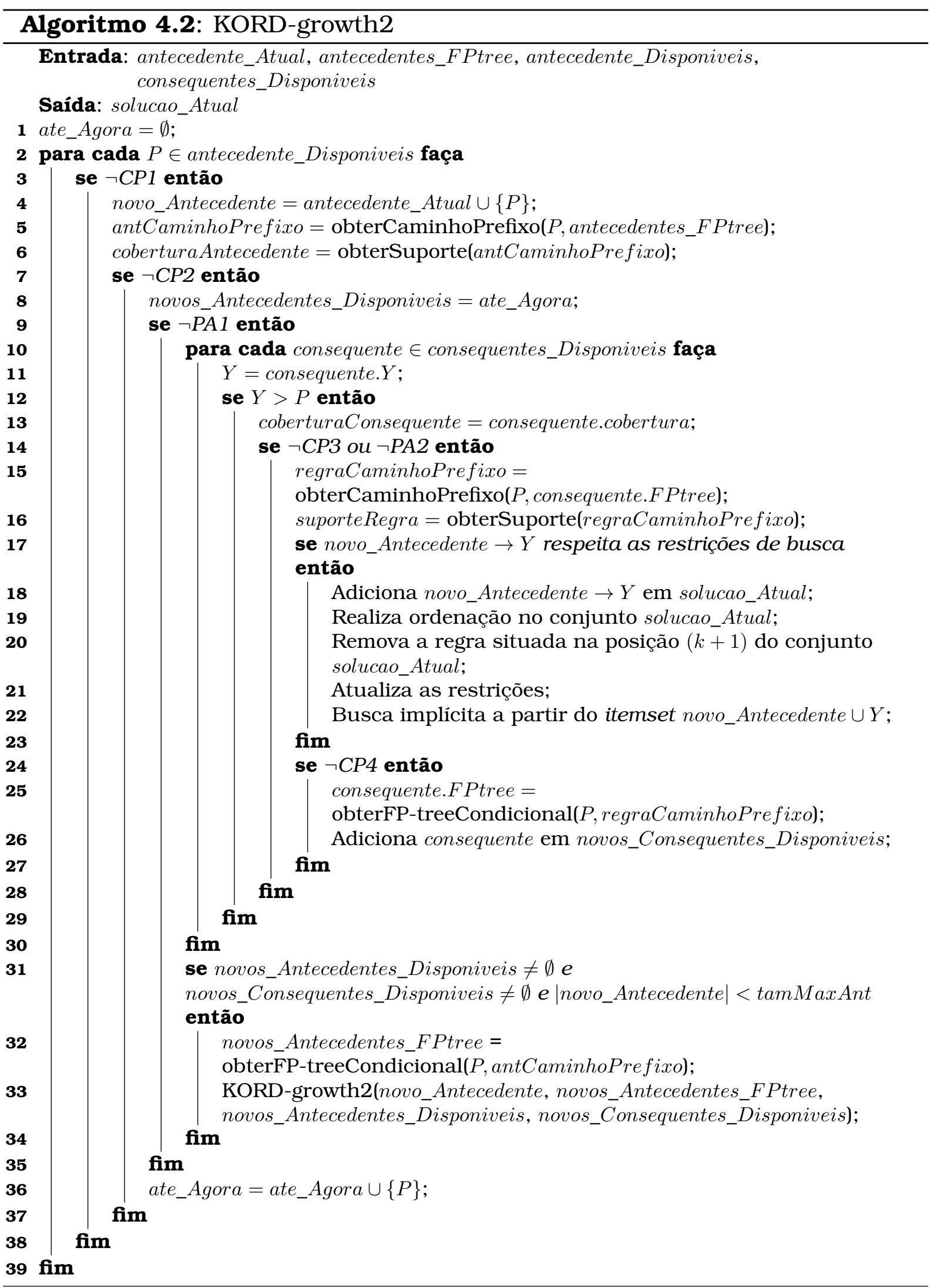


dentes mais específicos que posteriormente poderão ser explorados. O conjunto novos_Consequentes_Disponiveis mantém todos os consequentes que sobrevivem às podas existentes durante a busca na linha 26. Na Seção A.2 do Apêndice A é ilustrado um exemplo de execução para o KORD-growth2.

\section{Atualização dinâmica das restrições}

Embora as restrições menorSuporte e menorCobertura sejam iniciadas por um usuário, seus valores podem ser atualizados automaticamente durante a busca, linha 26 do KORD-growth1 e linha 21 do KORD-growth2. Tais mudanças, implementadas no algoritmo KORD e apresentadas na Seção 3.3.5, podem ser úteis para podar mais regiões do espaço de busca e poupar avaliações das regras. Essas restrições podem ser atualizadas após cada regra ser inserida no conjunto solucao_Atual e atualização do valor da restrição menor Medida.

\subsection{Aplicação das Podas}

A aplicação de podas é essencial para diminuir o espaço de busca da tarefa de descobrir as regras ótimas, pois removem regiões desse espaço sem regras promissoras. Isto é, nenhuma regra abaixo de um ponto da busca, onde foi aplicada a poda, tem valor de medida objetiva maior que a última regra da solucao_Atual. Nenhuma regra pertencente à região podada possui valor de medida objetiva maior que a regra com menor valor de medida objetiva encontrada no conjunto solução. Tais podas são encontradas em diferentes regiões dos algoritmos KORD-growth1 e KORD-growth2. Para aplicá-las é necessário conhecer as estatísticas dos componentes de uma regra, isto é, os valores da frequência do antecedente $P(X)$, do consequente $P(Y)$ e do par antecedenteconsequente, que é o suporte da regra em questão $P(X \rightarrow Y)$. A eficiência dos algoritmos KORD-growth1 e KORD-growth2, assim como o KORD, depende do poder dessas podas disponíveis.

As podas são encontradas em conjuntos de podas que ficam em regiões específicas dos algoritmos. O primeiro conjunto de podas (CP1) situa-se na linha 3 dos algoritmos KORD-growth1 e KORD-growth2, após conhecido o item $P$ que será adicionado ao novo_Antecedente. Tal conjunto possui podas que são aplicadas pelo conhecimento da cobertura do item $P$. Se alguma poda do primeiro conjunto de podas for aplicada, o item $P$ não será adicionado ao novo_Antecedente. Após disso, um novo item $P$ deve ser explorado. O segundo conjunto de podas (CP2), linha 7 do KORD-growth1 e KORD-growth2, é verificado caso o item $P$ seja adicionado ao novo_Antecedente. Nesse conjunto, utiliza-se a cobertura do itemset antecedente recém explorado, novo_Antecedente. Caso alguma poda do segundo conjunto de podas for 
aplicada, a busca por regras com novo_Antecedente não continua, e é necessário explorar um novo item $P$. As podas de ambos os conjuntos implicam que o item $P$ não será adicionado ao conjunto ate_Agora. Portanto, itemsets antecedentes mais específicos que contenham $P$ não serão explorados.

O terceiro conjunto de podas (CP3), linha 14 do KORD-growth1 e KORDgrowth2, verifica algumas relações entre o novo_Antecedente corrente e o consequente recém considerado na busca. Por conhecer ambas coberturas, $P(X)$ e $P(Y)$, é possível aplicar podas e evitar a necessidade de minerar o suporte da regra. Caso as podas encontradas no terceiro conjunto de podas sejam aplicadas, um novo consequente deve ser considerado e o consequente atual é podado de novos_Consequentes_Disponiveis, isto é, o consequente recém verificado não será propagado para pontos de busca mais profundos. Após avaliação da regra é possível utilizar as podas encontradas no quarto conjunto de podas (CP4), linha 28 do KORD-growth1 e linha 24 do KORD-growth2. Essas podas têm um alto poder para redução do espaço de busca em virtude da utilização do suporte da regra.

Além das podas de regras, há outra maneira de evitar a avaliação de regras não promissoras. Prevenções de acesso são técnicas que evitam o acesso ao conjunto de dados para a contagem do suporte de uma regra. Embora impeçam a avaliação de regras, as prevenções de acesso não são podas, em virtude de não excluírem regiões do espaço de busca. Tais técnicas são aplicadas quando o tamanho do itemset antecedente alcança o tamanho máximo de antecedente permitido na tarefa de descoberta, tamMaxAnt, ou quando o conjunto novos_Antecedentes_Disponiveis é vazio. Portanto, quando essas condições são satisfeitas, é possível evitar a contagem do suporte das possíveis regras utilizando as estatísticas já conhecidas, como coberturaAntecedente e coberturaConsequente e o suporte da última regra avaliada $P$ (antecedente_Atual $\rightarrow Y)$.

As prevenções de acesso são mantidas em conjuntos de prevenções de acesso. Tais conjuntos são encontrados em regiões específicas dos algoritmos KORD-growth 1 e KORD-growth2. O primeiro conjunto (PA1) é encontrado na linha 9 do KORD-growth1 e KORD-growth2, após ser conhecida a cobertura do novo_Antecedente. Se a prevenção for aplicada, não há necessidade de verificar os consequentes a partir de consequentes_Disponiveis e um novo item $P$ deve ser verificado. $\mathrm{O}$ segundo conjunto de prevenções de acesso (PA2) situa-se após conhecida a cobertura do consequente correntemente avaliado na busca, na linha 14 de ambos os algoritmos. Se alguma prevenção de acesso for aplicada não haverá a necessidade de conhecer o suporte da regra novo_Antecedente $\rightarrow Y$. Isso implica em menor custo computacional para a tarefa de descoberta das regras ótimas. 
Os conjuntos de prevenção de acesso apresentados anteriormente são aplicados durante a busca explícita no algoritmo KORD-growth2. Na busca implícita, linha 22, que existe nesse algoritmo é encontrado um novo conjunto de prevenção de acesso, PA3. Esse conjunto mantém uma prevenção que impede o acesso ao conjunto de dados para contagem da frequência dos possiveis antecedentes. Vale ressaltar que a aplicação do conjunto PA3 não depende das condições $\mid$ novo_Antecedente $\mid=$ tamMaxAnt e novos_Antecedentes_Disponiveis $=$ $\emptyset$.

As podas e prevenções de acesso consideradas neste trabalho são aplicadas na descoberta direta de regras ótimas para a medida $P S$, em virtude de serem bem definidas na literatura. Entretanto, caso seja necessário descobrir regras ótimas para outras medidas de interesse é necessário a modificação de algumas podas e prevenções de acesso. As podas 4 e 10 e as prevenções de acesso 4, 6 e 7 foram definidas e implementadas neste trabalho. Além disso, também foi definida a aplicação das prevenções de acesso quando novos_Antecedentes_Disponiveis $=\emptyset$. As podas e prevenções de acesso restantes foram definidas e implementadas em trabalhos passados (Webb, 2000; Webb e Zhang, 2005). Tais podas e prevenções de acesso são apresentadas em seguida por causa da adaptação das variáveis dos dois algoritmos expostos anteriormente.

Para facilitar o entendimento são citadas algumas propriedades antes de apresentar os conjuntos de podas e prevenções de acesso.

Lema 4.3.1 (Cobertura do Subconjunto.) Para qualquer itemset $I_{1}, I_{2} \subseteq I$, se $I_{1} \subseteq I_{2}$, então $\sigma\left(I_{2}\right) \subseteq \sigma\left(I_{1}\right)$, e portanto, cober $\left(I_{2}\right) \leq \operatorname{cober}\left(I_{1}\right)$.

Prova. Para qualquer $t \in \sigma\left(I_{2}\right)$, a partir da definição do conjunto de transações coberto por um itemset na Equação 2.1, então $I_{2} \subseteq t$. Visto que $I_{1} \subseteq I_{2}$, então $I_{1} \subseteq t$. Como $t \in \sigma\left(I_{1}\right)$, portanto $\sigma\left(I_{2}\right) \subseteq \sigma\left(I_{1}\right)$ é verdade.

Lema 4.3.2 (União da Cobertura.) Para qualquer itemset não-vazio $I_{1}, I_{2}, I_{3} \subseteq$ $I$, onde $I_{1} \cap I_{2}=\emptyset, I_{2} \cap I_{3}=\emptyset$ e $I_{1} \cap I_{3}=\emptyset$, se

$$
\operatorname{cober}\left(I_{1}\right)=\operatorname{cober}\left(I_{1} \cup I_{2}\right)
$$

então:

$$
\operatorname{cober}\left(I_{1} \cup I_{3}\right)=\operatorname{cober}\left(I_{1} \cup I_{2} \cup I_{3}\right)
$$

Prova. A partir de (4.1), é possível obter:

$$
\left|\sigma\left(I_{1}\right)\right|=\left|\sigma\left(I_{1} \cup I_{2}\right)\right|
$$


A partir do lema da cobertura do subconjunto:

$$
\sigma\left(I_{1}\right) \supseteq \sigma\left(I_{1} \cup I_{2}\right)
$$

De (4.3) e (4.4), é possível obter:

$$
\sigma\left(I_{1}\right)=\sigma\left(I_{1} \cup I_{2}\right)
$$

Para qualquer $t \in T \wedge I_{1} \cup I_{3} \subseteq t, I_{1} \subseteq t$ e $I_{3} \subseteq t$ são mantidos. A partir de $I_{1} \subseteq t$ e (4.5), é obtido $I_{1} \cup I_{2} \subseteq t$. Visto que $I_{3} \subseteq t$, então $I_{1} \cup I_{2} \cup I_{3} \subseteq t$. Portanto, obtém-se:

$$
\sigma\left(I_{1} \cup I_{3}\right) \subseteq \sigma\left(I_{1} \cup I_{2} \cup I_{3}\right)
$$

A partir do lema da cobertura do subconjunto:

$$
\sigma\left(I_{1} \cup I_{3}\right) \supseteq \sigma\left(I_{1} \cup I_{2} \cup I_{3}\right)
$$

A partir (4.6) e (4.7), então é verdade que $\sigma\left(I_{1} \cup I_{3}\right)=\sigma\left(I_{1} \cup I_{2} \cup I_{3}\right)$, provando (4.2).

\subsubsection{CP1 - Conjunto de Podas 1}

O conjunto de podas $1, \mathrm{CP} 1$, é aplicado antes do cálculo da cobertura do antecedente e após conhecer o item $P$. A poda 1 é aplicada se a cobertura do item $P$ for menor que a menorCobertura. Para entender esta poda, é necessário utilizar o lema a seguir.

Lema 4.3.3 (Menor cobertura para regras na solução.) Para qualquer regra $X \rightarrow Y$, se houver $X_{1} \subseteq X$ onde cober $\left(X_{1}\right)<$ menorCobertura, então $X \rightarrow Y$ não pertence à solução.

Prova. A partir do lema da cobertura do subconjunto e $X_{1} \subseteq X$, segue que:

$$
\operatorname{cobertura}(X \rightarrow Y)=\operatorname{cober}(X) \leq \operatorname{cober}\left(X_{1}\right)<\text { menorCobertura }
$$

Portanto $X \rightarrow Y$ não pertence à solucao_Atual.

Poda 1: Para qualquer item $P$, se $\operatorname{cober}(P)<$ menorCobertura, então $P$ pode ser podado de ate_Agora.

Em virtude da cobertura do item $P$ ser menor que menorCobertura, não é necessário verificar a cobertura do antecedente novo_Antecedente, que seria formado pela adição de $P$ juntamente com antecedente_Atual. Portanto, um novo item $P$ deve ser verificado. 


\subsubsection{CP2 - Conjunto de Podas 2}

O conjunto de podas 2 é aplicado após conhecida a cobertura do antecedente novo_Antecedente e antes de considerar os consequentes. A poda 2 é aplicada se a cobertura de novo_Antecedente, coberturaAntecedente, for menor que a menorCobertura.

Poda 2: Para qualquer novo_Antecedente $=$ antecedente_Atual $\cup P$, se coberturaAntecedente $<$ menorCobertura, então $P$ pode ser podado de ate_Agora.

Em virtude da cobertura de novo_Antecedente ser menor que menorCobertura, qualquer especialização formada sobre esse antecedente também seria menor que a menorCobertura. Conforme o lema da menor cobertura para regras na solução, não há qualquer regra $X \rightarrow Y$ na solução, se novo_Antecedente $\subseteq X$.

\subsubsection{CP3 - Conjunto de Podas 3}

O conjunto de podas 3 é aplicado após considerar um consequente e antes da avaliação da regra. A poda 3 é aplicada quando coberturaConsequente < menorSuporte. Para entender esta poda, é necessário observar o seguinte lema:

Lema 4.3.4 (Menor suporte para regras na solução.) Para qualquer regra $X$ $\rightarrow Y$, se houver $Z \subseteq X \cup Y$ onde cober $(Z)<$ menorSuporte, então $X \rightarrow Y$ não pertence à solução.

Prova. A partir do lema da cobertura do subconjunto e $Z \subseteq X \cup Y$, segue que:

$$
\sup (X \rightarrow Y)=\operatorname{cober}(X \cup Y) \leq \operatorname{cober}(Z)<\text { menorSuporte }
$$

Portanto, $X \rightarrow Y$ não pertence à solucao_Atual.

Poda 3: Para qualquer consequente consequente, onde consequente $\in$ consequentes_Disponiveis, se coberturaConsequente $<$ menorSuporte, então consequente pode ser podado de novos_Consequentes_Disponiveis.

Se coberturaConsequente $<$ menorSuporte, onde $Y=$ consequente. $Y$, então para qualquer antecedente $X, \sup (X \rightarrow Y)<$ menorSuporte. A poda 4 é baseada no Teorema 4.3.1, que se refere ao menor $P S$ para o consequente das regras na solução. O termo menor PS se refere ao termo menor Medida. Essa alteração ocorreu em virtude das podas listadas a seguir serem relacionadas com a medida de interesse $P S$.

Teorema 4.3.1 (Menor PS para consequente das regras na solução.) Para qualquer regra $X \rightarrow Y$, se cober $(Y) \times(1-\operatorname{cober}(Y))<$ menor $P S$, então $X \rightarrow Y$ não pertence à solução. 
Prova. Primeiro, considere cober $(X) \geq \operatorname{cober}(Y)$. Desta forma, é mantido 1 $\operatorname{cober}(Y) \geq 1-\operatorname{cober}(X)$. Conforme o lema da cobertura do subconjunto pode-se obter:

$$
\begin{aligned}
P S(X \rightarrow Y) & =\sup (X \rightarrow Y)-\operatorname{cober}(X) \times \operatorname{cober}(Y) \\
& =\operatorname{cober}(X \cup Y)-\operatorname{cober}(X) \times \operatorname{cober}(Y) \\
& \leq \operatorname{cober}(Y)-\operatorname{cober}(X) \times \operatorname{cober}(Y) \\
& \leq \operatorname{cober}(Y) \times(1-\operatorname{cober}(X)) \\
& \leq \operatorname{cober}(Y) \times(1-\operatorname{cober}(Y))<\text { menor } P S
\end{aligned}
$$

Neste caso, se $P S(X \rightarrow Y)<$ menor $P S$, então $X \rightarrow Y$ não pertence à solução. Da mesma forma, o teorema é provado quando $\operatorname{cober}(X) \times(1-\operatorname{cober}(X))<$ menorPS.

Poda 4: Para qualquer consequente consequente, onde consequente $\in$ consequentes_Disponiveis, se coberturaConsequente $\times(1$ - coberturaConsequente $) \leq$ menor PS, então consequente pode ser podado de novos_Consequentes_Disponiveis.

O consequente em questão não precisa ser considerado para avaliação de regras, pois para qualquer antecedente não haverá regras que possam ser inseridas na solução. Portanto, pode ser podado da busca, em virtude de o valor da coberturaConsequente ser fixo. Vale lembrar que se coberturaConsequente $\times$ $(1$ - coberturaConsequente $)=$ menor $P S$ também não é necessário avaliar as regras sobre tal consequente, pois a k-ésima regra do conjunto de soluções já possui o valor de menor $P S$. Isso também funciona para as outras podas que utilizam a restrição menor $P S$.

A próxima poda pode ser medida pelo limitante inferior menor $P S$ antes da avaliação da regra. O limitante inferior utilizado em menor $P S$ é o $P S$ da késima regra que satisfaz as restrições de busca até o momento.

Teorema 4.3.2 (Menor valor de $P S$ das regras na solução.) Para qualquer regra $X \rightarrow Y$, se cober $(Y)>1-\frac{\operatorname{menor} P S}{\operatorname{cober}(X)}$, então $X \rightarrow Y$ não pertence à solução.

Prova. A expressão é obtida da seguinte forma:

$$
\begin{aligned}
& \text { menorPS }>\sup (X \rightarrow Y)-\operatorname{cober}(X) \times \operatorname{cober}(Y)=P S(X \rightarrow Y) \\
& \text { menorPS }>\operatorname{cober}(X \cup Y)-\operatorname{cober}(X) \times \operatorname{cober}(Y)=P S(X \rightarrow Y)
\end{aligned}
$$


A partir do lema da cobertura do subconjunto, pode-se obter $\operatorname{cober}(X \cup Y) \leq$ $\operatorname{cober}(X)$.

$$
\begin{aligned}
\text { menor } P S & >\operatorname{cober}(X)-\operatorname{cober}(X) \times \operatorname{cober}(Y) \geq P S(X \rightarrow Y) \\
\operatorname{menor} P S-\operatorname{cober}(X) & >-\operatorname{cober}(X) \times \operatorname{cober}(Y) \\
\operatorname{cober}(X) \times \operatorname{cober}(Y) & >\operatorname{cober}(X)-\text { menor } P S \\
\operatorname{cober}(Y) & >1-\frac{\text { menor } P S}{\operatorname{cober}(X)}
\end{aligned}
$$

Assim, menor $P S>P S(X \rightarrow Y)$. Portanto, $X \rightarrow Y$ não pertence à solução. Da mesma forma, o teorema é provado quando $\operatorname{cober}(X)>1-\frac{\operatorname{menor} P S}{\operatorname{cober}(Y)}$ e $\operatorname{cober}(X \cup$ $Y) \leq \operatorname{cober}(Y)<\operatorname{cober}(X)$.

Poda 5: Para qualquer consequente consequente, onde consequente $\in$ consequentes_Disponiveis, se coberturaConsequente $\geq 1-\frac{\text { menorPS }}{\text { coberturaAntecedente }}$, então consequente pode ser podado de novos_Consequentes_Disponiveis.

Conforme o Teorema 4.3.2, nenhuma regra abaixo do atual ponto de busca se encontra na solução. Isso acontece em virtude do valor da coberturaConsequente ser fixo. Como as especializações do antecedente acarretam em menores coberturas, que pode ser observado pelo lema da cobertura do subconjunto $\operatorname{cober}\left(X \cup X_{1}\right) \leq \operatorname{cober}(X)$, então a expressão coberturaConsequente $\geq$ $1-\frac{\text { menorPS }}{\text { coberturaAntecedente }}$ será mantida verdadeira, e o consequente poderá ser podado da busca.

A poda 6 é aplicada para qualquer consequente que cobre todo conjunto de dados.

Teorema 4.3.3 (Total Cobertura.) Para qualquer regra $X \rightarrow Y$, se $\operatorname{cober}(Y)=$ 1 , então $P S(X \rightarrow Y)=0$.

Quando $\operatorname{cober}(Y)=1$, então $\operatorname{cober}(X \cup Y)=\operatorname{cober}(X)$. Portanto, pode-se obter o seguinte:

$$
\begin{aligned}
P S(X \rightarrow Y) & =\sup (X \rightarrow Y)-\operatorname{cober}(X) \times \operatorname{cober}(Y) \\
& =\operatorname{cober}(X \cup Y)-\operatorname{cober}(X) \times \operatorname{cober}(Y) \\
& =\operatorname{cober}(X)-\operatorname{cober}(X)=0
\end{aligned}
$$

Da mesma forma, pode-se obter $P S(X \rightarrow Y)=0$ quando $\operatorname{cober}(X)=1$.

Poda 6: Para qualquer consequente consequente, onde consequente $\in$ consequentes_Disponiveis, se coberturaConsequente $=1$ e menor $P S>0$, então consequente pode ser podado de novos_Consequentes_Disponiveis.

Conforme o Teorema 4.3.3, nenhuma regra abaixo do atual ponto de busca se encontra na solução. 


\subsubsection{CP4 - Conjunto de Podas 4}

O conjunto de podas 4 - CP4 - é aplicado após avaliação da regra. A poda 7 é aplicada quando o suporte da regra é menor que o menor Suporte.

Poda 7: Para a corrente regra novo_Antecedente $\rightarrow Y$, onde consequente $\in$ consequentes_Disponiveis e $Y=$ consequente.Y, se sup(novo_Antecedente $\rightarrow Y$ ) $<$ menorSuporte, então consequente pode ser podado de novos_Consequentes_ Disponiveis.

Uma restrição da tarefa de descoberta de regras ótimas é o suporte mínimo. Se o suporte da regra atual novo_Antecedente $\rightarrow Y$ for menor que o menorSuporte aceito na mineração, então consequente pode ser podado de novos_Consequentes_Disponiveis, pois qualquer regra mais específica terá suporte menor que menor Suporte.

A poda 8 é aplicada quando o suporte da regra sob avaliação for menor que o menorPS.

Teorema 4.3.4 (Suporte para regras na solução com relação à medida $P S$.) Para qualquer regra $X \rightarrow Y$, se $\sup (X \rightarrow Y) \geq$ menor $P S$, então $X \rightarrow Y$ pertence à solução.

Prova. Sabendo que $X \rightarrow Y$ pertence à solução, então:

$$
\begin{aligned}
& P S(X \rightarrow Y)=\sup (X \rightarrow Y)-\operatorname{cober}(X) \times \operatorname{cober}(Y) \\
& \sup (X \rightarrow Y)=P S(X \rightarrow Y)+\operatorname{cober}(X) \times \operatorname{cober}(Y) \\
& \sup (X \rightarrow Y) \geq P S(X \rightarrow Y) \geq \text { menor } P S
\end{aligned}
$$

Poda 8: Para a corrente regra novo_Antecedente $\rightarrow Y$, onde consequente $\in$ consequentes_Disponiveis e $Y=$ consequente.Y, se sup(novo_Antecedente $\rightarrow Y) \leq$ menorPS, então consequente pode ser podado de novos_Consequentes_Disponiveis.

O suporte da regra é um limitante superior para a medida $P S$. Desta forma, a regra atual e qualquer regra mais específica não estará na solução.

A poda 9 é aplicada quando é alcançada a máxima confiança pela regra avaliada e a medida $P S$ desta regra for menor ou igual ao menor $P S$. Tal poda é baseada no teorema do limitante superior da medida $P S$ a partir da confiança, descrito a seguir.

Teorema 4.3.5 (Limitante superior de $P S$ a partir da confiança.) Para qualquer regra $X \rightarrow Y$, se con $f(X \rightarrow Y)=1$ e $X_{1} \subset I$, tal que $X_{1} \cap X=\emptyset$ e $X_{1} \cap Y=\emptyset$, então pode-se obter o seguinte.

$$
P S\left(X \cup X_{1} \rightarrow Y\right) \leq P S(X \rightarrow Y)
$$


Prova. A partir de $\operatorname{con} f(X \rightarrow Y)=1$, pode-se obter:

$$
\operatorname{cober}(X)=\operatorname{cober}(X \cup Y)
$$

A partir de (4.8) é possível obter o seguinte:

$$
\begin{aligned}
P S(X \rightarrow Y) & =\sup (X \rightarrow Y)-\operatorname{cober}(X) \times \operatorname{cober}(Y) \\
& =\operatorname{cober}(X \cup Y)-\operatorname{cober}(X) \times \operatorname{cober}(Y) \\
& =\operatorname{cober}(X)-\operatorname{cober}(X) \times \operatorname{cober}(Y) \\
& =\operatorname{cober}(X) \times(1-\operatorname{cober}(Y))
\end{aligned}
$$

A partir de (4.8) e do lema da união da cobertura, pode-se obter:

$$
\operatorname{cober}\left(X \cup X_{1}\right)=\operatorname{cober}\left(X \cup X_{1} \cup Y\right)
$$

De acordo com (4.10), pode-se obter:

$$
\begin{aligned}
P S\left(X \cup X_{1} \rightarrow Y\right) & =\sup \left(X \cup X_{1} \rightarrow Y\right)-\operatorname{cober}\left(X \cup X_{1}\right) \times \operatorname{cober}(Y) \\
& =\operatorname{cober}\left(X \cup X_{1} \cup Y\right)-\operatorname{cober}\left(X \cup X_{1}\right) \times \operatorname{cober}(Y) \\
& =\operatorname{cober}\left(X \cup X_{1}\right)-\operatorname{cober}\left(X \cup X_{1}\right) \times \operatorname{cober}(Y) \\
& =\operatorname{cober}\left(X \cup X_{1}\right) \times(1-\operatorname{cober}(Y))
\end{aligned}
$$

A partir do lema da cobertura do subconjunto, pode-se obter cober $\left(X \cup X_{1}\right) \leq$ cober $(X)$. Desta forma, a partir de (4.9) e (4.11), é possível obter o seguinte.

$$
P S\left(X \cup X_{1} \rightarrow Y\right) \leq P S(X \rightarrow Y)
$$

Poda 9: Após avaliação da regra novo_Antecedente $\rightarrow Y$, onde consequente $\epsilon$ consequentes_Disponiveis e $Y=$ consequente. $Y$, se conf(novo_Antecedente $\rightarrow$ $Y)=1$ e $P S($ novo_Antecedente $\rightarrow Y) \leq$ menor $P S$, então consequente pode ser podado de novos_Consequentes_Disponiveis.

Nenhuma especialização da regra em questão conseguirá ter medida $P S$ superior que o menor $P S$, conforme o Teorema 4.3.5. A Poda 10 é baseada no limitante inferior da k-ésima regra do conjunto solucao_Atual, menorPS, conforme o teorema descrito a seguir.

Teorema 4.3.6 (Limitante inferior da k-ésima regra.) Para qualquer regra $X \rightarrow Y$, se cober $(Y)>1-\frac{\text { menor } P S}{\sup (X \rightarrow Y)}$, então $X \rightarrow Y$ não pertence à solução.

Prova. A expressão é obtida da seguinte forma:

$$
\text { menorPS }>\sup (X \rightarrow Y)-\operatorname{cober}(X) \times \operatorname{cober}(Y)=P S(X \rightarrow Y)
$$


A partir do lema da cobertura do subconjunto, pode-se obter $\sup (X \rightarrow Y)=$ $\operatorname{cober}(X \cup Y) \leq \operatorname{cober}(X)$.

$$
\begin{aligned}
\text { menorPS } & >\sup (X \rightarrow Y)-\sup (X \rightarrow Y) \times \operatorname{cober}(Y) \geq P S(X \rightarrow Y) \\
\text { menorPS }-\sup (X \rightarrow Y) & >-\sup (X \rightarrow Y) \times \operatorname{cober}(Y) \\
\sup (X \rightarrow Y) \times \operatorname{cober}(Y) & >\sup (X \rightarrow Y)-\text { menorPS } \\
\operatorname{cober}(Y) & >1-\frac{\text { menor } P S}{\sup (X \rightarrow Y)}
\end{aligned}
$$

Assim, menor $P S>P S(X \rightarrow Y)$. Portanto, $X \rightarrow Y$ não pertence à solução.

Poda 10: Para qualquer consequente consequente, onde consequente $\in$ consequentes_Disponiveis, se coberturaConsequente $\geq 1-\frac{\text { menorPS }}{\text { suporteRegra }}$, então consequente pode ser podado de novos_Consequentes_Disponiveis.

De acordo com o Teorema 4.3.6, nenhuma regra abaixo do atual ponto de busca se encontra na solução. Isso acontece em virtude de o valor da coberturaConsequente ser fixo. Como as especializações das regras acarretam em menores valores de suporte, que pode ser observado pelo lema da cobertura do subconjunto cober $\left(X \cup X_{1} \cup Y\right) \leq \operatorname{cober}(X \cup Y)$, então a expressão coberturaConsequente $\geq 1-\frac{\text { menor } P S}{\text { suporteRegra }}$ será mantida verdadeira, e o consequente poderá ser podado da busca.

Poda 11: Após a avaliação da regra novo_Antecedente $\rightarrow Y$, onde novo_Antecedente $=$ antecedente_Atual $\cup\{P\}$ e $P \in$ antecedentes_Disponiveis, consequente $\in$ consequentes_Disponiveis e $Y=$ consequente.Y, então opt_conf é computado como:

$$
\text { opt_conf }=\frac{\text { sup }(\text { novo_Antecedente } \rightarrow Y)}{\text { coberAux }}
$$

onde

coberAux $=$ maior $($ menorCobertura, coberturaAntecedente $)-$ max_spec $\times$ max_reducao $)$

onde

max_spec $=$ menor $(\operatorname{tam} M a x A n t-\mid$ novo_Antecedente $|$,$| novos_Antecedentes_Disponiveis \mid)$

e

max_reducao $=\underset{S \in \text { novos_Antecedentes_Disponiveis }}{\max }(\operatorname{cober}($ antecedente_Atual $)-$ cober $($ antecedente_Atual $\cup\{S\}))$ 
Se opt_conf $<$ menorConfianca, consequente pode ser podado de novos_Consequentes_Disponiveis. Considere o cálculo para opt_PS:

opt_PS $=$ sup $($ novo_Antecedente $\rightarrow Y)-$ coberAux $\times$ coberturaConsequente

se opt_PS $<$ menor PS, consequente pode ser podado de novos_Consequentes_Disponiveis.

Poda 12: Após a avaliação da regra novo_Antecedente $\rightarrow Y$, então opt_conf $f^{\prime}$ e opt_PS' são computados como:

$$
\text { opt_conf } f^{\prime}=\frac{\text { sup }(\text { novo_Antecedente } \rightarrow Y)}{\text { coberAux }}
$$

onde cober Aux' é similar ao coberAux, exceto que novo_Antecedente é utilizado no lugar de antecedente_Atual na definição de max_reducao. Se opt_conf $f^{\prime}<$ menorConfianca, consequente pode ser podado de novos_Consequentes_Disponiveis. Deixe

$$
\text { opt_PS }=\sup (r)-\operatorname{cober} A u x^{\prime} \times \operatorname{cober}(Y)
$$

se $o p t_{-} P S^{\prime}<$ menor $P S$, consequente pode ser podado de novos_Consequentes_Disponiveis.

As provas das podas 11 e 12 podem ser encontradas em Webb e Zhang (2005). A avaliação das estatísticas referentes ao antecedente, consequente e ao par antecendente-consequente exige acessar o conjunto de dados e é uma das tarefas mais custosas dos algoritmos desenvolvidos. Além de podar regiões do espaço de busca, uma outra técnica empregada no algoritmo KORD é a economia de tempo ao evitar acessos ao conjunto de dados. A seguir são relatadas algumas maneiras de evitar o acesso ao conjunto de dados sem que haja prejuízo à busca pelas regras ótimas.

Nos algoritmos KORD-growth1 e KORD-growth2 as prevenções de acesso ao conjunto de dados podem ser aplicadas. Tais prevenções, como já comentado, não removem regiões do espaço de busca, mas evitam o acesso desnecessário ao conjunto de dados para a contagem da frequência de um itemset. Isso geralmente acontece quando é alcançado o ponto mais inferior permitido pela busca, isto é, quando $\mid$ novo_Antecedente $\mid=$ maxTamAnt. Também pode ser aplicado quando novos_Antecedentes_Disponiveis $=\emptyset$, pois não será necessário acessar um itemset antecedente mais específico a partir do ponto de busca corrente. A seguir são apresentados os conjuntos de prevenção de acesso.

\subsubsection{PA 1 - Conjunto de prevenções de acesso 1}

A Prevenção de Acesso 1 evita acesso ao conjunto de dados por identificar antecedentes não-promissores. Portanto, não haverá necessidade de avaliar 
qualquer consequente. A primeira prevenção é baseada no Teorema 4.3.1, que se refere ao menor $P S$ para antecedente das regras na solução.

Prevenção de Acesso 1: Se $\mid$ novo_Antecedente $\mid=$ maxTamAnt ou novos_Antecedentes_Disponiveis $=\emptyset$ e coberturaAntecedente $\times(1-$ coberturaAntecedente $) \leq$ menor $P S$, para qualquer consequente $Y$, onde $Y=$ consequente. $Y$ e consequente $\in$ consequentes_Disponiveis, não há necessidade de avaliar a regra novo_Antecedente $\rightarrow Y$, pois ela não se encontra na solução.

Embora o antecedente novo_Antecedente $=$ antecedente_Atual $\cup P$ não seja qualificado para ser antecedente de qualquer regra na solução, o item $P$ não pode ser podado da busca, visto que podem existir antecedentes mais específicos viáveis para formação de regras ótimas. Por causa disso, há a necessidade da inclusão das condições $\mid$ novo_Antecedente $\mid=\operatorname{maxTamAnt}$ e novos_Antecedentes_Disponiveis $=\emptyset$.

Aplica-se a segunda prevenção quando todo conjunto de dados for coberto pelo novo_Antecedente e o menorPS atualmente considerado for maior que zero.

Prevenção de Acesso 2: Se $\mid$ novo_Antecedente $\mid=$ maxTamAnt ou novos_Antecedentes_Disponiveis $=\emptyset$, coberturaAntecedente $=1$ e menor $P S>0$, para qualquer $Y=$ consequente. $Y$ e consequente $\in$ consequentes_Disponiveis, não há necessidade de avaliar a regra novo_Antecedente $\rightarrow Y$, pois ela não se encontra na solução.

De acordo com o Teorema 4.3.3, que é baseada na cobertura total do conjunto de dados, o valor da medida $P S$ é zero para qualquer regra com coberturaAntecedente $=1$. Em virtude do itemset antecedente se especializar durante a busca, cober(novo_Antecedente) $\leq$ cober(atual_Antecedente), não é realizada a poda do item $P$. A prevenção de acesso é aplicada quando pelo menos uma das condições, |novo_Antecedente $\mid=$ maxTamAnt ou novos_Antecedentes_Disponiveis $=\emptyset$, for verdadeira.

\subsubsection{PA2 - Conjunto de prevenções de acesso 2}

O conjunto de prevenção de acesso 2 evita acesso ao conjunto de dados por identificar regras não-promissoras. A prevenção de acesso 3 é aplicada quando a razão entre a cobertura do consequente e a cobertura de novo_Antecedente forem menor que a menorConfianca.

Teorema 4.3.7 (Minima confiança para regras na solução.) Para qualquer regra $X \rightarrow Y$, se $\frac{\operatorname{cober}(Y)}{\operatorname{cober}(X)}>$ menorConfianca, então $X \rightarrow Y$ não pertence à solução. 
Prova. De acordo com o lema da cobertura do subconjunto é obtido o seguinte:

$$
\operatorname{conf}(X \rightarrow Y)=\frac{\sup (X \rightarrow Y)}{\operatorname{cober}(X)}=\frac{\operatorname{cober}(X \cup Y)}{\operatorname{cober}(X)} \leq \frac{\operatorname{cober}(Y)}{\operatorname{cober}(X)}
$$

Visto que $\frac{\operatorname{cober}(Y)}{\operatorname{cober}(X)}<$ menorConfianca, então conf $(X \rightarrow Y)<$ menorConfianca. Portanto, $X \rightarrow Y$ não pertence à solução.

Prevenção de Acesso 3: Se $\mid$ novo_Antecedente $\mid=$ maxTamAnt ou novos_Antecedentes_Disponiveis $=\emptyset$, e $\frac{\text { coberturaConsequente }}{\text { coberturaAntecedente }}<$ menorConfianca, não há necessidade de avaliar a regra novo_Antecedente $\rightarrow Y$, pois ela não se encontra na solução.

A prevenção de acesso 3 é baseada no Teorema 4.3.7. O motivo de evitar a avaliação da regra ao invés de podar o consequente é em virtude de que pode haver antecedentes mais específicos com baixos valores de cobertura, que ocasionaria em uma maior confiança. Portanto, é sugerido suspender a avaliação quando $\mid$ novo_Antecedente $\mid=\operatorname{maxTamAnt}$ ou novos_Antecedentes_Disponiveis $=\emptyset$, pois não haverá chamada recursiva e por conseguinte não haverá regra mais específica a partir daquele ponto de busca.

A prevenção de acesso 4 é aplicada quando a razão entre o suporte da regra recentemente avaliada e a cobertura de novo_Antecedente forem menor que a menorConfianca.

Prevenção de Acesso 4: Se $\mid$ novo_Antecedente $\mid=$ maxTamAnt ou novos_Antecedentes_Disponiveis $=\emptyset$, e $\frac{\text { sup(antecedente_Atual } \rightarrow Y)}{\text { coberturaAntecedente }}<$ menorConfianca, não há necessidade de avaliar a regra novo_Antecedente $\rightarrow Y$, pois ela não se encontra na solução.

Da mesma forma como a prevenção de acesso 3 pode-se aplicar a prevenção 4. Tal prevenção é mais poderosa, pois o suporte da última regra avaliada é menor ou igual à cobertura do consequente, que foi utilizada na prevenção 3. Conforme o lema da cobertura do subconjunto, a seguinte expressão é verdadeira sup $($ antecedente_Atual $\rightarrow Y)=$ cober $($ antecedente_Atual $\cup Y) \leq$ cober $(Y)$, então $\frac{\text { coberturaConsequente }}{\text { coberturaAntecedente }} \geq \frac{\text { sup }(\text { antecedente_Atual } \rightarrow Y)}{\text { coberturaAntecedente }}$.

Aplica-se a prevenção 5 por conhecer o limitante inferior menor $P S$ antes da avaliação da regra, conforme o Teorema 4.3.2. O limitante inferior utilizado é o valor de medida $P S$ da k-ésima regra encontrada no conjunto solução solucao_Atual.

Prevenção de Acesso 5: Se $\mid$ novo_Antecedente $\mid=$ maxTamAnt ou novos_Antecedentes_Disponiveis $=\emptyset$, e coberturaAntecedente $\geq 1-\frac{\text { menorPS }}{\text { coberturaConsequente }}$, não há necessidade de avaliar a regra novo_Antecedente $\rightarrow Y$, pois ela não se encontra na solução. 
Se a prevenção de acesso 5 for verdadeira, a regra novo_Antecedente $\rightarrow Y$ tem valor de medida $P S$ menor ou igual que o menor $P S$. Esta prevenção não é utilizada como poda, em virtude de haver especializações do antecedente da regra. Isto acarreta em menores valores da cobertura da regra, sendo ineficaz utilizar tal prevenção como poda. Portanto, é necessário que a busca esteja no ponto mais inferior, quando $\mid$ novo_Antecedente $\mid=$ maxTamAnt ou novos_Antecedentes_Disponiveis $=\emptyset$, isto é, quando não é mais possível aumentar o tamanho do antecedente.

A prevenção de acesso 6 é aplicada quando a busca se encontra no ponto mais inferior e por conhecer o suporte da regra recentemente avaliada sup(antecedente_Atual $\rightarrow Y$ ).

Prevenção de Acesso 6: Se $\mid$ novo_Antecedente $\mid=$ maxTamAnt ou novos_Antecedentes_Disponiveis $=\emptyset$, e sup $($ antecedente_Atual $\rightarrow Y)-($ coberturaAntecedente $\times$ coberturaConsequente $) \leq$ menor $P S$, não há necessidade de avaliar a regra novo_Antecedente $\rightarrow Y$, pois ela não se encontra na solução.

Em virtude do suporte da regra correntemente avaliada ser menor ou igual a última regra avaliada, novo_Antecedente $\rightarrow Y \leq$ antecedente_Atual $\rightarrow Y$, então o PS(novo_Antecedente $\rightarrow Y) \leq P S($ antecedente_Atual $\rightarrow Y)$. Portanto, a regra novo_Antecedente $\rightarrow Y$ tem valor de medida $P S$ menor ou igual que o menor $P S$.

\subsubsection{PA3 - Conjunto de prevenções de acesso 3}

No algoritmo KORD-growth2 é necessário realizar uma busca implícita, na linha 22, para investigar regras a partir de cada par antecedente-consequente sob avaliação, como discutido na Seção 4.1.2. Um problema para tal estratégia é o custo da recuperação da cobertura de todas as regras exploradas. Esse problema pode ser amenizado evitando-se que alguns antecedentes tenham sua cobertura recuperada. Isso é viável, se for possível conseguir identificar regras que não estejam na solução. Portanto, para identificar e evitar a avaliação dessas regras é utilizado o conjunto de prevenções de acesso 3 (PA3).

Inicialmente é necessário que o itemset antecedente $X=\left\{x_{1}, x_{2}, x_{3}, \ldots, x_{n}\right\}$ tenha os itens ordenados de forma crescente pela frequência, isto é, $P\left(x_{1}\right) \leq$ $P\left(x_{2}\right) \leq P\left(x_{3}\right) \leq \ldots \leq P\left(x_{n}\right)$. Desta forma, a ordem de avaliação das possiveis regras é a seguinte:

$$
\begin{aligned}
& 1^{\mathrm{a}}: Y, x_{2}, x_{3}, \ldots, x_{n} \rightarrow x_{1} \\
& 2^{\mathrm{a}}: x_{1}, Y, x_{3}, \ldots, x_{n} \rightarrow x_{2} \\
& 3^{\mathrm{a}}: x_{1}, x_{2}, Y, \ldots, x_{n} \rightarrow x_{3}
\end{aligned}
$$




$$
\mathrm{n}^{\mathrm{a}}: x_{1}, x_{2}, x_{3}, \ldots, Y \rightarrow x_{n}
$$

Se a prevenção de acesso 7 for aplicada em uma regra, então não é necessário conhecer o antecedente desta regra e também não é necessário avaliar as outras regras, pois a mesma prevenção de acesso também seria aplicada. Portanto, para cada regra $X \rightarrow Y$ sob avaliação, a prevenção de acesso encontrada no conjunto PA3 é descrita a seguir.

Aplica-se a prevenção 7 por conhecer o limitante inferior menor $P S$ antes da avaliação da regra, conforme o Teorema 4.3.6. O limitante inferior utilizado é o valor de medida $P S$ da k-ésima regra do conjunto solucao_Atual.

Prevenção de Acesso 7: Para qualquer regra $X \rightarrow Y$ avaliada durante a pesquisa implícita, se $\operatorname{cober}(Y) \geq 1-\frac{\operatorname{menor} P S}{\sup (X \rightarrow Y)}$, então não é preciso recuperar a cobertura do antecedente e não é necessário avaliar as regras restantes.

Tal prevenção de acesso evita a necessidade de investigar a frequência dos antecedentes das outras possíveis regras. Esta tarefa é muito importante para o algoritmo KORD-growth2, visto que as operações para conhecer a cobertura dos antecedentes são custosas.

Existe uma importante questão sobre a utilização das podas $11 \mathrm{e} 12$, e prevenção de acesso 6 no algoritmo KORD-growth2. A questão é que se houver pelo menos uma regra da busca implícita com confiança maior que a regra verificada pela busca explícita, então tais podas e prevenção de acesso não devem ser aplicadas. Se fossem aplicadas, regras ótimas deixariam de ser descobertas. Isso acontece em virtude de ser considerada apenas a cobertura da regra verificada pela busca explícita.

\subsection{Considerações Finais}

Alguns trabalhos adotaram a metodologia FP-growth para melhorar a eficiência na tarefa de mineração de regras ou padrões frequentes. Primeiramente, o trabalho de Han et al. (2000) propôs a metodologia FP-growth, que melhorou a eficiência da mineração dos itemsets frequentes. A metodologia FP-growth também foi empregada para aprimorar a eficiência da mineração de pares de itens correlacionados (He et al., 2005), e na descoberta de itemsets de máximo tamanho (Grahne e Zhu, 2003; Hu et al., 2008).

Neste capítulo foram apresentadas duas estratégias de travessia de regras para a tarefa de descoberta das regras ótimas utilizando a metodologia FPgrowth. A primeira estratégia foi baseada na mesma travessia utilizada pelo algoritmo KORD e a partir dela foi desenvolvido o algoritmo KORD-growth1. $\mathrm{Na}$ segunda estratégia, a travessia foi dividida em duas buscas, explícita e implícita. A busca explícita foi baseada na travessia do algoritmo KORD, no 
qual somente os consequentes que mantinham a FP-tree condicional prosseguiam na busca. Para avaliar as regras restantes foi elaborada a busca implícita, onde a partir de um ponto do espaço de busca, regras eram oriundas da combinação dos itens das regras avaliadas pela busca explícita. O algoritmo KORD-growth2 foi baseado nessa estratégia de travessia de regras.

Foram adaptadas e implementadas podas de regras e prevenções de acesso para que os algoritmos desenvolvidos funcionassem. Elas funcionam pela utilização das estatísticas encontradas nos membros das regras, como a cobertura do antecedente e do consequente, $P(X)$ e $P(Y)$ e o suporte da regra $P(X \rightarrow Y)$. Muitas podas e prevenções de acesso foram retiradas do trabalho original do algoritmo KORD (Webb e Zhang, 2005) e outras podas (4 e 10) e prevenções de acesso (4, 6 e 7) foram desenvolvidas neste trabalho. Todas funcionam adequadamente se a medida de interesse utilizada for a medida $P S$. É importante salientar que a aplicação das podas 11 e 12 e da prevenção de acesso 6, no algoritmo KORD-growth2, depende que a regra avaliada pela busca explícita tenha confiança maior que as outras regras oriundas a partir dela através da busca implícita.

Outro fato importante é que a contagem da frequência ou suporte de algumas regras não é realizada pela metodologia $\mathrm{FP}$-growth. Isso acontece pela inviabilidade de obter a árvore FP-tree condicional para um item mais específico, pois acarreta um maior custo computacional. Em virtude do custo de copiar a árvore FP-tree pode-se utilizar outras estratégias de contagem do suporte, por exemplo o algoritmo Apriori. Na implementação dos algoritmos KORD-growth1 e KORD-growth2 a contagem do suporte é realizada sobre a FP-tree condicional que minera os itemsets antecedentes. Essa contagem é feita sobre os caminhos de prefixos situados dentro da árvore. Desta forma, utiliza-se uma árvore FP-tree condicional, mas sem a compressão de seus caminhos. Tal estratégia é discutida no próximo capítulo.

No próximo capítulo são apresentadas as implementações e o desempenho dos algoritmos desenvolvidos. Para comparação, são utilizados os algoritmos baseline KORD, Apriori e FP-growth. Os experimentos em conjuntos de dados reais e artificiais são expostos e mostram a viabilidade das mudanças empregadas. 


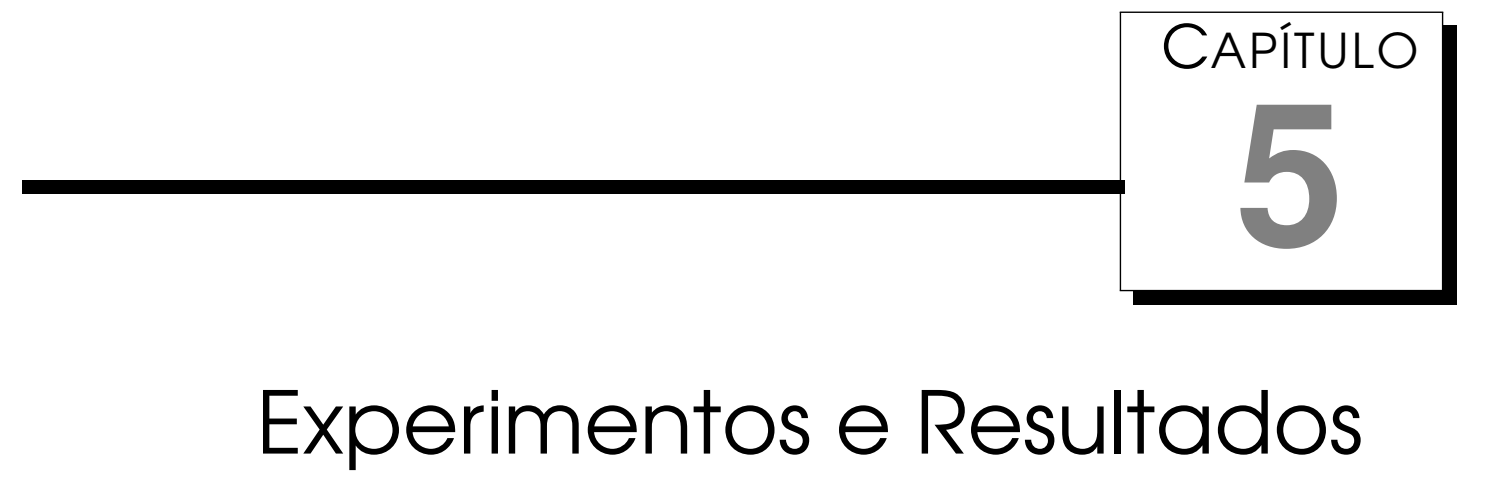

Neste capítulo são apresentados o desempenho e a aplicabilidade dos algoritmos KORD-growth1 e KORD-growth2. Os experimentos foram realizados por meio de testes que comparam os tempos de execução dos algoritmos desenvolvidos em relação ao algoritmo baseline KORD e em relação aos algoritmos tradicionais que recuperam padrões frequentes.

As avaliações dos desempenhos foram realizadas de duas formas, especificando-se a quantidade máxima de itens no antecedente ou tamanho máximo do antecedente de uma regra, bem como a quantidade de regras requeridas na tarefa de descoberta.

Os testes foram realizados sobre dez conjuntos de dados, sendo oito reais e dois artificiais. As propriedades ou características de cada conjunto de dados são descritas e analisadas. Os objetos utilizados durante os experimentos são os algoritmos KORD-growth1-SP, KORD-growth1-CP, KORD-growth2 e KORD. Os dois primeiros algoritmos são baseados no algoritmo KORD-growth1. Esses algoritmos foram desenvolvidos para descobrir $k$ regras que otimizam a medida de interesse $P S$, juntamente com outras restrições de busca, como suporte e confiança. Outros algoritmos considerados foram o FP-growth e Apriori. Tais algoritmos exploram FIs e a partir destes podem ser geradas regras de associação.

Por conhecer os objetos para experimentação são explicados a forma como os algoritmos são executados e o modo como avaliá-los. Os resultados das computações são informados e é feita uma breve análise dos desempenhos dos algoritmos. 


\section{1 Recursos Utilizados}

Nesta seção são descritos os algoritmos desenvolvidos neste trabalho e os algoritmos baseline. Também são apresentadas as características dos conjuntos de dados utilizados nos experimentos.

\subsubsection{Algoritmos}

Durante os experimentos foram utilizados algoritmos que descobrem regras ótimas e extraem padrões frequentes (FIs e regras de associação). Os FIs são conjuntos de itens recorrentes com frequência acima do limiar suporte mínimo. As regras de associação são geradas a partir desses FIs. Um conjunto de regras ótimas estabelece um ranking de quantidade finita para uma determinada medida de interesse objetiva. Neste trabalho, como já comentado, os algoritmos descobrem regras ótimas para a medida de interesse objetiva $P S$.

Todos os algoritmos utilizados nos experimentos foram desenvolvidos em linguagem C. A seguir são listados os algoritmos baseline. Tais algoritmos são artefatos que servem como referencial de desempenho para avaliação das técnicas desenvolvidas neste trabalho.

Apriori implementação desenvolvida por Borgelt e Kruse (2002), que explora FIs e gera regras de associação.

FP-growth: algoritmo que explora FIs. Tal implementação foi desenvolvida por Borgelt (2005).

KORD: algoritmo que descobre regras ótimas conforme a medida objetiva $P S$. É encontrado no aplicativo Magnum Opus ${ }^{1}$, que foi desenvolvido por Webb e Zhang (2005).

As implementações dos algoritmos Apriori e FP-growth são constantemente atualizadas por Borgelt e podem ser obtidas através de seu sítio web pessoal ${ }^{2}$. Os algoritmos desenvolvidos no trabalho são chamados de KORD-growth1 e KORD-growth2. Ambos utilizam a metodologia FP-growth para a contagem dos FIs e foram implementados em linguagem de programação C. O KORDgrowth1 pode ser dividido em dois algoritmos: KORD-growth1-SP e KORDgrowth1-CP. A seguir tais algoritmos são descritos.

KORD-growth 1: algoritmo desenvolvido neste trabalho para descobrir regras ótimas que segue a mesma estratégia de busca do algoritmo KORD. Foi dividido de duas maneiras para tentar identificar a eficácia da implementação das novas podas e prevenções de acesso.

\footnotetext{
$1_{\text {http }}: / /$ www.giwebb.com/

${ }^{2}$ http: / / www.borgelt. net/software.html
} 
KORD-growth 1-SP: é baseado no KORD-growth1, mas não implementa as podas e prevenções de acesso desenvolvidas no corrente trabalho.

KORD-growth 1-CP: é baseado no KORD-growth1 e possui, adicionalmente, as podas e prevenções de acesso desenvolvidas neste trabalho.

KORD-growth2: algoritmo desenvolvido neste trabalho que realiza pesquisa implícita de regras ótimas.

Enquanto o algoritmo KORD utiliza a metodologia do algoritmo Apriori para realizar a contagem da frequência dos itemsets, os outros três algoritmos desenvolvidos neste trabalho realizam a contagem da frequência dos itemsets por meio da metodologia do algoritmo FP-growth. A diferença entre o KORDgrowth 1-SP e o KORD-growth1-CP, é que o primeiro possui as mesmas podas e prevenções de acesso situados no algoritmo KORD, enquanto que o último mantém, adicionalmente, novas podas e prevenções de acesso desenvolvidas neste trabalho. Os algoritmos KORD, KORD-growth1-SP e KORD-growth 1-CP realizam a mesma travessia de regras e o KORD-growth2 realiza a travessia de forma inovadora com pesquisa implícita de regras, que foi desenvolvida neste trabalho e pode ser encontrada na Seção 4.1.2.

Nas Seções 4.1.1 e 4.1.2 é explicado que não há como obter a frequência de alguns itemsets na busca por meio da metodologia FP-growth. Para obter a frequência desses itemsets pode-se utilizar a metodologia Apriori, por exemplo. Neste trabalho, a solução para este problema foi baseada na inspeção dos caminhos de prefixos situados na árvore FP-tree. Tal abordagem não é eficiente, porém não foi necessário a criação de nenhuma estrutura de dados adicional para contagem da frequência.

A ideia é definida da seguinte forma. Conforme a árvore FP-tree exibida na Figura 5.1, existe a compactação de todas as transações do conjunto de dados encontrado na Tabela 2.3, cuja frequência mínima é 2. Para recuperar a frequência de um itemset qualquer, basta percorrer os caminhos de prefixos na árvore FP-tree. Por exemplo, para recuperar a frequência do itemset $\{b, d\}$ a partir da árvore FP-tree exibida na Figura 5.1, é necessário primeiramente percorrer todos os nós que mantêm o sufixo $d$, que é o item do itemset procurado que mantém o nó com maior profundidade. Após a identificação dos nós que mantêm o sufixo $d$, visita-se os nós ancestrais em busca do prefixo $b$. Na Figura 5.1 podem ser visualizados os caminhos marcados (com linhas de maior espessura) que registram a busca dos caminhos de prefixos que mantêm o itemset $\{b, d\}$. 


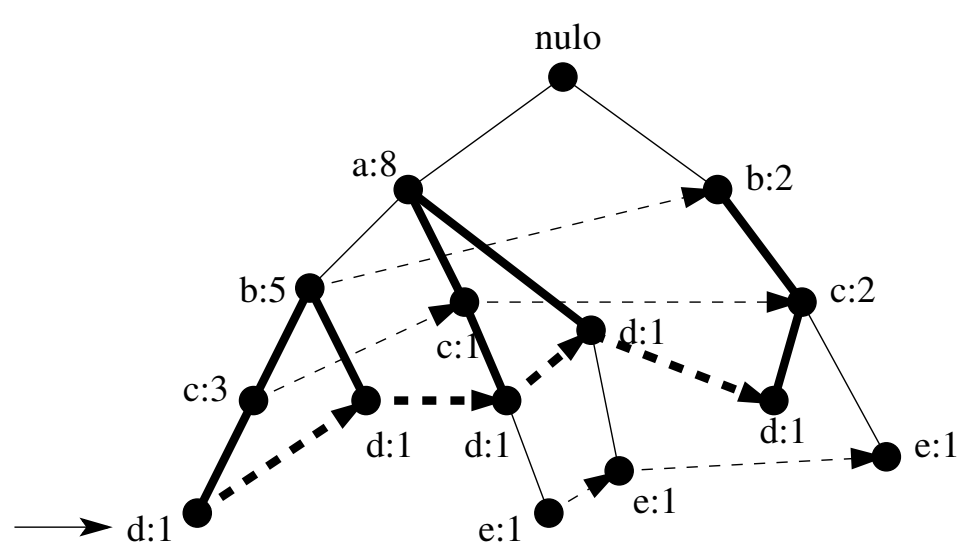

Figura 5.1: Contagem da frequência do itemset $\{b, d\}$ em uma árvore FP-tree. Este itemset é coberto por três transações, então sua frequência é 3.

\subsubsection{Conjunto de Dados}

Os conjuntos de dados reais e artificiais utilizados nos experimentos estão disponíveis na internet e são bem conhecidos em mineração de padrões frequentes. O conjunto de dados census foi obtido a partir do sítio web de Christian Borgelt ${ }^{3}$. Os outros conjuntos de dados são mantidos pelo repositório de conjuntos de dados Frequent Itemset Mining Dataset Repository ${ }^{4}$. São apresentadas na Tabela 5.1, as propriedades destes conjuntos de dados. São consideradas a quantidade de transações, a quantidade de itens e a média de itens por transação ou tamanho médio das transações.

Além das informações listadas na Tabela 5.1, é importante salientar a distribuição da frequência dos itens desses conjuntos de dados. Na Tabela 5.2 são informados dois valores para cada conjunto de dados. Esses valores são a média e o desvio padrão da distribuição da frequência dos itens. Tais valores são importantes para que seja interpretada a influência da distribuição dos itens de um conjunto de dados sobre o desempenho dos algoritmos desenvolvidos. A frequência de cada item é representada pela razão entre a quantidade de transações onde um item aparece e a quantidade de transações do conjunto de dados correspondente.

Na próxima seção é exibido como os testes foram programados, isto é, são descritos o ambiente e os parâmetros de execução.

\subsection{Detalhes da avaliação experimental}

Nesta seção discute-se acerca dos parâmetros utilizados nos experimentos. Além disso, é salientado o modo e o ambiente como os experimentos foram executados. Os algoritmos sob avaliação foram àqueles desenvolvidos neste

\footnotetext{
${ }^{3}$ http: //www.borgelt.net/data/census.zip

${ }^{4}$ http://fimi.ua.ac.be/data/
} 
Tabela 5.1: Características dos conjuntos de dados utilizados nos experimentos.

\begin{tabular}{lccc}
\hline $\begin{array}{l}\text { Conjunto } \\
\text { de Dados }\end{array}$ & $\begin{array}{c}\text { Quantidade } \\
\text { de Transações }\end{array}$ & $\begin{array}{c}\text { Quantidade } \\
\text { de Itens }\end{array}$ & $\begin{array}{c}\text { Tamanho Médio } \\
\text { da Transação }\end{array}$ \\
\hline \hline accidents & 340,183 & 468 & 33.8 \\
census & 48,842 & 135 & 14 \\
chess & 3,196 & 75 & 37 \\
connect-4 & 67,557 & 129 & 43 \\
kosarak & 990,002 & 41,270 & 8.09 \\
mushroom & 8,124 & 119 & 23 \\
pumsb & 49,046 & 2,113 & 74 \\
retail & 88,162 & 16,470 & 10.3 \\
T10I4D100K & 100,000 & 870 & 10.1 \\
T40I10D100K & 100,000 & 942 & 39.6 \\
\hline
\end{tabular}

Tabela 5.2: Estatísticas dos conjuntos de dados utilizados nos experimentos.

\begin{tabular}{lcc}
\hline Conjunto de Dados & Média & Desvio Padrão \\
\hline \hline accidents & 0.07224 & 0.18372 \\
census & 0.10370 & 0.20103 \\
chess & 0.49333 & 0.34410 \\
connect-4 & 0.33333 & 0.36817 \\
kosarak & 0.00020 & 0.00445 \\
mushroom & 0.19328 & 0.23763 \\
pumsb & 0.03502 & 0.13582 \\
retail & 0.00063 & 0.00644 \\
T10I4D100K & 0.01161 & 0.01125 \\
T40I10D100K & 0.04204 & 0.03910 \\
\hline
\end{tabular}


trabalho, como o KORD-growth1-SP, KORD-growth1-CP e KORD-growth2. Os algoritmos baseline são os algoritmos KORD, Apriori e FPGrowth. Os desempenhos dos dois últimos levam em consideração o tempo de execução na geração dos FIs.

Todos os experimentos apresentados foram conduzidos em um PC com processador Intel core 2 duo, $2.1 \mathrm{GHz}$ e 3GB de memória principal, executados no sistema operacional Windows Professional 7. Todos os tempos obtidos nos resultados são médias de cinco execuções. As restrições dos algoritmos sob execução são as seguintes.

- A restrição medidaObjetiva é a medida de interesse objetiva $P S$. Assim, menorPS se refere a menor Medida.

- Para as restrições menorCobertura, menorConfianca e menorPS foram atribuídos o valor zero.

- Para o suporteMinimo é atribuído o valor que garante a extração de $k$ regras ótimas de acordo com todas as restrições definidas. Os valores da restrição suporteMinimo para cada teste não serão exibidos nos gráficos das próximas seções. Tais valores são exibidos no Apêndice B.

- Na execução do algoritmo KORD é escolhida a opção de filtro NONE FILTERING do aplicativo Magnum Opus.

Diante dessas considerações relacionadas ao ambiente de execução, a avaliação dos experimentos foi estabelecida de dois modos:

1. pelo tamanho máximo do antecedente de uma regra; e

2. pela quantidade de regras requeridas pela tarefa.

O primeiro modo de avaliação considera o desempenho dos algoritmos em relação à quantidade de itens no antecedente de uma regra ou tamanho máximo do antecedente. Dessa forma, tal avaliação visa identificar o desempenho de uma técnica em contar a frequência de itemsets maiores e a capacidade das podas em excluir regiões do espaço de busca, isto é, saber quando não continuar com a busca em profundidade. Os valores discretos 2, 4, 6 e 8 são tomados como o tamanho máximo do antecedente de uma regra. Para cada tamanho máximo do antecedente é requerida a prospecção das 1000 regras ótimas conforme a medida de interesse $P S$.

A segunda forma de avaliação busca compreender o impacto que a quantidade de regras requeridas na mineração causa ao desempenho dos algoritmos sob investigação. Busca-se explorar $k$ regras ótimas de acordo com a medida 
de interesse $P S$. Tais regras devem conter no máximo quatro itens no antecedente. São estabelecidos cinco valores discretos para a variável $k$, que são 1 , 10, 100, 1000 e 10000 regras ótimas a serem exploradas.

Para esses dois modos de avaliação foram realizados dois tipos de testes. No primeiro, o intuito foi comparar o desempenho dos algoritmos que descobrem regras ótimas. O segundo teste visou conhecer se vale a pena utilizar tais algoritmos em relação aos algoritmos tradicionais Apriori e FP-growth, sob as mesmas condições de execução.

Durante os experimentos foram realizados dois tipos de testes para comparar os desempenhos dos algoritmos, que são citados a seguir:

1. comparativo entre os algoritmos que descobrem regras ótimas e;

2. comparativo entre os algoritmos tradicionais que extraem padrões frequentes.

No primeiro teste comparativo foram obtidos os tempos de execução dos algoritmos que extraem regras ótimas a partir dos conjuntos de dados transacionais. Nos testes executados foram extraídas regras que otimizaram a métrica de interesse objetiva $P S$. O comparativo pretendeu entender o impacto que as características dos algoritmos sob interesse podem causar em seus desempenhos.

Com este tipo de teste busca-se compreender se a inserção da metodologia FP-growth melhora o desempenho da tarefa de descoberta de regras ótimas. Visto que na extração de FIs esta metodologia é superior ao algoritmo Apriori em muitos conjuntos de dados e viável em mineração com baixo suporte mínimo. Também é levada em consideração a forma como é realizada a busca na travessia de regras. Essa travessia é realizada em profundidade e pode ser interessante a adoção da metodologia FP-growth, pois também realiza a pesquisa por itemsets via busca em profundidade.

No segundo tipo de teste é realizado o comparativo entre o algoritmo que explora regras ótimas mais eficiente e os algoritmos tradicionais que extraem FIs e regras a partir destes. Tal comparativo é importante para que se conheça a diferença de desempenho entre essas técnicas sob o mesmo suporte mínimo. Portanto, a intenção é conhecer quais condições do ambiente de execução favorecem uma técnica em detrimento de outra.

Para ser realizado esse tipo de teste é importante estabelecer dois parâmetros: o suporte mínimo e o tamanho máximo do antecedente de uma regra. Com isso, no primeiro modo de avaliação, que se refere aos valores de tamanho máximo do antecedente, a extração dos FIs leva em consideração o suporte mínimo e os valores discretos 3, 5, 7 e 9 para o tamanho máximo dos FIs a serem recuperados. A atribuição desses valores se deve pela existência 
de mais um item no consequente da regra, pois é necessário conhecer seu suporte. Para o segundo modo de avaliação, que se refere à quantidade de regras requeridas, leva-se em conta o suporte mínimo e o valor discreto 5 para o tamanho máximo dos FIs recuperados.

O algoritmo Apriori adotado neste trabalho tem a opção da geração dos FIs e de regras. No algoritmo FP-growth utilizado não há a opção para geração de regras a partir dos FIs. Neste caso, tal operação de geração de regras fica dependente da implementação adotada. Em virtude de haver várias formas de implementação para geração de regras a partir dos FIs, foi decidida a não implementação dessa funcionalidade sobre o algoritmo FP-growth. Dessa forma, apenas os tempos para extrair os FIs foram considerados nos experimentos. Se um algoritmo que extrai regras ótimas possuir desempenho parecido ou superior às tecnicas que exploram FIs, significa que é mais proveitoso utilizá-lo, pois ainda seria necessária a geração de regras por parte das técnicas tradicionais.

Esses testes são importantes para que seja conhecida a melhor técnica sob as mesmas condições de execução. Isso implica dizer que a eficiência de qualquer técnica pode ser influenciada por vários fatores, como as propriedades dos conjuntos de dados, suporte mínimo adotado, quantidade de regras requeridas e o tamanho máximo do antecedente. Para a realização das análises é importante conhecer a interferência desses fatores, pois a adoção de uma técnica pode acarretar em desperdício de tempo.

Além desses dois tipos de testes é realizado um terceiro teste sobre os algoritmos que descobrem regras ótimas. Esse experimento se refere à adoção do menor suporte mínimo possível. Isso foi verificado em virtude de não ser conhecido antecipamente o valor do suporte mínimo que garanta a extração de $k$ regras ótimas conforme a medida $P S$ a partir de um conjunto de dados transacional.

Os resultados e as análises dos desempenhos dos algoritmos são apresentados na próxima seção.

\subsection{Resultados e Análise}

Nesta seção são apresentados os resultados e as análises das execuções dos algoritmos envolvidos no trabalho. Conforme relatado na seção anterior, os testes realizados foram baseados em duas formas de avaliação: pela quantidade de regras requeridas e pelo tamanho máximo do antecedente de uma regra.

O primeiro teste realizado foi a comparação dos tempos de execução dos algoritmos que descobrem uma quantidade arbitrária de regras ótimas. $\mathrm{O}$ 
segundo teste comparou o tempo de execução do melhor algoritmo que descobre regras ótimas, em termos de desempenho, juntamente com algoritmos tradicionais que recuperam FIs.

Um terceiro teste comparativo é esboçado para avaliar o desempenho dos algoritmos quando não se sabe o suporte mínimo adequado para extrair $k$ regras ótimas para a medida de interesse $P S$.

Todos os testes foram realizados sobre dez conjuntos de dados, sendo que oito são reais e dois artificiais. Em seguida são visualizados os gráficos com os desempenhos dos algoritmos para os três tipos de testes comparativos. Além disso, são discutidos os resultados e feitas as análises acerca dos experimentos.

\subsubsection{Comparativo entre os algoritmos que descobrem regras ótimas}

Nesta seção são ilustrados os experimentos com o intuito de conhecer a técnica mais eficiente na recuperação de regras ótimas para a medida de interesse objetiva $P S$. A técnica baseline é o algoritmo KORD, que foi desenvolvido por Webb e Zhang (2005). Esse algoritmo, encontrado na ferramenta Magnus Opus, utiliza a metodologia Apriori para recuperar a frequência dos itemsets.

Os testes envolvidos nesse comparativo englobam a extração de regras ótimas a partir de dez conjuntos de dados, sendo que oito são reais e dois artificiais. Para cada conjunto de dados são realizadas duas avaliações, que são a extração de regras reguladas pelo tamanho máximo do antecedente e pela restrição na quantidade de regras a serem exploradas.

Após a visualização dos gráficos que exibem os tempos de execução, os resultados e as análises são descritos e discutidos. A descrição das análises acerca dos resultados obtidos foram baseados nas características dos algoritmos e nas propriedades de cada conjunto de dados. Tais propriedades foram estabelecidas e são exibidas nas Tabelas 5.1 e 5.2.

As avaliações que envolvem o tamanho máximo do antecedente para os conjuntos de dados accidents, census, chess, connect-4, kosarak, mushroom, pumsb, retail, T10I4D100K e T40I10D100K, são exibidas, respectivamente, pelas Figuras 5.2(a), 5.3(a), 5.4(a), 5.5(a), 5.6(a), 5.7(a), 5.8(a), 5.9(a), 5.10(a) e 5.11(a).

As avaliações que envolvem a quantidade de regras requeridas para os conjuntos de dados accidents, census, chess, connect-4, kosarak, mushroom, pumsb, retail, T1OI4D100K e T40I10D100K, são exibidas, respectivamente, pelas Figuras 5.2(b), 5.3(b), 5.4(b), 5.5(b), 5.6(b), 5.7(b), 5.8(b), 5.9(b), 5.10(b) e $5.11(\mathrm{~b})$.

Nos testes que envolveram os conjuntos de dados accidents, census, chess, 


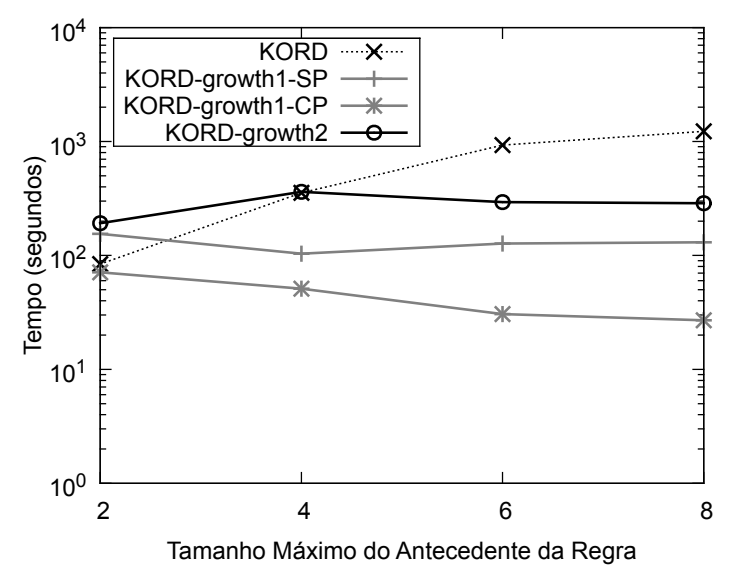

(a) Tamanho do Antecedente

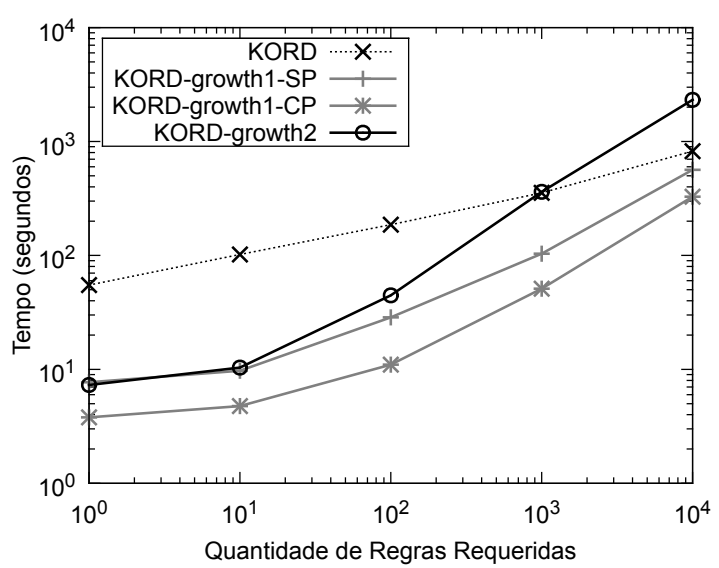

(b) Regras Requeridas

Figura 5.2: Desempenho dos algoritmos que descobrem regras ótimas para o conjunto de dados accidents.

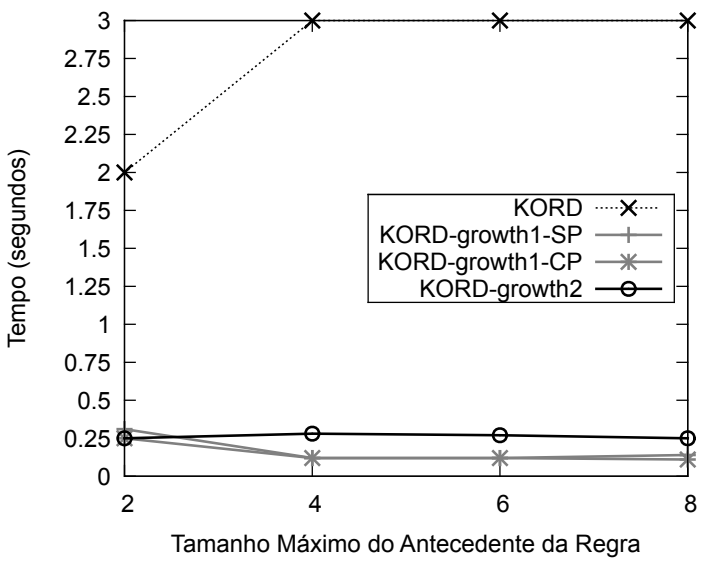

(a) Tamanho do Antecedente

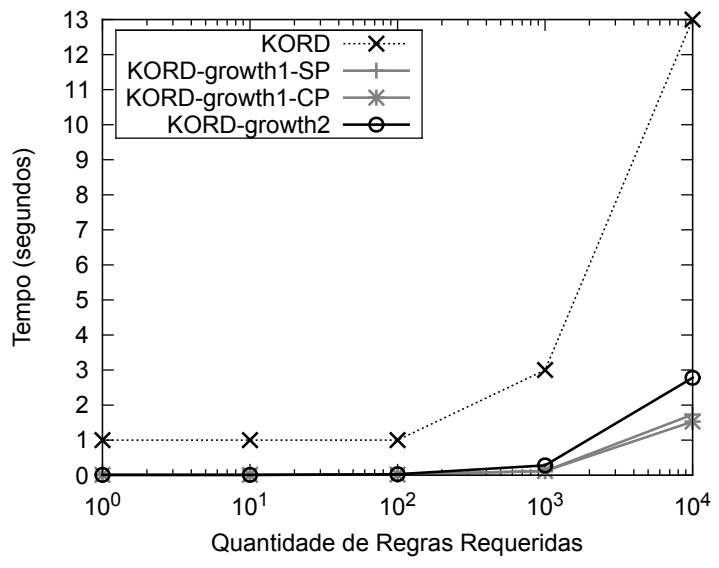

(b) Regras Requeridas

Figura 5.3: Desempenho dos algoritmos que descobrem regras ótimas para o conjunto de dados census.

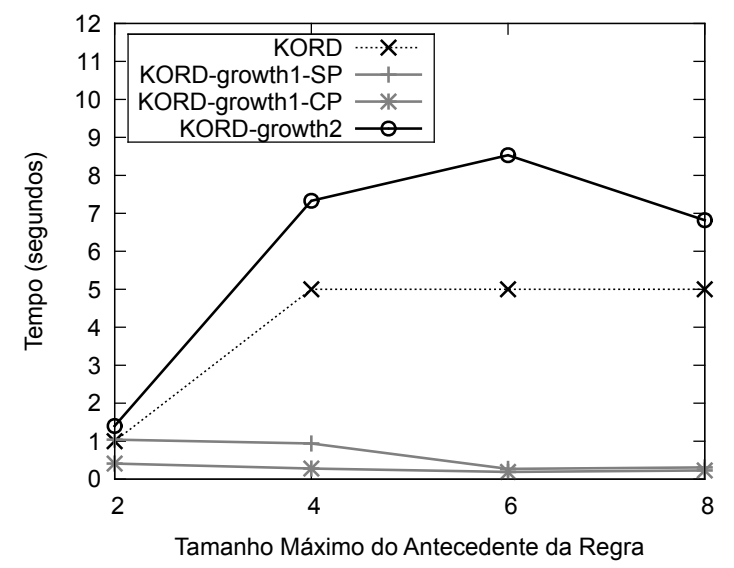

(a) Tamanho do Antecedente

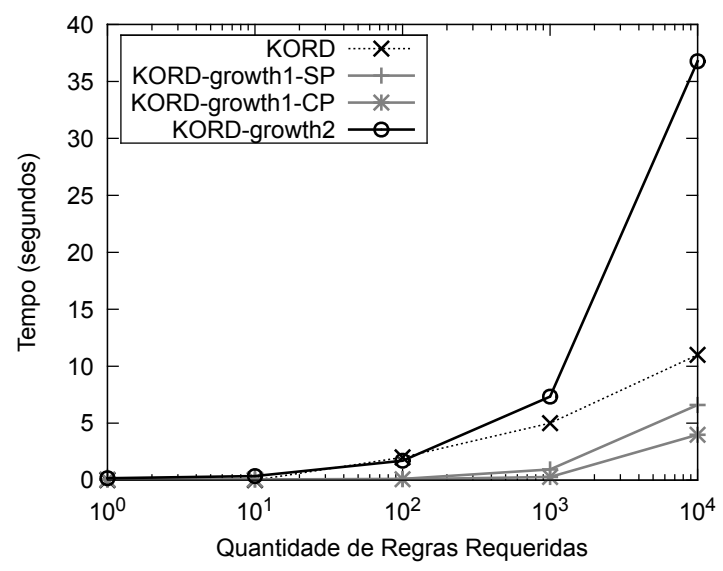

(b) Regras Requeridas

Figura 5.4: Desempenho dos algoritmos que descobrem regras ótimas para o conjunto de dados chess. 


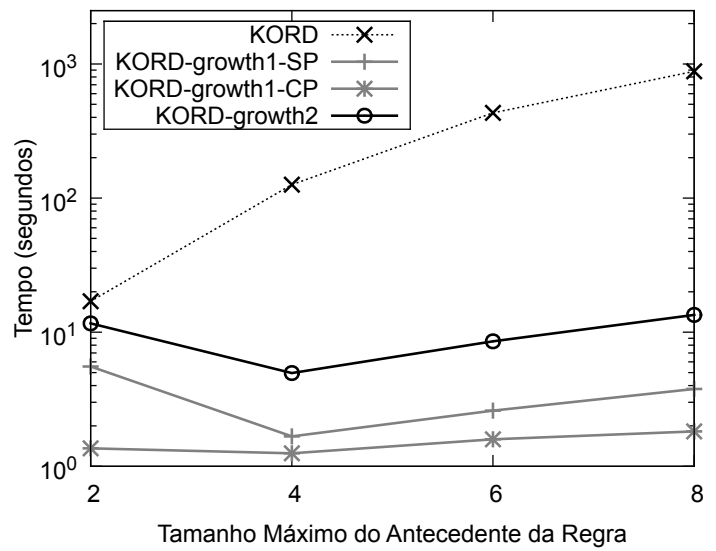

(a) Tamanho do Antecedente

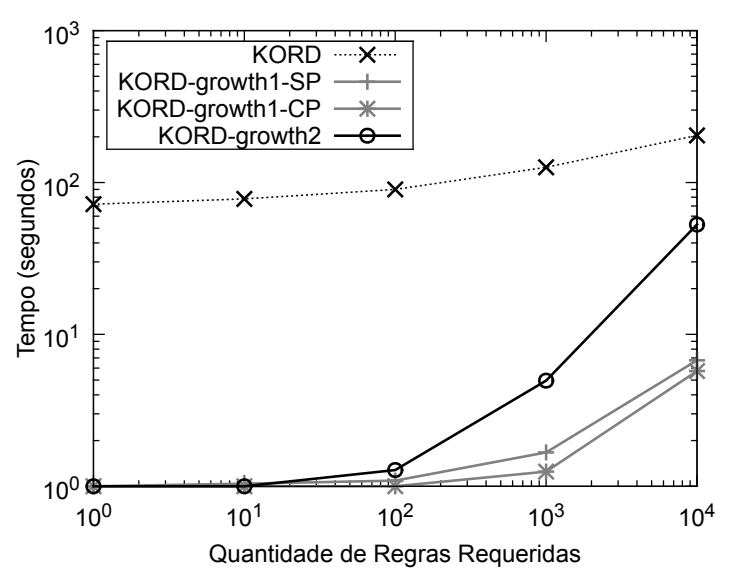

(b) Regras Requeridas

Figura 5.5: Desempenho dos algoritmos que descobrem regras ótimas para o conjunto de dados connect-4.

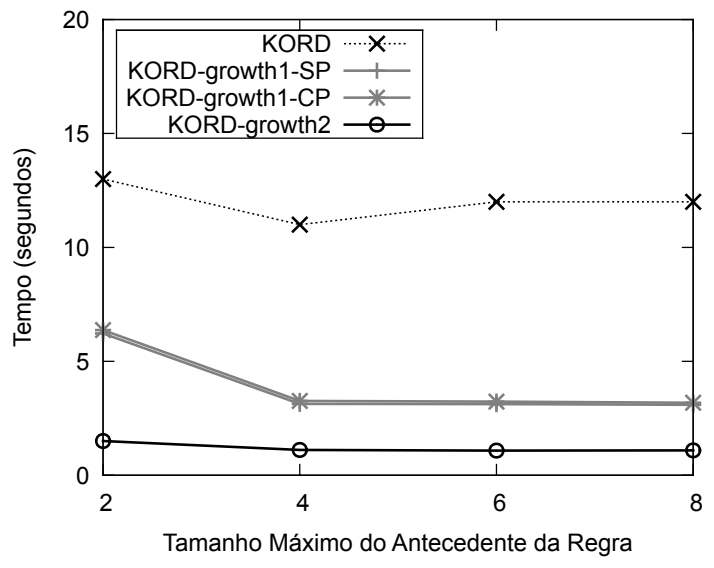

(a) Tamanho do Antecedente

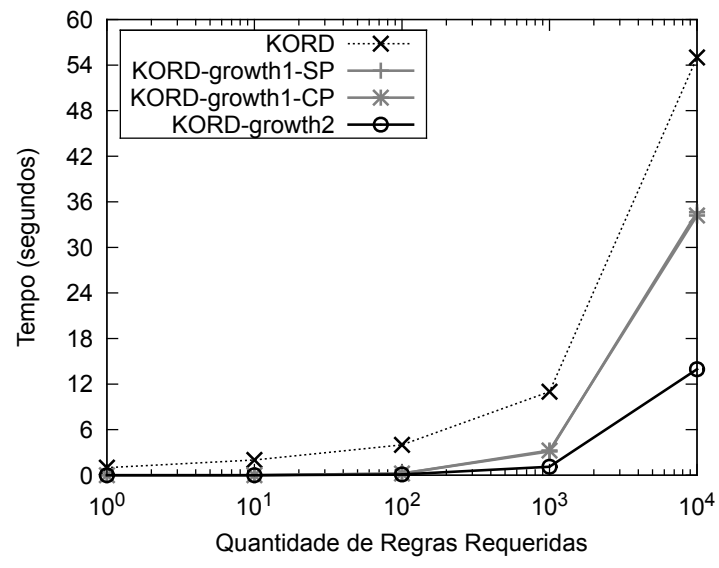

(b) Regras Requeridas

Figura 5.6: Desempenho dos algoritmos que descobrem regras ótimas para o conjunto de dados kosarak.

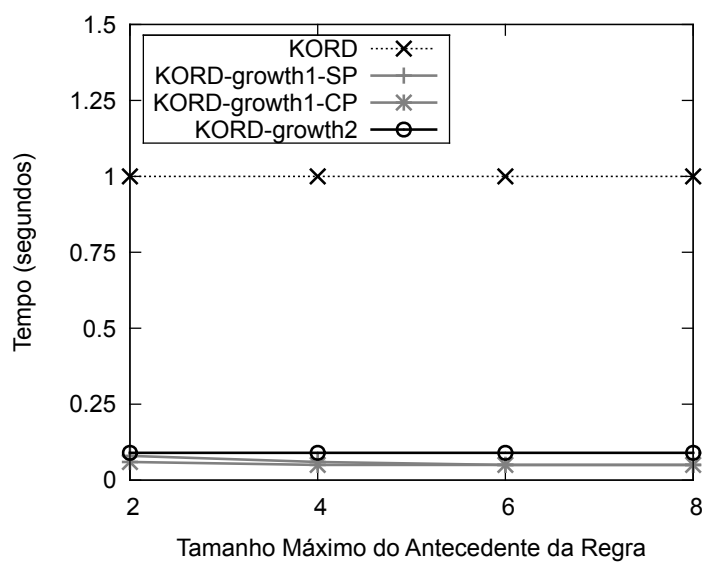

(a) Tamanho do Antecedente

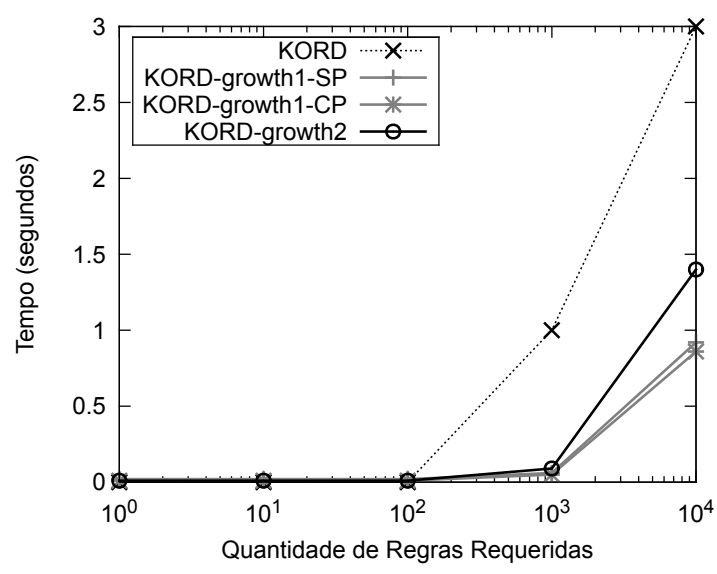

(b) Regras Requeridas

Figura 5.7: Desempenho dos algoritmos que descobrem regras ótimas para o conjunto de dados mushroom. 


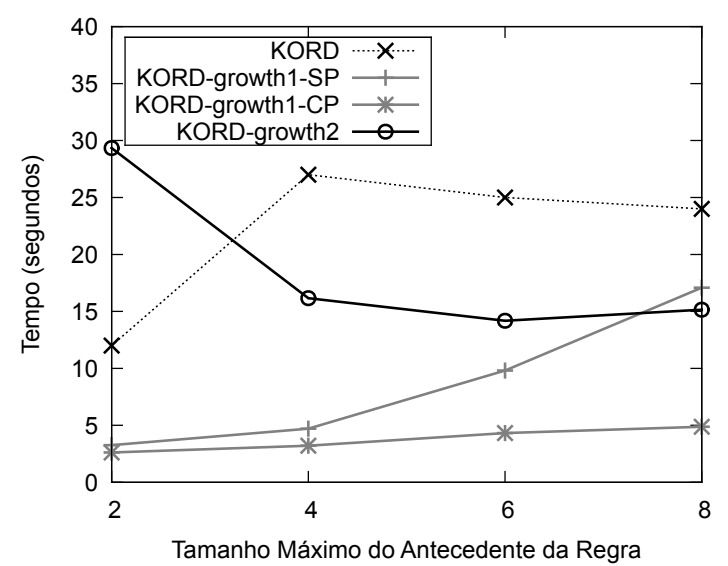

(a) Tamanho do Antecedente

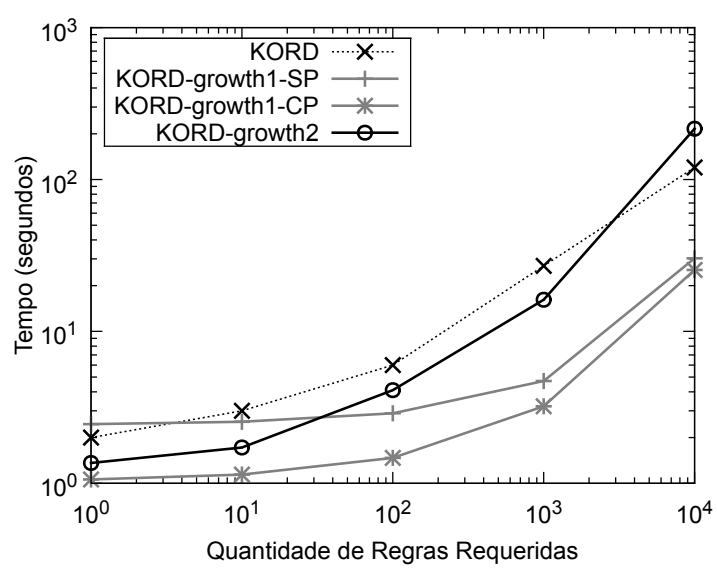

(b) Regras Requeridas

Figura 5.8: Desempenho dos algoritmos que descobrem regras ótimas para o conjunto de dados pumsb.

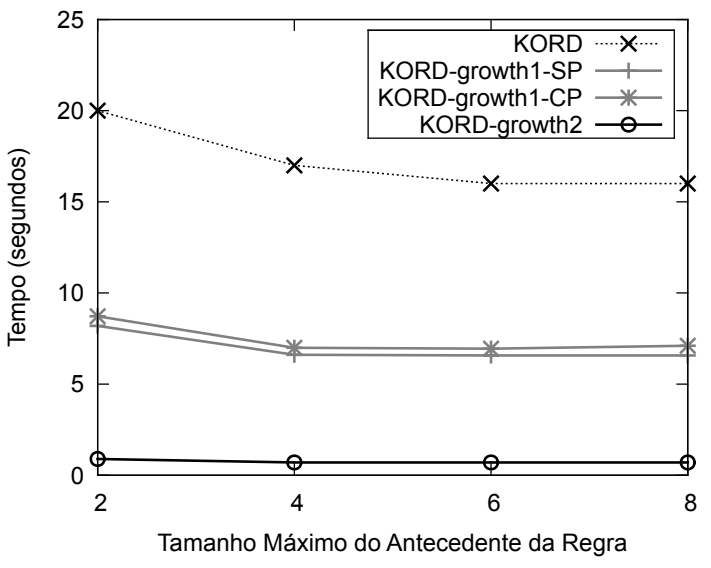

(a) Tamanho do Antecedente

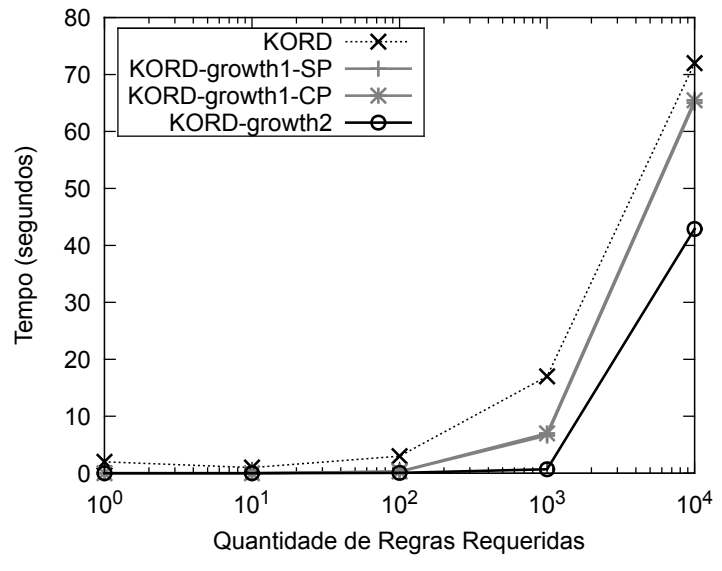

(b) Regras Requeridas

Figura 5.9: Desempenho dos algoritmos que descobrem regras ótimas para o conjunto de dados retail.

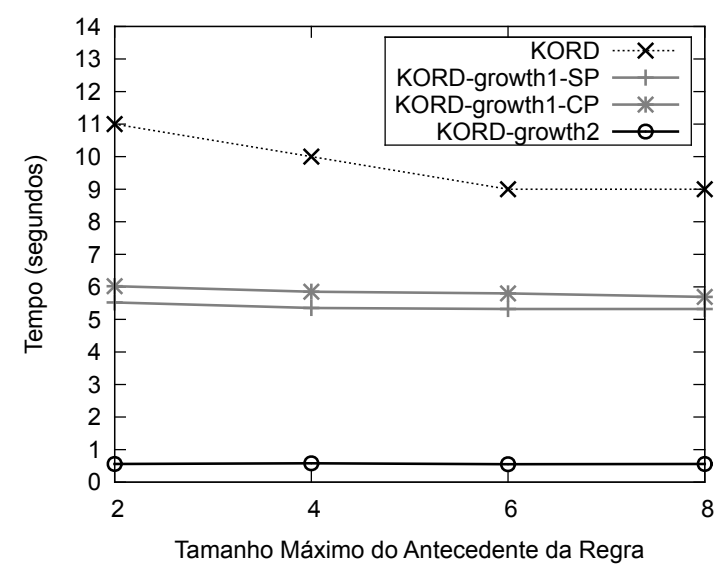

(a) Tamanho do Antecedente

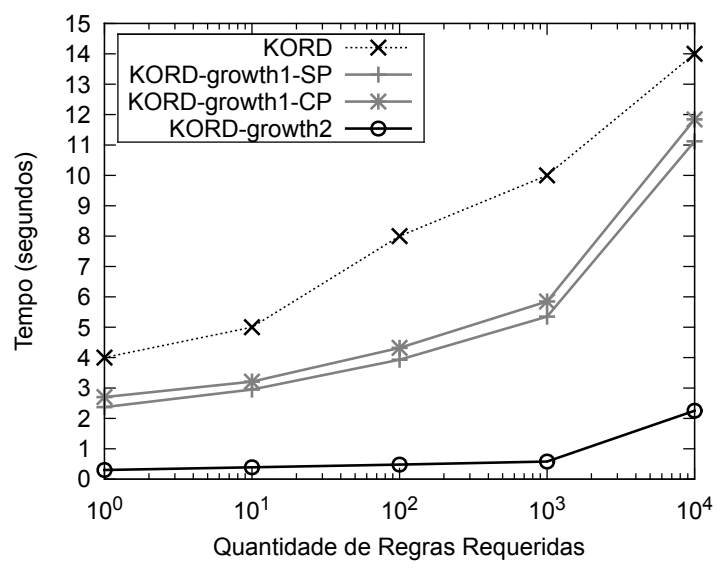

(b) Regras Requeridas

Figura 5.10: Desempenho dos algoritmos que descobrem regras ótimas para o conjunto de dados T1OI4D10OK. 


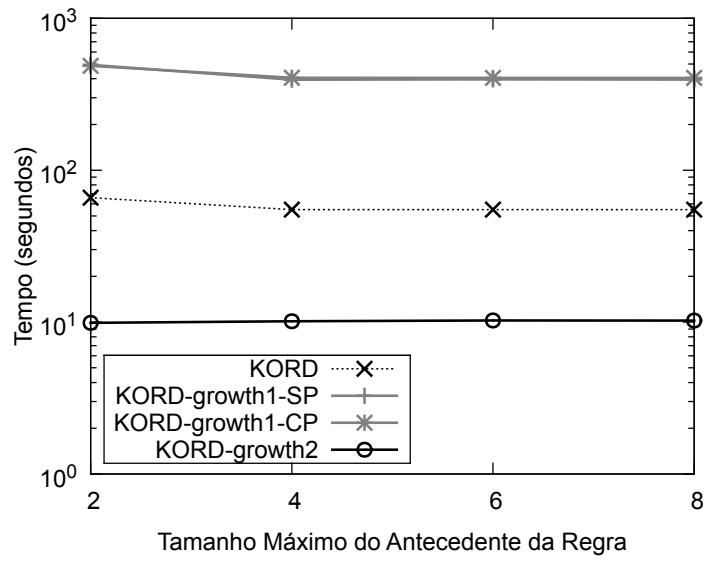

(a) Tamanho do Antecedente

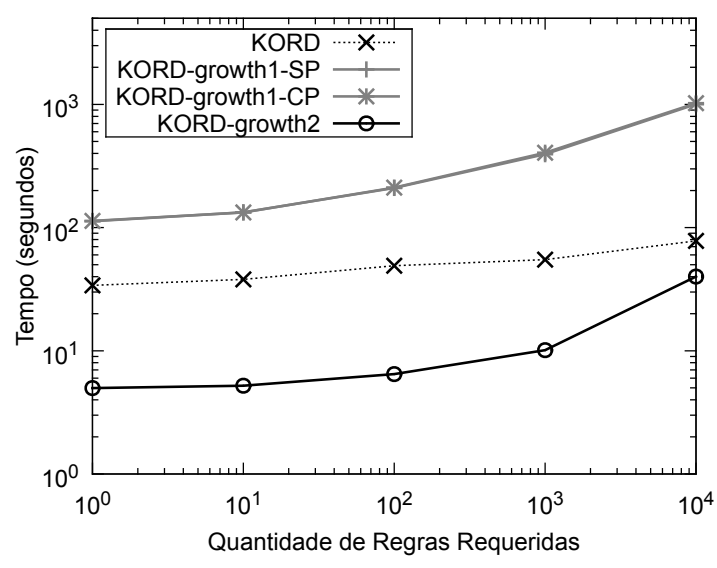

(b) Regras Requeridas

Figura 5.11: Desempenho dos algoritmos que descobrem regras ótimas para o conjunto de dados T4OI1OD1OOK.

connect-4, mushroom e pumsb, o algoritmo KORD-growth 1-CP foi o mais eficiente em todo domínio das avaliações que estabeleciam o tamanho máximo do antecedente e a quantidade de regras requeridas. Sobre esses dois tipos de avaliação, o algoritmo KORD-growth2 também obteve maior eficiência em todo domínio nos testes que envolveram os conjuntos de dados kosarak, retail, T1OI4D10OK e T4OI1OD10OK.

Os conjuntos de dados em que o algoritmo KORD-growth1-CP foi o mais eficiente possuem algumas características semelhantes. O tamanho médio de transação e o desvio padrão de distribuição da frequência dos itens desses conjuntos de dados possuem altos valores. Além disso, os melhores desempenhos foram encontrados nos conjuntos de dados em que os valores dessas características foram mais acentuados. Tais propriedades caracterizam conjuntos de dados densos. Por outro lado, os conjuntos de dados no qual o algoritmo KORD-growth2 obteve maior eficiência possuem o tamanho médio de transação e o desvio padrão com valores baixos. Essas propriedades caracterizam conjuntos de dados esparsos.

Para todos os conjuntos de dados, exceto os conjuntos chess e T40I10D100K, o algoritmo KORD foi o menos eficiente na maior parte do domínio das avaliações que envolviam o tamanho máximo do antecedente e a quantidade de regras requeridas. Os conjuntos de dados chess e T4OI1OD100K possuem características particulares. No caso do conjunto chess, há a presença de altos valores de desvio padrão e tamanho médio de transação, porém a quantidade de transações é pequena comparada ao restante dos conjuntos de dados. Tal característica propicia um bom desempenho ao KORD, pois utiliza a metodologia Apriori para recuperar a frequência dos itemsets. No conjunto chess o pior desempenho foi realizado pelo algoritmo KORD-growth2.

Em relação ao conjunto de dados T40I10D100K, há a presença de baixos 
valores de média e desvio padrão, porém o tamanho médio de transações é alto. Tais propriedades dificultam o desempenho dos algoritmos desenvolvidos em virtude de serem baseados na metodologia FP-growth. Essas características no conjunto de dados não acarretam na sobreposição das transações, isto é, dos caminhos que representam itemsets frequentes. Isto propicia a formação de uma maior árvore FP-tree. No conjunto T40I1OD10OK, os algoritmos KORD-growth1-CP e KORD-growth1-SP tiveram os piores desempenhos.

Nos conjuntos de dados census, chess, kosarak, mushroom, retail, T1OI4D10OK e T40I10D10OK, o tempo de execução dos algoritmos estacionou enquanto crescia o tamanho máximo do antecedente. Tal fato aconteceu por não existir regras ótimas com alta quantidade de itens no antecedente.

Algumas questões podem ser formuladas acerca dos experimentos apresentados anteriormente. A seguir, as questões e as devidas repostas são enumeradas.

1. Por quê os três algoritmos desenvolvidos tiveram melhor desempenho enquanto o tamanho da regra crescia?

Isso se deve a três características: contagem da frequência dos itemsets via metodologia FP-growth, às novas podas e novas prevenções de acesso.

2. Gual impacto da utilização da contagem da frequência dos itemsets nos caminhos representados na FP-tree?

Provoca desperdício de tempo, pois esse modo de contagem de frequência não é eficiente. Mesmo assim, os algoritmos desenvolvidos foram superiores ao KORD, pelo menos nos domínios sob avaliação. O desperdício é perceptível quando muitas regras são requeridas, como foi o caso da extração de 10000 regras. Guando poucas regras são requeridas, as podas e prevenções de acesso são mais eficazes e quando aplicadas evitam a contagem da frequência através dos caminhos de prefixos.

3. Gual o impacto das novas podas e prevenções de acesso no desempenho do KORD-growth 1-CP?

Em conjuntos de dados mais densos (alto tamanho médio da transação) e com alto desvio padrão existem fortes associações entre os itens. Diante dessa característica as novas podas encontradas no algoritmo KORDgrowth 1-CP removem com sucesso regiões do espaço de busca que não são removidas pelas podas herdadas a partir do KORD. No caso de conjuntos de dados mais esparsos, o algoritmo KORD-growth1-CP não só não consegue podar regiões como também prejudica a eficiência da mineração em virtude das rotinas das podas e prevenções de acesso serem executadas, mas não aplicadas. 
4. Por quê os tempos dos algoritmos são bem parecidos para uma pequena quantidade de regras requeridas?

A restrição menor $P S$ cresce rapidamente e isso otimiza o funcionamento das podas e prevenções de acesso.

5. Por quê não há boa eficiência quando o tamanho máximo do antecedente é pequeno?

Isso depende da quantidade de regras requeridas pela tarefa de busca. Se muitas regras são requeridas, a aplicação das podas e prevenções de acesso não será eficiente, pois o valor da restrição menor $P S$ não aumentará rapidamente. Se poucas regras forem requeridas o valor da restrição menor PS aumentará rapidamente e as podas e prevenções de acesso serão aplicadas de forma eficaz.

\subsubsection{Comparativo entre os algoritmos que extraem padrões fre- quentes}

Uma questão muito importante deve ser feita sobre os algoritmos desenvolvidos: vale a pena, em termos de desempenho, utilizar uma técnica que recupera regras ótimas ao invés da maneira tradicional de geração de regras? Ressalta-se que tal questionamento deve partir do pressuposto que se saiba antecipadamente o suporte mínimo que garanta a extração de $k$ regras ótimas para a medida de interesse $P S$.

Para esclarecer a dúvida imposta, é preciso comparar o desempenho do melhor algoritmo que descobre $k$ regras ótimas com o desempenho das técnicas tradicionais de geração de padrões frequentes, como Apriori e FP-growth.

É sabido que para gerar regras é necessário primeiramente extrair os FIs. O algoritmo Apriori utilizado nos experimentos possui as duas opções, que é a extração somente dos FIs e a geração das regras. No caso do algoritmo FPgrowth empregado nos experimentos não há a opção para geração das regras. Por existir muitos meios de implementação para extração das regras a partir dos FIs foi decidido a não implementação de tal abordagem.

Uma ideia que poderia ser adotada para conhecer o tempo que levaria para gerar as regras pelo algoritmo FP-growth, seria usar a diferença do tempo de execução na geração das regras pelo tempo gasto na extração dos FIs utilizando o algoritmo Apriori. Essa diferença poderia ser adicionada ao tempo que FP-growth gastou para recuperação dos FIs. No entanto, tal alternativa não seria justa, mesmo que ambos algoritmos sejam desenvolvidos pelo mesmo programador. Portanto, são considerados apenas os tempos de execução para geração dos FIs. 
Os testes realizados são exibidos por meio dos gráficos visualizados a seguir. As avaliações são similares àquelas registradas anteriormente. No caso da execução dos algoritmos Apriori e FP-growth são levados em conta somente dois parâmetros, que são o suporte mínimo e o tamanho máximo do antecedente. Vale lembrar que a avaliação de uma regra exige conhecer o suporte formado pela união do antecedente e consequente. Então se o antecedente de uma regra contém quatro itens é necessário descobrir os FIs de tamanho cinco, em virtude da regra requerida possuir um item no consequente.

Além dos algoritmos tradicionais é exibido o tempo de execução do algoritmo com melhor desempenho na recuperação de regras ótimas em cada conjunto de dados.

Quando o tempo de execução de um algoritmo não é exibido no gráfico, significa que não houve memória suficiente durante a execução do processo de mineração.

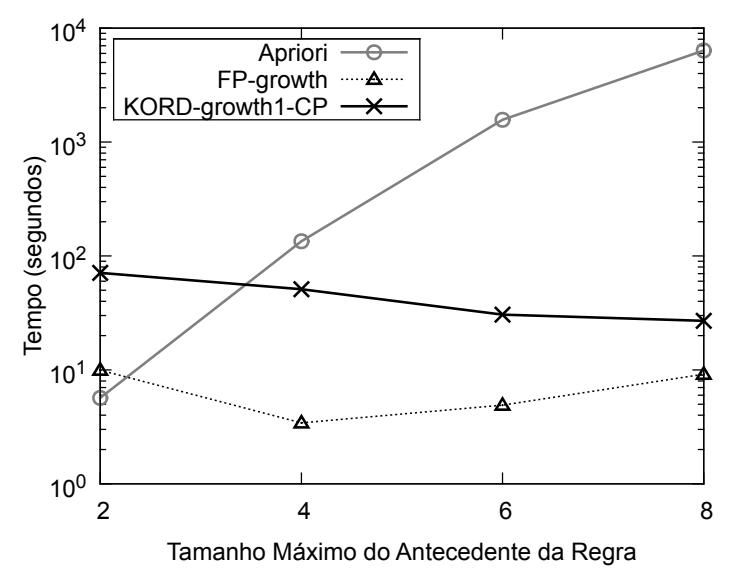

(a) Tamanho do Antecedente

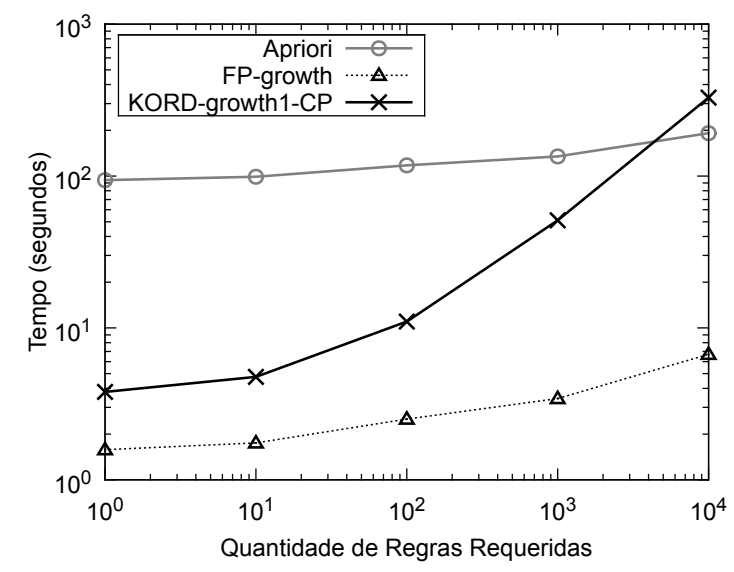

(b) Regras Requeridas

Figura 5.12: Desempenho dos algoritmos Apriori, FP-growth e KORD-growth 1-CP para o conjunto de dados accidents.

As avaliações que envolvem o tamanho máximo do antecedente para os conjuntos de dados accidents, census, chess, connect-4, kosarak, mushroom, pumsb, retail, T10I4D100K e T4OI10D100K, são exibidas, respectivamente, pelas Figuras 5.12(a), 5.13(a), 5.14(a), 5.15(a), 5.16(a), 5.17(a), 5.18(a), 5.19(a), 5.20 (a) e 5.21 (a).

As avaliações que envolvem a quantidade de regras requeridas para os conjuntos de dados accidents, census, chess, connect-4, kosarak, mushroom, pumsb, retail, T10I4D100K e T4OI10D100K, são exibidas, respectivamente, pelas Figuras 5.12(b), 5.13(b), 5.14(b), 5.15(b), 5.16(b), 5.17(b), 5.18(b), 5.19(b), 5.20(b) e 5.21(b).

Em cada teste são encontrados os tempos de execução para geração de FIs pelos algoritmos Apriori e FP-growth. Também há os tempos de execução do algoritmo que descobre regras ótimas com melhor desempenho conforme 


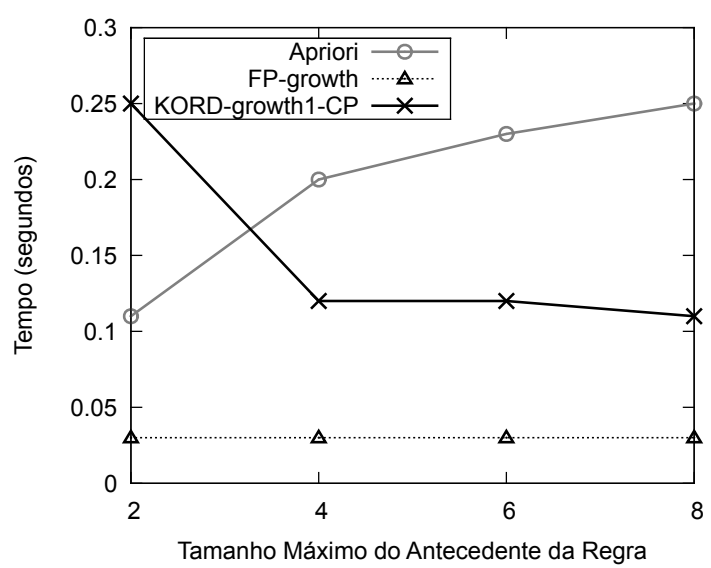

(a) Tamanho do Antecedente

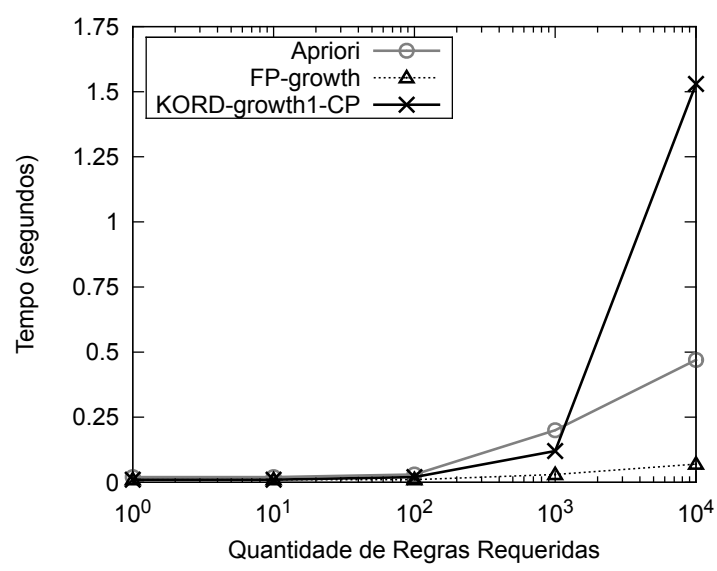

(b) Regras Requeridas

Figura 5.13: Desempenho dos algoritmos Apriori, FP-growth e KORD-growth1-CP para o conjunto de dados census.

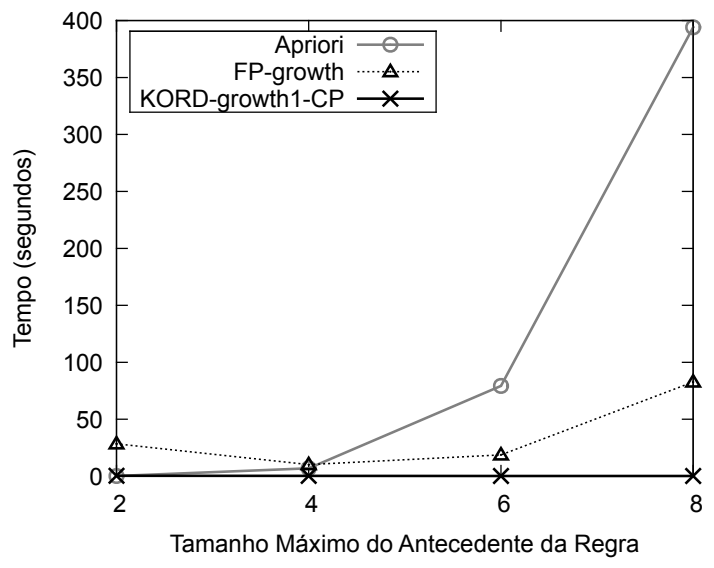

(a) Tamanho do Antecedente

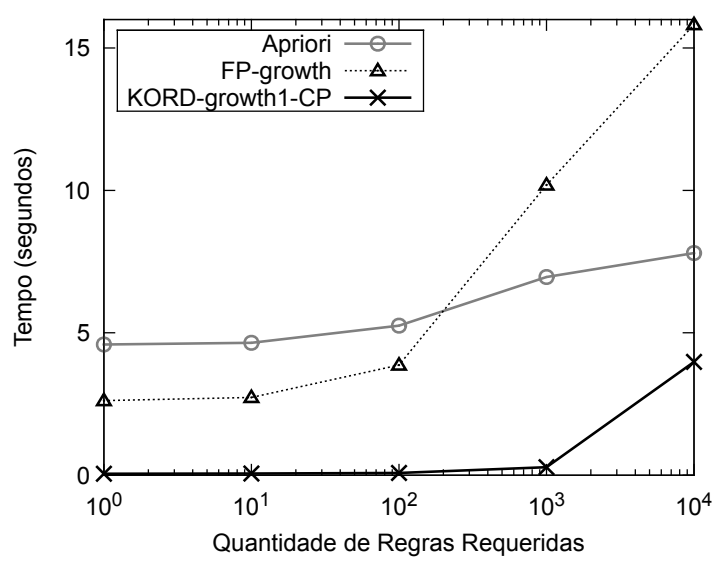

(b) Regras Requeridas

Figura 5.14: Desempenho dos algoritmos Apriori, FP-growth e KORD-growth1-CP para o conjunto de dados chess.

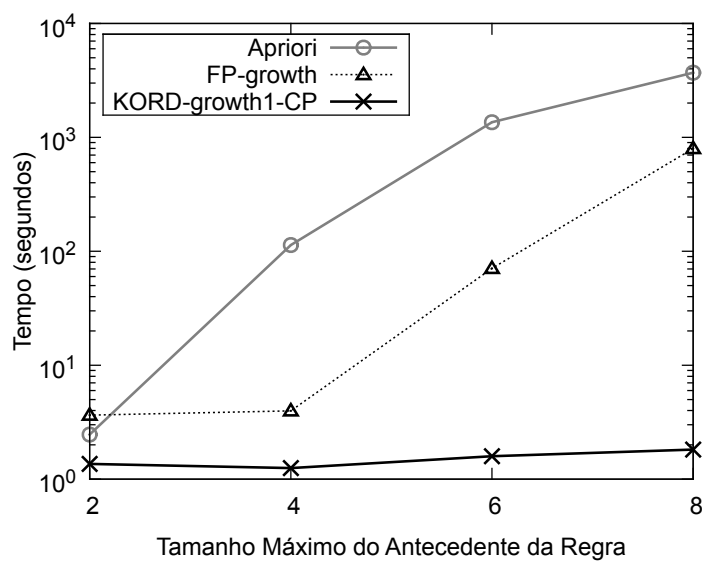

(a) Tamanho do Antecedente

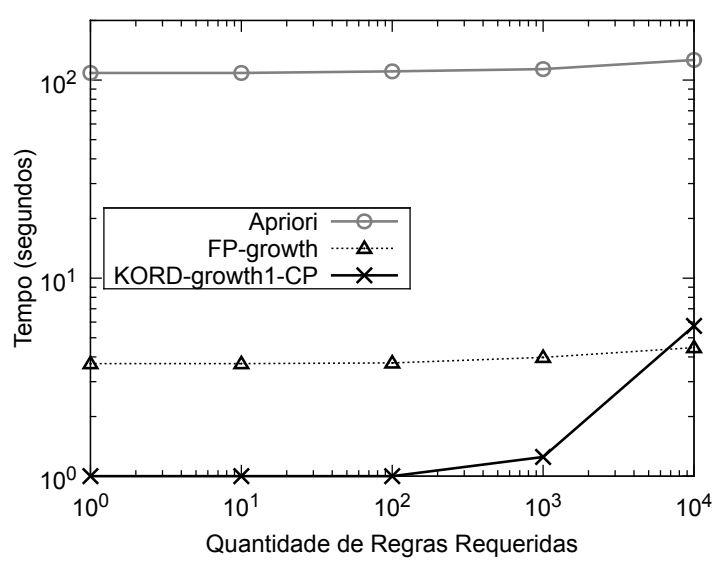

(b) Regras Requeridas

Figura 5.15: Desempenho dos algoritmos Apriori, FP-growth e KORD-growth1-CP para o conjunto de dados connect-4. 


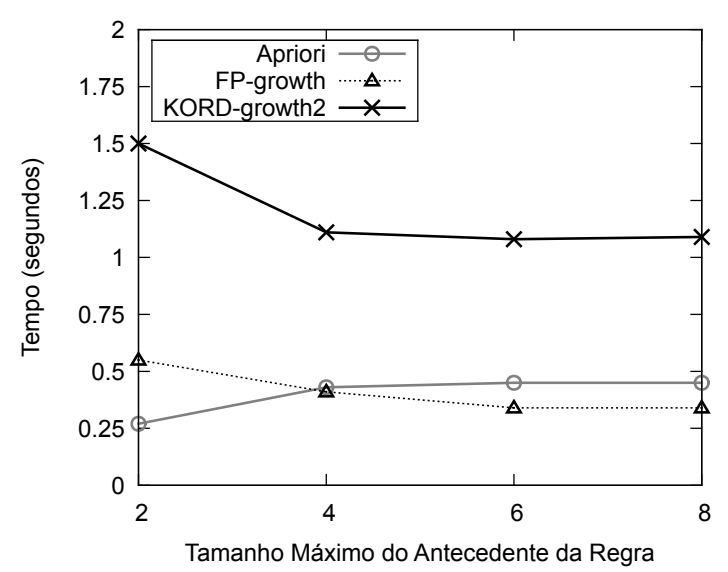

(a) Tamanho do Antecedente

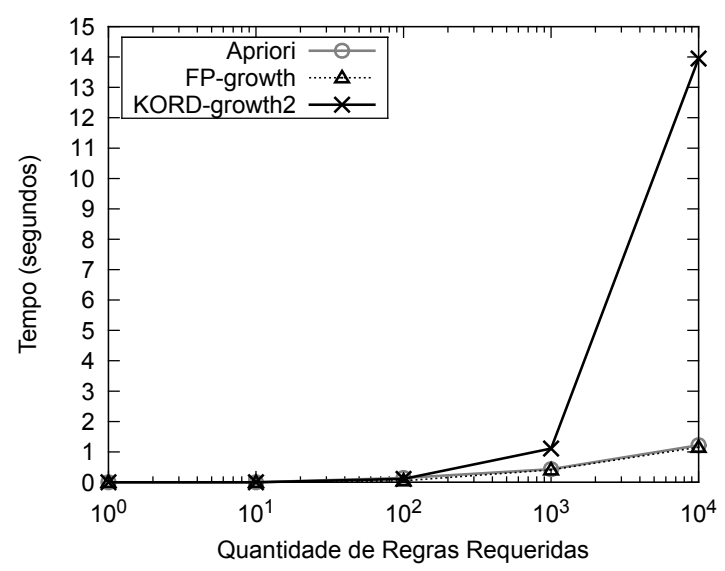

(b) Regras Requeridas

Figura 5.16: Desempenho dos algoritmos Apriori, FP-growth e KORD-growth2 para o conjunto de dados kosarak.

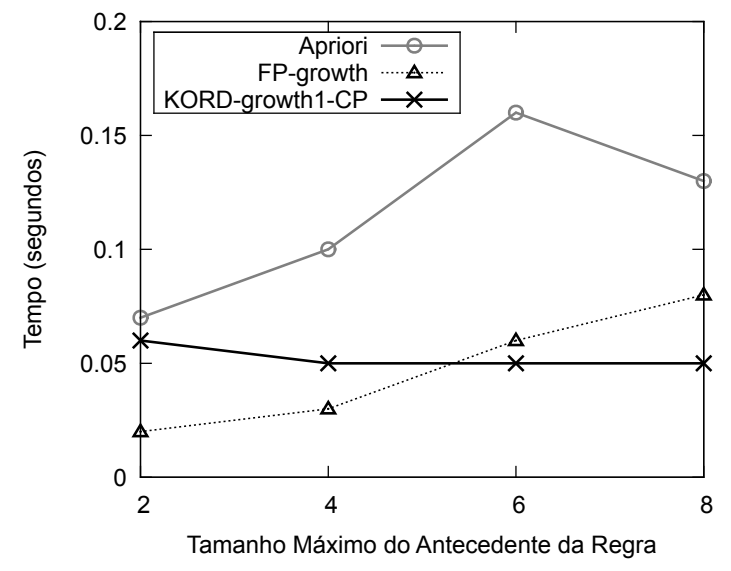

(a) Tamanho do Antecedente

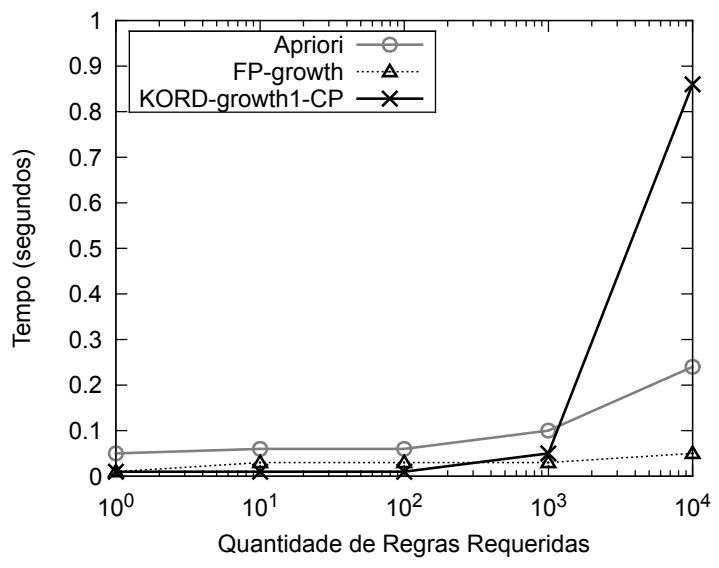

(b) Regras Requeridas

Figura 5.17: Desempenho dos algoritmos Apriori, FP-growth e KORD-growth1-CP para o conjunto de dados mushroom.

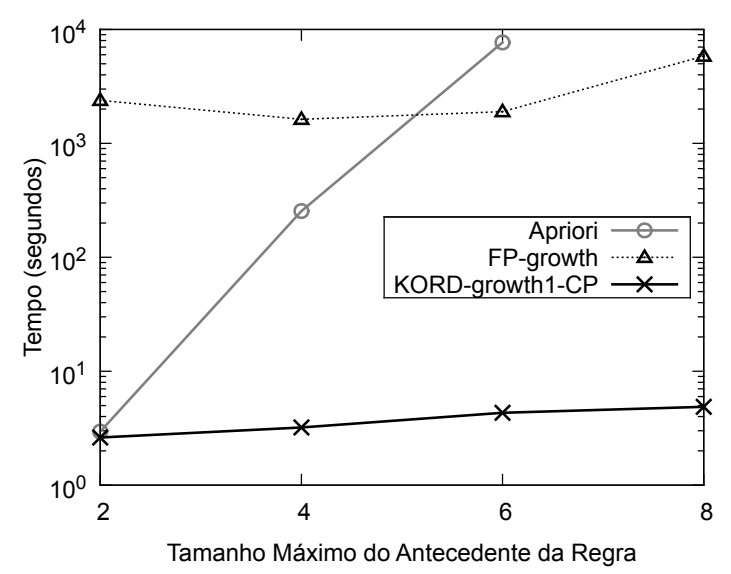

(a) Tamanho do Antecedente

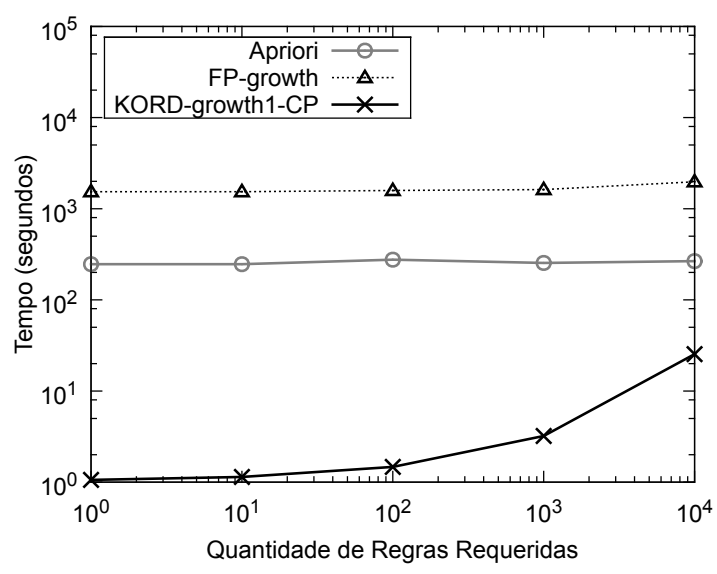

(b) Regras Requeridas

Figura 5.18: Desempenho dos algoritmos Apriori, FP-growth e KORD-growth1-CP para o conjunto de dados pumsb. 


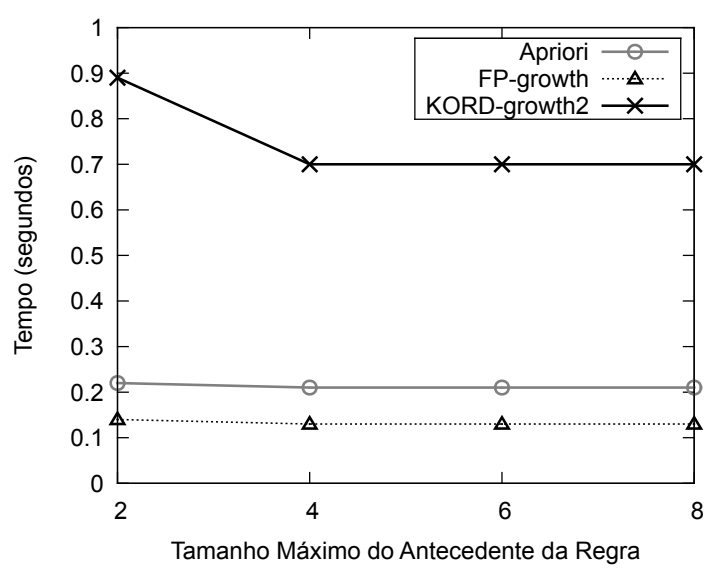

(a) Tamanho do Antecedente

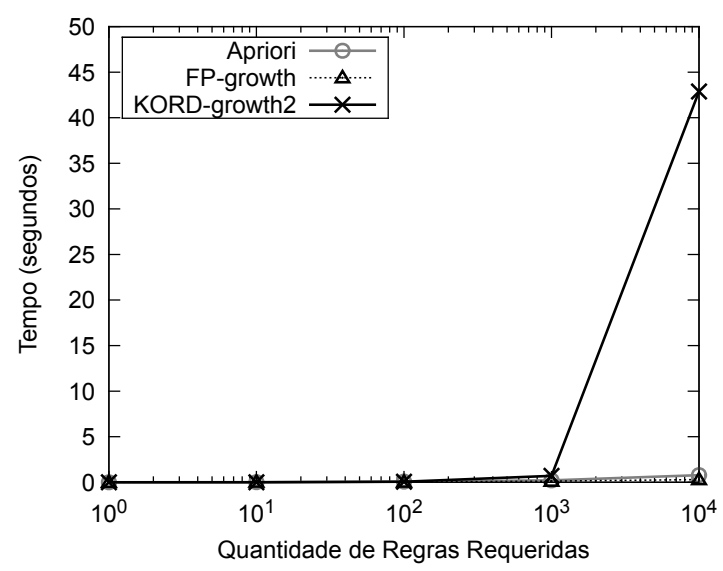

(b) Regras Requeridas

Figura 5.19: Desempenho dos algoritmos Apriori, FP-growth e KORD-growth2 para o conjunto de dados retail.

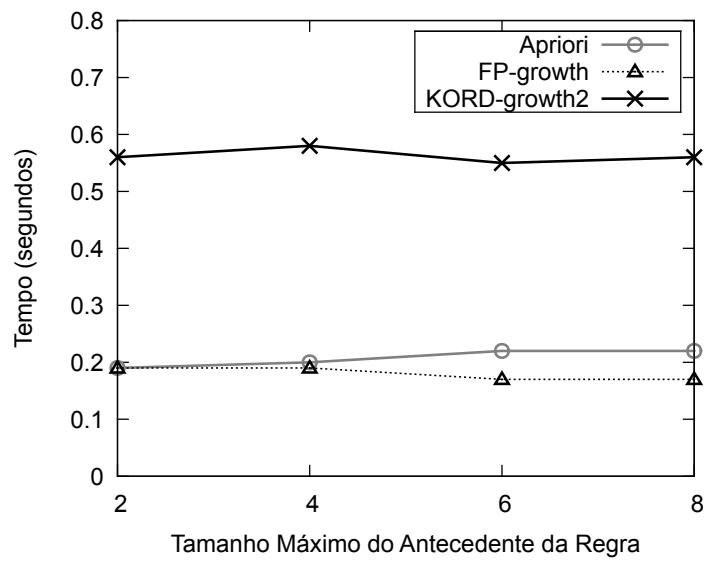

(a) Tamanho do Antecedente

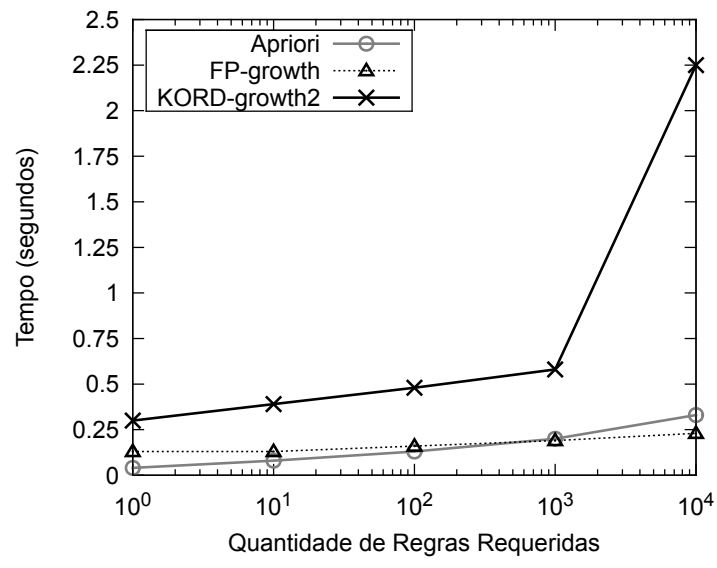

(b) Regras Requeridas

Figura 5.20: Desempenho dos algoritmos Apriori, FP-growth e KORD-growth2 para o conjunto de dados T1OI4D100K.

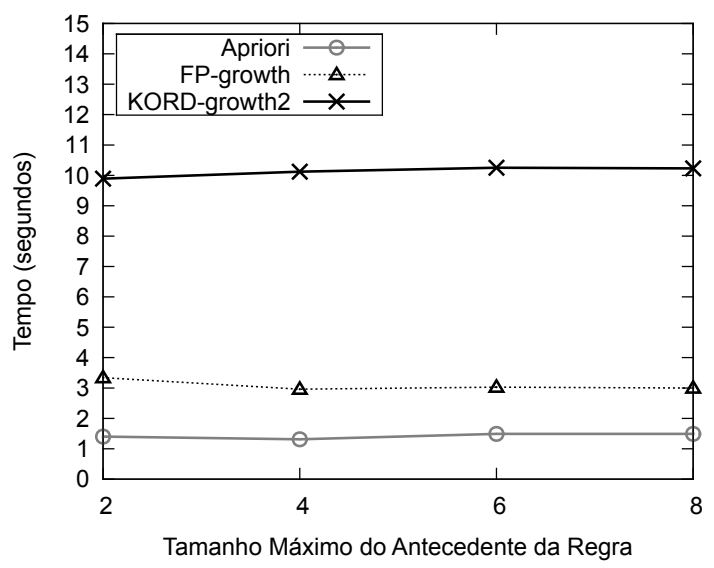

(a) Tamanho do Antecedente

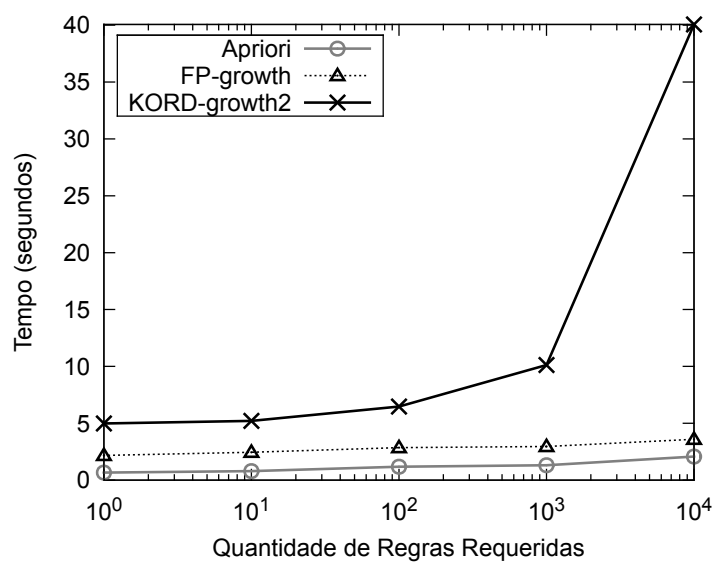

(b) Regras Requeridas

Figura 5.21: Desempenho dos algoritmos Apriori, FP-growth e KORD-growth2 para o conjunto de dados T4OI1OD10OK. 
o primeiro conjunto de testes da subseção anterior. Para os conjuntos de dados accidents, census, chess, connect-4, mushroom e pumsb, foi utilizado o algoritmo KORD-growth1-CP e para os conjuntos de dados kosarak, retail, T1OI4D100K e T4OI1OD100K foi utilizado o algoritmo KORD-growth2.

Em relação às avaliações que envolveram o tamanho máximo do antecedente e a quantidade de regras requeridas foi verificado que o algoritmo KORDgrowth1-CP teve melhor desempenho sobre os conjuntos de dados chess, connect-4 e pumsb. Uma semelhança entre esses conjuntos de dados é que os valores do desvio padrão da distribuição da frequência dos itens não são baixos e os valores dos tamanhos médios das transações são altos.

Sobre os conjuntos de dados kosarak, retail, T10I4D100K e T40I10D100K, o algoritmo KORD-growth2 obteve pior desempenho na avaliação que envolvia o tamanho do antecedente da regra. Esses conjuntos de dados compartilham baixos valores de desvio padrão da distribuição da frequência dos itens.

O algoritmo KORD-growth2 obteve pior desempenho sobre os conjuntos de dados T10I4D100K e T4OI1OD10OK na avaliação que envolvia a quantidade de regras requeridas. Tais conjuntos de dados possuem baixos valores de desvio padrão. Porém não são tão baixos quanto os desvios padrões encontrados nos conjuntos de dados kosarak e retail. Sobre esses conjuntos o desempenho do algoritmo KORD-growth2 foi pior somente quando a quantidade de regras requeridas foi grande.

Os algoritmos que descobrem regras ótimas, KORD-growth 1 e KORD-growth2, tiveram bons desempenhos nas avaliações que envolveram uma pequena quantidade de regras requeridas.

O desempenho do algoritmo FP-growth é peculiar. Na maioria dos conjuntos de dados testados teve melhor desempenho enquanto o tamanho do antecendente da regra crescia e enquanto aumentava a quantidade de regras requeridas. No primeiro caso, o desempenho do FP-growth é favorecido em virtude de ele não possuir a etapa de geração de candidatos. No segundo caso, seu desempenho é favorecido pelo fato de o suporte mínimo diminuir e manter o mesmo tamanho máximo do antecedente.

Para o conjunto de dados chess o desempenho do algoritmo FP-growth, na avaliação que considera a quantidade de regras requeridas, foi pior em virtude de este conjunto possuir poucas transações, o que favorece o algoritmo Apriori.

Sobre o conjunto de dados pumsb, durante a avaliação que considera a quantidade de regras requeridas, o desempenho do algoritmo FP-growth foi pior em virtude do grande tamanho médio de transação e mediano valor de desvio padrão. Da mesma forma isso aconteceu sobre o conjunto de dados T40I10D100K. Tal fato dificulta a mineração de FIs por esta abordagem, pois 
não existe muita sobreposição dos caminhos na árvore FP-tree.

Os piores desempenhos realizados pelo algoritmo Apriori aconteceram em conjuntos de dados densos. Isto é, conjuntos com altos valores de desvio padrão e tamanho médio da transação. Uma explicação para o baixo desempenho é que tais conjuntos de dados acarretam em uma grande quantidade de itemsets candidatos, que é uma dificuldade do algoritmo Apriori. Diferentemente, os melhores resultados desse algoritmo foram encontrados em conjuntos de dados com baixos valores dessas duas propriedades. Não obstante, o conjunto de dados T4OI1OD100K apresenta alto valor sobre o tamanho médio da transação e o desempenho do Apriori foi melhor de maneira mais acentuada.

Apesar da aparente eficiência dos algoritmos que descobrem FIs em relação aos algoritmos que descobrem regras ótimas, ainda existe o processo de geração de regras a partir desses FIs. Quanto maior a quantidade de FIs gerados, maior é o tempo gasto na descoberta de regras. A eficiência da geração de regras depende da implementação adotada, ou seja, depende da estruturada de dados que armazena os FIs. Em virtude de apenas o algoritmo Apriori existir essa funcionalidade, não foi possivel comparar com o algoritmo FP-growth. Os tempos de execução gastos pelo Apriori para geração de regras podem ser verificados no Apêndice B.

\subsubsection{Quando não se conhece o suporte mínimo que garanta $k$ regras ótimas}

Apesar da suposta eficiência em utilizar as abordagens tradicionais ao invés da abordagem que recupera regras ótimas, geralmente não se sabe de antemão qual o suporte mínimo que garante a recuperação de $k$ regras ótimas para a medida de interesse $P S$. Pois é necessário primeiro gerar as regras ótimas para conhecer a regra com menor valor de medida $P S$. Este menor valor correspondente à medida de interesse $P S$ poderia ser atribuído ao suporte mínimo.

Uma forma de superar esta dificuldade é estabelecer o menor suporte mínimo possivel para esta tarefa de descoberta. Isto pode ser feito pelo estabelecimento do suporte mínimo $\frac{1}{N}$, que garante a cobertura de pelo menos uma transação do conjunto de dados, sendo que $N$ representa a quantidade de transações. Dessa forma, fica impraticável a geração de regras via técnicas tradicionais. Portanto, torna-se oportuno a utilização das técnicas desenvolvidas neste trabalho para geração das regras ótimas.

Embora possa ser possível conhecer o suporte mínimo que garanta pelo menos $k$ regras ótimas com a utilização da medida $P S$, isso não é possível por meio de outras medidas de interesse. Por exemplo, por extrair regras ótimas 
com as medidas de interesse objetiva lift, is-measure, coeficiente de correlação e jaccard, não é possível a atribuição do suporte mínimo como limitante inferior na extração de $k$ regras ótimas. Essas medidas podem ser visualizadas na Seção 2.3.

A seguir são ilustrados na Tabela 5.3 os tempos de execução dos algoritmos que exploram regras ótimas para a medida de interesse objetiva $P S$. Os parâmetros de busca adotados foram a descoberta de 1000 regras ótimas com tamanho máximo do antecedente igual a 4 . O suporte mínimo deve garantir a cobertura de pelo menos uma transação. Portanto, ao suporte mínimo é atribuído $\frac{1}{N}$.

Tabela 5.3: Tabela com os tempos de execução em segundos dos algoritmos que descobrem 1000 regras ótimas. Suporte mínino estabelecido por $\frac{1}{N}$ e tamanho máximo do antecedente das regras igual a quatro. Em negrito encontra-se o melhor resultado.

\begin{tabular}{lcccc}
\hline Conjunto de Dados & KORD & KORD-growth1-SP & KORD-growth1-CP & KORD-growth2 \\
\hline \hline accidents & 390.40 & 117.20 & $\mathbf{5 6 . 7 6}$ & 268.90 \\
census & 4.20 & 0.17 & $\mathbf{0 . 1 4}$ & 0.34 \\
chess & 6.20 & 1.01 & $\mathbf{0 . 2 8}$ & 3.40 \\
connect-4 & 132.80 & 1.95 & $\mathbf{1 . 4 8}$ & 4.96 \\
kosarak & 28.60 & 25.96 & 25.54 & $\mathbf{2 1 . 6 2}$ \\
mushroom & 1.00 & $\mathbf{0 . 0 8}$ & $\mathbf{0 . 0 8}$ & 0.14 \\
pumsb & 26.60 & 7.52 & $\mathbf{6}$ & 20.33 \\
retail & 22.60 & 45.35 & 45.97 & $\mathbf{1 5 . 9 0}$ \\
T10I4D100K & 11.80 & 5.74 & 5.90 & $\mathbf{0 . 8 4}$ \\
T40I10D100K & 90.20 & 479.38 & 489.06 & $\mathbf{1 6 . 8 8}$ \\
\hline
\end{tabular}

Para todos os conjuntos de dados, o desempenho de pelo menos um dos algoritmos desenvolvidos neste trabalho foi superior ao desempenho do algoritmo baseline KORD. O algoritmo KORD-growth 1-CP obteve melhor desempenho sobre os conjuntos de dados que possuem altos valores de desvio padrão da distribuição da frequência dos itens. Por outro lado, o algoritmo KORDgrowth2 obteve melhor desempenho sobre conjuntos de dados que possuem baixos valores de desvio padrão.

\subsection{Considerações Finais}

Neste capítulo foram apresentados os conjuntos de dados e os algoritmos envolvidos nos experimentos. Os conjuntos de dados inseridos nos testes apresentaram muitas características distintas. Tais características puderam 
ser observadas pela informação da quantidade de itens, número de transações, tamanho médio das transações, assim como a média e desvio padrão da distribuição de frequência dos itens. Essas informações ajudaram a compreender o impacto que determinadas características causaram ao desempenho dos algoritmos empregados nos experimentos.

Os algoritmos avaliados neste capítulo foram os algoritmos KORD-growth1-SP, KORD-growth1-CP e KORD-growth2, em comparação com o KORD. Tais algoritmos tiveram como objetivo descobrir regras que otimizam a métrica de interesse objetiva $P S$. Os três primeiros algoritmos utilizam a metodologia FP-growth para contagem da frequência dos itemsets e o último utiliza a metodologia Apriori. Os algoritmos KORD-growth1-SP e KORD-growth1-CP são baseados no KORD-growth1, que segue a mesma estratégia de travessia de regras do algoritmo KORD. O algoritmo KORD-growth2 é baseado na pesquisa implícita de regras da estratégia de travessia.

Os testes foram realizados de duas formas. A primeira forma envolveu a comparação dos desempenhos dos algoritmos que descobrem regras ótimas. A segunda forma envolveu o desempenho dos algoritmos tradicionais que extraem padrões frequentes, Apriori e FP-growth, e o algoritmo que descobre regras ótimas com melhor desempenho em cada conjunto de dados. Em cada teste feito sobre um conjunto de dados foram realizadas duas avaliações. Na primeira avaliação houve o aumento gradativo do tamanho máximo do antecedente das regras a serem exploradas e na segunda avaliação houve o aumento da quantidade de regras requeridas pela tarefa.

Os algoritmos apresentaram comportamentos distintos. Isso ocorreu em virtude de suas características e das propriedades dos conjuntos de dados. Entre as propriedades mais importantes dos conjuntos de dados estão o tamanho médio da transação e o desvio padrão da distribuição do suporte entre os itens. Quanto maior ambos forem, melhor para o desempenho do algoritmo KORD-growth1-CP em relação aos outros algoritmos. Quanto menor ambos forem, melhor para o desempenho do algoritmo KORD-growth2 em relação aos outros algoritmos. Em relação às características dos algoritmos estão a adoção do algoritmo que explora FIs: Apriori e FP-growth. Os algoritmos desenvolvidos neste trabalho adotaram o FP-growth e obtiveram desempenho superior ao algoritmo baseline KORD, que adotou o Apriori.

Um teste comparativo foi realizado entre o melhor algoritmo que recupera regras ótimas e as técnicas tradicionais que exploram padrões frequentes. $\mathrm{O}$ algoritmo KORD-growth1-CP teve bom desempenho em conjuntos de dados que tiveram o desvio padrão com alto valor. Quando esse valor foi baixo, o algoritmo FP-growth obteve melhor desempenho para a geração das regras. No entanto, apesar de o conjunto de dados T4OI1OD1OOK ter desvio padrão 
baixo, o algoritmo Apriori obteve melhor desempenho. Isso ocorreu devido ao alto valor do tamanho médio da transação.

Em todos os testes realizados foi verificada a exatidão de todas as $k$ regras de associação ótimas exploradas. Ou seja, nenhuma regra ótima, dentre as $k$ melhores, que otimizou a medida de interesse $P S$ deixou de ser descoberta durante os experimentos.

Considerando que não se conhece o suporte mínimo que garanta a extração de $k$ regras ótimas, é necessário que seja atribuído o valor $\frac{1}{N}$ ao suporte mínimo para garantir a cobertura de pelo menos uma transação. Assim, não é viável a utilização das técnicas tradicionais para a extração de regras, visto que o tempo de mineração é impraticável. Portanto, é satisfatória a empregabilidade dos algoritmos desenvolvidos para a prospecção de regras ótimas. 


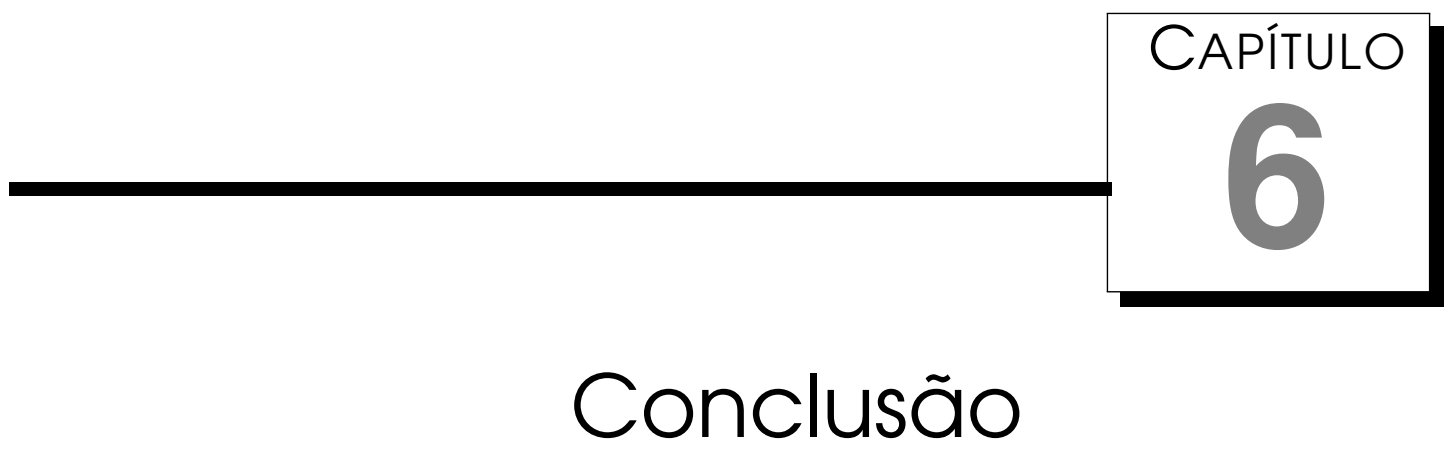

A pesquisa realizada durante este trabalho teve como objetivo geral propor algoritmos para descobrir, de forma direta e eficiente, um número arbitrário de regras de associação que otimizam uma determinada medida de interesse objetiva. Para alcançar esse objetivo, os algoritmos desenvolvidos tiveram que utilizar a metodologia do algoritmo FP-growth para contagem da frequência dos itemsets. Além disso, foram desenvolvidas podas e prevenções de acesso para otimizar mais ainda o processo de busca por regras ótimas.

Os algoritmos desenvolvidos foram baseados em duas estratégias de busca, que também foram chamadas de travessia do espaço de regras. A primeira travessia empregada foi baseada no algoritmo baseline KORD, que é uma das formas mais eficientes para recuperação de regras ótimas. A segunda estratégia de travessia de regras foi desenvolvida neste trabalho e foi baseada na realização de uma travessia com pesquisa implícita de regras.

A estratégia de travessia de regras similar ao KORD deu origem ao desenvolvimento do algoritmo KORD-growth1. A partir do algoritmo KORD-growth 1 foram desenvolvidos os algoritmos KORD-growth 1-SP e KORD-growth1-CP. O primeiro manteve as mesmas podas e prevenções de acesso encontradas no algoritmo KORD, isto é, sem podas e prevenções de acesso adicionais. Enquanto que o último adicionou as podas e prevenções de acesso desenvolvidas nesta pesquisa. O algoritmo KORD-growth2 implementou a travessia com pesquisa implícita de regras e as podas e prevenções de acesso foram herdadas do algoritmo KORD, como também àquelas desenvolvidas no corrente trabalho.

Os resultados obtidos foram animadores, pois o desempenho dos algoritmos desenvolvidos foi superior ao desempenho do algoritmo baseline KORD sob as mesmas condições de execução. O desempenho do algoritmo KORD- 
growth1-SP mostrou que a exclusiva adoção da metodologia FP-growth foi responsável por uma melhor eficiência na grande maioria das situações observadas nos experimentos. Isso justificou sua utilização em detrimento à adoção da metodologia Apriori, que é utilizada pelo algoritmo KORD.

O objetivo da implementação do algoritmo KORD-growth1-CP foi conhecer a capacidade de melhoria no desempenho por meio da utilização das novas podas e prevenções de acesso. O desempenho do algoritmo KORD-growth1-CP foi superior ao desempenho do algoritmo KORD-growth1-SP em alguns conjuntos de dados, principalmente enquanto crescia o valor da restrição sobre o tamanho máximo do antecedente das regras extraídas.

$\mathrm{O}$ algoritmo KORD-growth2 foi mais eficiente que o algoritmo KORD em muitos conjuntos de dados. Também obteve melhor desempenho em relação aos outros algoritmos quando os conjuntos de dados apresentaram valores baixos sobre o desvio padrão e a média da distribuição de frequência dos itens. Sobre esses conjuntos foi observada a baixa eficácia das novas podas e prevenções de acesso, que proporcionou degradação no tempo de execução do algoritmo KORD-growth1-CP em relação ao algoritmo KORD-growth1-SP.

Os experimentos também envolveram dois algoritmos tradicionais que recuperam padrões frequentes. Isso aconteceu em virtude da utilização da medida de interesse objetiva $P S$ como função objetivo na tarefa de busca. Assim, conhecendo a k-ésima ou última regra com menor valor de medida $P S$, é possivel atribuir esse valor como suporte mínimo, que garante a recuperação de todas as regras ótimas por uma técnica tradicional.

Embora aparenta ser viável a utilização dos algoritmos tradicionais, em virtude de melhor desempenho em alguns testes, é improvável conhecer antecipadamente o suporte mínimo que garanta a descoberta de $k$ regras ótimas conforme a medida de interesse objetiva PS. Sabendo disso, é necessário que a busca garanta a cobertura de pelo menos uma transação. Isto é, deve ser atribuído o valor $\frac{1}{N}$ ao suporte mínimo, sendo que $N$ é a quantidade de transações do conjunto de dados minerado. Com o menor suporte mínimo possível, torna-se impraticável a utilização de técnicas tradicionais que recuperam padrões frequentes. Portanto, sob essas condições, os algoritmos desenvolvidos neste trabalho tiveram melhor desempenho que o algoritmo KORD.

Uma das limitações encontradas neste trabalho é que na segunda estratégia de travessia de regras não é possivel explorar regras com mais de um item no consequente. Isso acontece por causa da pesquisa implícita encontrada nessa travessia, que impede a utilização do mecanismo de prevenção de acesso para as possiveis regras (com mais de um item no consequente) a serem exploradas. Se em tal travessia fosse requerido buscar regras com mais de um item no consequente, o tempo de extração das regras ótimas seria 
impraticável, em virtude da não aplicação da prevenção de acesso empregada para evitar a avaliação das outras possíveis regras.

Um aspecto de limitação observado durante o desenvolvimento das técnicas é a extração de uma grande quantidade de regras ótimas. Quanto mais regras são requeridas, maior é a chance que ocorra a contagem da frequência dos itemsets pelos caminhos representados em uma FP-tree, ou seja, de forma ineficiente. Por causa disso, pode-se observar nos experimentos, uma acentuada degradação no tempo de execução dos algoritmos desenvolvidos enquanto a quantidade de regras requeridas aumentava.

O problema na extração de muitas regras acarreta uma outra limitação. Quanto maior a quantidade de regras requeridas, mais demorado será o conhecimento do valor da restrição menor $P S$, que é o valor da medida $P S$ da k-ésima regra do conjunto solução de regras. Dessa forma, caso um conjunto de dados possua muitos itens, isto é, tenha alta dimensionalidade, será necessário gerar os caminhos de prefixo para cada item relacionado ao consequente, para que se conheça o suporte da regra $X \rightarrow Y$. Quanto maior a profundidade para se encontrar o item prefixo relacionado ao consequente na árvore FP-tree, mais custosa é a geração dos caminhos de prefixo relacionados com ele.

Como já relatado, não é possível conhecer o suporte mínimo adequado na recuperação de uma quantidade limitada de regras ótimas para uma determinada medida objetiva. Sabendo disso, atribui-se ao suporte mínimo a menor cobertura possível sobre o conjunto de dados, que é a cobertura de pelo menos uma transação. Sobre esse aspecto na mineração de regras ótimas, a utilização de métodos ou algoritmos tradicionais pode ser considerada inviável. Visto que o desempenho de tais algoritmos pode ser impraticável para aplicações sensíveis ao tempo de execução.

Sobre essas condições, pode-se afirmar que os algoritmos desenvolvidos realizaram satisfatoriamente os objetivos propostos neste trabalho. Pois o desempenho do algoritmo KORD foi superado em todos os testes. Esse resultado foi obtido pela aplicação das novas podas e prevenções de acesso, assim como na aplicação da metodologia FP-growth para contagem da frequência dos itemsets.

Portanto, entre os principais resultados encontrados deste trabalho, destacam-se: o desempenho do algoritmo KORD-growth1-CP foi melhor sobre conjuntos de dados considerados densos e com alto valor sobre o desvio padrão na distribuição da frequência dos itens. Por outro lado, o desempenho do algoritmo KORD-growth2 foi melhor sobre conjuntos de dados considerados esparsos e com baixo valor sobre o desvio padrão. Nesses conjuntos ditos esparsos o algoritmo KORD-growth1-SP teve melhor desempenho em relação ao 
algoritmo KORD-growth1-CP, em virtude da não aplicação das novas podas e prevenções de acesso. Tais características de conjuntos de dados ajudam a escolher o melhor algoritmo para descobrir regras ótimas.

Apesar de conseguir alcançar os objetivos definidos neste trabalho, alguns trabalhos futuros podem ser sugeridos para melhorar os resultados conquistados. Um trabalho futuro poderia ser a melhoria no desempenho da contagem da frequência dos itemsets não cobertos pela metodologia FP-growth. Isto é, utilizar ou desenvolver técnicas mais robustas para este fim. Outro possível trabalho futuro é o desenvolvimento de novas podas e prevenções de acesso, que podem ser relacionados de forma geral para qualquer critério objetivo, como também pode ser desenvolvido de forma ad hoc, que dependeria da medida de interesse objetiva. Portanto, novas medidas objetivas podem ser consideradas.

Acerca dos experimentos realizados é importante conhecer algumas aplicações práticas possíveis que seriam beneficiadas a partir dos resultados e conclusões obtidos neste trabalho. Uma aplicação possivel é o ferramental que envolve sistemas de recomendação, no qual é possivel a adoção de regras para sugerir recomendações de produtos para um cliente ou freguês. Isto é, existe a esperança de que novas compras sigam a mesma regularidade de compras passadas. Tais sistemas podem ter restrições de tempo de resposta severas.

Outra possivel utilização acerca dos resultados obtidos é a sua aplicação em tarefas de classificação. De forma mais apropriada, tais resultados poderiam ser aplicados em classificação associativa. Essa tarefa depende de regras que ajudam a criar uma hipótese para um determinado problema de classificação. Visto que muitas regras podem ser geradas, podas e restrições adicionais podem ser inseridas na tarefa de descoberta de regras - não mais necessariamente ótimas - e tais regras podem respeitar um ranking sobre uma medida de interesse objetiva arbitrária.

Os objetivos deste trabalho foram alcançados pela adoção de apropriadas hipóteses. A utilização da metodologia FP-growth foi efetiva em virtude do seu caráter de busca em profundidade e também pela travessia de regras seguir uma busca em profundidade. Assim, sucessivas compactações da árvore FP-tree contribuíram para o desempenho satisfatório dos algoritmos desenvolvidos neste trabalho. Além disso, o desenvolvimento de novas podas e prevenções de acesso propiciou a diminuição do espaço de busca explorado e isso também contribuiu para a eficácia da tarefa. Portanto, as ideias e esforços empregados no período do desenvolvimento deste trabalho acarretaram em melhor desempenho na tarefa de descoberta de regras ótimas para uma medida de interesse objetiva arbitrária. 


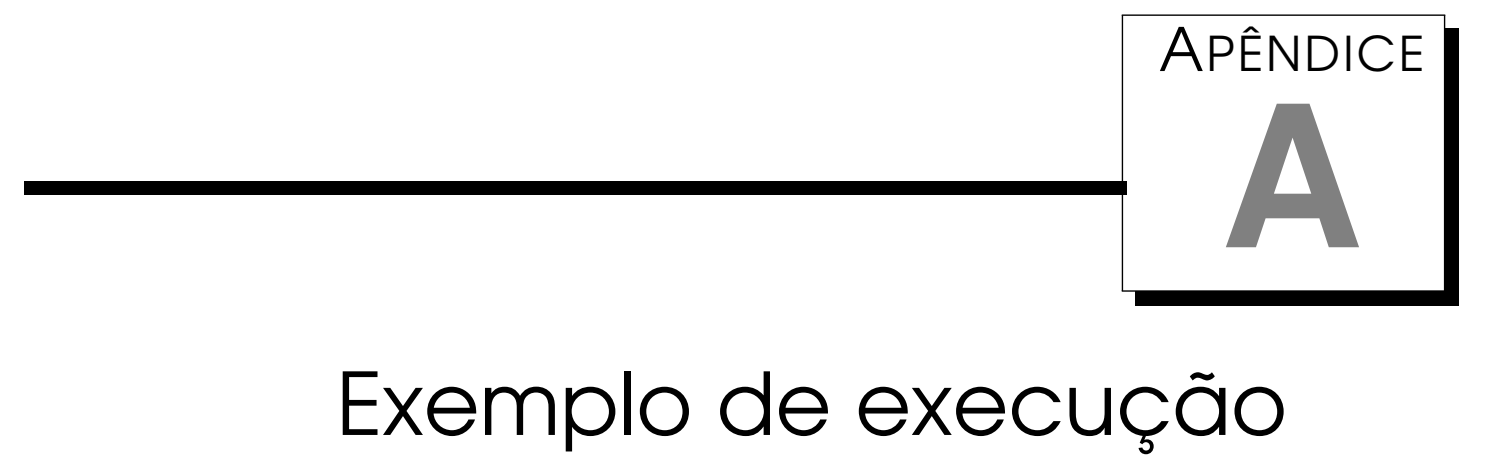

Um exemplo toy é exibido para descrever o funcionamento do algoritmo, assim como a aplicabilidade das podas e prevenções de acesso sobre regras não promissoras. A aplicação de podas garante a redução do espaço de busca a ser pesquisado sem risco à otimalidade das regras extraídas. Um conjunto de dados com seis itens e 10 transações é apresentado na Tabela A.1. Inicialmente é necessário conhecer as restrições de busca. Um usuário pode definir as seguintes restrições:

Suporte Mínimo: é a restrição que se refere à variável menorSuporte.

Cobertura Mínima: é a restrição que se refere à variável menorCobertura.

Confiança Mínima: é a restrição que se refere à variável menorConfianca.

Medida de Interesse: é a medida de interesse objetiva estabelecida para a busca.

Valor Mínino para a Medida de Interesse: é a restrição que se refere à variável menor $P S$, se a medida estabelecida for $P S$.

Tamanho Máximo do Antecedente: é a restrição que se refere à variável tamMaxAnt.

Guantidade Máxima de Regras Requeridas: é a restrição que se refere à variável $k$.

Nos exemplos de mineração de regras ótimas a seguir, é definido que o suporte mínimo, cobertura mínima, confiança mínima sejam igual a 0 . A 
medida de interesse a ser otimizada é a medida objetiva $P S$ e o valor mínimo é 0. O tamanho máximo de antecedente, tamMaxAnt, é 3 e a quantidade de regras extraídas $k, 3$.

Tabela A. 1: Conjunto de Dados

\begin{tabular}{|l|l|}
\hline TID & \multicolumn{1}{|c|}{ Itens } \\
\hline 1 & $\{\mathrm{a}, \mathrm{b}, \mathrm{c}\}$ \\
\hline 2 & $\{\mathrm{a}, \mathrm{b}, \mathrm{c}\}$ \\
\hline 3 & $\{\mathrm{a}, \mathrm{c}\}$ \\
\hline 4 & $\{\mathrm{a}, \mathrm{b}\}$ \\
\hline 5 & $\{\mathrm{a}, \mathrm{b}\}$ \\
\hline 6 & $\{\mathrm{a}, \mathrm{b}\}$ \\
\hline 7 & $\{\mathrm{a}, \mathrm{b}, \mathrm{c}, \mathrm{d}, \mathrm{e}, \mathrm{f}\}$ \\
\hline 8 & $\{\mathrm{a}, \mathrm{b}, \mathrm{d}, \mathrm{e}\}$ \\
\hline 9 & $\{\mathrm{a}, \mathrm{b}, \mathrm{d}\}$ \\
\hline 10 & $\{\mathrm{c}\}$ \\
\hline
\end{tabular}

Antes de chamar a execução do procedimento principal de cada algoritmo é necessário contruir a FP-tree que registra a frequência de todos os itemsets do conjunto de dados. A FP-tree inicial é construída a partir do conjunto de dados exemplificado pela Tabela A.1. Tal FP-tree será representada pela variável antecedentes_FPTree na chamada inicial dos algoritmos KORDgrowth1 e KORD-growth2. A variável consequentes_Disponiveis é composta por uma FP-tree condicional para cada itemset consequente. Como os consequentes são formados por itemsets de tamanho igual a 1 , cada consequente $\epsilon$ consequentes_Disponiveis contém uma árvore FP-tree condicional dos itens $a, b$, $c, d, e$ e $f$.

\section{A. 1 Para o KORD-growth 1}

Os parâmetros para a chamada inicial do algoritmo KORD-growth1 são antecedente_Atual que é vazio, antecedentes_FPTree, que mantêm a FP-tree inicial para minerar a frequência dos antecedentes, antecedentes_Disponiveis, que mantêm todos os itens frequentes, e o conjunto consequentes_Disponiveis, que mantém as árvores FP-tree condicionais dos consequentes, como também o suporte do consequente e da última regra avaliada. A variável antecedentes_FPTree não é relacionada a seguir e a variável coberturaAntecedente representa a frequência do antecedente recuperada a partir dela.

Na primeira chamada ao procedimento, são conhecidos antecedente_Atual = $\emptyset$, antecedentes_Disponiveis $=\{a, b, c, d, e$ e $f\}$ e o conjunto consequentes_Disponiveis com os itens $a, b, c, d, e$ e $f$. 
Linha 1: ate_Agora $=\emptyset$

Laço na linha 2: (Sobre cada $P \in$ antecedentes_Disponiveis)

- $P=a$ novoAntecedente $=\{a\}$ coberturaAntecedente $=0.9$ novos_Antecedentes_Disponiveis $=\emptyset$

Laço na linha 6: (Sobre cada consequente $\in$ consequentes_Disponiveis)

$-Y=b$

Avaliar a regra $\{a\} \rightarrow\{b\}$

coberturaConsequente $=0.8$

suporteRegra $=0.8$

$\lambda=0.08$

O conjunto solucao_Atual ainda não contém $k$ regras, então qualquer regra que satisfaz as restrições pode ser adicionada.

solucao_Atual $=\{\{a\} \rightarrow\{b\} \lambda=0.08\}$

$-Y=c$

Avaliar a regra $\{a\} \rightarrow\{c\}$

coberturaConsequente $=0.5$

suporteRegra $=0.4$

$\lambda=-0.05$

A medida $P S$ para a nova regra é menor que menor $P S, \lambda<$ menor $P S$, então a regra sob avaliação não deve ser adicionada à solucao_Atual.

- $Y=d$

Avaliar a regra $\{a\} \rightarrow\{d\}$

coberturaConsequente $=0.3$

suporteRegra $=0.3$

$\lambda=0.03$

O conjunto solucao_Atual ainda não contém $k$ regras, então qualquer regra que satisfaz as restrições pode ser adicionada.

solucao_Atual $=\{\{\{a\} \rightarrow\{b\} \lambda=0.08\},\{\{a\} \rightarrow\{d\} \lambda=0.03\}\}$

- $Y=e$

Avaliar a regra $\{a\} \rightarrow\{e\}$

coberturaConsequente $=0.2$

suporteRegra $=0.2$

$\lambda=0.02$

O conjunto solucao_Atual ainda não contém $k$ regras, então qualquer regra que satisfaz as restrições pode ser adicionada.

solucao_Atual $=\{\{\{a\} \rightarrow\{b\} \lambda=0.08\},\{\{a\} \rightarrow\{d\} \lambda=0.03\},\{\{a\} \rightarrow$ $\{e\} \lambda=0.02\}\}$ 
menor $P S=0.02$

menor Suporte $=0.02$

- $Y=f$

Avaliar a regra $\{a\} \rightarrow\{f\}$

coberturaConsequente $=0.1$

suporteRegra $=0.1$

$\lambda=0.01$

A medida $P S$ para a nova regra é menor que menor $P S, \lambda<$ menor $P S$, então a regra sob avaliação não deve ser adicionada à solucao_Atual.

Linha 31: ate_Agora $=\{a\}$

- $P=b$

novoAntecedente $=\{b\}$

coberturaAntecedente $=0.8$

novos_Antecedentes_Disponiveis $=\{a\}$

Laço na linha 6.

- $Y=a$

Avaliar a regra $\{b\} \rightarrow\{a\}$

coberturaConsequente $=0.8$

suporteRegra $=0.8$

$\lambda=0.08$

A valor da medida $P S$ para a regra sob avaliação é maior que o menor $P S, \lambda>$ menor $P S$, então a nova regra deve ser adicionada ao conjunto solucao_Atual.

solucao_Atual $=\{\{\{a\} \rightarrow\{b\} \lambda=0.08\},\{\{b\} \rightarrow\{a\} \lambda=0.08\}\},\{\{a\} \rightarrow$ $\{d\} \lambda=0.03\}$

A regra com menor valor de medida $P S,\{a\} \rightarrow\{e\}$, foi removida de solucao_Atual.

menor $P S=0.03 ;$ menor Suporte $=0.03 ;$ menorCobertura $=0.03$

$-Y=c$

Avaliar a regra $\{b\} \rightarrow\{c\}$

coberturaConsequente $=0.5$

suporteRegra $=0.3$

$\lambda=-0.1$

A medida $P S$ para a nova regra é menor que menor $P S, \lambda<$ menor $P S$, então a regra sob avaliação não deve ser adicionada à solucao_Atual.

$-Y=d$

Avaliar a regra $\{b\} \rightarrow\{d\}$

coberturaConsequente $=0.3$ 
suporteRegra $=0.3$

$\lambda=0.06$

A valor da medida $P S$ para a regra sob avaliação é maior que o menor $P S, \lambda>$ menor $P S$, então a nova regra deve ser adicionada ao conjunto solucao_Atual.

solucao_Atual $=\{\{\{a\} \rightarrow\{b\} \lambda=0.08\},\{\{b\} \rightarrow\{a\} \lambda=0.08\}\},\{\{b\} \rightarrow$ $\{d\} \lambda=0.06\}$

A regra com menor valor de medida $P S,\{a\} \rightarrow\{d\}$, foi removida de solucao_Atual.

menorPS $=0.06$; menor Suporte $=0.06$; menorCobertura $=0.06$

- $Y=e$

Avaliar a regra $\{b\} \rightarrow\{e\}$

coberturaConsequente $=0.2$

suporteRegra $=0.2$

$\lambda=0.04$

A medida $P S$ para a nova regra é menor que menor $P S, \lambda<$ menor $P S$, então a regra sob avaliação não deve ser adicionada à solucao_Atual.

- $Y=f$

Avaliar a regra $\{b\} \rightarrow\{f\}$

coberturaConsequente $=0.1$

suporteRegra $=0.1$

$\lambda=0.02$

A medida $P S$ para a nova regra é menor que menor $P S, \lambda<$ menor $P S$, então a regra sob avaliação não deve ser adicionada à solucao_Atual.

Chamada Recursiva na linha 12.

antecedente_Atual $=\{b\}$

antecedentes_Disponiveis $=\{a\}$

consequentes_Disponiveis com os itens $a, c, d, e$ e $f$

Linha 1: ate_Agora $=\emptyset$

Laço na linha 2.

$-P=a$

novoAntecedente $=\{b, a\}$

coberturaAntecedente $=0.8$

novos_Antecedentes_Disponiveis $=\{\}$

Laço na linha 6.

$* Y=c$

Avaliar a regra $\{b, a\} \rightarrow\{c\}$

coberturaConsequente $=0.5$

Aplica-se a Prevenção 6. 
$* Y=d$

Avaliar a regra $\{b, a\} \rightarrow\{d\}$

coberturaConsequente $=0.3$

Aplica-se a Prevenção 5.

* $Y=e$

Avaliar a regra $\{b, a\} \rightarrow\{e\}$

coberturaConsequente $=0.2$

Aplica-se a Prevenção 5.

* $Y=f$

Avaliar a regra $\{b, a\} \rightarrow\{f\}$

coberturaConsequente $=0.1$

Aplica-se a Prevenção 5.

Linha 31: ate_Agora $=\{a, b\}$

- $P=c$

novoAntecedente $=\{c\}$

coberturaAntecedente $=0.5$

novos_Antecedentes_Disponiveis $=\{a, b\}$

Laço na linha 6.

- $Y=a$

Avaliar a regra $\{c\} \rightarrow\{a\}$

coberturaConsequente $=0.9$

Aplica-se a Poda 5.

- $Y=b$

Avaliar a regra $\{c\} \rightarrow\{b\}$

coberturaConsequente $=0.8$

suporteRegra $=0.3$

Aplica-se a Poda 10.

- $Y=d$

Avaliar a regra $\{c\} \rightarrow\{d\}$

coberturaConsequente $=0.3$

suporteRegra $=0.1$

$\lambda=-0.05$

A medida $P S$ para a nova regra é menor que menor $P S, \lambda<$ menor $P S$, então a regra sob avaliação não deve ser adicionada à solucao_Atual.

- $Y=e$

Avaliar a regra $\{c\} \rightarrow\{e\}$

coberturaConsequente $=0.2$

suporteRegra $=0.1$ 
$\lambda=0.00$

A medida $P S$ para a nova regra é menor que menor $P S, \lambda<$ menor $P S$, então a regra sob avaliação não deve ser adicionada à solucao_Atual.

- $Y=f$

Avaliar a regra $\{c\} \rightarrow\{f\}$

coberturaConsequente $=0.1$

suporteRegra $=0.1$

$\lambda=0.05$

A medida $P S$ para a nova regra é menor que menor $P S, \lambda<$ menor $P S$, então a regra sob avaliação não deve ser adicionada à solucao_Atual.

Chamada Recursiva na linha 12.

antecedente_Atual $=\{c\}$

antecedentes_Disponiveis $=\{a, b\}$

consequentes_Disponiveis com os itens $d, e$ e $f$

Linha 1: ate_Agora $=\emptyset$

Laço na linha 2.

- $P=a$

novoAntecedente $=\{c, a\}$

coberturaAntecedente $=0.4$

novos_Antecedentes_Disponiveis $=\emptyset$

Laço na linha 6.

$* Y=d$

Avaliar a regra $\{c, a\} \rightarrow\{d\}$

coberturaConsequente $=0.3$

Aplica-se a Prevenção 6.

* $Y=e$

Avaliar a regra $\{c, a\} \rightarrow\{e\}$

coberturaConsequente $=0.2$

Aplica-se a Prevenção 6.

* $Y=f$

Avaliar a regra $\{c, a\} \rightarrow\{f\}$

coberturaConsequente $=0.1$

Aplica-se a Prevenção 5.

Linha 31: ate_Agora $=\{a\}$

- $P=b$

novoAntecedente $=\{c, b\}$

coberturaAntecedente $=0.3$

novos_Antecedentes_Disponiveis $=\{a\}$

Laço na linha 6. 
* $Y=d$

Avaliar a regra $\{c, b\} \rightarrow\{d\}$

coberturaConsequente $=0.3$

suporteRegra $=0.1$

$\lambda=0.01$

A medida $P S$ para a nova regra é menor que menor $P S, \lambda<$ menor $P S$, então a regra sob avaliação não deve ser adicionada à solucao_Atual.

* $Y=e$

Avaliar a regra $\{c, b\} \rightarrow\{e\}$

coberturaConsequente $=0.2$

suporteRegra $=0.1$

$\lambda=0.04$

A medida $P S$ para a nova regra é menor que menor $P S, \lambda<$ menor $P S$, então a regra sob avaliação não deve ser adicionada à solucao_Atual.

$* Y=f$

Avaliar a regra $\{c, b\} \rightarrow\{f\}$

coberturaConsequente $=0.1$

suporteRegra $=0.1$

$\lambda=0.07$

A valor da medida $P S$ para a regra sob avaliação é maior que o menor $P S, \lambda>$ menor $P S$, então a nova regra deve ser adicionada ao conjunto solucao_Atual.

solucao_Atual $=\{\{\{a\} \rightarrow\{b\} \lambda=0.08\},\{\{b\} \rightarrow\{a\} \lambda=0.08\}$, $\{\{c, b\} \rightarrow\{f\} \lambda=0.07\}\}$

A regra com menor valor de medida $P S,\{b\} \rightarrow\{d\}$, foi removida de solucao_Atual.

menor $P S=0.07 ;$ menor Suporte $=0.07 ;$ menorCobertura $=0.07$

Chamada Recursiva na linha 12.

antecedente_Atual $=\{c, b\}$

antecedentes_Disponiveis $=\{a\}$

consequentes_Disponiveis com os itens $d, e$ e $f$

Linha 1: ate_Agora $=\emptyset$

Laço na linha 2.

$* P=a$

novoAntecedente $=\{c, b, a\}$

coberturaAntecedente $=0.3$

novos_Antecedentes_Disponiveis $=\emptyset$ Laço na linha 6 .

- $Y=d$ 
Avaliar a regra $\{c, b, a\} \rightarrow\{d\}$

coberturaConsequente $=0.3$

Aplica-se Prevenção 6.

- $Y=e$

Avaliar a regra $\{c, b, a\} \rightarrow\{e\}$

coberturaConsequente $=0.2$

Aplica-se Prevenção 6.

- $Y=f$

Avaliar a regra $\{c, b, a\} \rightarrow\{f\}$

coberturaConsequente $=0.1$

Aplica-se Prevenção 5.

Linha 31: ate_Agora $=\{a, b, c\}$

- $P=d$

novoAntecedente $=\{d\}$

suporteAntecedente $=0.3$

novos_Antecedentes_Disponiveis $=\{a, b, c\}$

Laço na linha 6.

- $Y=a$

Avaliar a regra $\{d\} \rightarrow\{a\}$

coberturaConsequente $=0.9$

Aplica-se Poda 5.

- $Y=b$

Avaliar a regra $\{d\} \rightarrow\{b\}$

coberturaConsequente $=0.8$

Aplica-se Poda 5.

- $Y=c$

Avaliar a regra $\{d\} \rightarrow\{c\}$

coberturaConsequente $=0.5$

suporteRegra $=0.1$

Aplica-se a Poda 10.

$-Y=e$

Avaliar a regra $\{d\} \rightarrow\{e\}$

coberturaConsequente $=0.2$

suporteRegra $=0.2$

$\lambda=0.14$

A valor da medida $P S$ para a regra sob avaliação é maior que o menor $P S, \lambda>$ menor $P S$, então a nova regra deve ser adicionada ao conjunto solucao_Atual. 
solucao_Atual $=\{\{\{d\} \rightarrow\{e\} \lambda=0.14\},\{\{a\} \rightarrow\{b\} \lambda=0.08\}$, $\{\{b\} \rightarrow\{a\} \lambda=0.08\}\}$

A regra com menor valor de medida $P S,\{c, b\} \rightarrow\{f\}$, foi removida de solucao_Atual.

menor PS $=0.08 ;$ menor Suporte $=0.08 ;$ menorCobertura $=0.08$

- $Y=f$

Avaliar a regra $\{d\} \rightarrow\{f\}$

coberturaConsequente $=0.1$

suporteRegra $=0.1$

$\lambda=0.07$

A medida $P S$ para a nova regra é menor que menor $P S, \lambda<$ menor $P S$, então a regra sob avaliação não deve ser adicionada à solucao_Atual.

Chamada Recursiva na linha 12.

antecedente_Atual $=\{d\}$

antecedentes_Disponiveis $=\{a, b, c\}$

consequentes_Disponiveis com os itens e e $f$

Linha 1: ate_Agora $=\emptyset$

Laço na linha 2.

- $P=a$

novoAntecedente $=\{d, a\}$

coberturaAntecedente $=0.3$

novos_Antecedentes_Disponiveis $=\emptyset$

Laço na linha 6.

$* Y=e$

Avaliar a regra $\{d, a\} \rightarrow\{e\}$

coberturaConsequente $=0.2$

suporteRegra $=0.2$

$\lambda=0.14$

A valor da medida $P S$ para a regra sob avaliação é maior que o menor $P S, \lambda>$ menor $P S$, então a nova regra deve ser adicionada ao conjunto solucao_Atual.

solucao_Atual $=\{\{\{d\} \rightarrow\{e\} \lambda=0.14\},\{\{d, a\} \rightarrow\{e\} \lambda=0.14\}$,

$\{\{a\} \rightarrow\{b\} \lambda=0.08\}\}$

A regra com menor valor de medida $P S,\{b\} \rightarrow\{a\}$, foi removida de solucao_Atual.

* $Y=f$

Avaliar a regra $\{d, a\} \rightarrow\{f\}$

coberturaConsequente $=0.1$

Aplica-se a Prevenção 5. 
Linha 31: ate_Agora $=\{a\}$

$-P=b$

novoAntecedente $=\{d, b\}$

suporteAntecedente $=0.3$

novos_Antecedentes_Disponiveis $=\{a\}$

Laço na linha 6.

$* Y=e$

Avaliar a regra $\{d, b\} \rightarrow\{e\}$

coberturaConsequente $=0.2$

suporteRegra $=0.2$

$\lambda=0.14$

A valor da medida $P S$ para a regra sob avaliação é maior que o menor $P S, \lambda>$ menor $P S$, então a nova regra deve ser adicionada ao conjunto solucao_Atual.

solucao_Atual $=\{\{\{d\} \rightarrow\{e\} \lambda=0.14\},\{\{d, a\} \rightarrow\{e\} \lambda=0.14\}$,

$\{\{d, b\} \rightarrow\{e\} \lambda=0.14\}\}$

A regra com menor valor de medida $P S,\{a\} \rightarrow\{b\}$, foi removida de solucao_Atual.

menor PS $=0.14 ;$ menor Suporte $=0.14$; menorCobertura $=0.14$

$* Y=f$

Avaliar a regra $\{d, b\} \rightarrow\{f\}$

coberturaConsequente $=0.1$

Aplica-se a Poda 3.

Chamada Recursiva na linha 12.

antecedente_Atual $=\{d, b\}$

antecedentes_Disponiveis $=\{a\}$

consequentes_Disponiveis com o item $e$

Linha 1: ate_Agora $=\emptyset$

Laço na linha 2.

* $P=a$

novoAntecedente $=\{d, b, a\}$

coberturaAntecedente $=0.3$

novos_Antecedentes_Disponiveis $=\emptyset$

Laço na linha 6.

- $Y=e$

Avaliar a regra $\{d, b, a\} \rightarrow\{e\}$

coberturaConsequente $=0.2$

Aplica-se a Prevenção 5.

Linha 31: ate_Agora $=\{a, b\}$ 
- $P=c$

novoAntecedente $=\{d, c\}$

coberturaAntecedente $=0.1$

Aplica-se a Poda 2.

Linha 31: ate_Agora $=\{a, b, c, d\}$

- $P=e$

novoAntecedente $=\{e\}$

suporteAntecedente $=0.2$

novos_Antecedentes_Disponiveis $=\{a, b, c, d\}$

Laço na linha 6.

- $Y=a$

Avaliar a regra $\{e\} \rightarrow\{a\}$

coberturaConsequente $=0.9$

Aplica-se a Poda 5.

- $Y=b$

Avaliar a regra $\{e\} \rightarrow\{b\}$

coberturaConsequente $=0.8$

Aplica-se a Poda 5.

- $Y=c$

Avaliar a regra $\{e\} \rightarrow\{c\}$

coberturaConsequente $=0.5$

Aplica-se a Poda 5.

- $Y=d$

Avaliar a regra $\{e\} \rightarrow\{d\}$

coberturaConsequente $=0.3$

Aplica-se a Poda 5.

- $Y=f$

Avaliar a regra $\{e\} \rightarrow\{f\}$

coberturaConsequente $=0.1$

Aplica-se a Poda 3.

Linha 31: ate_Agora $=\{a, b, c, d, e\}$

- $P=f$

novoAntecedente $=\{f\}$

Aplica-se a Poda 1. 


\section{A.2 Para o KORD-growth2}

Os parâmetros para a chamada inicial do algoritmo KORD-growth2 são antecedente_Atual que é vazio, antecedentes_Disponiveis que mantêm todos os itens frequentes e o conjunto consequentes_Disponiveis, que mantém as FP-tree condicionais dos consequentes, como também o suporte do consequente e da última regra avaliada. As árvores FP-tree condicionais consideradas no conjunto consequentes_Disponiveis devem ser escolhidas de acordo com a ordem da busca dos antecedentes. Se a busca por antecedentes iniciar pelo item mais frequente, pós-fixa, então os possíveis consequentes no conjunto consequentes_Disponiveis são $b, c, d, e$ e $f$. Caso comece pelo item menos frequente, pré-fixa, então os possiveis consequentes seriam os itens $a, b, c, d$ e $e$. Como dito anteriormente na descrição do exemplo para o KORD-growth1, a variável antecedentes_FPTree não é relacionada pois a variável coberturaAntecedente representa a frequência do antecedente recuperada a partir dela.

A busca por antecedentes segue a ordem pós-fixa. Então, na primeira chamada ao procedimento, são conhecidos antecedente_Atual $=\emptyset$, antecedentes_Disponiveis $=\{a, b, c, d, e\}$ e o conjunto consequentes_Disponiveis com os itens $b, c, d, e$ e $f$.

Linha 1: ate_Agora $=\emptyset$

Laço na linha 2. (Sobre cada $P \in$ antecedentes_Disponiveis)

- $P=a$ novoAntecedente $=\{a\}$

coberturaAntecedente $=0.9$ novos_Antecedentes_Disponiveis $=\emptyset$

Laço na linha 6. (Sobre cada consequente $\in$ consequentes_Disponiveis)

$-Y=b$

Avaliar a regra $\{a\} \rightarrow\{b\}$

coberturaConsequente $=0.8$

suporteRegra $=0.8$

$\lambda=0.08$

O conjunto solucao_Atual ainda não contém $k$ regras, então qualquer regra que satisfaz as restrições pode ser adicionada.

solucao_Atual $=\{\{a\} \rightarrow\{b\} \lambda=0.08\}$

Busca Implícita: com mesmo suporteRegra

$Y=a$

antecedente $=\{b\}$

Avaliar a regra $\{b\} \rightarrow\{a\}$

coberturaConsequente $=0.9$ 
coberturaAntecedente $=0.8$

$\lambda=0.08$

O conjunto solucao_Atual ainda não contém $k$ regras, então qualquer regra que satisfaz as restrições pode ser adicionada.

solucao_Atual $=\{\{\{a\} \rightarrow\{b\} \lambda=0.08\},\{\{b\} \rightarrow\{a\} \lambda=0.08\}\}$

$-Y=c$

Avaliar a regra $\{a\} \rightarrow\{c\}$

coberturaConsequente $=0.5$

suporteRegra $=0.4$

$\lambda=-0.05$

A medida $P S$ para a nova regra é menor que menor $P S, \lambda<$ menor $P S$, então a regra sob avaliação não deve ser adicionada à solucao_Atual.

Busca Implícita: com mesmo suporteRegra

$Y=a$

antecedente $=\{c\}$

Avaliar a regra $\{c\} \rightarrow\{a\}$

coberturaConsequente $=0.9$

coberturaAntecedente $=0.5$

$\lambda=-0.05$

A medida $P S$ para a nova regra é menor que menor $P S, \lambda<$ menor $P S$, então a regra sob avaliação não deve ser adicionada à solucao_Atual.

$-Y=d$

Avaliar a regra $\{a\} \rightarrow\{d\}$

coberturaConsequente $=0.3$

suporteRegra $=0.3$

$\lambda=0.03$

O conjunto solucao_Atual ainda não contém $k$ regras, então qualquer regra que satisfaz as restrições pode ser adicionada.

solucao_Atual $=\{\{\{a\} \rightarrow\{b\} \lambda=0.08\},\{\{b\} \rightarrow\{a\} \lambda=0.08\}$,

$\{\{a\} \rightarrow\{d\} \lambda=0.03\}\}$

menor $P S=0.03$; menor Suporte $=0.03$; menorCobertura $=0.03$

Busca Implícita: com mesmo suporteRegra

$Y=a$

antecedente $=\{d\}$

Avaliar a regra $\{d\} \rightarrow\{a\}$

coberturaConsequente $=0.9$

Aplica-se a Prevenção 7.

- $Y=e$

Avaliar a regra $\{a\} \rightarrow\{e\}$

coberturaConsequente $=0.2$ 
Aplica-se a Prevenção 5.

$-Y=f$

Avaliar a regra $\{a\} \rightarrow\{f\}$

coberturaConsequente $=0.1$

Aplica-se a Prevenção 5.

Linha 31: ate_Agora $=\{a\}$

- $P=b$

novoAntecedente $=\{b\}$

coberturaAntecedente $=0.8$

novos_Antecedentes_Disponiveis $=\{a\}$

Laço na linha 6.

- $Y=c$

Avaliar a regra $\{b\} \rightarrow\{c\}$

coberturaConsequente $=0.5$

suporteRegra $=0.3$

$\lambda=-0.01$

A medida $P S$ para a nova regra é menor que menor $P S, \lambda<$ menor $P S$, então a regra sob avaliação não deve ser adicionada à solucao_Atual. Busca Implícita: com mesmo suporteRegra

$Y=b$

antecedente $=\{c\}$

Avaliar a regra $\{c\} \rightarrow\{b\}$

coberturaConsequente $=0.8$

coberturaAntecedente $=0.5$

$\lambda=-0.01$

A medida $P S$ para a nova regra é menor que menor $P S, \lambda<$ menor $P S$, então a regra sob avaliação não deve ser adicionada à solucao_Atual.

$-Y=d$

Avaliar a regra $\{b\} \rightarrow\{d\}$

coberturaConsequente $=0.3$

suporteRegra $=0.3$

$\lambda=0.06$

A valor da medida $P S$ para a regra sob avaliação é maior que o menor $P S, \lambda>$ menor $P S$, então a nova regra deve ser adicionada ao conjunto solucao_Atual.

solucao_Atual $=\{\{\{a\} \rightarrow\{b\} \lambda=0.08\},\{\{b\} \rightarrow\{a\} \lambda=0.08\}$,

$\{\{b\} \rightarrow\{d\} \lambda=0.06\}\}$

A regra com menor valor de medida $P S,\{a\} \rightarrow\{d\}$, foi removida de solucao_Atual. 
menor PS $=0.06$; menor Suporte $=0.06$; menorCobertura $=0.06$

Busca Implícita: com mesmo suporteRegra

$Y=b$

antecedente $=\{d\}$

Avaliar a regra $\{d\} \rightarrow\{b\}$

coberturaConsequente $=0.8$

Aplica-se a Prevenção 7.

- $Y=e$

Avaliar a regra $\{b\} \rightarrow\{e\}$

coberturaConsequente $=0.2$

suporteRegra $=0.2$

$\lambda=0.04$

A medida $P S$ para a nova regra é menor que menor $P S, \lambda<$ menor $P S$, então a regra sob avaliação não deve ser adicionada à solucao_Atual.

Busca Implícita: com mesmo suporteRegra

$Y=b$

antecedente $=\{e\}$

Avaliar a regra $\{e\} \rightarrow\{b\}$

coberturaConsequente $=0.8$

Aplica-se a Prevenção 7.

- $Y=f$

Avaliar a regra $\{b\} \rightarrow\{f\}$

coberturaConsequente $=0.1$

suporteRegra $=0.1$

$\lambda=0.02$

A medida $P S$ para a nova regra é menor que menor $P S, \lambda<$ menor $P S$, então a regra sob avaliação não deve ser adicionada à solucao_Atual.

Busca Implícita: com mesmo suporteRegra

$Y=b$

antecedente $=\{f\}$

Avaliar a regra $\{f\} \rightarrow\{b\}$

coberturaConsequente $=0.8$

Aplica-se a Prevenção 7.

Chamada Recursiva na linha 12.

antecedente_Atual $=\{b\}$

antecedentes_Disponiveis $=\{a\}$

consequentes_Disponiveis com os itens $c, d, e$ e $f$

Linha 1: ate_Agora $=\emptyset$

Laço na linha 2. 
- $P=a$

novoAntecedente $=\{b, a\}$

coberturaAntecedente $=0.8$

novos_Antecedentes_Disponiveis $=\emptyset$

Laço na linha 6.

$* Y=c$

Avaliar a regra $\{b, a\} \rightarrow\{c\}$

coberturaConsequente $=0.5$

Aplica-se a Prevenção 6.

$* Y=d$

Avaliar a regra $\{b, a\} \rightarrow\{d\}$

coberturaConsequente $=0.3$

Aplica-se a Prevenção 5.

$* Y=e$

Avaliar a regra $\{b, a\} \rightarrow\{e\}$

coberturaConsequente $=0.2$

Aplica-se a Prevenção 5.

* $Y=f$

Avaliar a regra $\{b, a\} \rightarrow\{f\}$

coberturaConsequente $=0.1$

Aplica-se a Prevenção 5.

Linha 31: ate_Agora $=\{a, b\}$

- $P=c$

novoAntecedente $=\{c\}$

coberturaAntecedente $=0.5$

novos_Antecedentes_Disponiveis $=\{a, b\}$

Laço na linha 6.

- $Y=d$

Avaliar a regra $\{c\} \rightarrow\{d\}$

coberturaConsequente $=0.3$

suporteRegra $=0.1$

$\lambda=-0.05$

A medida $P S$ para a nova regra é menor que menor $P S, \lambda<$ menor $P S$, então a regra sob avaliação não deve ser adicionada à solucao_Atual.

Busca Implícita: com mesmo suporteRegra

$Y=c$

antecedente $=\{d\}$

Avaliar a regra $\{d\} \rightarrow\{c\}$ 
coberturaConsequente $=0.5$

Aplica-se a Prevenção 7.

- $Y=e$

Avaliar a regra $\{c\} \rightarrow\{e\}$

coberturaConsequente $=0.2$

suporteRegra $=0.1$

$\lambda=0.00$

A medida $P S$ para a nova regra é menor que menor $P S, \lambda<$ menor $P S$, então a regra sob avaliação não deve ser adicionada à solucao_Atual.

Busca Implícita: com mesmo suporteRegra

$Y=c$

antecedente $=\{e\}$

Avaliar a regra $\{e\} \rightarrow\{c\}$

coberturaConsequente $=0.5$

Aplica-se a Prevenção 7.

- $Y=f$

Avaliar a regra $\{c\} \rightarrow\{f\}$

coberturaConsequente $=0.1$

suporteRegra $=0.1$

$\lambda=0.05$

A medida $P S$ para a nova regra é menor que menor $P S, \lambda<$ menor $P S$, então a regra sob avaliação não deve ser adicionada à solucao_Atual.

Busca Implícita: com mesmo suporteRegra

$Y=c$

antecedente $=\{f\}$

Avaliar a regra $\{f\} \rightarrow\{c\}$

coberturaConsequente $=0.5$

Aplica-se a Prevenção 7.

Chamada Recursiva na linha 12.

antecedente_Atual $=\{c\}$

antecedentes_Disponiveis $=\{a, b\}$

consequentes_Disponiveis com os itens $d, e$ e $f$

Linha 1: ate_Agora $=\emptyset$

Laço na linha 2.

- $P=a$

novoAntecedente $=\{c, a\}$

coberturaAntecedente $=0.4$

novos_Antecedentes_Disponiveis $=\emptyset$

Laço na linha 6. 
$* Y=d$

Avaliar a regra $\{c, a\} \rightarrow\{d\}$

coberturaConsequente $=0.3$

Aplica-se a Prevenção 6.

* $Y=e$

Avaliar a regra $\{c, a\} \rightarrow\{e\}$

coberturaConsequente $=0.2$

Aplica-se a Prevenção 6.

* $Y=f$

Avaliar a regra $\{c, a\} \rightarrow\{f\}$

coberturaConsequente $=0.1$

Aplica-se a Prevenção 5.

Linha 31: ate_Agora $=\{a\}$

- $P=b$

novoAntecedente $=\{c, b\}$

coberturaAntecedente $=0.3$

novos_Antecedentes_Disponiveis $=\{a\}$

Laço na linha 6.

* $Y=d$

Avaliar a regra $\{c, b\} \rightarrow\{d\}$

coberturaConsequente $=0.3$

suporteRegra $=0.1$

$\lambda=0.01$

A medida $P S$ para a nova regra é menor que menor $P S, \lambda<$ menor $P S$, então a regra sob avaliação não deve ser adicionada à solucao_Atual. Busca Implícita: com mesmo suporteRegra $Y=c$

antecedente $=\{d, b\}$

Avaliar a regra $\{d, b\} \rightarrow\{c\}$

coberturaConsequente $=0.5$

Aplica-se a Prevenção 7.

* $Y=e$

Avaliar a regra $\{c, b\} \rightarrow\{e\}$

coberturaConsequente $=0.2$

suporteRegra $=0.1$

$\lambda=0.04$

A medida $P S$ para a nova regra é menor que menor $P S, \lambda<$ menor $P S$, então a regra sob avaliação não deve ser adicionada à solucao_Atual. Busca Implícita: com mesmo suporteRegra $Y=c$ 
antecedente $=\{e, b\}$

Avaliar a regra $\{e, b\} \rightarrow\{c\}$

coberturaConsequente $=0.5$

Aplica-se a Prevenção 7.

* $Y=f$

Avaliar a regra $\{c, b\} \rightarrow\{f\}$

coberturaConsequente $=0.1$

suporteRegra $=0.1$

$\lambda=0.07$

A valor da medida $P S$ para a regra sob avaliação é maior que o menor $P S, \lambda>$ menor $P S$, então a nova regra deve ser adicionada ao conjunto solucao_Atual.

solucao_Atual $=\{\{\{a\} \rightarrow\{b\} \lambda=0.08\},\{\{b\} \rightarrow\{a\} \lambda=0.08\}$,

$\{\{c, b\} \rightarrow\{f\} \lambda=0.07\}\}$

A regra com menor valor de medida $P S,\{b\} \rightarrow\{d\}$, foi removida de solucao_Atual.

menor $P S=0.07$; menor Suporte $=0.07$; menorCobertura $=0.07$

Busca Implícita: com mesmo suporteRegra

$Y=c$

antecedente $=\{f, b\}$

Avaliar a regra $\{f, b\} \rightarrow\{c\}$

coberturaConsequente $=0.5$

Aplica-se a Prevenção 7.

Chamada Recursiva na linha 12.

antecedente_Atual $=\{c, b\}$

antecedentes_Disponiveis $=\{a\}$

consequentes_Disponiveis com os itens $d, e$ e $f$

Linha 1: ate_Agora $=\emptyset$

Laço na linha 2.

* $P=a$

novoAntecedente $=\{c, b, a\}$

coberturaAntecedente $=0.3$

novos_Antecedentes_Disponiveis $=\emptyset$

Laço na linha 6.

- $Y=d$

Avaliar a regra $\{c, b, a\} \rightarrow\{d\}$

coberturaConsequente $=0.3$

Aplica-se a Prevenção 6.

- $Y=e$

Avaliar a regra $\{c, b, a\} \rightarrow\{e\}$ 
coberturaConsequente $=0.2$

Aplica-se a Prevenção 6.

- $Y=f$

Avaliar a regra $\{c, b, a\} \rightarrow\{f\}$

coberturaConsequente $=0.1$

Aplica-se a Prevenção 5.

Linha 31: ate_Agora $=\{a, b, c\}$

- $P=d$

novoAntecedente $=\{d\}$

coberturaAntecedente $=0.3$

novos_Antecedentes_Disponiveis $=\{a, b, c\}$

Laço na linha 6.

- $Y=e$

Avaliar a regra $\{d\} \rightarrow\{e\}$

coberturaConsequente $=0.2$

suporteRegra $=0.2$

$\lambda=0.14$

A valor da medida $P S$ para a regra sob avaliação é maior que o menor $P S, \lambda>$ menor $P S$, então a nova regra deve ser adicionada ao conjunto solucao_Atual.

solucao_Atual $=\{\{\{d\} \rightarrow\{e\} \lambda=0.14\},\{\{a\} \rightarrow\{b\} \lambda=0.08\}$,

$\{\{b\} \rightarrow\{a\} \lambda=0.08\}\}$

A regra com menor valor de medida $P S,\{c, b\} \rightarrow\{f\}$, foi removida de solucao_Atual.

menor PS $=0.08$; menor Suporte $=0.08$; menorCobertura $=0.08$

Busca Implícita: com mesmo suporteRegra

$Y=d$

antecedente $=\{e\}$

Avaliar a regra $\{e\} \rightarrow\{d\}$

coberturaConsequente $=0.3$

coberturaAntecedente $=0.2$

$\lambda=0.14$

A valor da medida $P S$ para a regra sob avaliação é maior que o menor $P S, \lambda>$ menor $P S$, então a nova regra deve ser adicionada ao conjunto solucao_Atual.

solucao_Atual $=\{\{\{d\} \rightarrow\{e\} \lambda=0.14\},\{\{e\} \rightarrow\{d\} \lambda=0.14\},\{\{a\} \rightarrow$ $\{b\} \lambda=0.08\}\}$

A regra com menor valor de medida $P S,\{b\} \rightarrow\{a\}$, foi removida de solucao_Atual. 
- $Y=f$

Avaliar a regra $\{d\} \rightarrow\{f\}$

coberturaConsequente $=0.1$

suporteRegra $=0.1$

$\lambda=0.07$

A medida $P S$ para a nova regra é menor que menor $P S, \lambda<$ menor $P S$, então a regra sob avaliação não deve ser adicionada à solucao_Atual. Busca Implícita: com mesmo suporteRegra

$Y=d$

antecedente $=\{f\}$

Avaliar a regra $\{f\} \rightarrow\{d\}$

coberturaConsequente $=0.3$

Aplica-se a Prevenção 7.

Chamada Recursiva na linha 12.

antecedente_Atual $=\{d\}$

antecedentes_Disponiveis $=\{a, b, c\}$

consequentes_Disponiveis com os itens e e $f$

Linha 1: ate_Agora $=\emptyset$

Laço na linha 2.

- $P=a$

novoAntecedente $=\{d, a\}$

coberturaAntecedente $=0.3$

novos_Antecedentes_Disponiveis $=\emptyset$

Laço na linha 6.

$* Y=e$

Avaliar a regra $\{d, a\} \rightarrow\{e\}$

coberturaConsequente $=0.2$

suporteRegra $=0.2$

$\lambda=0.14$

A valor da medida $P S$ para a regra sob avaliação é maior que o menor $P S, \lambda>$ menor $P S$, então a nova regra deve ser adicionada ao conjunto solucao_Atual.

solucao_Atual $=\{\{\{d\} \rightarrow\{e\} \lambda=0.14\},\{\{e\} \rightarrow\{d\} \lambda=0.14\},\{\{d, a\} \rightarrow$ $\{e\} \lambda=0.14\}\}$

A regra com menor valor de medida $P S,\{a\} \rightarrow\{b\}$, foi removida de solucao_Atual.

menor PS $=0.14 ;$ menor Suporte $=0.14 ;$ menorCobertura $=0.14$

Busca Implícita: com mesmo suporteRegra

$Y=d$ 
antecedente $=\{e, a\}$

Avaliar a regra $\{e, a\} \rightarrow\{d\}$

coberturaConsequente $=0.3$

Aplica-se a Prevenção 7.

* $Y=f$

Avaliar a regra $\{d\} \rightarrow\{f\}$

coberturaConsequente $=0.1$

Aplica-se a Poda 3.

Linha 31: ate_Agora $=\{a\}$

$-P=b$

novoAntecedente $=\{d, b\}$

coberturaAntecedente $=0.3$

novos_Antecedentes_Disponiveis $=\{a\}$

Laço na linha 6.

* $Y=e$

Avaliar a regra $\{d, b\} \rightarrow\{e\}$

coberturaConsequente $=0.2$

suporteRegra $=0.2$

$\lambda=0.14$

A medida $P S$ para a nova regra é menor ou igual que menor $P S$, $\lambda \leq$ menor $P S$, então a regra sob avaliação não deve ser adicionada à solucao_Atual.

Busca Implícita: com mesmo suporteRegra

$Y=c$

antecedente $=\{e, b\}$

Avaliar a regra $\{e, b\} \rightarrow\{d\}$

coberturaConsequente $=0.3$

Aplica-se a Prevenção 7.

* $Y=f$

Avaliar a regra $\{d, b\} \rightarrow\{f\}$

coberturaConsequente $=0.1$

Aplica-se a Poda 3.

Chamada Recursiva na linha 12.

antecedente_Atual $=\{d, b\}$

antecedentes_Disponiveis $=\{a\}$

consequentes_Disponiveis com o item $e$

Linha 1: ate_Agora $=\emptyset$

Laço na linha 2.

* $P=a$ 


$$
\begin{aligned}
& \text { novoAntecedente }=\{d, b, a\} \\
& \text { coberturaAntecedente }=0.3 \\
& \text { novos_Antecedentes_Disponiveis }=\emptyset
\end{aligned}
$$

Laço na linha 6.

$$
\text { - } Y=e
$$

Avaliar a regra $\{d, b, a\} \rightarrow\{e\}$

coberturaConsequente $=0.2$

\section{Aplica-se a Prevenção 5.}

Linha 31: ate_Agora $=\{a, b\}$

- $P=c$

novoAntecedente $=\{d, c\}$

coberturaAntecedente $=0.1$

Aplica-se a Poda 2.

Linha 31: ate_Agora $=\{a, b, c, d\}$

- $P=e$

novoAntecedente $=\{e\}$

coberturaAntecedente $=0.2$

novos_Antecedentes_Disponiveis $=\{a, b, c, d\}$

Laço na linha 6.

- $Y=f$

Avaliar a regra $\{e\} \rightarrow\{f\}$

coberturaConsequente $=0.1$

Aplica-se Poda 3. 
APÊNDICE

\section{Resultados dos Experimentos}

A seguir são exibidos os tempos de execução dos algoritmos tradicionais que extraem padrões frequentes e dos algoritmos que descobrem regras ótimas.

\section{B. 1 Experimentos que envolvem o tamanho máximo do antecedente para uma regra}

Nesta seção são apresentados os tempos de execução dos testes que avaliaram a restrição tamMaxAnt, ou seja, o tamanho máximo do antecedente para uma regra ou a quantidade máxima de itens que o antecedente de uma regra poderia conter. Foram extraídas 1000 regras que otimizaram a medida de interesse objetiva $P S$.

Tabela B.1: Experimentos para o conjunto de dados accidents com algoritmos que exploram regras ótimas.

\begin{tabular}{cccccc}
\hline tamMaxAnt & minsup & KORD & KORD-growth1-SP & KORD-growth1-CP & KORD-growth2 \\
\hline \hline 2 & $6.33 \%$ & 84.20 & 154.80 & 71.14 & 191.91 \\
4 & $11.14 \%$ & 354.40 & 103.62 & 51.12 & 361.35 \\
6 & $11.74 \%$ & 930.80 & 127.23 & 30.55 & 293.81 \\
8 & $11.81 \%$ & 1230.20 & 130.42 & 26.97 & 287.03 \\
\hline
\end{tabular}


Tabela B.2: Experimentos para o conjunto de dados accidents com algoritmos que exploram padrões frequentes.

\begin{tabular}{ccccc}
\hline tamMaxAnt & minsup & Apriori-itemsets & Apriori-regras & FP-growth \\
\hline \hline 2 & $6.33 \%$ & 5.68 & 6.21 & 9.95 \\
4 & $11.14 \%$ & 134.58 & 178.43 & 3.43 \\
6 & $11.74 \%$ & 1567.57 & 2253.43 & 4.90 \\
8 & $11.81 \%$ & 6369.91 &. & 9.16 \\
\hline
\end{tabular}

Tabela B.3: Experimentos para o conjunto de dados census com algoritmos que exploram regras ótimas.

\begin{tabular}{cccccc}
\hline tamMaxAnt & minsup & KORD & KORD-growth1-SP & KORD-growth1-CP & KORD-growth2 \\
\hline \hline 2 & $2.50 \%$ & 2.00 & 0.31 & 0.25 & 0.25 \\
4 & $7.64 \%$ & 3.00 & 0.12 & 0.12 & 0.28 \\
6 & $8.72 \%$ & 3.00 & 0.12 & 0.12 & 0.27 \\
8 & $8.75 \%$ & 3.00 & 0.14 & 0.11 & 0.25 \\
\hline
\end{tabular}

Tabela B.4: Experimentos para o conjunto de dados census com algoritmos que exploram padrões frequentes.

\begin{tabular}{ccccc}
\hline tamMaxAnt & minsup & Apriori-itemsets & Apriori-regras & FP-growth \\
\hline \hline 2 & $2.50 \%$ & 0.11 & 0.12 & 0.03 \\
4 & $7.64 \%$ & 0.20 & 0.28 & 0.03 \\
6 & $8.72 \%$ & 0.23 & 0.39 & 0.03 \\
8 & $8.75 \%$ & 0.25 & 0.43 & 0.03 \\
\hline
\end{tabular}

Tabela B.5: Experimentos para o conjunto de dados chess com algoritmos que exploram regras ótimas.

\begin{tabular}{cccccc}
\hline tamMaxAnt & minsup & KORD & KORD-growth1-SP & KORD-growth1-CP & KORD-growth2 \\
\hline \hline 2 & $8.62 \%$ & 1.00 & 1.04 & 0.41 & 1.40 \\
4 & $14.49 \%$ & 5.00 & 0.94 & 0.28 & 7.33 \\
6 & $20.00 \%$ & 5.00 & 0.27 & 0.19 & 8.53 \\
8 & $20.48 \%$ & 5.00 & 0.31 & 0.23 & 6.82 \\
\hline
\end{tabular}


Tabela B.6: Experimentos para o conjunto de dados chess com algoritmos que exploram padrões frequentes.

\begin{tabular}{ccccc}
\hline tamMaxAnt & minsup & Apriori-itemsets & Apriori-regras & FP-growth \\
\hline \hline 2 & $8.62 \%$ & 0.16 & 0.20 & 28.48 \\
4 & $14.49 \%$ & 6.96 & 18.92 & 10.19 \\
6 & $20.00 \%$ & 79.27 & 356.74 & 18.69 \\
8 & $20.48 \%$ & 394.08 &. & 82.70 \\
\hline
\end{tabular}

Tabela B.7: Experimentos para o conjunto de dados connect-4 com algoritmos que exploram regras ótimas.

\begin{tabular}{cccccc}
\hline tamMaxAnt & minsup & KORD & KORD-growth1-SP & KORD-growth1-CP & KORD-growth2 \\
\hline \hline 2 & $6.86 \%$ & 17.00 & 5.55 & 1.36 & 11.64 \\
4 & $12.79 \%$ & 126.20 & 1.67 & 1.25 & 4.96 \\
6 & $12.99 \%$ & 432.20 & 2.60 & 1.59 & 8.55 \\
8 & $13 \%$ & 882.40 & 3.77 & 1.82 & 13.45 \\
\hline
\end{tabular}

Tabela B.8: Experimentos para o conjunto de dados connect-4 com algoritmos que exploram padrões frequentes.

\begin{tabular}{ccccc}
\hline tamMaxAnt & minsup & Apriori-itemsets & Apriori-regras & FP-growth \\
\hline \hline 2 & $6.86 \%$ & 2.46 & 2.73 & 3.65 \\
4 & $12.79 \%$ & 113.57 & 245.99 & 3.98 \\
6 & $12.99 \%$ & 1359.66 & 8186.64 & 70.82 \\
8 & $13 \%$ & 3698.69 &. & 798.63 \\
\hline
\end{tabular}

Tabela B.9: Experimentos para o conjunto de dados kosarak com algoritmos que exploram regras ótimas.

\begin{tabular}{cccccc}
\hline tamMaxAnt & minsup & KORD & KORD-growth1-SP & KORD-growth1-CP & KORD-growth2 \\
\hline \hline 2 & $0.49 \%$ & 13.00 & 6.22 & 6.37 & 1.50 \\
4 & $0.61 \%$ & 11.40 & 3.13 & 3.26 & 1.11 \\
6 & $0.61 \%$ & 12.20 & 3.12 & 3.23 & 1.08 \\
8 & $0.61 \%$ & 12.20 & 3.09 & 3.18 & 1.09 \\
\hline
\end{tabular}


Tabela B.10: Experimentos para o conjunto de dados kosarak com algoritmos que exploram padrões frequentes.

\begin{tabular}{ccccc}
\hline tamMaxAnt & minsup & Apriori-itemsets & Apriori-regras & FP-growth \\
\hline \hline 2 & $0.49 \%$ & 0.27 & 0.31 & 0.55 \\
4 & $0.61 \%$ & 0.43 & 0.55 & 0.41 \\
6 & $0.61 \%$ & 0.45 & 0.62 & 0.34 \\
8 & $0.61 \%$ & 0.45 & 0.61 & 0.34 \\
\hline
\end{tabular}

Tabela B.11: Experimentos para o conjunto de dados mushroom com algoritmos que exploram regras ótimas.

\begin{tabular}{cccccc}
\hline tamMaxAnt & minsup & KORD & KORD-growth1-SP & KORD-growth1-CP & KORD-growth2 \\
\hline \hline 2 & $10.49 \%$ & 1.00 & 0.08 & 0.06 & 0.09 \\
4 & $16.48 \%$ & 1.00 & 0.06 & 0.05 & 0.09 \\
6 & $16.75 \%$ & 1.00 & 0.05 & 0.05 & 0.09 \\
8 & $16.75 \%$ & 1.00 & 0.05 & 0.05 & 0.09 \\
\hline
\end{tabular}

Tabela B.12: Experimentos para o conjunto de dados mushroom com algoritmos que exploram padrões frequentes.

\begin{tabular}{ccccc}
\hline tamMaxAnt & minsup & Apriori-itemsets & Apriori-regras & FP-growth \\
\hline \hline 2 & $10.49 \%$ & 0.07 & 0.09 & 0.02 \\
4 & $16.48 \%$ & 0.10 & 0.52 & 0.03 \\
6 & $16.75 \%$ & 0.16 & 1.79 & 0.06 \\
8 & $16.75 \%$ & 0.13 & 3.27 & 0.08 \\
\hline
\end{tabular}

Tabela B.13: Experimentos para o conjunto de dados pumsb com algoritmos que exploram regras ótimas.

\begin{tabular}{cccccc}
\hline tamMaxAnt & minsup & KORD & KORD-growth1-SP & KORD-growth1-CP & KORD-growth2 \\
\hline \hline 2 & $23.33 \%$ & 12.20 & 3.26 & 2.62 & 29.34 \\
4 & $24.67 \%$ & 27.00 & 4.71 & 3.21 & 16.16 \\
6 & $24.67 \%$ & 25.20 & 9.81 & 4.32 & 14.18 \\
8 & $24.67 \%$ & 24.00 & 17.08 & 4.87 & 15.15 \\
\hline
\end{tabular}


Tabela B.14: Experimentos para o conjunto de dados pumsb com algoritmos que exploram padrões frequentes.

\begin{tabular}{ccccc}
\hline tamMaxAnt & minsup & Apriori-itemsets & Apriori-regras & FP-growth \\
\hline \hline 2 & $23.33 \%$ & 2.95 & 4.13 & 2387.22 \\
4 & $24.67 \%$ & 254.28 & 598.28 & 1624.90 \\
6 & $24.67 \%$ & 7700.00 &. & 1900.50 \\
8 & $24.67 \%$ &. &. & 5841.13 \\
\hline
\end{tabular}

Tabela B.15: Experimentos para o conjunto de dados retail com algoritmos que exploram regras ótimas.

\begin{tabular}{cccccc}
\hline tamMaxAnt & minsup & KORD & KORD-growth1-SP & KORD-growth1-CP & KORD-growth2 \\
\hline \hline 2 & $0.12 \%$ & 20.00 & 8.19 & 8.72 & 0.89 \\
4 & $0.14 \%$ & 17.20 & 6.61 & 6.99 & 0.70 \\
6 & $0.14 \%$ & 16.20 & 6.57 & 6.94 & 0.70 \\
8 & $0.14 \%$ & 16.20 & 6.57 & 7.10 & 0.70 \\
\hline
\end{tabular}

Tabela B.16: Experimentos para o conjunto de dados retail com algoritmos que exploram padrões frequentes.

\begin{tabular}{ccccc}
\hline tamMaxAnt & minsup & Apriori-itemsets & Apriori-regras & FP-growth \\
\hline \hline 2 & $0.12 \%$ & 0.22 & 0.35 & 0.14 \\
4 & $0.14 \%$ & 0.21 & 0.28 & 0.13 \\
6 & $0.14 \%$ & 0.21 & 0.26 & 0.13 \\
8 & $0.14 \%$ & 0.21 & 0.26 & 0.13 \\
\hline
\end{tabular}


Tabela B.17: Experimentos para o conjunto de dados T10I4D100K com algoritmos que exploram regras ótimas.

\begin{tabular}{cccccc}
\hline tamMaxAnt & minsup & KORD & KORD-growth1-SP & KORD-growth1-CP & KORD-growth2 \\
\hline \hline 2 & $0.45 \%$ & 11.00 & 5.52 & 6.02 & 0.56 \\
4 & $0.48 \%$ & 10.00 & 5.35 & 5.85 & 0.58 \\
6 & $0.48 \%$ & 9.00 & 5.32 & 5.80 & 0.55 \\
8 & $0.48 \%$ & 9.00 & 5.32 & 5.69 & 0.56 \\
\hline
\end{tabular}

Tabela B.18: Experimentos para o conjunto de dados T1OI4D100K com algoritmos que exploram padrões frequentes.

\begin{tabular}{ccccc}
\hline tamMaxAnt & minsup & Apriori-itemsets & Apriori-regras & FP-growth \\
\hline \hline 2 & $0.45 \%$ & 0.19 & 0.22 & 0.19 \\
4 & $0.48 \%$ & 0.20 & 0.25 & 0.19 \\
6 & $0.48 \%$ & 0.22 & 0.29 & 0.17 \\
8 & $0.48 \%$ & 0.22 & 0.29 & 0.17 \\
\hline
\end{tabular}

Tabela B.19: Experimentos para o conjunto de dados T40I10D100K com algoritmos que exploram regras ótimas.

\begin{tabular}{cccccc}
\hline tamMaxAnt & minsup & KORD & KORD-growth1-SP & KORD-growth1-CP & KORD-growth2 \\
\hline \hline 2 & $1.31 \%$ & 66.20 & 494.02 & 486.43 & 9.89 \\
4 & $1.49 \%$ & 55.60 & 394.36 & 405.60 & 10.12 \\
6 & $1.49 \%$ & 55.60 & 396.51 & 405.32 & 10.25 \\
8 & $1.49 \%$ & 55.40 & 395.04 & 405.04 & 10.23 \\
\hline
\end{tabular}

Tabela B.20: Experimentos para o conjunto de dados T40I10D100K com algoritmos que exploram padrões frequentes.

\begin{tabular}{ccccc}
\hline tamMaxAnt & minsup & Apriori-itemsets & Apriori-regras & FP-growth \\
\hline \hline 2 & $1.31 \%$ & 1.40 & 1.97 & 3.34 \\
4 & $1.49 \%$ & 1.31 & 1.89 & 2.96 \\
6 & $1.49 \%$ & 1.49 & 2.09 & 3.03 \\
8 & $1.49 \%$ & 1.49 & 2.16 & 3.00 \\
\hline
\end{tabular}




\section{B.2 Segundo Experimento}

Nesta seção são apresentados os tempos de execução dos testes que avaliaram o impacto do aumento da quantidade de regras requeridas pela tarefa de descoberta de regras ótimas. O tamanho máximo para o antecedente foi 4 e os valores discretos $k$ de regras foram 1, 10, 100, 1000 e 10000. As regras otimizaram a medida de interesse objetiva $P S$.

Tabela B.21: Experimentos para o conjunto de dados accidents com algoritmos que exploram regras ótimas.

\begin{tabular}{lccccc}
\hline$k$ & minsup & KORD & KORD-growth1-SP & KORD-growth1-CP & KORD-growth2 \\
\hline \hline 1 & $15.96 \%$ & 55.20 & 7.71 & 3.79 & 7.29 \\
10 & $15.11 \%$ & 102.20 & 9.72 & 4.76 & 10.36 \\
100 & $12.70 \%$ & 186.20 & 28.58 & 11.01 & 44.65 \\
1000 & $11.14 \%$ & 354.40 & 103.62 & 51.12 & 361.35 \\
10000 & $8.08 \%$ & 822.40 & 564.36 & 328.07 & 2321.34 \\
\hline
\end{tabular}

Tabela B.22: Experimentos para o conjunto de dados accidents com algoritmos que exploram padrões frequentes.

\begin{tabular}{cccc}
\hline minsup & Apriori-itemsets & Apriori-regras & FP-growth \\
\hline \hline $15.96 \%$ & 93.99 & 118.22 & 1.58 \\
$15.11 \%$ & 98.92 & 126.33 & 1.75 \\
$12.70 \%$ & 117.64 & 152.82 & 2.51 \\
$11.14 \%$ & 134.58 & 178.43 & 3.43 \\
$8.08 \%$ & 191.55 & 242.66 & 6.71 \\
\hline
\end{tabular}


Tabela B.23: Experimentos para o conjunto de dados census com algoritmos que exploram regras ótimas.

\begin{tabular}{lccccc}
\hline$k$ & minsup & KORD & KORD-growth1-SP & KORD-growth1-CP & KORD-growth2 \\
\hline \hline 1 & $23.89 \%$ & 1.00 & 0.01 & 0.01 & 0.01 \\
10 & $21.06 \%$ & 1.00 & 0.01 & 0.01 & 0.01 \\
100 & $16.19 \%$ & 1.00 & 0.02 & 0.02 & 0.03 \\
1000 & $7.64 \%$ & 3.00 & 0.12 & 0.12 & 0.28 \\
10000 & $2.46 \%$ & 13.80 & 1.73 & 1.53 & 2.78 \\
\hline
\end{tabular}

Tabela B.24: Experimentos para o conjunto de dados census com algoritmos que exploram padrões frequentes.

\begin{tabular}{cccc}
\hline minsup & Apriori-itemsets & Apriori-regras & FP-growth \\
\hline \hline $23.89 \%$ & 0.02 & 0.03 & 0.01 \\
$21.06 \%$ & 0.02 & 0.03 & 0.01 \\
$16.19 \%$ & 0.03 & 0.06 & 0.01 \\
$7.64 \%$ & 0.20 & 0.28 & 0.03 \\
$2.46 \%$ & 0.47 & 0.68 & 0.07 \\
\hline
\end{tabular}

Tabela B.25: Experimentos para o conjunto de dados chess com algoritmos que exploram regras ótimas.

\begin{tabular}{lccccc}
\hline$k$ & minsup & KORD & KORD-growth1-SP & KORD-growth1-CP & KORD-growth2 \\
\hline \hline 1 & $23.57 \%$ & 0 & 0.06 & 0.05 & 0.17 \\
10 & $23.15 \%$ & 0 & 0.06 & 0.06 & 0.36 \\
100 & $20.70 \%$ & 2.00 & 0.11 & 0.08 & 1.70 \\
1000 & $14.49 \%$ & 5.00 & 0.94 & 0.28 & 7.33 \\
10000 & $11.88 \%$ & 11.40 & 6.60 & 3.98 & 36.77 \\
\hline
\end{tabular}


Tabela B.26: Experimentos para o conjunto de dados chess com algoritmos que exploram padrões frequentes.

\begin{tabular}{cccc}
\hline minsup & Apriori-itemsets & Apriori-regras & FP-growth \\
\hline \hline $23.57 \%$ & 4.59 & 12.16 & 2.62 \\
$23.15 \%$ & 4.65 & 12.46 & 2.73 \\
$20.70 \%$ & 5.25 & 14.04 & 3.87 \\
$14.49 \%$ & 6.96 & 18.92 & 10.19 \\
$11.88 \%$ & 7.80 & 21.69 & 15.82 \\
\hline
\end{tabular}

Tabela B.27: Experimentos para o conjunto de dados connect-4 com algoritmos que exploram regras ótimas.

\begin{tabular}{lccccc}
\hline$k$ & minsup & KORD & KORD-growth1-SP & KORD-growth1-CP & KORD-growth2 \\
\hline \hline 1 & $13.23 \%$ & 72.20 & 0.98 & 0.70 & 0.83 \\
10 & $13.23 \%$ & 78.00 & 1.04 & 0.73 & 0.84 \\
100 & $13.18 \%$ & 90.40 & 1.09 & 0.78 & 1.28 \\
1000 & $12.79 \%$ & 126.20 & 1.67 & 1.25 & 4.96 \\
10000 & $11.51 \%$ & 204.80 & 6.75 & 5.74 & 52.90 \\
\hline
\end{tabular}

Tabela B.28: Experimentos para o conjunto de dados connect-4 com algoritmos que exploram padrões frequentes.

\begin{tabular}{cccc}
\hline minsup & Apriori-itemsets & Apriori-regras & FP-growth \\
\hline \hline $13.23 \%$ & 108.68 & 232.73 & 3.70 \\
$13.18 \%$ & 110.67 & 235.64 & 3.73 \\
$12.79 \%$ & 113.57 & 245.99 & 3.98 \\
$11.51 \%$ & 126.41 & 280.81 & 4.46 \\
\hline
\end{tabular}


Tabela B.29: Experimentos para o conjunto de dados kosarak com algoritmos que exploram regras ótimas.

\begin{tabular}{lccccc}
\hline$k$ & minsup & KORD & KORD-growth1-SP & KORD-growth1-CP & KORD-growth2 \\
\hline \hline 1 & $10.39 \%$ & 1.00 & 0.00 & 0.00 & 0.00 \\
10 & $4.60 \%$ & 2.00 & 0.00 & 0.00 & 0.00 \\
100 & $1.42 \%$ & 4.00 & 0.22 & 0.23 & 0.11 \\
1000 & $0.61 \%$ & 11.40 & 3.13 & 3.26 & 1.11 \\
10000 & $0.27 \%$ & 55.20 & 34.63 & 34.20 & 13.95 \\
\hline
\end{tabular}

Tabela B.30: Experimentos para o conjunto de dados kosarak com algoritmos que exploram padrões frequentes.

\begin{tabular}{cccc}
\hline minsup & Apriori-itemsets & Apriori-regras & FP-growth \\
\hline \hline $10.39 \%$ & 0.00 & 0.01 & 0.00 \\
$4.60 \%$ & 0.00 & 0.01 & 0.00 \\
$1.42 \%$ & 0.14 & 0.18 & 0.05 \\
$0.61 \%$ & 0.43 & 0.55 & 0.41 \\
$0.27 \%$ & 1.22 & 1.89 & 1.15 \\
\hline
\end{tabular}

Tabela B.31: Experimentos para o conjunto de dados mushroom com algoritmos que exploram regras ótimas.

\begin{tabular}{lccccc}
\hline$k$ & minsup & KORD & KORD-growth1-SP & KORD-growth1-CP & KORD-growth2 \\
\hline \hline 1 & $21.09 \%$ & 0 & 0.02 & 0.01 & 0.01 \\
10 & $20.68 \%$ & 0 & 0.02 & 0.01 & 0.01 \\
100 & $18.76 \%$ & 0 & 0.02 & 0.01 & 0.01 \\
1000 & $16.48 \%$ & 1.00 & 0.06 & 0.05 & 0.09 \\
10000 & $12.18 \%$ & 3.00 & 0.92 & 0.86 & 1.40 \\
\hline
\end{tabular}


Tabela B.32: Experimentos para o conjunto de dados mushroom com algoritmos que exploram padrões frequentes.

\begin{tabular}{cccc}
\hline minsup & Apriori-itemsets & Apriori-regras & FP-growth \\
\hline \hline $21.09 \%$ & 0.05 & 0.30 & 0.01 \\
$20.68 \%$ & 0.06 & 0.31 & 0.03 \\
$18.76 \%$ & 0.06 & 0.36 & 0.03 \\
$16.48 \%$ & 0.10 & 0.52 & 0.03 \\
$12.18 \%$ & 0.24 & 0.95 & 0.05 \\
\hline
\end{tabular}

Tabela B.33: Experimentos para o conjunto de dados pumsb com algoritmos que exploram regras ótimas.

\begin{tabular}{lccccc}
\hline$k$ & minsup & KORD & KORD-growth1-SP & KORD-growth1-CP & KORD-growth2 \\
\hline \hline 1 & $25.00 \%$ & 2.00 & 2.45 & 1.06 & 1.36 \\
10 & $25.00 \%$ & 3.00 & 2.54 & 1.14 & 1.72 \\
100 & $24.81 \%$ & 6.40 & 2.89 & 1.47 & 4.10 \\
1000 & $24.67 \%$ & 27.00 & 4.71 & 3.21 & 16.16 \\
10000 & $23.98 \%$ & 120.40 & 30.26 & 25.36 & 215.91 \\
\hline
\end{tabular}

Tabela B.34: Experimentos para o conjunto de dados pumsb com algoritmos que exploram padrões frequentes.

\begin{tabular}{cccc}
\hline minsup & Apriori-itemsets & Apriori-regras & FP-growth \\
\hline \hline $25.00 \%$ & 246.60 & 618.81 & 1538.07 \\
$24.81 \%$ & 276.49 & 619.68 & 1585.51 \\
$24.67 \%$ & 254.28 & 598.28 & 1624.90 \\
$23.98 \%$ & 266.16 & 637.75 & 1977.34 \\
\hline
\end{tabular}


Tabela B.35: Experimentos para o conjunto de dados retail com algoritmos que exploram regras ótimas.

\begin{tabular}{lccccc}
\hline$k$ & minsup & KORD & KORD-growth1-SP & KORD-growth1-CP & KORD-growth2 \\
\hline \hline 1 & $5.58 \%$ & 2.00 & 0.00 & 0.00 & 0.00 \\
10 & $2.53 \%$ & 1.00 & 0.00 & 0.00 & 0.00 \\
100 & $0.54 \%$ & 3.00 & 0.28 & 0.30 & 0.06 \\
1000 & $0.14 \%$ & 17.20 & 6.61 & 6.99 & 0.70 \\
10000 & $0.04 \%$ & 72.60 & 65.03 & 65.47 & 42.88 \\
\hline
\end{tabular}

Tabela B.36: Experimentos para o conjunto de dados retail com algoritmos que exploram padrões frequentes.

\begin{tabular}{cccc}
\hline minsup & Apriori-itemsets & Apriori-regras & FP-growth \\
\hline \hline $5.58 \%$ & 0.00 & 0.00 & 0.00 \\
$2.53 \%$ & 0.01 & 0.02 & 0.02 \\
$0.54 \%$ & 0.07 & 0.08 & 0.03 \\
$0.14 \%$ & 0.21 & 0.28 & 0.13 \\
$0.04 \%$ & 0.78 & 1.04 & 0.30 \\
\hline
\end{tabular}

Tabela B.37: Experimentos para o conjunto de dados T10I4D100K com algoritmos que exploram regras ótimas.

\begin{tabular}{lccccc}
\hline$k$ & minsup & KORD & KORD-growth1-SP & KORD-growth1-CP & KORD-growth2 \\
\hline \hline 1 & $1.15 \%$ & 4.00 & 2.37 & 2.70 & 0.30 \\
10 & $1.00 \%$ & 5.00 & 2.95 & 3.21 & 0.39 \\
100 & $0.76 \%$ & 8.00 & 3.93 & 4.32 & 0.48 \\
1000 & $0.48 \%$ & 10.00 & 5.35 & 5.85 & 0.58 \\
10000 & $0.29 \%$ & 14.20 & 11.12 & 11.84 & 2.25 \\
\hline
\end{tabular}


Tabela B.38: Experimentos para o conjunto de dados T10I4D100K com algoritmos que exploram padrões frequentes.

\begin{tabular}{cccc}
\hline minsup & Apriori-itemsets & Apriori-regras & FP-growth \\
\hline \hline $1.15 \%$ & 0.04 & 0.09 & 0.13 \\
$1.00 \%$ & 0.08 & 0.13 & 0.13 \\
$0.76 \%$ & 0.13 & 0.18 & 0.16 \\
$0.48 \%$ & 0.20 & 0.25 & 0.19 \\
$0.29 \%$ & 0.33 & 0.38 & 0.23 \\
\hline
\end{tabular}

Tabela B.39: Experimentos para o conjunto de dados T40I10D100K com algoritmos que exploram regras ótimas.

\begin{tabular}{lccccc}
\hline$k$ & minsup & KORD & KORD-growth1-SP & KORD-growth1-CP & KORD-growth2 \\
\hline \hline 1 & $2.16 \%$ & 34.40 & 112.68 & 113.26 & 4.98 \\
10 & $1.88 \%$ & 38.40 & 132.90 & 132.60 & 5.21 \\
100 & $1.57 \%$ & 49.20 & 209.68 & 211.35 & 6.47 \\
1000 & $1.49 \%$ & 55.60 & 394.36 & 405.60 & 10.12 \\
10000 & $1.21 \%$ & 78.60 & 1002.95 & 1024.05 & 40.06 \\
\hline
\end{tabular}

Tabela B.40: Experimentos para o conjunto de dados T40I10D100K com algoritmos que exploram padrões frequentes.

\begin{tabular}{cccc}
\hline minsup & Apriori-itemsets & Apriori-regras & FP-growth \\
\hline \hline $2.16 \%$ & 0.66 & 0.91 & 2.17 \\
$1.88 \%$ & 0.79 & 1.17 & 2.45 \\
$1.57 \%$ & 1.18 & 1.68 & 2.86 \\
$1.49 \%$ & 1.31 & 1.89 & 2.96 \\
$1.21 \%$ & 2.07 & 3.13 & 3.59 \\
\hline
\end{tabular}




\section{Referências Bibliográficas}

Agrawal, R., Imieliński, T., e Swami, A. (1993). Mining association rules between sets of items in large databases. Em SIGMOD'93: Proceedings of the 1993 ACM SIGMOD International Conference on Management of Data, páginas 207-216. Citado nas páginas 1, 2, e 7 .

Agrawal, R. e Srikant, R. (1994). Fast algorithms for mining association rules in large databases. Em VLDB'94: Proceedings of the 20th International Conference on Very Large Data Bases, páginas 487-499. Citado nas páginas 2, 10,14 , e 22 .

Bayardo, R. e Agrawal, R. (1999). Mining the most interesting rules. Em KDD'99: Proceedings of the 5th ACM SIGKDD International Conference on Knowledge Discovery and Data Mining, páginas 145-154. Citado nas páginas $3,30,33,35,36,39$, e 40 .

Bayardo, R., Agrawal, R., e Gunopulos, D. (1999). Constraint-Based Rule Mining in Large, Dense Databases. Em ICDE'99: Proceedings of the 15th International Conference on Data Engineering, páginas 188-197. Citado nas páginas 31 e 36.

Borgelt, C. (2005). An implementation of the fp-growth algorithm. Em OSDM'05: Proceedings of the 1st International Workshop on Open Source Data Mining: Frequent Pattern Mining Implementations, páginas 1-5. Citado na página 82.

Borgelt, C. e Kruse, R. (2002). Induction of association rules: Apriori implementation. Em Compstat: Proceedings of the 15th Conference on Computational Statistics, páginas 389-395. Citado nas páginas 2, 15, e 82.

Brin, S., Motwani, R., e Silverstein, C. (1997). Beyond market baskets: Generalizing association rules to correlations. ACM SIGMOD Record, 26(2):265276. Citado nas páginas 2, 25, e 27. 
Ceglar, A. e Roddick, J. (2006). Association Mining. ACM Computing Surveys, 38(2):1-42. Citado na página 13.

Creighton, C. e Hanash, S. (2003). Mining gene expression databases for association rules. Bioinformatics, 19(1):79. Citado na página 1.

Feldman, R., Fresko, M., Kinar, Y., Lindell, Y., Liphstat, O., Rajman, M., Schler, Y., e Zamir, O. (1998). Text mining at the term level. Em PKDD'98: Proceedings of the 2nd European Symposium on Principles of Data Mining and Knowledge Discovery, páginas 65-73. Citado na página 1.

Frank, A. e Asuncion, A. (2010). UCI Machine Learning Repository. Citado na página 31 .

Grahne, G. e Zhu, J. (2003). High performance mining of maximal frequent itemsets. Em HPDM '03: Proceedings of the 6th SIAM International Workshop on High Performance Data Mining, páginas 135-143. Citado na página 78.

Han, J., Pei, J., e Yin, Y. (2000). Mining frequent patterns without candidate generation. Em SIGMOD'O0: Proceedings of the 2000 ACM SIGMOD International Conference on Management of Data, páginas 1-12. Citado nas páginas $2,3,15,21$, e 78 .

He, Z., Deng, S., e Xu, X. (2005). An fp-tree based approach for mining all strongly correlated item pairs. Em Computational Intelligence and Security, volume 3801 of Lecture Notes in Computer Science, páginas 735-740. Citado na página 78 .

Hu, T., Sung, S. Y., Xiong, H., e Fu, Q. (2008). Discovery of maximum length frequent itemsets. Information Sciences, 178(1):69-87. Citado na página 78.

Jiang, N. e Gruenwald, L. (2006). Research issues in data stream association rule mining. SIGMOD Record, 35(1):14-19. Citado na página 1.

Li, J. (2006). On optimal rule discovery. IEEE Transactions on Knowledge and Data Engineering, 18:460-471. Citado na página 39.

Li, J., Shen, H., e Topor, R. W. (2001). Mining the smallest association rule set for predictions. Em ICDM '01: Proceedings of the 2001 IEEE International Conference on Data Mining, páginas 361-368. Citado na página 39.

Li, J. e Zhang, Y. (2003). Direct interesting rule generation. Em ICDM '03: Proceedings of the 3rd IEEE International Conference on Data Mining, páginas 155-162. Citado nas páginas 29 e 39. 
Lopes, A. A., Pinho, R., Paulovich, F. V., e Minghim, R. (2007). Visual text mining using association rules. Computers \& Graphics, 31(3):316-326. Citado nas páginas 1 e 29.

Morishita, S. e Sese, J. (2000). Traversing itemset lattice with statistical metric pruning. Em PODS 'OO: Proceedings of the 19th ACM SIGMOD-SIGACTSIGART Symposium on Principles of Database Systems, páginas 226-236. Citado nas páginas 3, 34, 37, 38, 39, e 40.

Mosteller, F. (1968). Association and estimation in contingency tables. Journal of the American Statistical Association, 63(321):1-28. Citado na página 26.

Omiecinski, E. R. (2003). Alternative interest measures for mining associations in databases. IEEE Transactions on Knowledge and Data Engineering, 15(1):57-69. Citado nas páginas 26 e 32.

Piatetsky-Shapiro, G. e Frawley, W. J. (1991). Knowledge Discovery in Databases. AAAI/MIT Press. Citado nas páginas 24 e 26.

Plasse, M., Niang, N., Saporta, G., Villeminot, A., e Leblond, L. (2007). Combined use of association rules mining and clustering methods to find relevant links between binary rare attributes in a large data set. Computational Statistics and Data Analysis, 52(1):596-613. Citado na página 34.

Sahar, S. e Mansour, Y. (1999). An empirical evaluation of objective interestingness criteria. Em SPIE '99: Conference on Data Mining and Knowledge Discovery, páginas 63-74. Citado na página 27.

Said, A., Dominic, P., e Abdullah, A. (2009). A Comparative Study of FP-growth Variations. IJCSNS, 9(5):266-272. Citado nas páginas 21 e 46.

Shin, S. J. e Lee, W. S. (2008). On-line generation association rules over data streams. Information \& Software Technology, 50(6):569-578. Citado na página 1 .

Tan, P. e Kumar, V. (2000). Interestingness measures for association patterns: A perspective. Em KDD 'OO: Workshop on Postprocessing in Machine Learning and Data Mining. Citeseer. Citado nas páginas 2, 23, 26, e 27.

Tan, P., Kumar, V., e Srivastava, J. (2004). Selecting the right objective measure for association analysis. Information Systems, 29(4):293-313. Citado nas páginas 27 e 35 .

Tan, P., Steinbach, M., Kumar, V., et al. (2006). Introduction to data mining. Pearson Addison Wesley Boston. Citado nas páginas 1, 8, 10, 11, 15, 18, 20, 21, e 23 . 
Wakabi-Waiswa, P. e Baryamureeba, V. (2007). Extraction of Interesting Association Rules Using Genetic Algorithms. Strengthening the Role of ICT in Development, página 101. Citado na página 34.

Webb, G. I. (1995). OPUS: An Efficient Admissible Algorithm for Unordered Search. Journal of Artificial Intelligence Research, 3:431-465. Citado nas páginas 34,37 , e 40.

Webb, G. I. (2000). Efficient search for association rules. Em KDD '00: Proceedings of the 6th ACM SIGKDD International Conference on Knowledge Discovery and Data Mining, páginas 99-107. Citado nas páginas 3, 29, 40, e 66.

Webb, G. I. (2007). Discovering significant patterns. Machine Learning, 68(1):1-33. Citado na página 31.

Webb, G. I. e Zhang, S. (2005). K-optimal rule discovery. Data Mining and Knowledge Discovery, 10(1):39-79. Citado nas páginas 3, 4, 22, 40, 43, 45, $47,48,49,56,66,74,79,82$, e 89.

Wong, P., Whitney, P., e Thomas, J. (1999). Visualizing association rules for text mining. Em INFOVIS '99: Proceedings of the 1999 IEEE Symposium on Information Visualization, volume 120. Citado na página 1.

Xiong, H., Tan, P.-N., e Kumar, V. (2003). Mining strong affinity association patterns in data sets with skewed support distribution. Em ICDM '03: Proceedings of the 3rd IEEE International Conference on Data Mining, páginas 387-394. Citado na página 32.

Yan, X., Zhang, C., Zhang, S., et al. (2005). ARMGA: Identifying interesting association rules with genetic algorithms. Applied Artificial Intelligence, 19(7):679-689. Citado na página 34.

Yen, S. e Chen, A. (1996). An efficient approach to discovering knowledge from large databases. Em PDIS '96: Proceedings of the 4th International Conference on Parallel and Distributed Information Systems, páginas 8-18. Citado na página 2.

Zaki, M. (2000). Generating non-redundant association rules. Em KDD 'OO: Proceedings of the 6th ACM SIGKDD International Conference on Knowledge Discovery and Data Mining, páginas 34-43. Citado na página 31.

Zaki, M., Parthasarathy, S., Ogihara, M., Li, W., et al. (1997). New algorithms for fast discovery of association rules. Em KDD '97: Proceedings of the 3rd ACM SIGKDD International Conference on Knowledge Discovery and Data Mining, páginas 283-286. Citado na página 2. 
Zhao, Y., Zhang, C., e Zhang, S. (2004). Discovering interesting association rules by clustering. Em AI '04: Proceedings of the 17th Australian Joint Conference on Artificial Intelligence, páginas 1055-1061. Citado na página 33. 